\title{
Energy, Environmental, and Economic Analyses of Design Concepts for the Co-Production of Fuels and Chemicals with Electricity via Co- Gasification of Coal and Biomass
}

\author{
Final Technical Report \\ Covering 1 October 2010 - 31 March 2012 \\ Under DOE Agreement DE-FE0005373 \\ Prepared by \\ Eric D. Larson (PI), Robert H. Williams, and Thomas G. Kreutz \\ Princeton Environmental Institute \\ Guyot Hall, Washington Road \\ Princeton University \\ Princeton, New Jersey \\ with contributions from \\ Ilkka Hannula \\ Technical Research Center of Finland, Helsinki \\ Andrea Lanzini \\ Politecnico di Torino, Italy \\ Guangjian Liu \\ North China Electric Power University, Beijing
}

30 June 2012 
This report was prepared as an account of work sponsored by an agency of the United States Government. Neither the United States Government nor any agency thereof, nor any of their employees, makes any warranty, express or implied, or assumes any legal liability or responsibility for the accuracy, completeness, or usefulness of any information, apparatus, product, or process disclosed, or represents that its use would not infringe privately owned rights. Reference herein to any specific commercial product, process, or service by trade name, trademark, manufacturer, or otherwise does not necessarily constitute or imply its endorsement, recommendation, or favoring by the United States Government or any agency thereof. The views and opinions of authors expressed herein do not necessarily state or reflect those of the United States Government or any agency thereof.

Primary financial support for this work was provided by the National Energy Technology Laboratory. Additional support from the Edgerton Foundation and from Princeton University's Carbon Mitigation Initiative is gratefully acknowledged. 


\section{Contents}

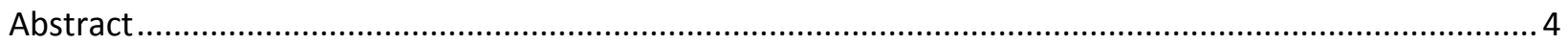

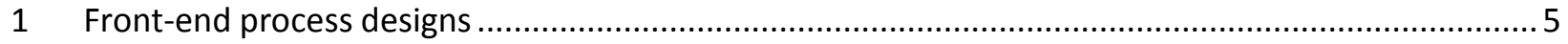

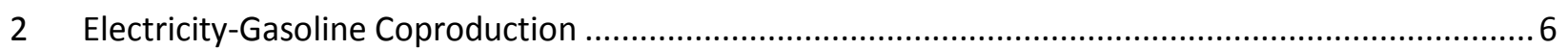

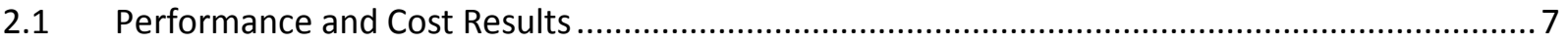

$2.2 \quad$ Economics with captured $\mathrm{CO}_{2}$ sold for EOR ...................................................................

2.3 Economics of co-production vs. liquids-only production under a carbon mitigation policy .......11

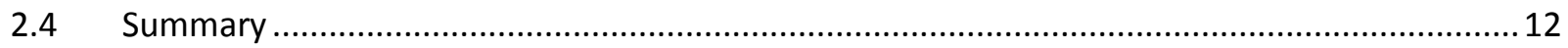

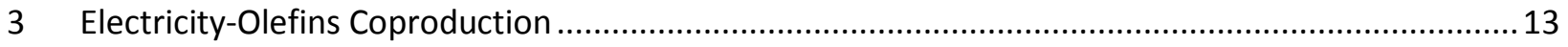

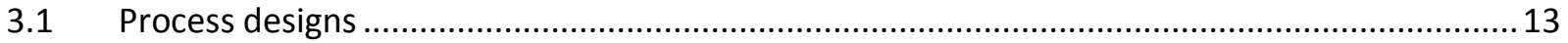

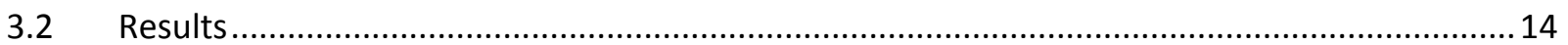

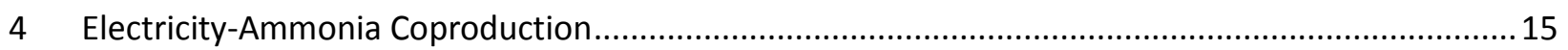

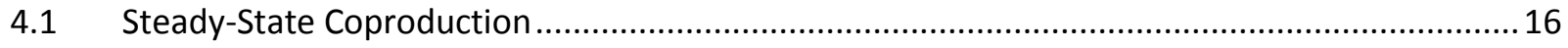

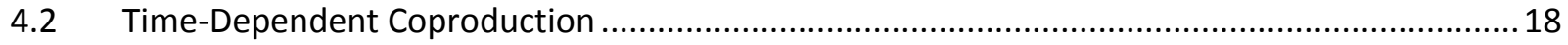

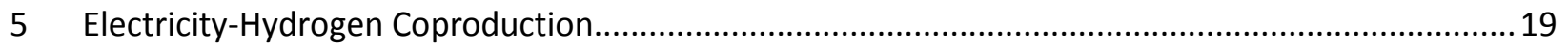

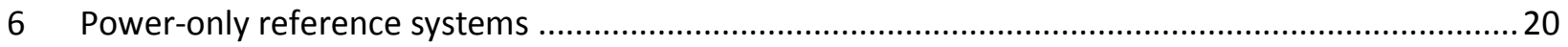

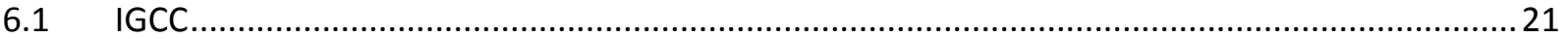

6.2 IGFC

Appendix A: Co-Processing of Coal and Biomass in Entrained Flow Coal Gasifiers: Front-End Process

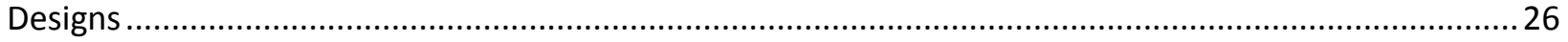

Appendix B: Process Design and Analysis for Co-Production of Electricity and Synthetic Gasoline via CoGasification of Coal and Biomass with CCS.

Appendix C: Process Design and Analysis for Co-Production of Electricity and Light Olefins via Co-

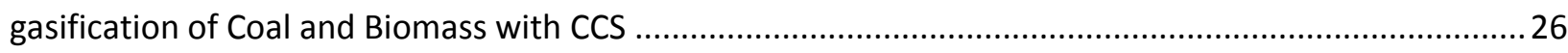

Appendix D: Preliminary Assessments of: Coal to Electricity plus Ammonia with CCS, and Coal to

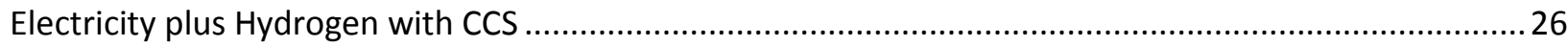

Appendix E: Process Design and Analysis for Stand-Alone Solid Oxide Fuel Cell Power Generation.........26 


\section{Abstract}

The overall objective of this project was to quantify the energy, environmental, and economic performance of industrial facilities that would coproduce electricity and transportation fuels or chemicals from a mixture of coal and biomass via co-gasification in a single pressurized, oxygen-blown, entrainedflow gasifier, with capture and storage of $\mathrm{CO}_{2}$ (CCS). The work sought to identify plant designs with promising ( $\mathrm{N}^{\text {th }}$ plant) economics, superior environmental footprints, and the potential to be deployed at scale as a means for simultaneously achieving enhanced energy security and deep reductions in U.S. GHG emissions in the coming decades. Designs included systems using primarily alreadycommercialized component technologies, which may have the potential for near-term deployment at scale, as well as systems incorporating some advanced technologies at various stages of R\&D.

Table 1 shows the feedstock inputs and primary final product outputs for the systems investigated. All of the coproduction designs have the common attribute of producing some electricity and also of capturing $\mathrm{CO}_{2}$ for storage. For each of the co-product pairs shown in Table 1 detailed process mass and energy simulations (using Aspen Plus software) were developed for a set of alternative process configurations, on the basis of which lifecycle greenhouse gas emissions, $\mathrm{N}^{\text {th }}$ plant economic performance, and other characteristics were evaluated for each configuration. In developing each set of process configurations, focused attention was given to understanding the influence of biomass input fraction and electricity output fraction. Self-consistent evaluations were also carried out for gasificationbased reference systems producing only electricity from coal, including integrated gasification combined cycle (IGCC) and integrated gasification solid-oxide fuel cell (IGFC) systems, as indicated in Table 1.

Table 1. Input feedstocks and exported products for system designs developed in this project.

\begin{tabular}{|l|c|c|c|c|c|c|}
\hline \hline Inputs & Outputs & $\begin{array}{c}\text { Electricity } \\
\text { +Gasoline }\end{array}$ & $\begin{array}{c}\text { Electricity } \\
\text { +Olefins }\end{array}$ & $\begin{array}{c}\text { Electricity + } \\
\text { Ammonia }\end{array}$ & $\begin{array}{c}\text { Electricity } \\
\text { +Hydrogen }\end{array}$ & \multicolumn{2}{|c|}{ Electricity only, via } \\
\hline Coal & & & & & & GTCC \\
\hline Dry-feed gasifier & $\mathbf{x}$ & $\mathbf{x}$ & $\mathbf{x}$ & $\mathbf{x}$ & $\mathbf{x}$ & $\mathbf{x}$ \\
\hline Slurry-feed gasifier & $\mathbf{x}$ & & & & $\mathbf{x}$ & $\mathbf{x}$ \\
\hline Coal + torrefied biomass & & & & & & \\
\hline Dry-feed gasifier & $\mathbf{x}$ & $\mathbf{x}$ & & & & \\
\hline Slurry-feed gasifier & $\mathbf{x}$ & & & & & \\
\hline Coal + ground biomass & & & & & & \\
\hline Dry-feed gasifier & $\mathbf{x}$ & & & & \\
\hline
\end{tabular}

The reason biomass is considered as a co-feed with coal in cases when gasoline or olefins are coproduced with electricity is to help reduce lifecycle greenhouse gas (GHG) emissions for these systems. Storing biomass-derived $\mathrm{CO}_{2}$ underground represents negative $\mathrm{CO}_{2}$ emissions if the biomass is grown sustainably (i.e., if one ton of new biomass growth replaces each ton consumed), and this offsets positive $\mathrm{CO}_{2}$ emissions associated with the coal used in these systems. Different coal:biomass input ratios will produce different net lifecycle greenhouse gas (GHG) emissions for these systems, which is the reason that attention in our analysis was given to the impact of the biomass input fraction. In the case of systems that produce only products with no carbon content, namely electricity, ammonia and hydrogen, only coal was considered as a feedstock because it is possible in theory to essentially fully decarbonize such products by capturing all of the coal-derived $\mathrm{CO}_{2}$ during the production process.

Key findings from the work are summarized in the main body of this report. Supporting details, references, and complete descriptions of the work completed are provided in the appendices: Front-end process designs (Appendix A), Electricity/Gasoline Coproduction (Appendix B), Electricity/Olefins 
Coproduction (Appendix C), Electricity/Ammonia and Electricity/Hydrogen (Appendix D), and standalone electricity production (Appendix E).

\section{Front-end process designs}

Initial work in the project involved research to define the performance and cost characteristics of the front end feedstock preparation and gasification systems that were subsequently adopted across different plant configurations. Details of this work are described in Appendix A.

The feedstocks considered for the analysis were Illinois \#6 bituminous coal and corn stover biomass (Table 2). Trade-offs between dry-feed oxygen-blown entrained-flow coal gasification (based on GE Energy technology) and slurry-feed gasification (based on Shell technology) were examined, and effort was spent on understanding the status of biomass torrefaction technologies. Torrefaction may be essential for enabling use of

Table 2. Gasifier input feedstock characteristics.

\begin{tabular}{|l|c|c|c|}
\hline & $\begin{array}{c}\text { AR } \\
\text { Coal }\end{array}$ & $\begin{array}{c}\text { AR } \\
\text { Biomass }\end{array}$ & $\begin{array}{c}\text { Torrefied } \\
\text { biomass }\end{array}$ \\
\hline Proximate Analysis (wt \%) & $11.12 \%$ & $20.0 \%$ & $0.9 \%$ \\
\hline Moisture & $44.19 \%$ & $17.3 \%$ & $15.6 \%$ \\
\hline Fixed Carbon & $34.99 \%$ & $76.4 \%$ & $77.0 \%$ \\
\hline Volatile Matter & $9.70 \%$ & $6.3 \%$ & $7.4 \%$ \\
\hline Ash & 25.861 & 12.478 & 16.822 \\
\hline LHV, wet basis, MJ/kg & 27.114 & 14.167 & 18.170 \\
\hline HHV, wet basis, MJ/kg & \multicolumn{1}{|l|}{} \\
\hline Ultimate Analysis (wt\%, dry basis) \\
\hline Fixed Carbon & $49.72 \%$ & $17.30 \%$ & $15.60 \%$ \\
\hline Volatile Matter & $39.37 \%$ & $76.40 \%$ & $77.00 \%$ \\
\hline Ash & $10.91 \%$ & $6.30 \%$ & $7.40 \%$ \\
\hline $\mathrm{C}$ & $71.72 \%$ & $47.86 \%$ & $49.82 \%$ \\
\hline $\mathrm{H}$ & $5.06 \%$ & $6.88 \%$ & $6.13 \%$ \\
\hline $\mathrm{N}$ & $1.41 \%$ & $0.81 \%$ & $0.90 \%$ \\
\hline $\mathrm{Cl}$ & $0.33 \%$ & $0.00 \%$ & $0.00 \%$ \\
\hline $\mathrm{S}$ & $2.82 \%$ & $0.00 \%$ & $0.00 \%$ \\
\hline $\mathrm{O}$ & $7.75 \%$ & $38.15 \%$ & $35.75 \%$ \\
\hline $\mathrm{HHV}, \mathrm{MJ} / \mathrm{kg}$ dry & 30.506 & 17.709 & 18.335 \\
\hline
\end{tabular}
biomass in a slurry-feed gasifier, while either torrefied or non-torrefied biomass can be used in a dry-feed gasifier. Aspen Plus simulations were developed for three alternative front-end process configurations (Figure 1).

(a) Ground biomass, dry feed gasifier
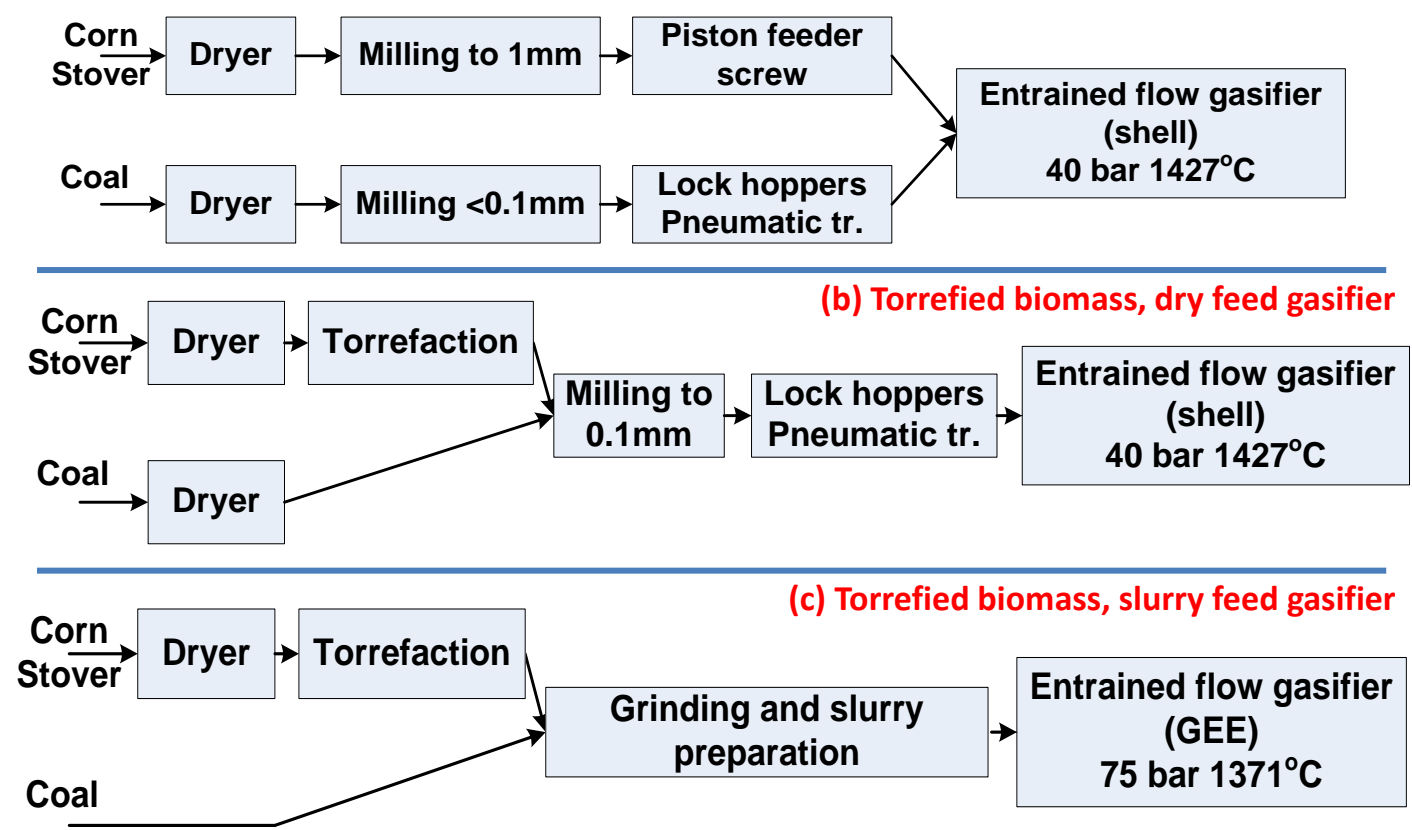

Figure 1. Alternative front-end process configurations for co-gasification of coal and biomass. 
Our work on the front-end configurations found, not surprisingly, that much higher cold gas efficiency is achievable with dry-feed gasification than with slurry-feed gasification. More surprisingly, we found that cold-gas efficiency for either gasifier design depends strongly on the input biomass/coal ratio, with lower efficiencies corresponding to higher biomass/coal ratios. These findings, together with unanswered questions about the feasibility of pumping a coal/biomass slurry with solids concentration as high as the $64 \%$ level that we assumed and the fact that the only entrained flow coal+biomass cogasification system proven in commercial operation today (at Buggenum in the Netherlands) uses dryfeed gasification, led us to focus much of our subsequent design and simulation work on systems using dry-feed gasification. We nevertheless carried forward analysis of several system designs with the slurryfed gasification as well so as to have an understanding of the costs and benefits of this option should the high solids content slurry-feeding of torrefied biomass ultimately be proven feasible.

\section{Electricity-Gasoline Coproduction}

As described in detail in Appendix B, Aspen Plus mass and energy balance simulations were developed for sixteen process designs for co-production of electricity with synthetic gasoline from biomass and coal, with capture and storage of byproduct $\mathrm{CO}_{2}$. Systems incorporating each of the three front-end configurations (Figure 1) were designed. Figure 2 shows a simplified system diagram for cofeeding dried crushed biomass with crushed coal into a dry-feed gasifier (Shell design). Figure 3 shows the system design when torrefied biomass and coal are the feedstocks for either a dry-feed or a slurry-feed gasifer. The latter is based on a GE Energy quench-gasifier design.

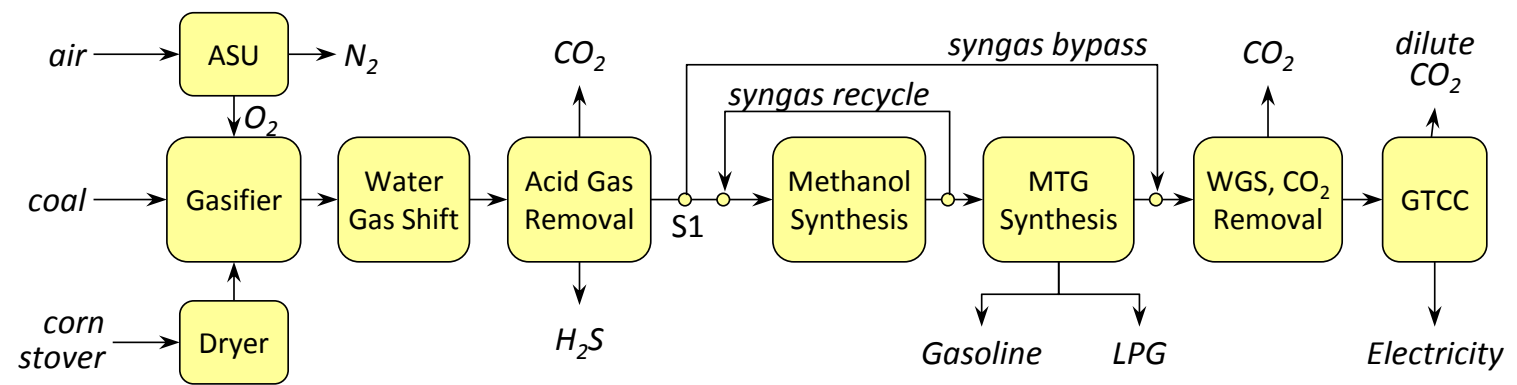

Figure 2. Simplified process diagram for co-production of electricity and gasoline via co-gasification of coal and dried biomass in a dry-feed gasifier. Grinding of the feedstocks (to $<1 \mathrm{~mm}$ for the dried corn stover and $<0.1 \mathrm{~mm}$ for the coal) is not shown.

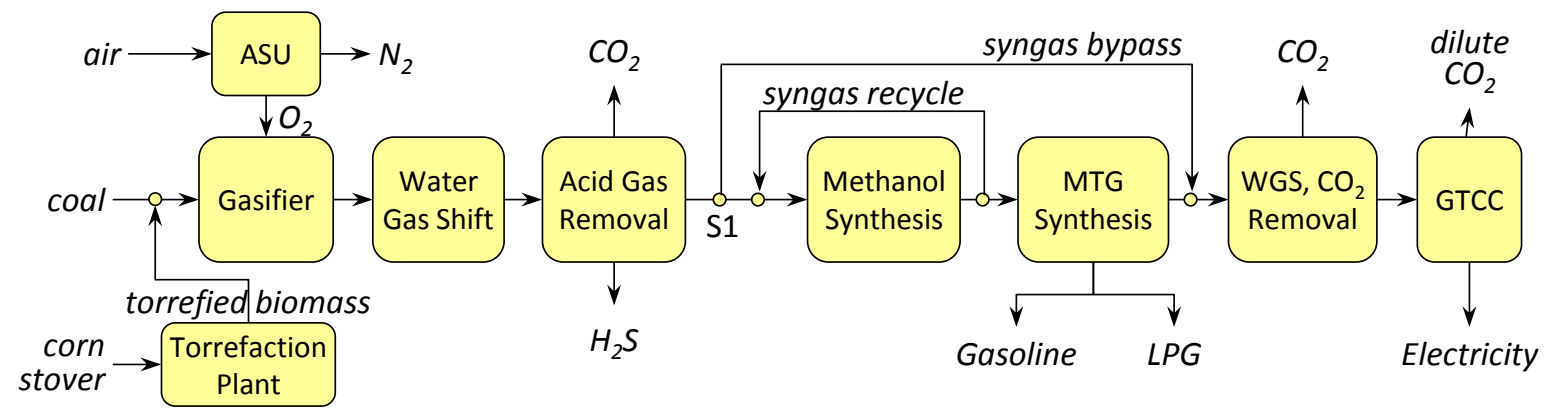

Figure 3. Simplified process diagram for co-production of electricity and gasoline via co-gasification of coal and torrefied biomass. Both dry-feed and slurry-feed gasifiers were examined. Grinding of the feedstocks (to $<0.1 \mathrm{~mm}$ ) is not shown.

With either gasifier design, the coal and biomass feedstocks are co-gasified with oxygen from a stand-alone cryogenic air separation unit, and the resulting syngas is cooled and cleaned via wet 
scrubbing before passing to a water gas shift (WGS) reactor used to tune the $\mathrm{H}_{2} / \mathrm{CO}$ content of the syngas to the desired value of approximately 2 at the entrance to the methanol synthesis island. Most of the $\mathrm{CO}_{2}$ is then removed from the syngas utilizing a Rectisol system, and the resulting gas is sent to methanol synthesis. The removed $\mathrm{CO}_{2}$ is compressed to 150 bar for pipeline transport to storage. The methanol is delivered to the gasoline production area (MTG synthesis reactor), which produces a finished gasoline blendstock and a byproduct LPG-like stream. The LPG-like stream contains about $10 \%$ of the energy value of the gasoline product. To further reduce the carbon footprint of the plant, unconverted syngas leaving the synthesis area, along with light gas produced during synthesis, is subjected to additional water gas shift, followed by $\mathrm{CO}_{2}$ removal, before going to a gas turbine combined cycle power island that generates sufficient power to meet onsite requirements and export power to the grid. The amount of power generated is adjusted by controlling the recycle of unconverted syngas back to methanol synthesis or the syngas bypass around the synthesis reactors.

The overall scales of facilities, as defined by total feedstock input, were selected assuming that the maximum biomass input rate for any facility would be one million dry metric tonnes per year, ${ }^{1}$ a plausible level for truck-delivered biomass in the longer term. ${ }^{2}$ We also assumed that the maximum coal input rate would be 8,000 metric tonnes per day (as-received), which corresponds to the rate of coal use at a large coal-fired power plant in the U.S. today. Neither the maximum biomass input rate nor the maximum coal input rate are necessarily practical maxima, since rail or barge transport of biomass would enable larger supply rates, and coal facilities could presumably be larger.

Table 3 summarizes key features of the 16 cases that we designed and analyzed. $\mathrm{BF}$ refers to the biomass fraction of the input feedstocks (before torrefaction, $\mathrm{HHV}$ basis) and EF refers to the electricity fraction of the output products (LHV basis for the fuels). BF values from 0 (coal only) to 0.30 and $\mathrm{EF}$ values from 0 to 0.50 were examined.
Table 3. Process designs for which preliminary simulation results were generated. See Appendix A for detailed performance and cost estimates for each case.

\begin{tabular}{|c|c|c|c|c|c|}
\hline Case \# & Gasifier & Biomass & $\mathbf{B F}^{*}$ & $\mathbf{E F} * *$ & $\begin{array}{c}\text { MeOH Synthesis } \\
\text { Technology }\end{array}$ \\
\hline 1 & Dry-feed & coal only & 0 & 0.50 & Liquid Phase \\
\hline 2 & Dry-feed & dried & 0.30 & 0.50 & Gas Phase \\
\hline 3 & Dry-feed & dried & 0.30 & 0.50 & Liquid Phase \\
\hline 4 & Dry-feed & torrefied & 0.05 & 0.26 & Liquid Phase \\
\hline 5 & Dry-feed & torrefied & 0.05 & 0.45 & Liquid Phase \\
\hline 6 & Dry-feed & torrefied & 0.28 & 0.28 & Liquid Phase \\
\hline 7 & Dry-feed & torrefied & 0.28 & 0.45 & Liquid Phase \\
\hline 8 & Dry-feed & torrefied & 0.28 & 0.02 & Liquid Phase \\
\hline 9 & Dry-feed & torrefied & 0.30 & 0.50 & Liquid Phase \\
\hline 10 & Dry-feed & torrefied & 0.30 & 0.50 & Gas Phase \\
\hline 11 & Slurry feed & coal only & 0 & 0.50 & Liquid Phase \\
\hline 12 & Slurry feed & torrefied & 0.05 & 0.21 & Liquid Phase \\
\hline 13 & Slurry feed & torrefied & 0.05 & 0.44 & Liquid Phase \\
\hline 14 & Slurry feed & torrefied & 0.26 & 0.21 & Liquid Phase \\
\hline 15 & Slurry feed & torrefied & 0.26 & 0.44 & Liquid Phase \\
\hline 16 & Slurry feed & torrefied & 0.26 & 0.03 & Liquid Phase \\
\hline \multicolumn{6}{|c|}{$\begin{array}{l}* \mathrm{BF} \text { is the fraction of energy input to the system that is biomass: } \\
\mathrm{BF} \equiv \mathrm{HHV}_{\text {biomass }} /\left(\mathrm{HHV}_{\text {biomass }}+\mathrm{HHV}_{\text {coal }}\right) \text {. For cases using torrefied biomass, the } \mathrm{BF} \\
\text { is calculated on the basis of } \mathrm{HHV} \text { of the biomass prior to torrefying it. } \\
* * \mathrm{EF} \text { is the fraction of the product mix that is electricity: } \\
\mathrm{EF} \equiv \mathrm{MW}_{\text {electric }} /\left(\mathrm{MW}_{\text {electric }}+\mathrm{MW}_{\text {gasoline. LHV }}+\mathrm{MW}_{\mathrm{LPG}, \mathrm{LHV}}\right) \text {. }\end{array}$} \\
\hline
\end{tabular}

\subsection{Performance and Cost Results}

Collectively these 16 designs enabled performance and cost comparisons for different $\mathrm{BF}$ and $\mathrm{EF}$ values, for dried biomass feed versus torrefied biomass feed, for dry-feed gasifiers versus slurry-feed gasifiers, and for gas-phase methanol synthesis vs. liquid-phase synthesis. Appendix B (Tables 6 and 7) give detailed mass/energy balances and capital and operating cost estimates on which comparisons were

\footnotetext{
${ }^{1}$ When operating with $90 \%$ capacity factor.

${ }^{2}$ Larson, E.D., Fiorese, G., Liu, G., Williams, R.H., Kreutz, T.G., and Consonni, S., “Co-production of decarbonized synfuels and electricity from coal + biomass with $\mathrm{CO}_{2}$ capture and storage: an Illinois case study, Energy Env Sci, 3: 28-42, 2010.
} 
based. The impacts on performance and cost of the BF and EF, which were found to be the most consequential design parameters, are illustrated using results for four cases (Table 4). Each of these designs utilizes torrefied biomass, dry-feed gasification, and liquid phase methanol synthesis, which appears to be the most promising physical hardware configuration for co-production.

The lifecycle carbon footprint for each process configuration is quantified using the greenhouse gas emissions index (GHGI), which is calculated as the net lifecycle greenhouse gas emissions for the system divided by the lifecycle emissions of a reference ("business-as-usual", BAU) system. ${ }^{3} \mathrm{As}$ illustrated in Table 4, the GHGI decreases with either increasing BF or increasing EF. An increase in EF lowers GHGI for two

reasons: 1) the

"business-as-usual"

alternative used in the calculation of GHGI is coal-fired power generation, which is more carbon-intensive than production and use of petroleum-derived gasoline, the BAU alternative to the gasoline produced by the coal/biomass system; and 2) less of the carbon in the feedstock reaches the atmosphere via combustion of the liquid fuel produced and more of the carbon in the feedstock is captured and stored underground. An increase in BF lowers GHGI because carbon originating from photosynthesis is counted as an extraction of carbon from the atmosphere, offsetting some of the additions of carbon originating from the co-production system and the combustion of the liquid fuels produced. For Case 7, where BF is 0.28 and EF is 0.45, GHGI is zero. For higher values of BF or EF than these, the GHGI is negative. Even the low value of $\mathrm{BF}(0.05)$ provides for a $50 \%$ reduction in emissions $(\mathrm{GHGI}=0.5)$ when the electricity fraction is 0.26 (case 4 in Table 4).

The economics of these coproduction systems, including the cost of transporting and storing the captured $\mathrm{CO}_{2}$ in a saline aquifer, become less favorable with decreasing GHGI in the absence of a greenhouse gas emissions price. Only case 4 (low BF and low EF) has a levelized cost of electricity (LCOE), \$55/MWh, and a breakeven oil price (BEOP), \$87/bbl, that might be plausibly competitive with electricity generating costs or petroleum fuel costs prevailing today (Table 4).

\footnotetext{
${ }^{3}$ The numerator comprises all greenhouse gas emissions associated with the co-production facility, including emissions from mining and delivering coal, from producing and delivering biomass, from converting the coal and biomass to fuels and electricity, from delivery of the liquid fuels to end users, and from combustion of the liquid fuels by end users. Since carbon in the biomass arriving at the plant gate has been extracted from the atmosphere during plant growth, this carbon is counted as a negative emission in the lifecycle accounting, assuming that the biomass is grown on a sustainable basis (1 GJ/year of new biomass is grown for each GJ/year consumed). The "business as usual" emissions in the denominator of the GHGI are estimated lifecycle GHG emissions associated with producing the same amount of electricity and fuels as the co-production plant, but doing so at separate stand-alone facilities: electricity from a supercritical pulverized coal plant $\left(831 \mathrm{kgCO}_{2}\right.$-eq/MWh), gasoline from crude oil (91 $\mathrm{kgCO}_{2}$-eq/GJ $\left.\mathrm{LHV}_{\mathrm{LH}}\right)$, and $\mathrm{LPG}$ from crude oil $\left(86 \mathrm{kgCO}_{2}-\mathrm{eq} / \mathrm{GJ}_{\mathrm{LHV}}\right)$.
} 
The introduction of a greenhouse gas emissions price dramatically alters the economics. For example, Figure 4 shows internal rates of return on equity (IRRE) for the cases in Table 4. For this calculation, electricity revenues are assumed to be $\$ 60 / \mathrm{MWh}$, plus a GHG emissions charge corresponding to that for the U.S. grid-average emission rate (in 2007) of $636 \mathrm{kgCO}_{2}$-equivalent per $\mathrm{MWh}$. The $\$ 60 / \mathrm{MWh}$ price is approximately the U.S. average grid sale price today. Liquid fuel revenues are assumed to be equivalent to the wholesale price of these products made from crude oil costing $\$ 90 / \mathrm{bbl}$ plus a greenhouse gas emission charge of $91 \mathrm{kgCO}_{2} \mathrm{e} / \mathrm{GJ}_{\mathrm{LHV}}$ for petroleum-derived gasoline. Case 4 , with the lowest $\mathrm{BF}$ and $\mathrm{EF}$, provides the highest IRRE across a broad range of GHG emission prices. Beyond about $\$ 80 / \mathrm{tCO}_{2} \mathrm{e}$, case 6 (with a much higher $\mathrm{BF}$ ) provides the highest return.

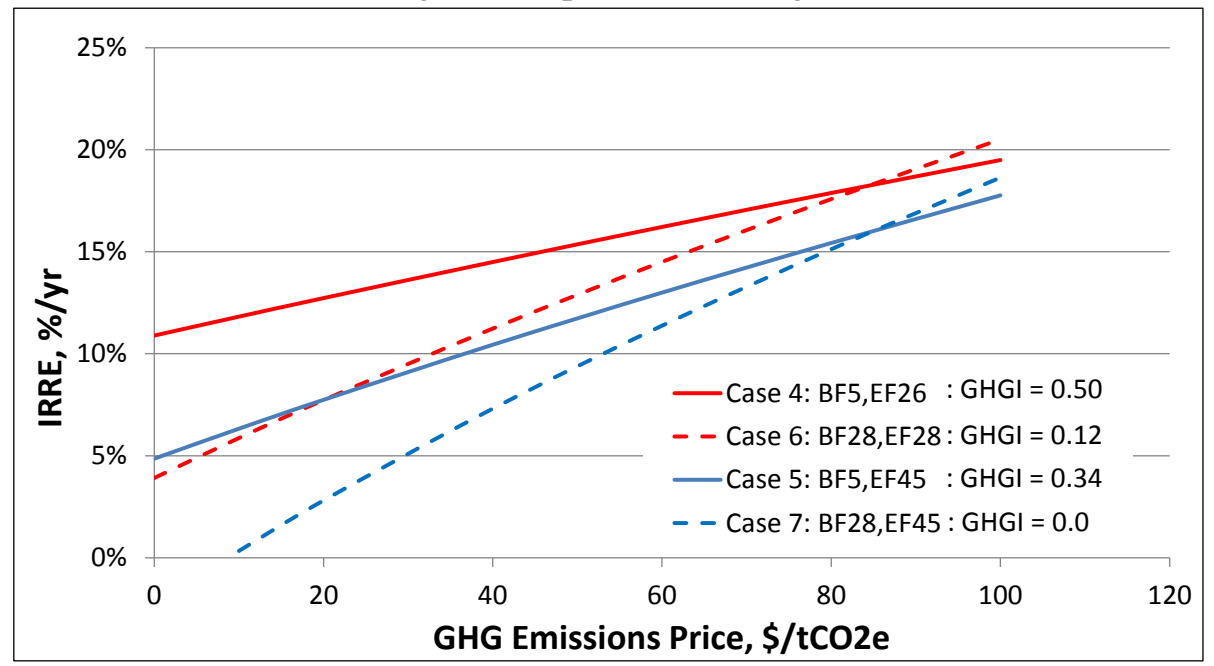

Figure 4. Internal rate of return on equity for cases 4, 5, 6, and 7.

\subsection{Economics with captured $\mathrm{CO}_{2}$ sold for EOR}

In the results discussed above, it was assumed that captured $\mathrm{CO}_{2}$ is compressed, transported by pipeline, and injected into a deep underground saline aquifer for long-term storage. An alternative means of storage would be injection into existing oil wells to promote enhanced oil recovery (EOR). With this option, the injected $\mathrm{CO}_{2}$ would ultimately be stored in the well reservoir once production of oil ended and the well was plugged. We did not evaluate this option in detail, but we made some preliminary estimates of how the economics would change when a coproduction facility receives revenue for $\mathrm{CO}_{2}$.

Figure 5 shows our estimates of the $\mathrm{LCOE}$ as a function of the sale price of $\mathrm{CO}_{2}$ in the absence of any greenhouse gas emission price. (The LCOE estimates when $\mathrm{CO}_{2}$ is stored in aquifers are also indicated.) Results are shown for a $\mathrm{CO}_{2}$ sale price range from $\$ 20 / \mathrm{t}$ to $\$ 35 / \mathrm{t}$. Current market prices for $\mathrm{CO}_{2}$ sold for EOR are estimated to range from $\$ 25 / \mathrm{t}$ to $\$ 40 / \mathrm{t}$. (As in earlier cost analyses, the liquid coproducts are assumed to be sold into a transportation fuels market characterized by a $\$ 90 / \mathrm{bbl}$ crude oil price.) Also shown in Figure 5, for reference, is the LCOE for a new supercritical pulverized coal (PC) plant venting $\mathrm{CO}_{2}$. Cases 3, 4, and 5 all have LCOE lower than that for the PC plant across the full range of plotted $\mathrm{CO}_{2}$ selling prices. Case 4 , with the lowest BF and EF values has a LCOE of $\$ 10$ per MWh when $\mathrm{CO}_{2}$ sells for $\$ 20 / \mathrm{t}$ and $\$ 0 / \mathrm{MWh}$ for $\mathrm{CO}_{2}$ selling for $\$ 27 /$ t. Case 7 , with high BF and high $\mathrm{EF}$, has $\mathrm{LCOE}$ above that for the $\mathrm{PC}$ until the selling price of $\mathrm{CO}_{2}$ reaches $\$ 35 / \mathrm{t}$.

Figure 6 shows how the LCOE for cases 6 and 7, each of which achieves large reductions in GHG emissions, change with GHG emissions price when $\mathrm{CO}_{2}$ is sold for EOR at a price of $\$ 27.5 /$ t the average of the range considered in Figure 5). Shown for comparison are LCOE values for two conventional power plants venting $\mathrm{CO}_{2}$ : a new supercritical pulverized coal plant $(\mathrm{GHGI}=1.0)$ and a new natural gas 
combined cycle $(\mathrm{GHGI}=0.51)$. With zero $\mathrm{GHG}$ emission price, case 6 is the lowest-cost performer. For case 7, when the GHG emission price reaches $\$ 5 /$ t the LCOE competes with that for the coal plant and when the price reaches $\$ 10 / t$, the LCOE competes with the natural gas plant.

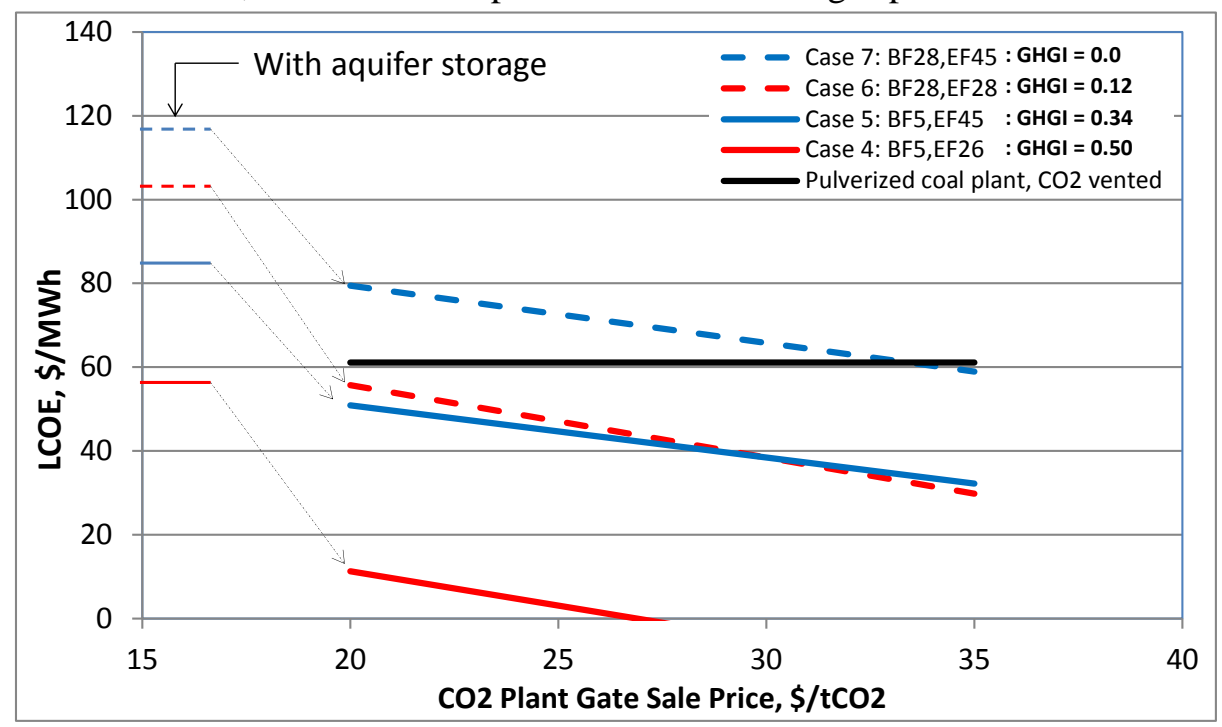

Figure 5. $\mathrm{LCOE}$ as a function of $\mathrm{CO}_{2}$ selling price for cases 4, 5, 6, and 7, assuming $\mathrm{CO}_{2}$ is sold for EOR. Also shown for reference is the LCOE (based on NETL estimates ${ }^{4}$ ) for a new supercritical pulverized coal plant venting $\mathrm{CO}_{2}$. $\mathrm{LCOE}$ 's for these four cases with aquifer storage of $\mathrm{CO}_{2}$ (discussed earlier) are also shown. The coal price is $\$ 2.04 / \mathbf{G} \mathbf{J}_{\mathrm{HHV}}$.

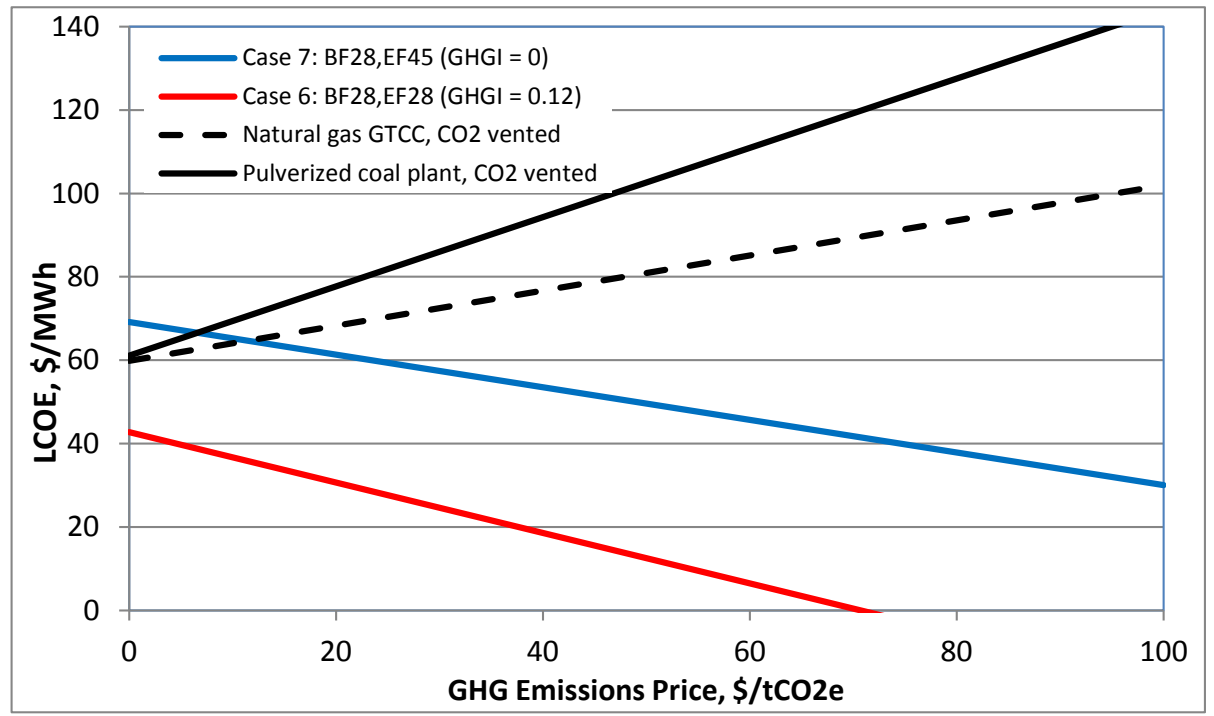

Figure 6. LCOE as a function of greenhouse gas emission price for coproduction case $\mathbf{6}$ (GHGI = 0.12) and case 7 (GHGI $=0$ ) when the facilities sell $\mathrm{CO}_{2}$ for EOR at a price of $\$ 27.5 /$ t. Shown for comparison are LCOE estimates (based on NETL analysis) for a new supercritical pulverized coal plant and a new natural gas combined cycle, both venting $\mathrm{CO}_{2}$. Assumed fossil fuel prices are \$6.35/GJ $\mathbf{J}_{\mathrm{HHV}}$ for natural gas and $\$ 2.04 / \mathrm{GJ}_{\mathrm{HHV}}$ for coal. The fossil fuel plants are assumed to operate with $85 \%$ capacity factor.

\footnotetext{
${ }^{4}$ NETL, Cost and Performance Baseline for Fossil Energy Plants, Volume 1: Bituminous Coal and Natural Gas to Electricity, DOE/NETL2007/1281, Final Report, May 2007. (Also, DOE/NETL-2010/1397, (Rev. 2), November 2010.)
} 


\subsection{Economics of co-production vs. liquids-only production under a carbon mitigation policy}

A comparison of Cases 6 and 8 shows that for systems coprocessing the same percentage of biomass in the feedstock (28\%), a much lower GHGI is realized for the coproduction option $(\mathrm{EF}=0.28)$ than for the option making mainly liquid fuels $(\mathrm{EF}=0.02)$ : 0.12 for Case 6 vs 0.42 for Case 8 . Figure 7 provides a perspective on the relative profitability of these two options under a range of GHG emission prices: Case 8 offers a higher IRRE for low GHG emissions prices, but Case 6 is more profitable at high GHG emissions prices. In both cases the systems would be much more profitable than a coal IGCC-CCS (built around the same dry-feed gasifier), for which GHGI is 0.16 . The latter comparison suggests the importance of examining the LCOE for Case 6 in relation to the LCOEs for alternative power only systems offering low GHGI values.

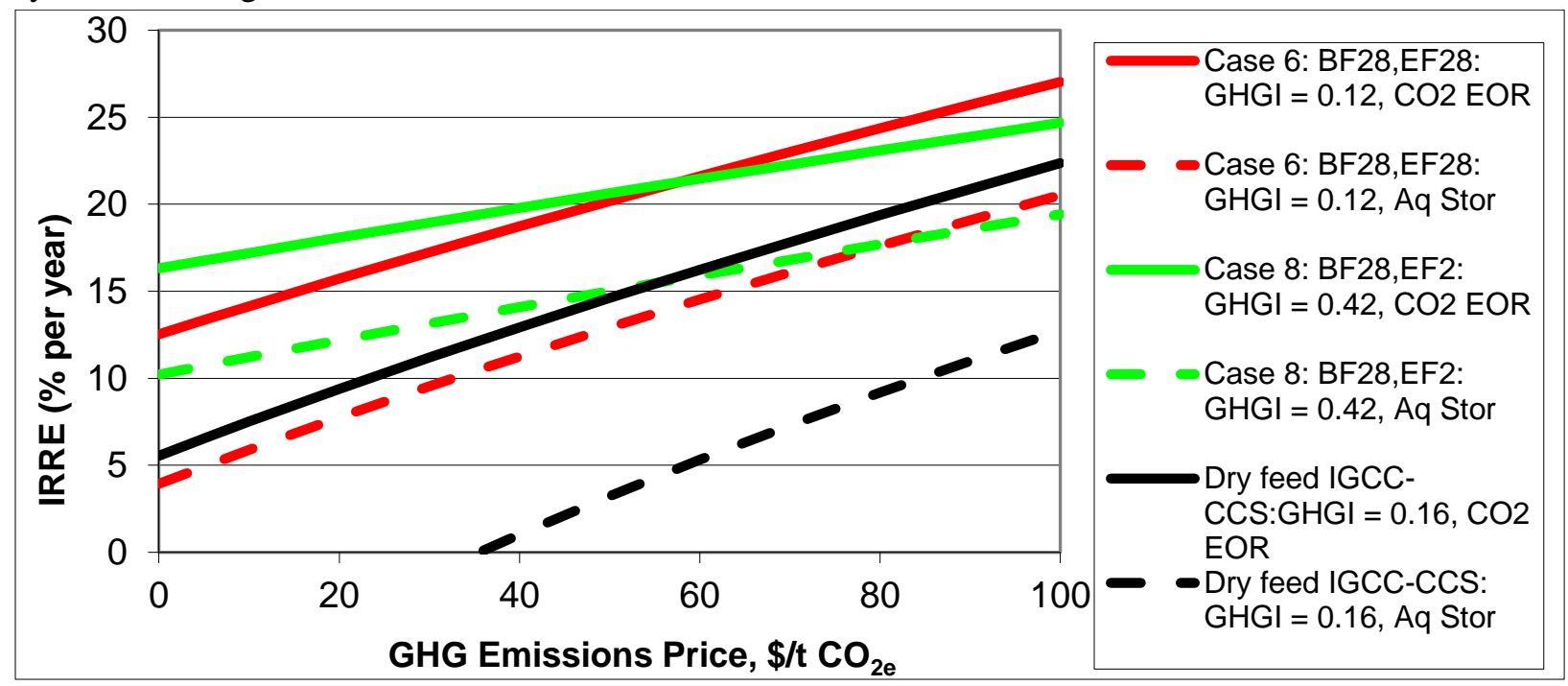

Figure 7. IRRE as a function of greenhouse gas emission price for Case 6 (Co-production with GHGI $=0.12$ ) and Case 8 (primarily liquids production with GHGI = 0.42) and an IGCC using dry-feed (Shell) gasifier based on Princeton IGCC analysis results (see Table 12 in Section 6.1). Two curves are shown for each case, one assuming aquifer storage of $\mathrm{CO}_{2}$ and one assuming $\mathrm{CO}_{2}$ storage via use for enhanced oil recovery. The assumed $\mathrm{CO}_{2}$ sale price for $\mathrm{EOR}$ is $\$ 27.5 / \mathrm{t}$. Assumed coal price is $\$ 2.04 / \mathbf{G J}_{\mathrm{HHV}}$. The IGCC is assumed to operate with $85 \%$ capacity factor.

Figure 8 makes such a comparison for both aquifer storage and $\mathrm{CO}_{2} \mathrm{EOR}$ applications, again assuming in the latter case a plant-gate $\mathrm{CO}_{2}$ selling price of $\$ 27.5 / \mathrm{t}$ and also including in the comparison NGCC options without and with CCS. This figure shows that not only is the LCOE for Case 6 lower than that for IGCC-CCS at all GHG emissions prices in both the aquifer storage and $\mathrm{CO}_{2} \mathrm{EOR}$ cases, but also that Case 6 would be a strong competitor to NGCC systems.

In the EOR application the Case $6 \mathrm{LCOE}$ is $\sim 2 / 3$ of the LCOE for a NGCC-V system at a zero GHG emissions price, and the LCOE gap between these options grows rapidly with GHG emissions price. In the aquifer storage application, the GHG emissions price at which Case 6 and the NGCC-CCS have the same LCOE is $\$ 20 / \mathrm{tCO}_{2} \mathrm{e}$. The breakeven between Case 6 and NGCC-V occurs at $\$ 41 / \mathrm{CO}_{2} \mathrm{e}$. At the $\$ 82 / \mathrm{t} \mathrm{GHG} \mathrm{emissions} \mathrm{price} \mathrm{at} \mathrm{which} \mathrm{IRRE} \mathrm{breakeven} \mathrm{occurs} \mathrm{between} \mathrm{Case} 6$ and Case 8 options for aquifer storage (see Figure 7), the natural gas price would have to be less than $\$ 1.0 / \mathrm{GJ}$ in order for the least-costly NGCC option at this GHG emission price (NGCC-CCS) to have a lower LCOE value than that for Case 6. This shows that in the presence of a strong carbon mitigation policy coal-consuming coproduction options such as Case 6 would be strong competitors with natural gas. 


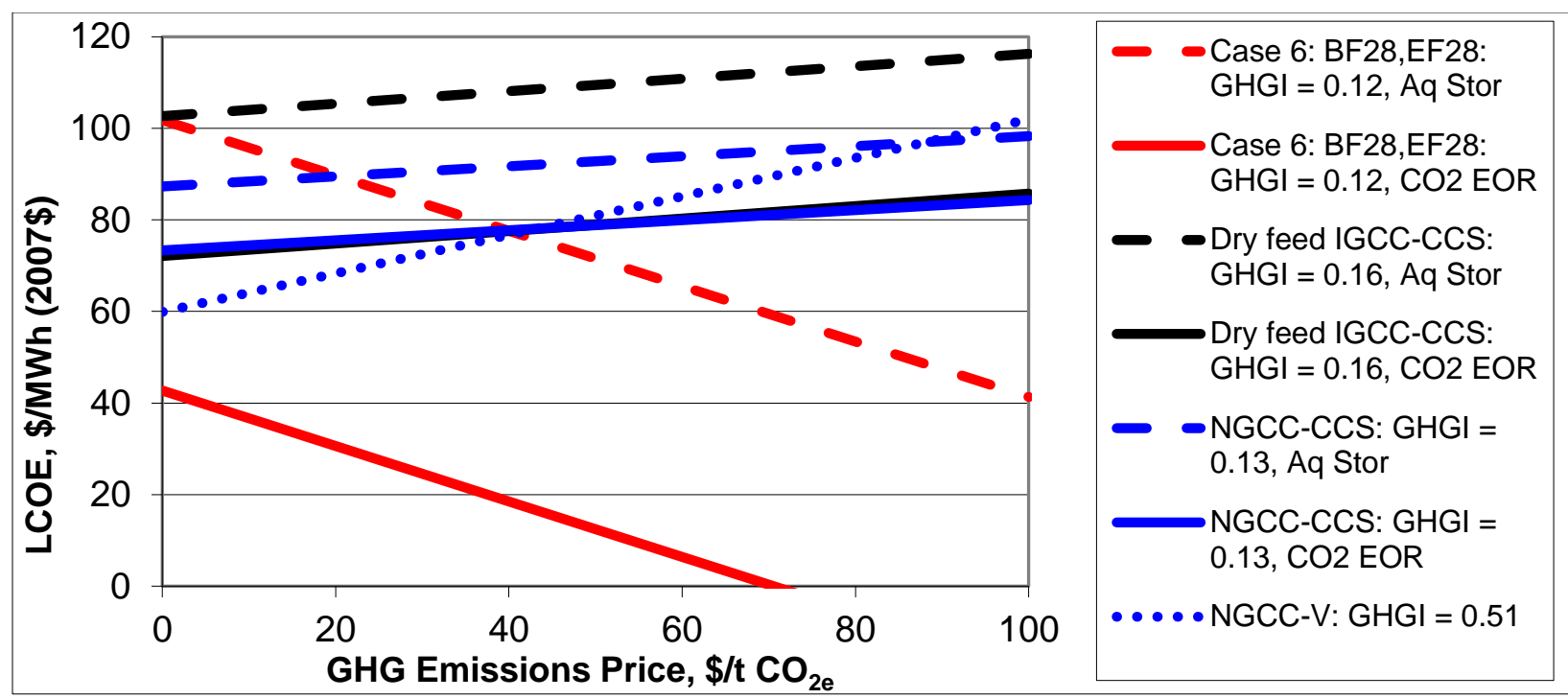

Figure 8. LCOE as a function of greenhouse gas emission price for Case 6 (Co-production with GHGI = 0.12), an IGCC using dry-feed (Shell) gasifier based on Princeton IGCC analysis (see Table 12 in Section 6.1), and for NGCC without with CCS. Two curves are shown for each case involving CCS, one assuming aquifer storage of $\mathrm{CO}_{2}$ and one assuming $\mathrm{CO}_{2}$ storage via use for enhanced oil recovery. The assumed $\mathrm{CO}_{2}$ sale price for $\mathrm{EOR}$ is $\$ 27.5 /$ t. Assumed coal price is $\$ 2.04 / G J_{H H V}$. The IGCC and NGCC are assumed to operate with $85 \%$ capacity factor.

\subsection{Summary}

Our major findings for co-production of electricity and gasoline from coal and biomass (as described fully in Appendix B) are:

1) Systems with dry-feed and slurry-feed gasification show comparable economics when the biomass portion of the feed to the gasifier is torrefied. Given the uncertainties regarding the feasibility of high-solids slurries of torrefied biomass (see Appendix A), dry-feed gasification is a more promising direction in the near term for cogasification in the context of MTG/power systems with CCS.

2) With dry-feed gasification, torrefaction of the biomass provides a slight economic benefit over the use of non-torrefied biomass. The greater technical challenges with feeding non-torrefied material to an entrained flow gasifier further increase the attractiveness of torrefaction.

3) Advanced liquid-phase methanol synthesis provides a modest cost benefit over the use of conventional gas-phase synthesis.

4) The electricity fraction, $\mathrm{EF}$, and the biomass fraction, $\mathrm{BF}$, are design parameters that significantly impact the environmental and economic performance of CBTG systems.

a) A 50\% reduction in greenhouse gas emissions $(\mathrm{GHGI}=0.5)$ is achieved with a small $\mathrm{BF}$ $(0.05)$ and a modest EF (0.26). Greater GHG emission reductions can be achieved with higher $\mathrm{EF}$ values, but economics are less favorable. In the absence of a greenhouse gas emissions price, these values of $\mathrm{BF}$ and $\mathrm{EF}$ provide a levelized cost of electricity comparable to that for a new pulverized coal-fired power plant, if the oil price is about $\$ 90$ per barrel. Selling the $\mathrm{CO}_{2}$ for enhanced oil recovery significantly improves the competitiveness of the coproduction option, presenting a strategic opportunity not only for early market launch of coproduction systems with CCS but also for launching lignocellulosic biomass supplies in the market.

- With a higher biomass fraction $(\mathrm{BF}=0.30)$, larger reductions in greenhouse gas emissions (up to $100 \%$ reduction) can be achieved, but no plant design with this $\mathrm{BF}$ can provide competitive economics without a price on GHG emissions when the oil price is $\$ 90 / \mathrm{bbl}$. A 
GHG emission price of $\$ 30$ to $\$ 50$ per $\mathrm{tCO}_{2} \mathrm{e}$ would make the LCOE for some high BF systems competitive with a new pulverized coal plant that vents $\mathrm{CO}_{2}$. If $\mathrm{CO}_{2}$ could be sold into EOR markets, the required GHG emission price would be only $\$ 10$ per $\mathrm{tCO}_{2} \mathrm{e}$ for a coproduction system achieving a GHGI of zero. No GHG emission price would be needed for coproduction systems that achieve GHGI of 0.1 (or higher) to be competitive.

5) In the presence of a strong carbon mitigation policy (high GHG emissions price) the use of coal in coproduction options has the potential to strongly compete in power generation markets with natural gas combined cycles.

\section{Electricity-Olefins Coproduction}

\subsection{Process designs}

Plant designs for co-producing electricity and light olefins (ethylene and propylene) from coal and/or biomass with $\mathrm{CO}_{2}$ capture closely resemble systems for co-producing electricity and gasoline described above. Both processes involve intermediate synthesis of methanol that is subsequently converted to the final product. Figure 9 shows the basic process layout for a coal-only design. Dry-feed gasification, liquid-phase methanol synthesis, and UOP/Hydro's Methanol-to-Olefins (MTO) technology were adopted in all cases. For plants co-processing some biomass, torrefaction of the biomass was assumed. We designed and analyzed five process configurations with varying BF and EF values (Table 5). Details of our analysis are provided in Appendix C.

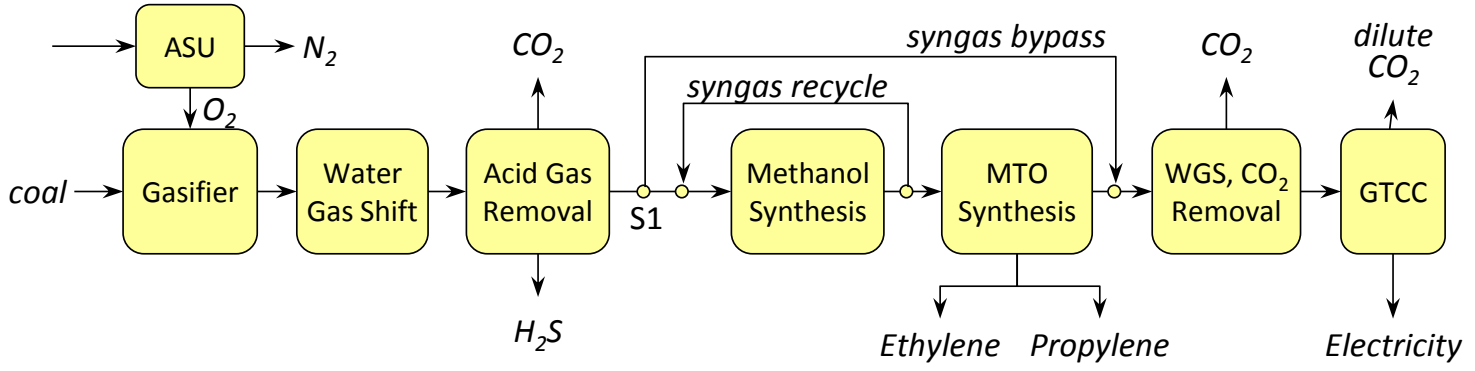

Figure 9. Simplified process diagram for coal conversion to light olefins and electricity.

The scales of facilities were selected to enable meaningful comparisons between cases:

- The CBTO-EF50HB case co-processes a large biomass fraction (HB = high biomass fraction) and produces half of its output as electricity (EF50). For this case, we set an annual biomass consumption of 1 million dry metric tonnes per year (at $90 \%$ capacity factor), a likely practical biomass supply limit under a variety of conditions, as noted in Section 2. The coal input rate for this case is then set by the stipulated $30 \%$ biomass input fraction.

- The CBTO-EF25HB case maintains the same inputs of coal and biomass as CBTO-EF50HB, but the plant is designed with $\mathrm{EF}=25 \%$.

- For the CBTO-EF25LB, the coal input rate was maintained as in the other two CBTO cases. The biomass fraction was set at 5\% ( $\mathrm{LB}=$ low biomass fraction), and the EF was set to $25 \%$.

- The CTO-EF50 case utilizes coal only, and half of its output is electricity. The coal input rate was set such that the olefins production rate equalled the production rate for the CBTO-EF50HB case (705 metric tonnes per day). 
- The CTO-EF25 case also utilizes only coal but has an electricity fraction of $25 \%$. For this case the coal input was fixed at the same level as for the CTO-EF50 case.

Table 5. Process designs considered for co-production of light olefins and electricity. $\mathrm{CO}_{2}$ capture and storage is included in all five designs.

\begin{tabular}{|c|c|c|c|c|c|}
\hline Process acronym $\gg>$ & $\begin{array}{l}\text { CTO- } \\
\text { EF50 }\end{array}$ & $\begin{array}{l}\text { CTO- } \\
\text { EF25 }\end{array}$ & $\begin{array}{l}\text { CBTO- } \\
\text { EF50HB }\end{array}$ & $\begin{array}{c}\text { CBTO- } \\
\text { EF25HB }\end{array}$ & $\begin{array}{c}\text { CBTO- } \\
\text { EF25LB }\end{array}$ \\
\hline $\begin{array}{l}\text { Biomass Fraction, BF } \\
\left(\mathrm{MW}_{\text {bio }} / \mathrm{MW}_{\text {coal+bio }}\right), \mathrm{HHV}\end{array}$ & \multicolumn{2}{|c|}{0} & \multicolumn{2}{|c|}{0.30} & 0.05 \\
\hline $\begin{array}{l}\text { Electricity Fraction, EF } \\
{\left[\mathrm{MW}_{\mathrm{e}} /\left(\mathrm{MW}_{\mathrm{e}}+\mathrm{MW}_{\text {olefins,LHV }}\right)\right]}\end{array}$ & 0.50 & 0.25 & 0.50 & 0.25 & 0.25 \\
\hline
\end{tabular}

\subsection{Results}

Process mass and energy balances are described in Appendix C. Here we focus on cost-related findings. Key assumptions in this regard are the market values for the co-products. For electricity, we use (as above) \$60/MWh plus a GHG emissions credit assuming displacement of electricity having GHG emissions of $636 \mathrm{kgCO}_{2} \mathrm{e} / \mathrm{MWh}$. For light olefins we consider two reference values: $\$ 0.52 / \mathrm{lb}$ (2007\$), the weighted-average CMAI benchmark contract price in 2010, and $\$ 0.75 / \mathrm{lb}$, the projected value for 2015 . We also consider a GHG emissions credit assuming displacement of conventionally-produced olefins with GHG emissions of $32.9 \mathrm{kgCO}_{2} \mathrm{e} / \mathrm{GJ}_{\mathrm{LHV} \text {,olefin. }}$ This emissions level assumes that olefin-containing products are landfilled at the end of their useful life, effectively permanently sequestering their contained carbon away from the atmosphere.

Figure 10 shows LCOE estimates as a function of GHG emissions price. In the left-hand graph, the cases using coal only (CTO-) show only a modest change with GHG emission price because of the relatively low assumed GHG emissions credit for petroleum-derived olefins displaced. For cases using high biomass fractions (CBTO-EFxxHB), LCOE declines with GHG emissions price due to the negative emissions contributed by the use of CCS with biomass. For the case using a low BF and low EF, the LCOE is relatively flat with GHG emissions price. A GHG price of about $\$ 20 / \mathrm{tCO}_{2} \mathrm{e}$ is sufficient to make all but the CBTO-EF50-HB case competitive with a new coal fired plant (PC-V). The CBTO-EF50HB case requires a still-modest $\$ 35 / \mathrm{tCO}_{2} \mathrm{e}$ to be competitive with the PC-V plant. The dramatically lower LCOE's in the right graph of Figure 10, which assumes the projected 2015 olefin sale price, indicate that LCOE's are quite sensitive to olefin price.

Figure 11 shows internal rates of return as a function of the olefin selling price and for two different GHG emission prices ( $\$ 0$ and $\$ 100 / \mathrm{tCO}_{2} \mathrm{e}$ ). With zero GHG emission price (dashed lines), the cases with the highest olefin output fraction and lowest biomass input fractions give the highest returns. With $\$ 100 / \mathrm{tCO}_{2}$ GHG price (solid lines), the IRRE increases with olefins price in all cases, and the ordering of IRREs changes with the olefin price. The biggest increases in IRRE in going from $\$ 0$ to $\$ 100 / \mathrm{tCO}_{2} \mathrm{e}$ are seen in the two high-biomass cases (CBTO-EF50HB and CBTO-EF25HB), the blue and green pairs of lines in Figure 11. 

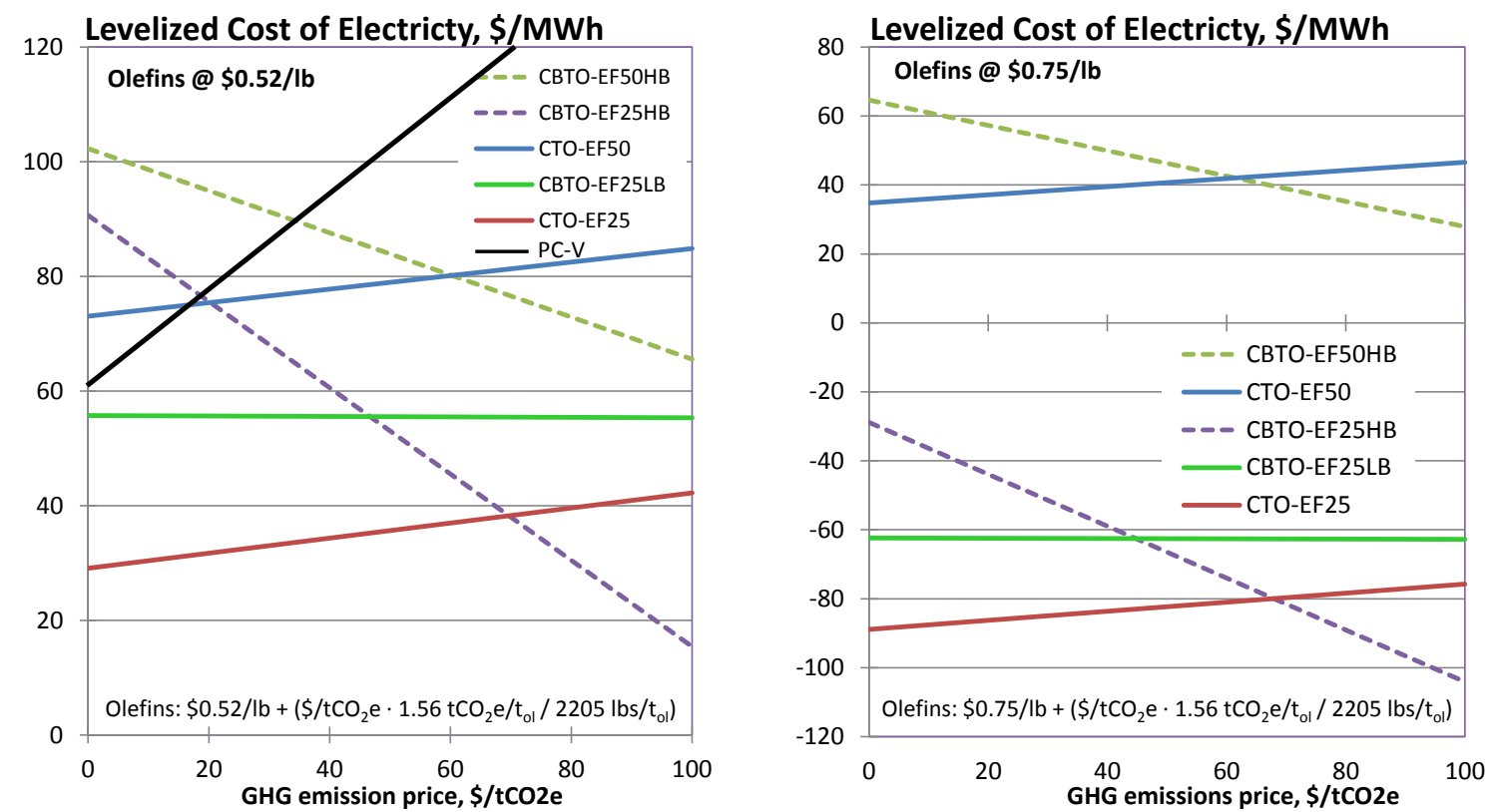

Figure 10. LCOE versus greenhouse gas emissions price for olefin sale price of $\$ 0.52 / \mathrm{lb}$ (left) and $\$ 0.75 / \mathrm{lb}$ (right) plus a GHG emissions credit of $32.87 \mathrm{kgCO}_{2} \mathrm{e} / \mathrm{GJ}_{\mathrm{LHV} \text {,olefins }}$. Also shown on the left is the $\mathrm{LCOE}$ for a new supercritical pulverized coal plant with venting of $\mathrm{CO}_{2}$. The $\mathrm{LCOE}$ for the PC-V incurs a GHG emission charge of $831 \mathrm{kgCO}_{2} \mathrm{e} / \mathrm{MWh}$, the estimated lifecycle emissions for a supercritical pulverized coal plant.

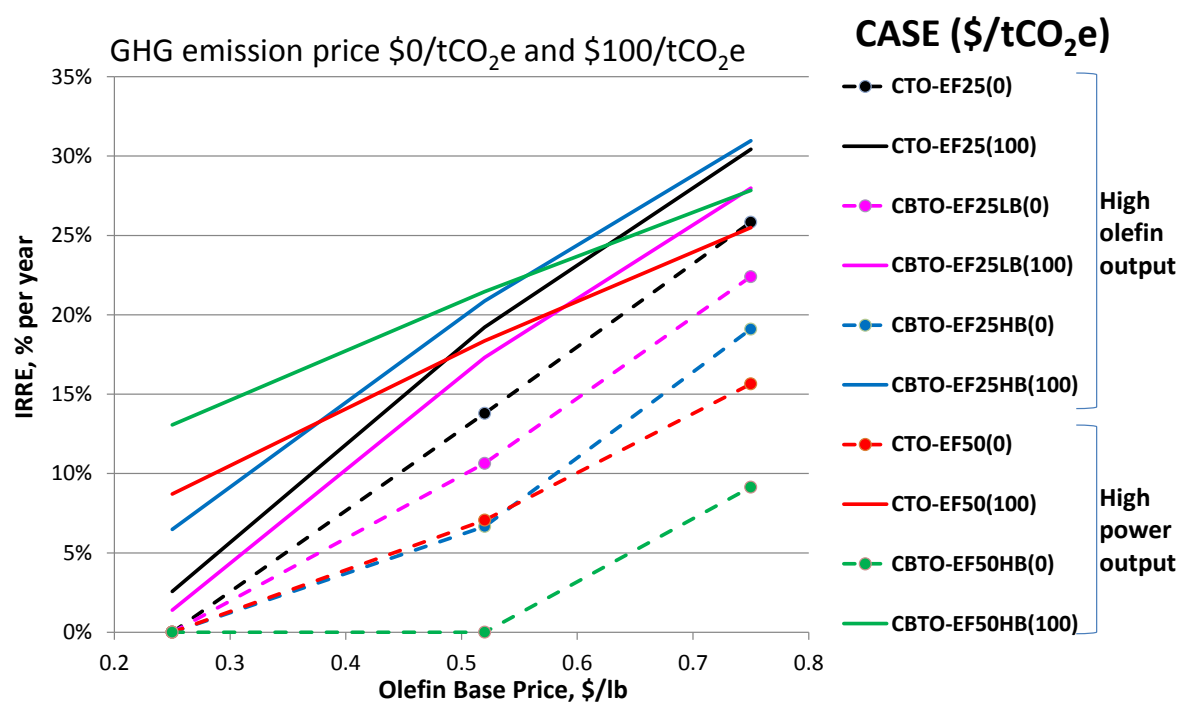

Figure 11. Internal rates of return on equity for olefin-electricity co-production for zero and $\$ 100 / \mathrm{CO}_{2} \mathrm{e} \mathrm{GHG}$ emissions price. IRRE is shown as a function of the olefin base price (to which a GHG emissions credit is added in the case with $\$ 100 / \mathrm{tCO}_{2} \mathrm{e}$ GHG emissions price).

\section{Electricity-Ammonia Coproduction}

Analyses were undertaken for systems coproducing electricity with the agrichemical, ammonia. Since neither of these co-products contain carbon, it is possible to achieve near-complete decarbonization with such systems by employing CCS, but without the need for use of biomass. Accordingly, only coal was considered as the feedstock for these sysetms. Two sets of coproduction cases were developed. One 
set considered steady-state plant operation and a second set examined the potential impacts of timevarying production rates aimed at capitalizing on higher electricity sale prices during peak electricity demand periods to improve overall plant economics. A summary of results is provided here. For detailed discussions and results see Appendix D.

\subsection{Steady-State Coproduction}

Our process simulations and cost estimates for electricity/ammonia co-production from coal with CCS were based on an underlying process design utilizing a Shell dry-feed gasifier that we developed in earlier work for a coal-IGCC system with CCS (Figure 12). This design was modified such that after exiting the acid gas removal unit (AGR), a fraction, $f$, of the $\mathrm{H}_{2}$-rich syngas is sent to the $\mathrm{NH}_{3}$ synthesis

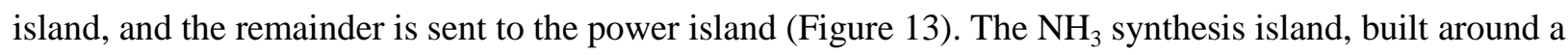
simulated Haldor Topsoe S-300 synthesis reactor, produces purge gas from a pressure swing adsorption (PSA) unit, which is compressed and combined with the remaining syngas $(f-1)$ going to the power island. This fuel gas is humidified, diluted, and heated prior to combustion in the gas turbine. In addition, the $\mathrm{NH}_{3}$ synthesis island produces high quality waste heat, which is integrated with the waste heat recovery steam turbine bottoming cycle.

We set the split fraction, $f$, to $57.8 \%$, which yields a fuel gas stream to the power island that exactly satisfies a single GE 9FB gas turbine operating at full load. For the same coal input rate, the reference IGCC-CCS utilizes two GE 9FB turbines. The performance of both the IGCC-CCS and the $\mathrm{NH}_{3}$ coproduction plant are given in Table 6 . The output power of the coproduction facility is $76 \%$ less than for the IGCC due to the elimination of one gas turbine and the addition of significant parasitic power requirements for the $\mathrm{NH}_{3}$ synthesis island. The latter is a feature of the synthesis process since its inception over a century ago. The resulting electricity fraction for the coproduction plant is $\mathrm{EF}=18 \%$.

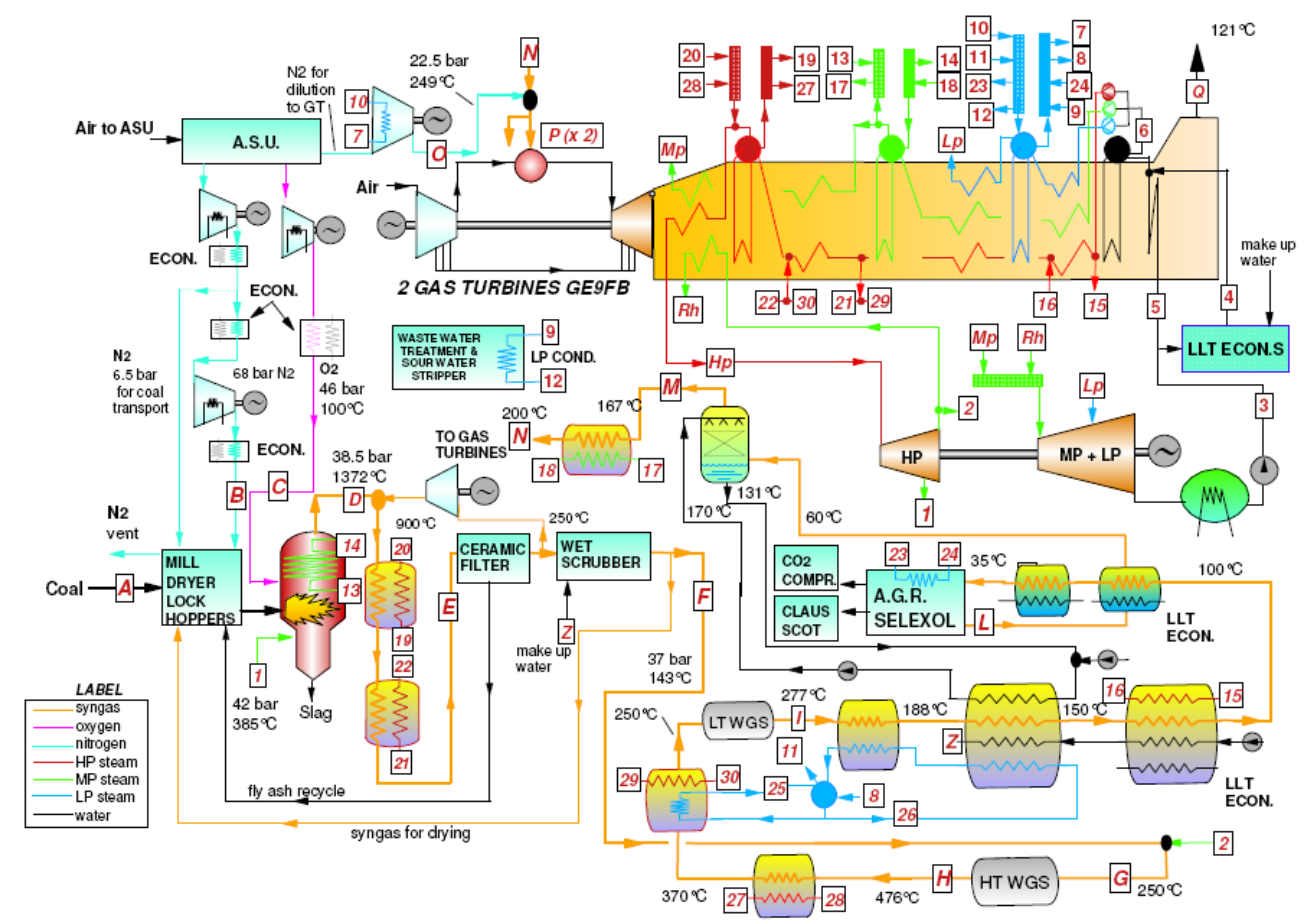

Figure 12. Plant schematic for a reference coal-IGCC system utilizing a Shell gasifier and $\mathrm{CO}_{2}$ capture. This figure shows a conventional water-gas shift (WGS) arrangement. Our modeling considered a modestly advanced WGS system, as described in Appendix D. 
Table 6. Performance comparison for coproduction and stand-alone electricity production with CCS.

\begin{tabular}{|c|c|c|}
\hline & $I G C C$ & $\mathrm{Pwr}+\mathrm{NH}_{3}$ \\
\hline \multicolumn{3}{|l|}{ Power Consumption, $M W_{e}$ : } \\
\hline Coal handling, gasifier & 18.42 & 18.42 \\
\hline ASU, $\mathrm{O}_{2} \& \mathrm{~N}_{2}$ compr., pumps & 128.69 & 128.69 \\
\hline AGR, Claus, SCOT units & 19.75 & 19.75 \\
\hline $\mathrm{CO}_{2}$ drying \& compression & 35.18 & 35.18 \\
\hline Ammonia $\mathrm{N}_{2}$ compressor & 0 & 13.52 \\
\hline Ammonia plant compressors & 0 & 37.59 \\
\hline Ammonia refrigeration & 0 & 22.01 \\
\hline PSA purge gas compressor & 0 & 26.82 \\
\hline Total onsite power need, $M W_{e}$ & 202.04 & 301.98 \\
\hline GT net power (GE $9 F B), M_{e}$ & 593.92 & 296.56 \\
\hline ST net power, $\mathrm{MW}_{\mathrm{e}}$ & 300.58 & 171.03 \\
\hline Net power export, $M W_{e}$ & 692.46 & 165.61 \\
\hline Co-product $\mathrm{NH}_{3}$, tonne/day & 0 & $2,824.3$ \\
\hline Coal input, $\mathrm{MW}_{\text {th }} \mathrm{LHV}$ & $1,841.6$ & $1,841.6$ \\
\hline Overall carbon capture, $\%$ & 93.09 & 93.09 \\
\hline GHG emiss., $\mathrm{kg} \mathrm{CO} \mathrm{CO}_{2 \text { eq }} / \mathrm{MWh}$ & 101.39 & 423.96 \\
\hline
\end{tabular}

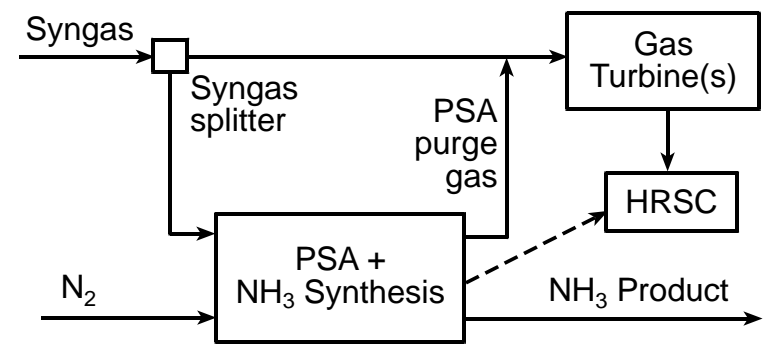

Figure 13. Schematic of the $\mathrm{NH}_{3}$ and power islands.

Table 7 gives estimated total plant cost (TPC) for the IGCC and the coproduction design. The TPC's are within about $5 \%$ of each other.

For purposes of economic analysis, both the revenue received for $\mathrm{NH}_{3}$ and for electricity are assumed to vary with the natural gas price, since $\mathrm{NH}_{3}$ is conventionally produced from natural gas and since a natural gas combined cycle (NGCC) is

typically the marginal generator on the grid in the U.S. A 20 -year levelized natural gas price of $\$ 6 / \mathrm{GJ}_{\mathrm{HHV}}$ is taken as a reference value. (With zero GHG emissions price, the selling price of electricity generated by a NGCC with these assumptions is $\$ 49 / \mathrm{MWh}$.)

Levelized costs of electricity $(L C O E)$ and internal rates of return on equity (IRRE) are shown in Table 8 for both the reference IGCC-CCS and the coproduction plant at two greenhouse gas emission prices: 0 and $100 \$$ /tonne $\mathrm{CO}_{2} \mathrm{e}$. (See Appendix D for detailed financial parameter assumptions.) The LCOE metric is of doubtful significance for this coproduction facility since it is producing only a modest electricity fraction. ${ }^{5}$ In any case, at $100 \$ /$ tonne $\mathrm{CO}_{2} \mathrm{e}$ and $\$ 6 / \mathrm{GJ}_{\mathrm{HHV}}$ gas, neither the IGCC-CCS nor the coproduction plant have particularly attractive IRRE (Table 8 ). If the price of natural gas were $8 \$ / G_{\mathrm{HHV}}$, the profitability of either plant design improves (Table 8). The IRRE of the coproduction plant exceeds that of the IGCC, which will be the case for any natural gas price because the selling prices of both coproducts are tied to the price and carbon intensity of natural gas, and thus highly correlated. See Appendix D for additional discussion.

Table 7. "Overnight" capital costs $\left(10^{6} 2008 \$\right)$ by major component, and total plant costs (TPC).

\begin{tabular}{|c|c|c|}
\hline Plant component & $I G C C$ & $\mathrm{Pwr}+\mathrm{NH}_{3}$ \\
\hline Coal and sorbent handling & 43.8 & 43.8 \\
\hline Coal preparation $\&$ feeding & 220.0 & 220.0 \\
\hline Ash handling & 51.5 & 51.5 \\
\hline Stand-alone ASU $+\mathrm{O}_{2}$ compressor & 204.0 & 204.0 \\
\hline Shell gasifier \& SG coolers & 385.6 & 385.6 \\
\hline LT heat recovery \& FG saturation & 37.5 & 37.5 \\
\hline Water-gas shift reactors & 2.3 & 2.3 \\
\hline Gas cleanup BOP & 12.3 & 12.3 \\
\hline AGR $\left(\mathrm{H}_{2} \mathrm{~S}\right.$ capture only) & 49.8 & 49.8 \\
\hline AGR $2^{\text {nd }}$ stage $\left(\mathrm{CO}_{2}\right.$ capture $)$ & 116.8 & 116.8 \\
\hline Claus plant & 19.9 & 19.9 \\
\hline $\mathrm{CO}_{2}$ compression and drying & 50.9 & 50.9 \\
\hline GE F9B gas turbine(s) & 127.8 & 68.5 \\
\hline HRSG, ductwork, \& stack & 74.4 & 46.7 \\
\hline Steam turbine, condenser $\&$ aux. & 78.6 & 53.9 \\
\hline Pressure Swing Adsorption (PSA) & 0.0 & 33.8 \\
\hline PSA purge gas compressor & 0.0 & 17.9 \\
\hline Ammonia production (minus PSA) & 0.0 & 140.7 \\
\hline Balance of plant & 269.6 & 284.4 \\
\hline Total Plant Cost (TPC), $10^{6} 2008 \$$ & 1,745 & 1,840 \\
\hline
\end{tabular}

\footnotetext{
${ }^{5}$ Note that LCOE must rise to infinity as the electricity/ $\mathrm{NH}_{3}$ product ratio approaches zero.
} 
Table 8. LCOE and IRRE, with gas price of $6 \$ / G J_{H H V}$ except were indicated.

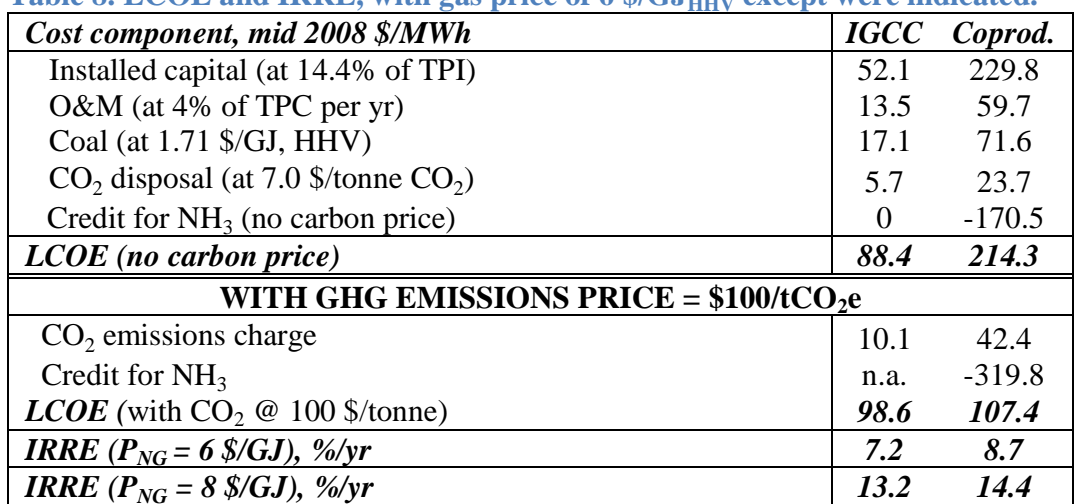

Note: Based on correlations given in Appendix D, the assumed market prices of the coproducts, when the GHG emission price is $\$ 100 / \mathrm{tCO}_{2} \mathrm{e}$ and the natural gas price is $\$ 6 / \mathrm{GJ}_{\mathrm{HHV}}$, are $91.5 \$ / \mathrm{MWh}$ for electricity and $\$ 450 / \mathrm{t}$ for $\mathrm{NH}_{3}$.

\subsection{Time-Dependent Coproduction}

Considering that electricity prices fluctuate in the course of any given day, a preliminary analysis was carried out to investigate the potential for improving coproduction economics by varying the ratio of electricity-to- $\mathrm{NH}_{3}$ produced as a function of the electricity sale price. This idealized analysis ignores the practical challenges of relatively rapidly turning up or turning down different plant components, efficiency penalties that might be suffered with equipment cycling, and long-term maintenance and equipment fatigue issues with repeated cycling. Such issues are non-negligible ones that would need to be considered should this preliminary analysis suggest promising economics for time-dependent operation.

For this analysis, we model the electricity price over the course of a day based on a 3-year average of the actual Locational Marginal Price (LMP) at the PSEG node of the PJM independent system operator. A sinusoidal curve represents these averaged data reasonably well (Figure 14) and is used for analytical simplicity.

Three Year Average (2009-2011)

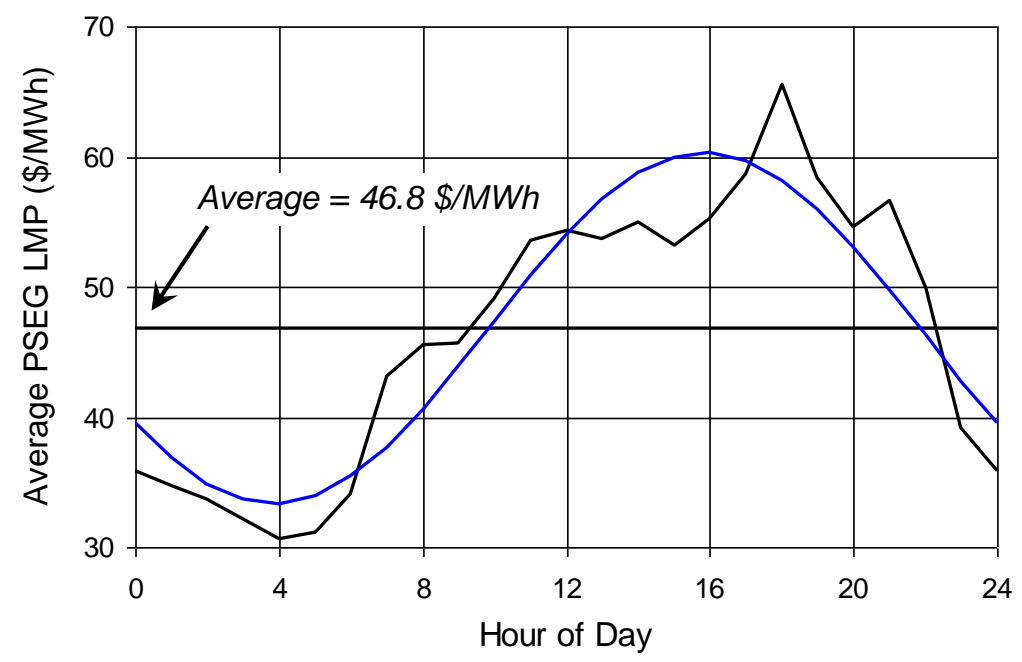

Figure 14. Three-year daily average of real-time hourly Locational Marginal Prices from the PSEG node of the PJM ISO. 
The plant design that we adopt is a hybrid of the IGCC and coproduction plant designs described in the previous section. In particular, the design of the upstream syngas production area is kept fixed, but the power island is designed with two gas turbines, and an $\mathrm{NH}_{3}$ synthesis island is included in the configuration as well. The estimated TPC for this hybrid plant design is $\$ 1,973$ million, readily calculated from the disaggregated component costs in Table 7.The operating strategy for this hybrid plant is to maintain constant syngas production at all times. The syngas is sufficient to run either the full power island (IGCC-mode) or one gas turbine plus the $\mathrm{NH}_{3}$ synthesis island (co-production mode). The IGCC mode would be "turned on" (and the synthesis island turned off) during periods of sufficiently high electricity prices. The $\mathrm{NH}_{3}$ sales price is assumed to remain constant at $\$ 450 / \mathrm{t}$, the estimated value when natural gas is $\$ 6 / \mathrm{GJ}$ and the GHG emissions price is $\$ 100 / \mathrm{tCO}_{2} \mathrm{e}$. Appendix D discusses the details of the algorithm for determining when the electricity price was sufficiently high to justify operating in the IGCC mode.

We found that for the sinusoidal electricity price profile representative of the LMPs at the PSEG node on the PJM grid, the IRRE for the hybrid plant exceeds that of the dedicated IGCC-CCS (described in Table 8) by less than 1 percentage point. It is actually about half a percentage point lower than the IRRE for the steady-state coproduction plant (also shown in Table 8). Thus, rather than commit to the additional capital and operational complexity for a flexible hybrid, it would appear to make more economic sense to build a dedicated coproduction plant. It is also worth noting that, because the market prices of both ammonia and electric power are tied to the price of natural gas, a hybrid plant will not offer any particular hedge against the possibility of falling gas prices.

\section{Electricity-Hydrogen Coproduction}

Systems for coproducing hydrogen plus electricity were analyzed in a similar fashion as the systems for ammonia plus electricity described in Section 4. Two plant designs are developed and compared. Each

Table 9. Plant performance, with breakdown of power consumption by unit.

\begin{tabular}{|l|cc|}
\hline & IGCC & H $_{2}$ Plant \\
\hline Power Consumption, $M W_{e}:$ & & \\
$\mathrm{O}_{2}$ production & 28.5 & 53.9 \\
$\mathrm{O}_{2}$ compression & 18.2 & 34.4 \\
$\mathrm{~N}_{2}$ compression & 28.5 & 0.0 \\
$\mathrm{CO}_{2}$ drying \& compression & 22.8 & 43.1 \\
PSA purge gas compressor & 0.0 & 11.7 \\
Auxiliaries (+ Selexol, PSA) & 23.0 & 36.3 \\
Auxiliary power, $M W e$ & 120.9 & 179.4 \\
GT net power & 293.7 & 78.8 \\
ST net power & 179.3 & 139.5 \\
Syngas expander & 9.8 & 0.0 \\
Net electric power, $M W e$ & 361.9 & 38.9 \\
Co-product $\mathrm{H}_{2}$, tonne/day & - & 771.0 \\
\hline Coal input, $\mathrm{MW}_{\text {th }} \mathrm{LHV}$ & 983.6 & $1,862.7$ \\
Overall carbon capture, $\%$ & 91.3 & 91.3 \\
\hline
\end{tabular}

9, and Table 10 gives disaggregated component capital cost estimates developed used the same capital costing model employed throughout this study. uses coal as the feedstock, and each captures $\mathrm{CO}_{2}$ for underground storage. One plant makes only electricity (IGCC-CCS), and other makes primarily $\mathrm{H}_{2}$ with a small electricity co-product. Earlier work (outside of the present project) indicated that electricity plus $\mathrm{H}_{2}$ coproduction would be more economical when the raw syngas leaving the gasifier is cooled using a total water quench instead of radiative + convective heat exchange, so the former (with a GE gasifier) is employed. The IGCC design is otherwise very similar to that shown above in Figure 12. The power island is based on a Siemens V94.3a gas turbine ( 266 MWe on natural gas) when producing only power and a V64.3a ( $\sim 67 \mathrm{MWe}$ on natural gas) when producing $\mathrm{H}_{2}$. The performance of the IGCC and the $\mathrm{H}_{2}+$ electricity plant are summarized in Table 
Economics for the two plants are summarized in Table 11. Note that $\mathrm{CO}_{2}$ disposal costs vary between the plants because of the different flow rates of stored $\mathrm{CO}_{2}$. The LCOE for the GE-quench-based IGCC (Table 11) is quite similar to (but slightly higher than) for the Shell-based IGCC (Table 8). At a natural gas price of $\$ 6 / \mathrm{GJ}_{\mathrm{HHV}}$ and a $\mathrm{GHG}$ emissions price of $\$ 100 / \mathrm{tCO}_{2} \mathrm{e}$, the value of the produced electricity is $\sim 91$ \$/MWh, making for low-profitability for this IGCC plant $(I R R E<6 \%)$. In the case of the $\mathrm{H}_{2}$ plant, however, the relatively high value of the produced $\mathrm{H}_{2}\left(\$ 2.6 / \mathrm{kg}\right.$, the estimated cost of making $\mathrm{H}_{2}$ from $\$ 6 /$ GJ natural gas via steam methane reforming, with GHG emissions priced at $\$ 100 / \mathrm{tCO}_{2} \mathrm{e}$ ) yields a veryprofitable IRRE of $27.7 \%$. Because the market value of the product for the IGCC and the $\mathrm{H} 2$ plant are both tied to the price of natural gas, the $\mathrm{H}_{2}$ plant will always be more profitable than the IGCC regardless of the gas price. This result was also found in the ammonia and electricity analysis in Section 4, but the difference in profitability between the power-only and coproduction plants is substantially larger with coproduction.

Table 10. "Overnight" capital costs (M\$) for major plant components, and total plant cost (TPC) for each case.

\begin{tabular}{|l|cc|}
\hline Plant component & IGCC & H $_{2}$ Plant \\
\hline Coal and sorbent handling & 29.6 & 45.4 \\
\hline Coal preparation \& feeding & 40.6 & 73.0 \\
\hline Ash handling & 37.4 & 57.3 \\
\hline Stand-alone ASU + O $_{2}$ comp. & 127.2 & 231.0 \\
\hline Shell gasifier \& SG coolers & 86.0 & 154.8 \\
\hline LT heat recovery \& FG saturation & 22.9 & 41.1 \\
\hline Water-gas shift reactors & 10.6 & 19.0 \\
\hline Gas cleanup BOP & 6.9 & 12.4 \\
\hline AGR (H2S capture only) & 72.0 & 129.6 \\
\hline AGR 2nd stage (CO2 capture) & 64.0 & 115.2 \\
\hline Claus plant & 33.8 & 51.9 \\
\hline CO2 compression and drying & 38.0 & 68.4 \\
\hline Siemens V64.3A gas turbine & 0.0 & 45.2 \\
\hline Siemens V94.3A gas turbine & 107.4 & - \\
\hline HRSG, ductwork, \& stack & 39.6 & 16.4 \\
\hline Steam turbine, condenser \& aux. & 55.6 & 47.0 \\
\hline Pressure Swing Adsorption (PSA) & 0.0 & 38.1 \\
\hline PSA purge gas compressor & 0.0 & 12.1 \\
\hline Balance of plant & 141.0 & 211.6 \\
\hline Total Plant Cost (TPC), M\$ & $\mathbf{9 1 2 . 6}$ & $\mathbf{1 , 3 6 9}$ \\
\hline
\end{tabular}

Table 11. $L C O E, L C O H$ and IRRE, with gas price of $\$ 6 / G_{\mathrm{HHV}}$ except were indicated.

\begin{tabular}{|c|c|c|}
\hline Cost component (mid-2008 US \$) & $\begin{array}{c}\boldsymbol{I} \boldsymbol{G C C} \\
(\$ / \mathrm{MWh})\end{array}$ & $\begin{array}{c}\mathrm{H}_{2} \text { Plant } \\
\left(\$ / \mathrm{kg} \mathrm{H}_{2}\right)\end{array}$ \\
\hline Installed capital (at $14.4 \%$ of TPI) & 52.16 & 0.882 \\
\hline O\&M (at $4 \%$ of TPC per yr) & 13.54 & 0.229 \\
\hline Coal (at $\left.1.71 \$ / \mathrm{GJ}_{\mathrm{HHV}}\right)$ & 17.62 & 0.376 \\
\hline $\mathrm{CO}_{2}$ disposal (at 8.4/6.9\$/mt $\mathrm{CO}_{2}$ ) & 7.02 & 0.123 \\
\hline Electricity credit (at $49.4 \$ / \mathrm{MWh}$ ) & 0.00 & -0.060 \\
\hline LCOE, LCOH (no carbon price) & 90.33 & 1.550 \\
\hline \multicolumn{3}{|c|}{ WITH GHG EMISSIONS PRICE $=\$ 100 / \mathrm{tCO}_{2} \mathrm{e}$} \\
\hline $\mathrm{CO}_{2}$ emissions charge & 11.59 & 0.247 \\
\hline Electricity credit (at $91.45 \$ / \mathrm{MWh}$ ) & n.a. & -0.111 \\
\hline LCOE, LCOH $\left(@ \$ 100 / \mathrm{tCO}_{2} \mathrm{e}\right)$ & 101.92 & 1.746 \\
\hline Coproduct values (for $P_{N G}=\$ 6 / G_{\mathrm{HHV}}$ ) $*$ & 91.45 & 2.609 \\
\hline $\operatorname{IRRE}\left(\mathrm{P}_{\mathrm{NG}}=\$ 6 / \mathrm{GJ}_{\mathrm{HHV}}\right), \% / \mathrm{yr}$ & 5.7 & 27.7 \\
\hline $\boldsymbol{I R R E}\left(\mathrm{P}_{\mathrm{NG}}=\$ 8 / \mathrm{GJ}_{\mathrm{HHV}}\right), \% / \mathrm{yr}$ & 11.9 & 35.9 \\
\hline
\end{tabular}

*Based on correlations given in Appendix D, these are the costs of making electricity via $\mathrm{NGCC}$ or making $\mathrm{H}_{2}$ via steam methane reforming, in both cases with no $\mathrm{CO}_{2}$ capture, when the natural gas price is $\$ 6 / \mathrm{GJ}_{\mathrm{HHV}}$ and emissions of greenhouse gases are charged at a rate of $\$ 100 / \mathrm{tCO}_{2} \mathrm{e}$.

\section{Power-only reference systems}

The majority of the effort in this project was on systems coproducing electricity and fuels or chemicals, but some analysis was also completed for reference power-only systems. Process design and simulation of three stand-alone coal gasification-based power generating systems was completed: integrated gasification combined cycle (IGCC) with dry-feed gasification, IGCC with slurry-feed gasification, and integrated-gasification fuel cell (IGFC) encompassing a solid-oxide fuel cell and steam bottoming cycle. The two IGCC designs, described in Section 6.1, are relatively straightforward extensions of co-production simulations described in Section 2. The IGFC work, summarized in Section 6.2 and described in detail in Appendix E, involved a more substantial effort. 


\subsection{IGCC}

Process designs and performance simulations were developed for coal-IGCC systems using Illinois \#6 bituminous coal. Designs with and without $\mathrm{CO}_{2}$ capture and storage were developed for both the slurry-feed gasifier and dry-feed gasifier designs. The designs are consistent with the gasification and power island designs used in the coproduction systems described in Sections 2 and 3. Table 12 shows simulation results and compares these with the performance of comparable power plants as reported in the NETL Baseline Power study. ${ }^{4}$ The Princeton simulation results are generally consistent with the NETL results, but predict electricity generating efficiencies about one percentage point lower for each case.

Princeton's capital cost estimates are slightly higher than NETL estimates in all cases except for the dry-feed system without CCS, but the Princeton and NETL estimates can be considered essentially the same, given the uncertainties inherent in the estimates. Differences between Princeton's and NETL's LCOE estimates reflect the differences in the capital costs. Figure 15 shows how Princeton's LCOE estimates vary with GHG emissions price. Also shown for comparison are LCOEs for supercritical pulverized coal plants and natural gas combined cycle plants, both without and with CCS. The latter are based on NETL estimates. ${ }^{4}$

Table 12. Comparison of Princeton and NETL coal-IGCC performance simulations and cost estimates. The assumed coal price is $\$ 2.04 / G J_{H H V}$ and plant capacity factor is $85 \%$.

\begin{tabular}{|c|c|c|c|c|c|c|c|c|}
\hline \multirow[b]{3}{*}{ Gasifier design $\gg>$} & \multicolumn{4}{|c|}{ Princeton simulation results } & \multicolumn{4}{|c|}{ NETL Baseline Power Study results } \\
\hline & \multicolumn{2}{|c|}{ IGCC-CCS } & \multicolumn{2}{|c|}{ IGCC-Vent $\mathrm{CO}_{2}$} & \multicolumn{2}{|c|}{ IGCC-CCS } & \multicolumn{2}{|c|}{ IGCC-Vent $\mathrm{CO}_{2}$} \\
\hline & Dry-feed & Slurry & Dry-feed & Slurry & Dry-feed & Slurry & Dry-feed & Slurry \\
\hline Feedstocks & & & & & & & & \\
\hline Coal input rate, $\mathrm{AR}$ metric $\mathrm{t} / \mathrm{day}$ & 5,151 & 5,447 & 4,927 & 5,330 & 5,151 & 5,447 & 4,927 & 5,330 \\
\hline Coal input rate, MW (HHV) & 1,616 & 1,709 & 1,546 & 1,673 & 1,616 & 1,709 & 1,546 & 1,673 \\
\hline Electricity balance, MWe & & & & & & & & \\
\hline Gross production & 676 & 708 & 772 & 707 & 694 & 745 & 748.02 & 770 \\
\hline Gas turbine & 465 & 441 & 478 & 420 & 464 & 464 & 464.03 & 464 \\
\hline Steam turbine & 211 & 254 & 294 & 272 & 230 & 275 & 283.99 & 299 \\
\hline Expander & 0 & 13 & 0 & 16 & 0 & 6 & 0 & 7 \\
\hline On-site consumption & 169 & 178 & 126 & 79 & 176 & 189 & 112.17 & 130 \\
\hline Net export to grid & 507 & 530 & 646 & 628 & 517 & 556 & 635.85 & 640 \\
\hline Net electricity / Energy in (HHV) & $31.3 \%$ & $31.0 \%$ & $41.8 \%$ & $37.5 \%$ & $32.0 \%$ & $32.5 \%$ & $41.1 \%$ & $38.3 \%$ \\
\hline Carbon accounting & & & & & & & & \\
\hline $\mathrm{C}$ input in feedstock, $\mathrm{kgC} / \mathrm{sec}$ & 38.0 & 40.2 & 36.4 & 39.3 & 38.0 & 40.2 & 36.4 & 39.3 \\
\hline $\mathrm{C}$ stored as $\mathrm{CO} 2, \%$ of feedstock $\mathrm{C}$ & 90.1 & 88.3 & 0.0 & 0 & 90.3 & 88.4 & 0 & 0 \\
\hline $\mathrm{C}$ in char, $\%$ of feedstock $\mathrm{C}$ & 1.0 & 4.0 & 1.0 & 4 & 0.5 & 2.01 & 0.50 & 2.01 \\
\hline $\mathrm{C}$ vented to atm, $\%$ of feedstock $\mathrm{C}$ & 8.9 & 7.7 & 99.0 & 96 & 9.2 & 9.6 & 99.50 & 97.99 \\
\hline GHGI & 0.16 & 0.15 & 0.93 & 1.00 & 0.16 & 0.17 & 0.95 & 1.00 \\
\hline Total plant investment, $\$ / \mathrm{kW}$ net & 3,011 & 2,879 & 2,133 & 2,085 & 2,952 & 2,643 & 2,224 & 1,999 \\
\hline Levelized Cost of Electricity, $\$ / M W h$ & & & & & & & & \\
\hline Installed capital (at $14.38 \%$ of TPI) & 58 & 56 & 41 & 40 & 57 & 51 & 43 & 39 \\
\hline O\&M (at $4 \%$ of TPC per yr) & 15 & 14 & 11 & 10 & 15 & 13 & 11 & 10 \\
\hline Coal (at $2.04 \$ / G J, H H V)$ & 23 & 24 & 18 & 20 & 23 & 23 & 18 & 19 \\
\hline $\mathrm{CO} 2$ emissions (at $0 \$$ tonne $\mathrm{CO} 2$ ) & 0 & 0 & 0 & 0 & 0 & 0 & 0 & 0 \\
\hline $\mathrm{CO} 2$ disposal (at 0 \$tonne $\mathrm{CO} 2$ ) & 6 & 6 & 0 & 0 & 6 & 6 & 0 & 0 \\
\hline Total LCOE, \$/MWh & 103 & 100 & 69 & 70 & 101 & 92 & 72 & 68 \\
\hline
\end{tabular}




\subsection{IGFC}

We describe here various plant designs in which Illinois \#6 bituminous coal is gasified in a dry-feed Shell gasifier, and the cleaned and processed syngas is fed to a pressurized solid-oxide fuel cell (SOFC) power island. The SOFC technology that is the basis for these plant designs is the planar design developed by various manufacturers. A SOFC naturally produces an (anode) exhaust stream with a high $\mathrm{CO}_{2}$ concentration, which facilitates the $\mathrm{CO}_{2}$ capture that was employed in all plant designs. $\mathrm{CO}_{2}$ capture occurs after the SOFC, where the anode exhaust is oxy-combusted to obtain a stream containing only steam and $\mathrm{CO}_{2}$, and the $\mathrm{CO}_{2}$ is separated by flashing. The SOFC is the main power generator in the plant, but it is coupled to a bottoming cycle by recovery of additional power from the hot SOFC exhaust. Waste heat was recovered for steam generation in all plant designs. The IGFC designs described here have net electricity outputs ranging around 850 to $900 \mathrm{MW}_{\mathrm{e}}$. Appendix E gives details.

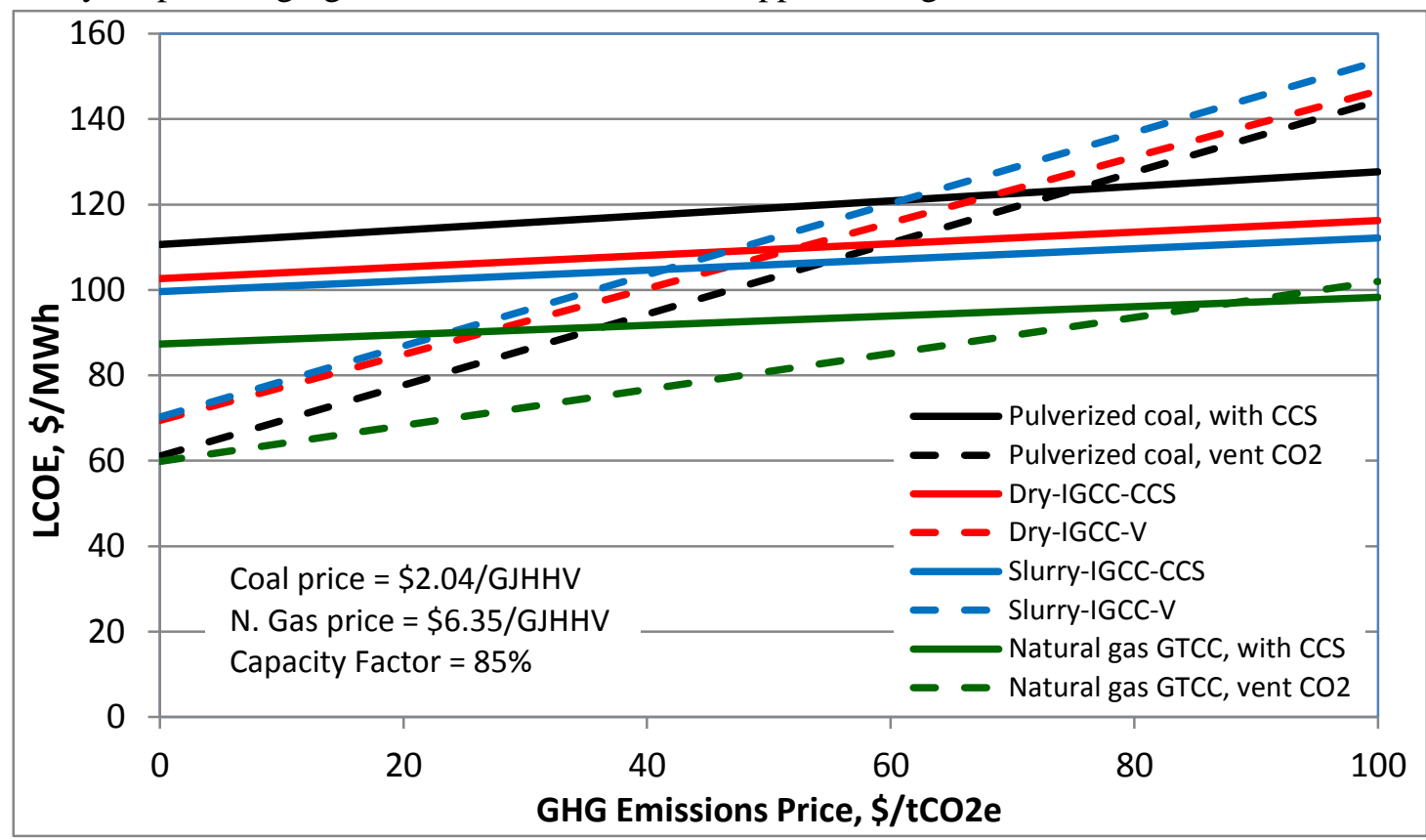

Figure 15. Levelized cost of electricity (LCOE) as a function of GHG emissions price for simulated coal-IGCC systems ("Princeton results" in Table 12). Results for dry-feed gasification and slurry-feed gasification are shown, without and with CCS. Shown for comparison are LCOE for conventional coal and NGCC power plants without and with CCS.

One set of plant designs utilizes a conventional cryogenic air separation unit (ASU) to supply oxygen to the gasifier and the anode exhaust oxy-combustor. In this set, alternative designs examined the effect of partial methanation of the syngas upstream of the SOFC to form methane that is subsequently reformed back to $\mathrm{CO}$ and $\mathrm{H}_{2}$ as it enters the fuel cell. We explored this non-intuitive option recognizing that the exothermic methanation reaction would help pre-heat the fuel gas feed to the SOFC (avoiding the cost of an expensive high-temperature heat exchanger) and also enable cooling of the SOFC by reforming at the anode. We developed three plant designs (Figure 16): two cases with alternative methanation technologies (TREMP and HICOM) and a third case in which clean syngas was directly fed to the SOFC. 


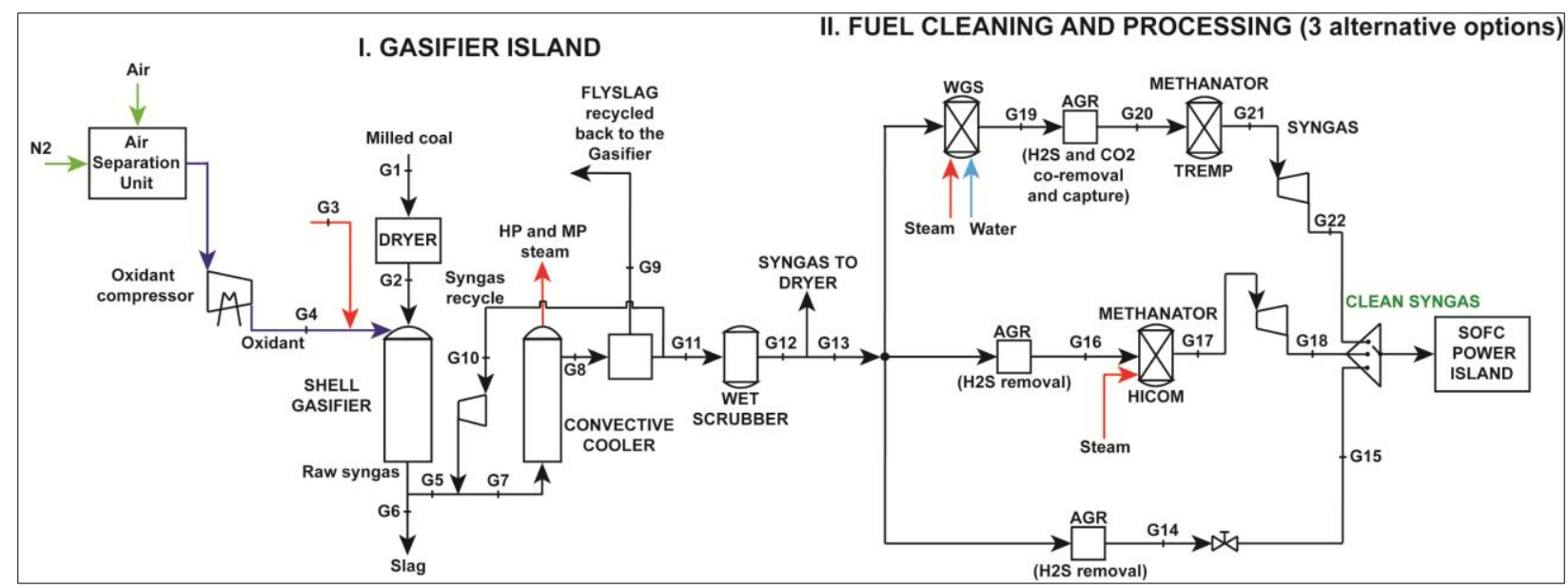

Figure 16. Gasifier island, syngas cleaning and processing, and SOFC power island are shown. The Shell gasifier island is common to all IGFC cases studied. Three alternative equipment configurations were evaluated for fuel gas cleaning and processing ahead of the SOFC power island.

A second set of results was generated in which oxygen was provided not by an ASU but by an ion transport membrane (ITM) using pressurized cathode exhaust as the feed. The IGFC-HICOM plant configuration with a conventional cryogenic ASU was found to provide the highest efficiency of the plant designs that utilized conventional cryogenic air separation, so this configuration was chosen for analyzing the impact of an ITM replacing the ASU. (However, the efficiency gain achieved by replacing an ASU with an ITM is essentially independent of the specific IGFC configuration.) For reference, the IGFCHICOM case, both the ASU and ITM variants, was analyzed with $\mathrm{CO}_{2}$ vented to the atmosphere, as well as with $\mathrm{CO}_{2}$ captured for storage.

Figure 17 shows efficiency results for IGFC-HICOM cases with and without $\mathrm{CO}_{2}$ capture. Shown for comparison are IGCC efficiencies. As expected, the IGFC using the ITM provides the highest efficiency, exceeding the IGCC efficiency by more than 12 percentage points when $\mathrm{CO}_{2}$ is vented and by more than 17 percentage points when $\mathrm{CO}_{2}$ is captured. The efficiency penalty for $\mathrm{CO}_{2}$ capture with the IGFC is $\sim 4$ percentage points, regardless of whether a cryogenic ASU or ITM is used for oxygen production.

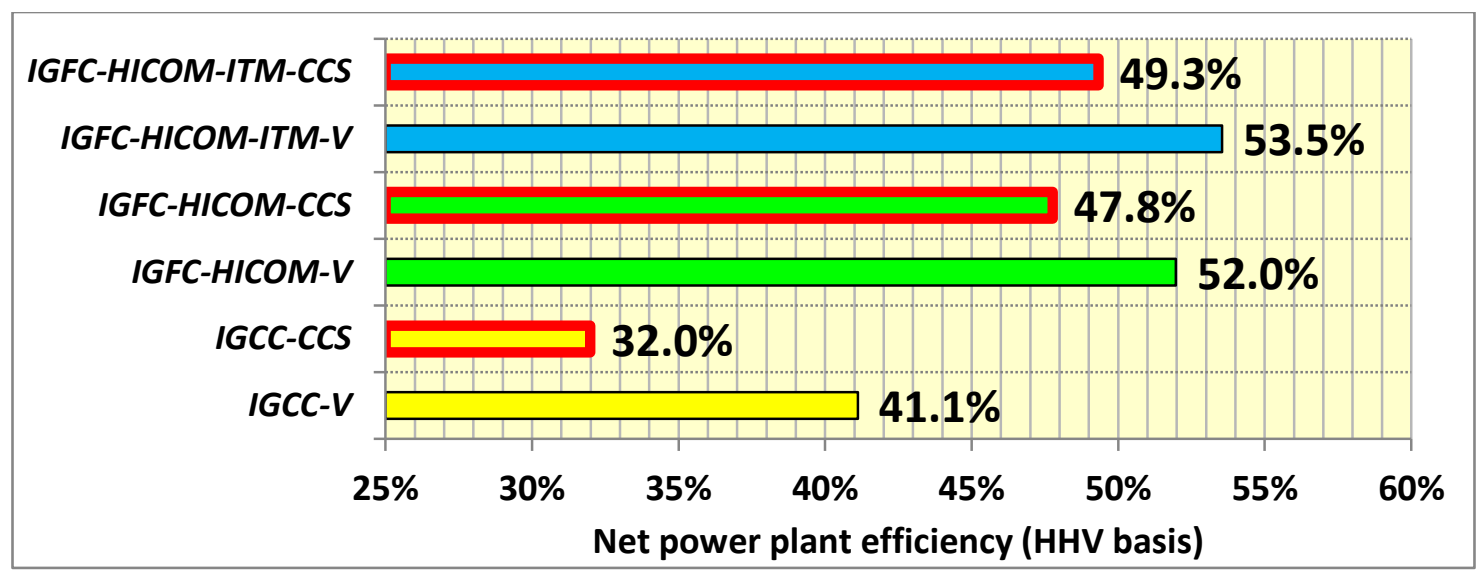

Figure 17. Net electricity generating efficiencies for IGFC power plants without and with carbon capture. IGCC efficiencies (NETL cases from Table 12) are shown for comparison,

Estimated levelized costs of electricity (LCOE) for the IGFC-HICOM plant designs are shown in Figure 18. The LCOE for pulverized coal (PC) and IGCC systems are shown for comparison. For these 
estimates, the specific cost (per unit of active area) of the SOFC was assumed to be the DOE-NETL target cost for 2010-2011. (Sensitivity of the LCOE to this assumption is discussed below.) The assumed SOFC power density represents state-of-the-art performance achieved by planar cells ${ }^{6}$ and is believed by SOFC manufacturers to be achievable in commercial cells within the next 3-5 years. For these pressurized SOFC designs, the active area is roughly one fifth of the total bare erected cost of the SOFC module, which includes cell (and stack) active area, pressure vessel, insulation, and piping.

For the assumed SOFC specific cost, the LCOE for the IGFC plants are lower than that for either the IGCC or PC options, with the IGFC incorporating the ITM for oxygen production having the lowest LCOE. The difference in LCOE between the IGFC and the PC and IGCC options increases with increasing GHG emissions price due to the higher efficiency of the IGFCs. Importantly, the GHG emissions price at which a given plant configuration becomes less costly with CCS than without CCS is much lower for the IGFC systems $\left(\$ 25-\$ 30 / \mathrm{tCO}_{2} \mathrm{e}\right)$ than for the PC $\left(\sim \$ 7 / \mathrm{tCO}_{2} \mathrm{e}\right)$ or IGCC $\left(\sim 45 / \mathrm{tCO}_{2} \mathrm{e}\right)$. The low breakeven GHG emission price for the IGFC systems arise because of the lower added capital cost and the lower efficiency penalty with $\mathrm{CO}_{2}$ capture.

Figure 19 shows the sensitivity of the LCOE to SOFC power density and specific cost for the IGFC configuration with $\mathrm{CO}_{2}$ capture and ITM oxygen production, assuming a GHG emissions price of $\$ 50 / \mathrm{tCO}_{2} \mathrm{e}$. For context, some estimates of specific costs today from SOFC manufacturers range from $\$ 3,000 / \mathrm{kW}_{\mathrm{e}}$ to $\$ 9,000 / \mathrm{kW}_{\mathrm{e}}{ }^{7}$ The cost range labeled 'market entry' represents, for different assumed power densities, the DOE-NETL target cost for 2010 increased by an order of magnitude. This approximates what might be achieved now, i.e. with current technology maturity, but scaled up to moderate production volumes.

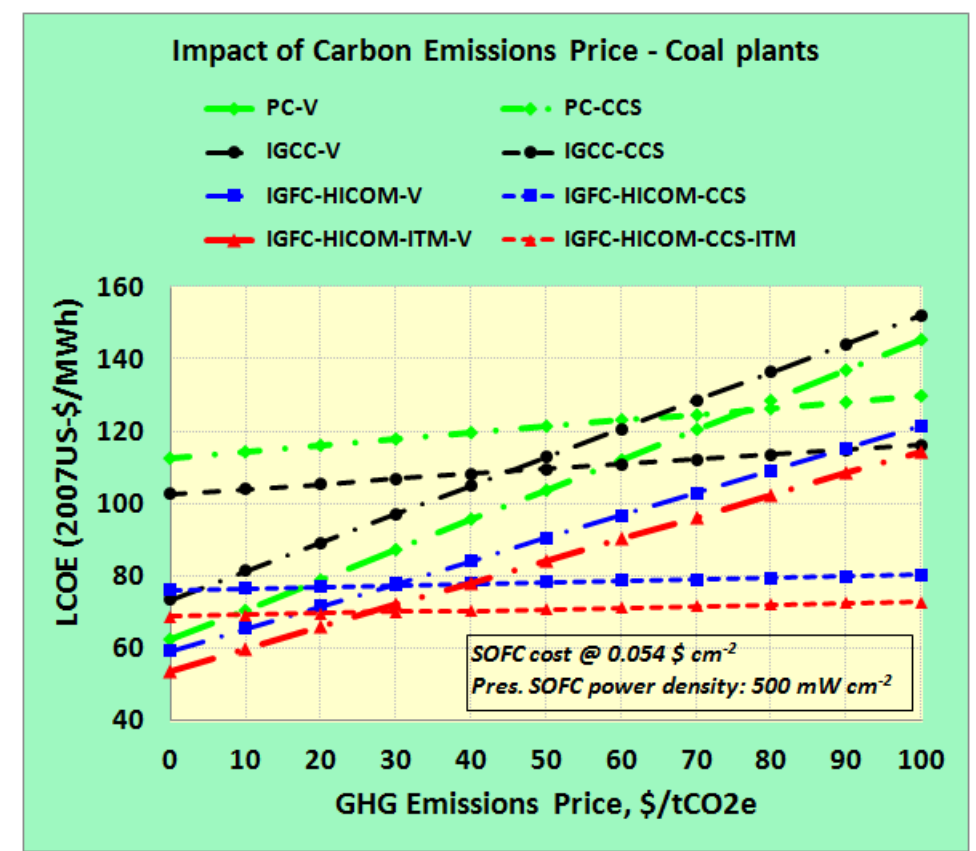

Figure 18. Calculated levelized costs of electricity generation for alternative IGFC and other coal-based power systems.

\footnotetext{
${ }^{6}$ In single cell lab tests, SOFC planar cells can readily achieve 500-1000 $\mathrm{mW} \mathrm{cm}^{-2}$ (with current densities up to 0.5-0.7 A $\mathrm{cm}^{-2}$ ). However, in real stacks, the current density is normally limited to $0.2-0.3 \mathrm{~A} \mathrm{~cm}^{-2}$ in order to limit polarization losses and thus achieve higher conversion efficiency. ${ }^{7}$ The U.S. based BloomEnergy declared in 2010 that an SOFC module cost of $\$ 7000-8000 / \mathrm{kW}_{\mathrm{e}}$. The CEO of SOFCPower (Italy/Switzerland) declared in November 2011 that a cost of around $\$ 3000-\$ 5000 / \mathrm{kW}_{\mathrm{e}}$ could be achieved today with large production volumes. In November 2011, JX Nippon Oil \& Energy Corp. commenced commercialization of SOFC units with a nominal output of $700 \mathrm{~W}$ for residential applications in Japan. The single unit costs $25,000-30,000$ US- $\$$, but the company plans to sell units for 6,000 US- $\$\left(\$ 8600 / \mathrm{kW}_{\mathrm{e}}\right)$ once fully commercialized.
} 


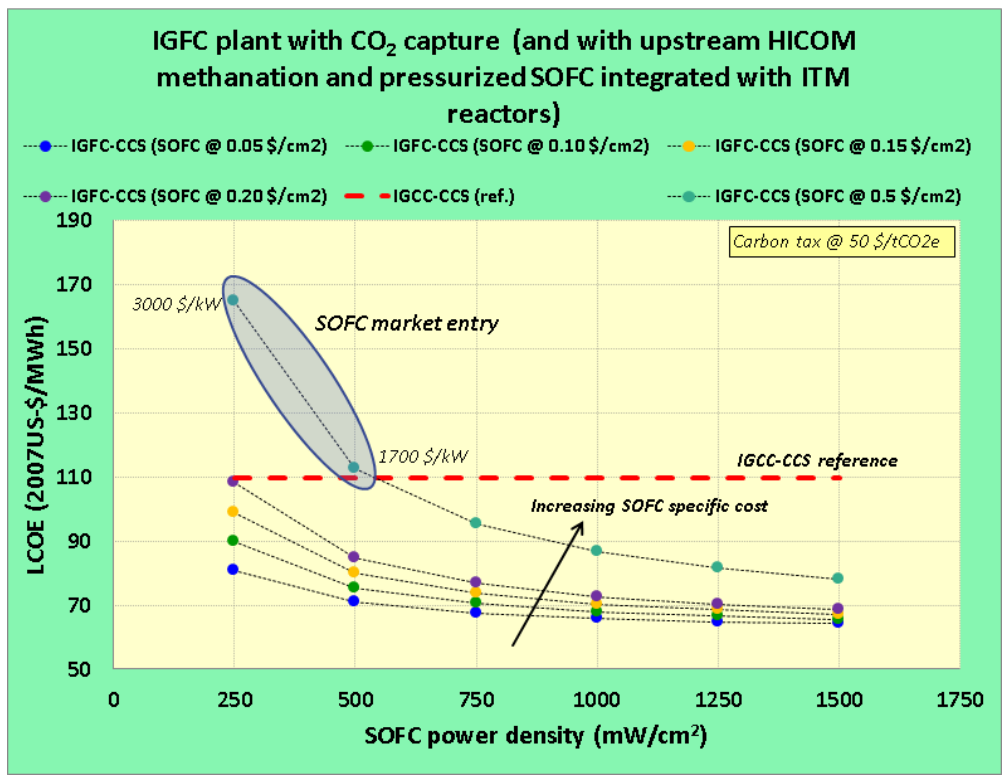

Figure 19. Sensitivity of LCOE for IGFC-HICOM-ITM-CCS plant on SOFC power density and bulk specific cost. 


\section{LIST OF APPENDICES}

Appendix A: Co-Processing of Coal and Biomass in Entrained Flow Coal Gasifiers: Front-End Process Designs

Appendix B: Process Design and Analysis for Co-Production of Electricity and Synthetic Gasoline via Co-Gasification of Coal and Biomass with CCS

Appendix C: Process Design and Analysis for Co-Production of Electricity and Light Olefins via Co-gasification of Coal and Biomass with CCS

Appendix D: Preliminary Assessments of: Coal to Electricity plus Ammonia with CCS, and Coal to Electricity plus Hydrogen with CCS

Appendix E: Process Design and Analysis for Stand-Alone Solid Oxide Fuel Cell Power Generation 


\title{
Appendix A
}

\section{Co-Processing of Coal and Biomass in Entrained Flow Coal Gasifiers: Front-End Process Designs}

\author{
Guangjian Liu \\ Eric D. Larson \\ Thomas G. Kreutz \\ Robert H. Williams \\ Ilkka Hannula
}

\section{Contents}

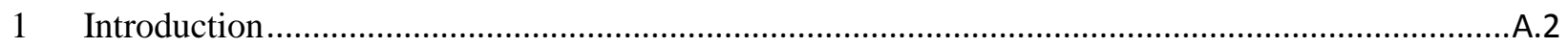

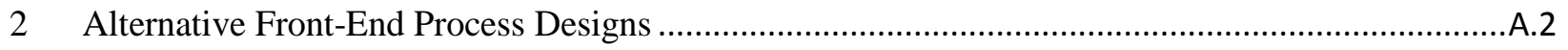

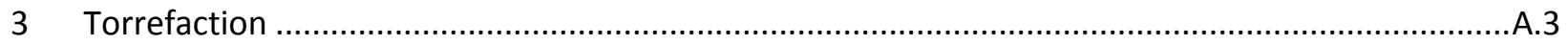

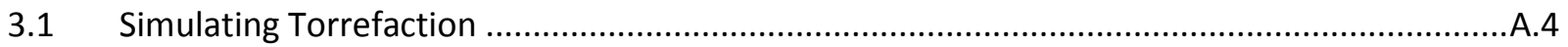

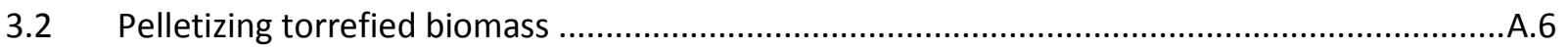

3.3 Uncertainties with slurrying behavior of torrefied biomass ...................................................

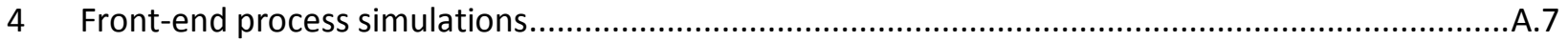

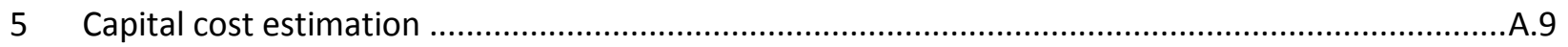

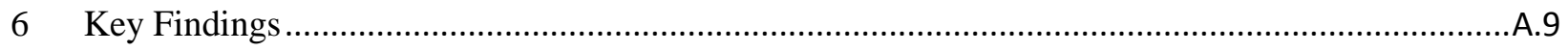

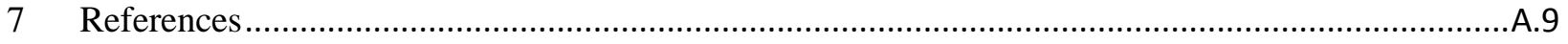




\section{Introduction}

To our knowledge, there are only two commercial-scale plants where co-gasification of coal and biomass has been tried in an entrained flow coal gasifier. One was a very limited duration testing at Tampa Electric's IGCC facility in Florida in a GE slurry-feed gasifier (Teco Energy, 2003). The other commercial-scale co-gasification has been carried out at the $250 \mathrm{MW}_{\mathrm{e}} \mathrm{IGCC}$ at Buggenum in the Netherlands, which operates with a Shell dry-feed gasifier. This plant has co-processed a variety of biomass feedstocks with coal since 2006. In addition to using various biomass feedstocks, pilot-scale testing of the use of torrefied biomass as a co-feed with coal is being pursued at Buggenum today. The owner of the plant, Nuon, has published relatively little detailed information regarding their co-processing experience. Given the lack of substantial real-world experience with co-gasification, we decided to evaluate three alternative co-gasification process designs in developing our co-production systems. We simulated these in Aspen Plus and drew input assumptions from the literature to facilitate the simulations. This appendix describes the three front-end syngas production configurations we examined and conclusions drawn from this analysis.

\section{Alternative Front-End Process Designs}

The three designs we considered are shown schematically in Figure 1. Two of these (Figure 1a and 1b) utilize a dry-feed pressurized, oxygen-blown, entrained-flow gasifier (simulated based on the Shell gasifier). The third uses a slurry-feed pressurized, oxygen-blown, entrained-flow gasifier (simulated based on the GE Energy gasifier. The characteristics of the coal and biomass feedstocks for our simulations are

\begin{tabular}{|c|c|c|c|}
\hline & $\begin{array}{c}\text { AR } \\
\text { Coal }\end{array}$ & $\begin{array}{c}\text { AR } \\
\text { Biomass }\end{array}$ & $\begin{array}{c}\text { Torrefied } \\
\text { biomass }\end{array}$ \\
\hline \multicolumn{4}{|c|}{ Proximate Analysis (wt\%) } \\
\hline Moisture & $11.12 \%$ & $20.0 \%$ & $0.9 \%$ \\
\hline Fixed Carbon & $44.19 \%$ & $17.3 \%$ & $15.6 \%$ \\
\hline Volatile Matter & $34.99 \%$ & $76.4 \%$ & $77.0 \%$ \\
\hline Ash & $9.70 \%$ & $6.3 \%$ & $7.4 \%$ \\
\hline LHV, wet basis, MJ $/ \mathrm{kg}$ & 25.861 & 12.478 & 16.822 \\
\hline $\begin{array}{l}\text { HHV, wet basis, } \\
\mathrm{MJ} / \mathrm{kg}\end{array}$ & 27.114 & 14.167 & 18.170 \\
\hline \multicolumn{4}{|c|}{ Ultimate Analysis (wt\%, dry basis) } \\
\hline Fixed Carbon & $49.72 \%$ & $17.30 \%$ & $15.60 \%$ \\
\hline Volatile Matter & $39.37 \%$ & $76.40 \%$ & $77.00 \%$ \\
\hline Ash & $10.91 \%$ & $6.30 \%$ & $7.40 \%$ \\
\hline $\mathrm{C}$ & $71.72 \%$ & $47.86 \%$ & $49.82 \%$ \\
\hline $\mathrm{H}$ & $5.06 \%$ & $6.88 \%$ & $6.13 \%$ \\
\hline $\mathrm{N}$ & $1.41 \%$ & $0.81 \%$ & $0.90 \%$ \\
\hline $\mathrm{Cl}$ & $0.33 \%$ & $0.00 \%$ & $0.00 \%$ \\
\hline $\mathrm{S}$ & $2.82 \%$ & $0.00 \%$ & $0.00 \%$ \\
\hline $\mathrm{O}$ & $7.75 \%$ & $38.15 \%$ & $35.75 \%$ \\
\hline HHV, MJ/kg dry & 30.506 & 17.709 & 18.335 \\
\hline
\end{tabular}

given in Table 1. Each configuration involves pregasification processing of the coal and biomass.

In the first design (Figure 1a) coal and biomass are processed in parallel. Each feedstock is dried and then milled to the requisite particle size for injection into the gasifier. Because of the higher reactivity of biomass in the gasifier, the requisite particle size $(<1 \mathrm{~mm})$ is larger than required for coal $(<0.1 \mathrm{~mm})$. The coal particles are pressurized using a conventional, commercially-available lock-hopper system and subsequently transported pneumatically to the gasifier. Technology for feeding of biomass into a pressurized reactor (40 bar) is not commercially well-established. Lock hopper pressurization is feasible, but requires more inert pressurization gas per unit of energy delivered than with coal due to the low bulk density of biomass. Pneumatic transport to the gasifier of the pressurized biomass is unlikely to be suitable because of the poor flow characteristics of milled biomass. Because of these shortcomings with lock hoppers and pneumatic transport for biomass, our design instead considers screw metering/transport to a piston feeder for pressurization. This combination would have relatively low inert gas consumption (Lau, et al., 2003), but is not commercially proven for feeding to the required pressure.

The second front-end configuration (Figure 1b) involves a similar coal processing train as the configuration in Figure 1a, but the biomass is processed instead by drying and torrefaction. As discussed more fully in the next section, torrefaction is a mild thermal treatment of biomass that renders a dry, brittle, hydrophobic and easily milled material, with properties similar to those of coal. Torrefaction 
enables the biomass to be milled to $0.1 \mathrm{~mm}$ particle size using the same milling equipment as for coal. Lock hopper pressurization and pneumatic transport are carried out in tandem with the milled coal.

The third front-end configuration (Figure 1c) also utilizes torrefaction for the biomass and also co-processes the torrefied material with the coal. However, in this design, after grinding of the coal and torrefied biomass, a slurry is prepared for pumping into the gasifier, since the feeding of untreated biomass into a slurry-fed gasifier is considered infeasible. With coal, a solids content in the slurry of 64 $\mathrm{wt} \%$ is common. We assumed that a mixture of coal and torrefied biomass could be slurried to this same solids fraction. As discussed further in the next section, there are no empirical data available to confirm the feasibility of feeding mixtures of coal and torrefied biomass at this solids fraction.
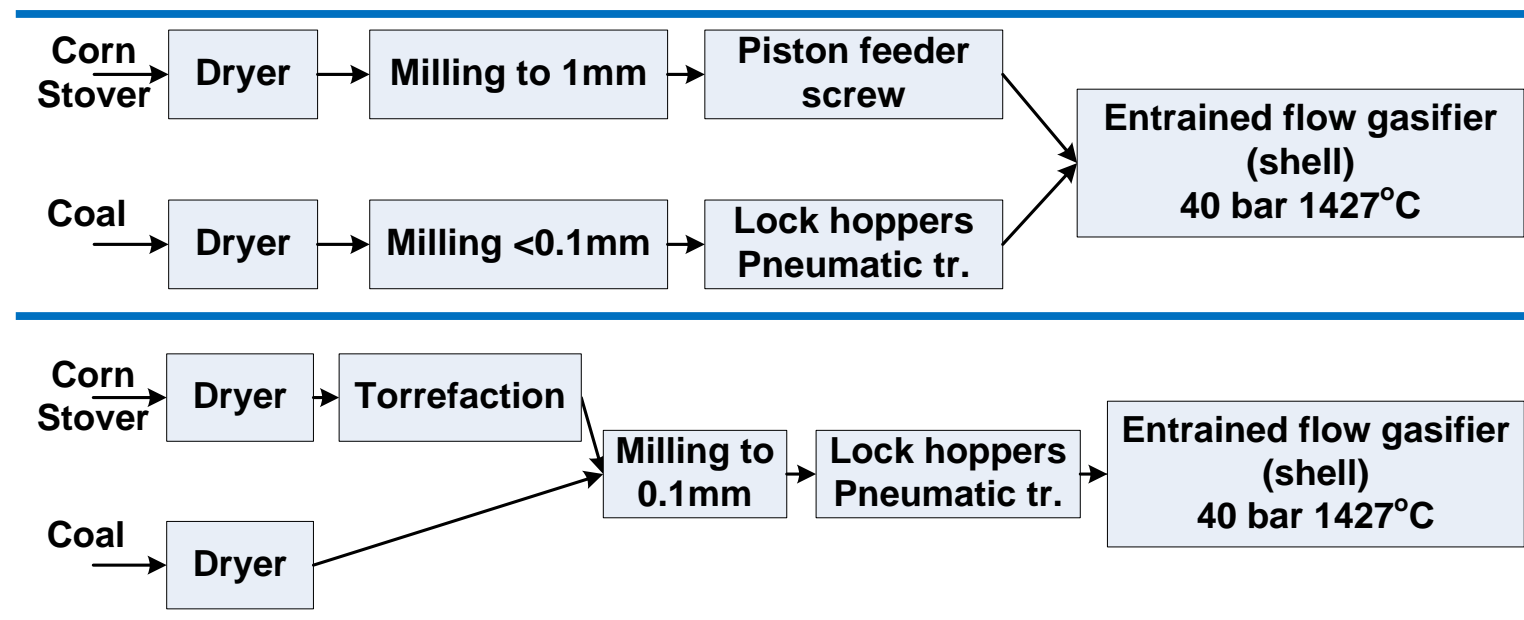

Entrained flow gasifier (shell)

40 bar $1427^{\circ} \mathrm{C}$

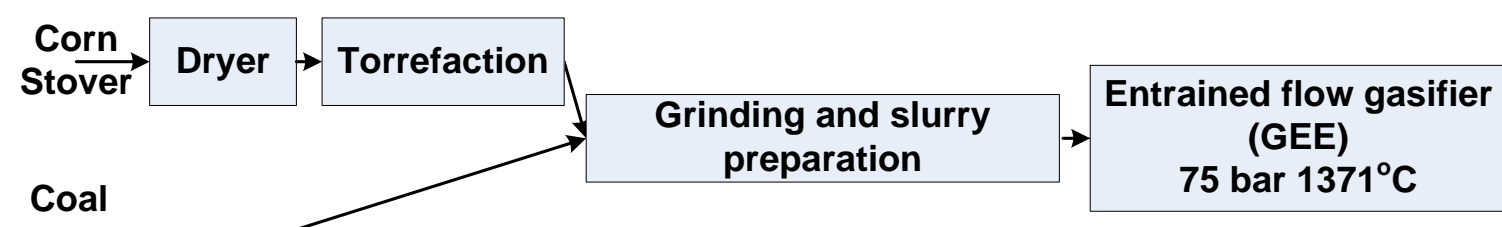

(c)

Figure 1. Alternative front-end process configurations for co-gasification of coal and biomass.

\section{Torrefaction}

We considered torrefaction of biomass in our process configurations for three main reasons: $i$ ) it facilitates transporting biomass long distances more cost-effectively, $i i)$ it enables the production of a common gasifier feed material regardless of the biomass source, and iii) it should facilitate feeding into entrained-flow gasifiers originally designed for coal. The first two factors enable larger-scale biomass inputs to a conversion facility.

The third factor is key to effective conversion of coal/biomass mixtures. The feed to an entrained flow gasifier must be a uniform mixture of very finely ground material. The Shell gasifier requires milling of the coal to $100 \mu \mathrm{m}(0.1 \mathrm{~mm})$ before the resulting coal dust is pressurized with nitrogen in lock-hoppers and sent to the gasifier using a dense-phase pneumatic conveying system. The feeder design enables smooth, continuous feeding, which keeps fluctuations in the gasifier operating temperature within an acceptable range. With a slurry-feed entrained flow gasifier, raw coal is finely ground to a carefully controlled size distribution before mixing with water in the slurry preparation unit and then being pumped into the gasifier.

Pulverizing, transporting and feeding fibrous biomass to an entrained flow gasifier is more challenging than with coal. For dry-feed gasification, to feed biomass pneumatically using the same feeding system as for coal would require milling the biomass to $100 \mu \mathrm{m}$ particle size, a highly energy 
intensive task because of the fibrous nature of biomass (Bergman et al., 2005). Moreover, achieving the requisite uniform particle size distribution is difficult (Van der Drift et al., 2004). For slurry feed gasification, the challenge of grinding to appropriate particle size is compounded by the hydrophilic nature of biomass, which makes difficult the production of a slurry with as high a solids concentration as achieved in coal slurries: He et al., (2009) indicate that a slurry of ground woody biomass $(<150 \mu \mathrm{m}$ particle size) with water would require that the solids weight fraction be no greater than $12.5 \%$ for the slurry to be pumpable. Coal slurries routinely have solids fractions exceeding $60 \%$.

We identified torrefaction as a potentially key strategy for addressing the challenges of cofeeding biomass with coal into either a slurry-feed or dry-feed entrained flow gasifier. Torrefaction is the thermal treatment of biomass in an inert atmosphere at a temperature between $200^{\circ} \mathrm{C}$ and $300^{\circ} \mathrm{C}$ and near

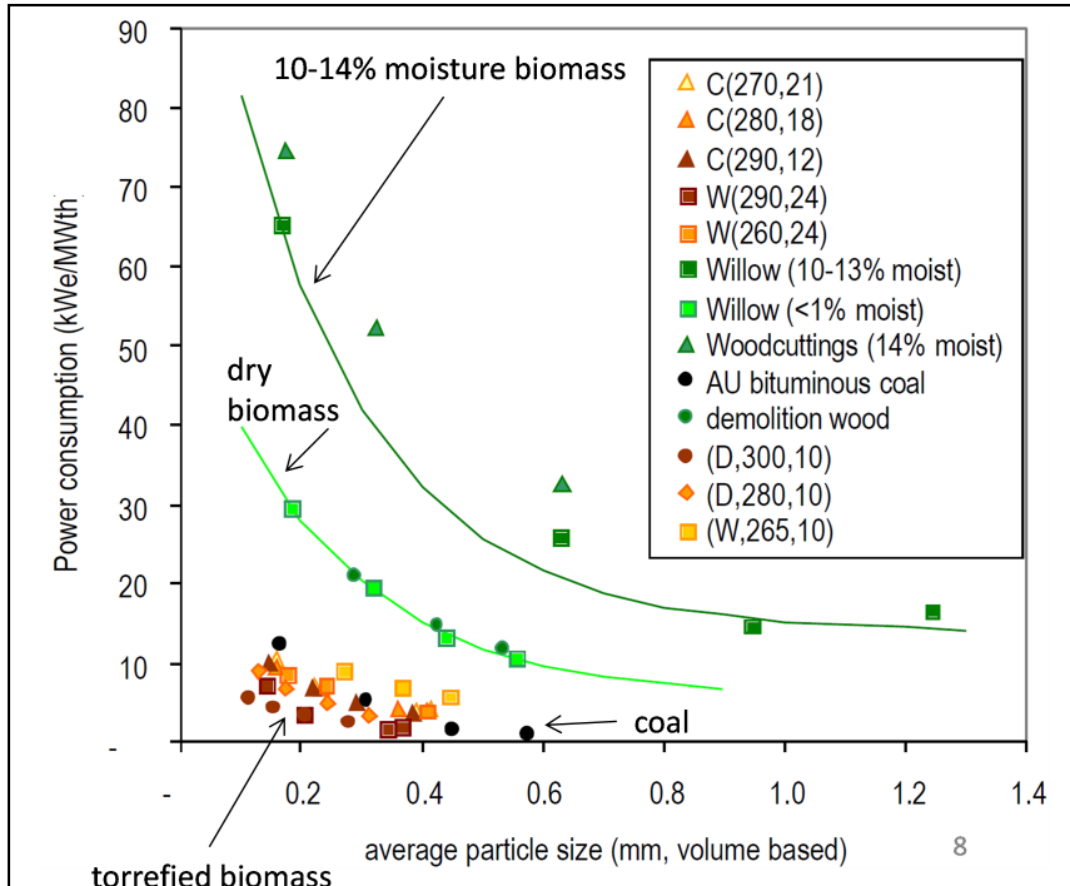

Figure 2. Grinding energy required for woody biomass with $10-14 \%$ moisture content (upper, dark green), dry woody biomass (light green, lower line), various torrefied biomass feedstocks (lower cluster of orange/brown points), and bituminous coal (black circles) (Bergman and Kiel. 2005). atmospheric pressure. Mild chemical reactions destroy the fibrous structure and tenacity of the biomass and greatly improve its grindability. Energy for grinding to $0.1 \mathrm{~mm}$ particle size is approximately four times less for torrefied biomass than for untreated dry biomass and approximately eight times less than for grinding untreated biomass with $10-14 \%$ moisture content (Figure 1). Additionally, the chemical reactions during torrefaction include the destruction of $\mathrm{OH}$ groups in the biomass, which causes the biomass to lose its capability to form hydrogen bonds with water (Bergman et al., 2004; Arias et al., 2008; Bridgeman et al., 2010). Experimental work suggests that about 70 percent of the mass and about 90 percent of the energy in the biomass can be retained in the torrefied product (Bergman et al., 2005; Prins, 2005).

\subsection{Simulating Torrefaction}

Torrefaction technology can be classified by the method used to heat the biomass: direct-contact heat transfer or indirect heating. Direct-contact heat exchange enables more uniform heating, as well as a smaller reactor for a given throughput (Bergman et al., 2005; Bergman and Kiel, 2005). We have chosen to simulate direct-contact torrefaction based on a reactor design and equipment configuration (Figure 3) developed at the Energy Research Center of the Netherlands (ECN), a leading research center for torrefaction. As-received biomass is dried to below 5\% moisture using combustion product gas available from a furnace. If necessary, some of the biomass (prior to drying) is diverted as fuel for the furnace. The bulk of the biomass is heated in the moving-bed torrefaction reactor using recycled torrefaction gases that have been pre-heated to the requisite temperature. The pre-heating is provided via heat exchange with product gases from the furnace. The furnace burns the unrecycled portion of the torrefaction gases, supplemented if necessary by some of the as-received biomass. The heat carried in furnace flue gases goes mostly to drying rather than torrefaction, given the relatively small heat of reaction involved with torrefaction (Bergman et al., 2005; Bergman and Kiel, 2005). 


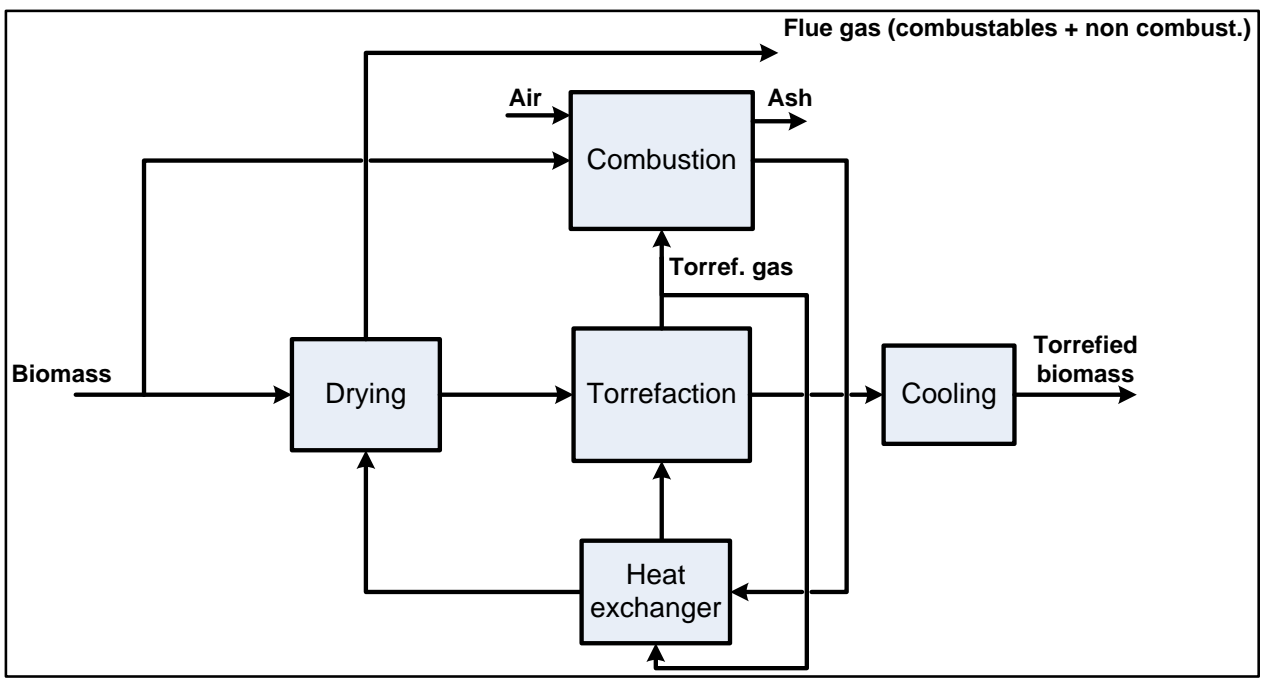

Figure 3. Configuration simulated for direct-contact torrefaction (Bergman et al., 2005).

Because torrefaction is a highly non-equilibrium process, there is little theoretical basis for simulating the torrefaction reactor. Some efforts have been made to quantify the weight loss kinetics of the torrefaction of woody biomass (see, e.g., Prins et al., 2006) and the kinetics of gas generation (see, e.g., Deng et al., 2009), but accurate prediction of torrefaction mass and energy balances from first principles is difficult. Recognizing this difficulty, we have chosen to build our Aspen Plus simulation of torrefaction based on empirical data published by Bridgeman et al. (2008). These data were selected over other published data because the ultimate analysis composition and the higher heating value of the raw biomass feedstock that Bridgeman torrefied (wheat straw) are very similar to that of the corn stover feedstock considered in this project (Table 2).

The torrefaction data reported by Bridgeman et al. are provided in Table 3 . The composition and heating value of the product of torrefaction shows a significant dependence on the reactor temperature. In

\begin{tabular}{|c|c|c|}
\hline & Corn stover $^{\mathrm{a}}$ & Wheat Straw $^{\text {b }}$ \\
\hline \multicolumn{3}{|c|}{ Proximate Analysis (weight $\%$, as received) } \\
\hline Moisture & 20 & 20 \\
\hline Fixed carbon & not available & 13.84 \\
\hline Volatile matter & not available & 61.12 \\
\hline Ash & not available & 5.04 \\
\hline Total & not available & 100 \\
\hline \multicolumn{3}{|c|}{ Ultimate Analysis (weight $\%$, dry basis) } \\
\hline $\mathrm{C}$ & 44.5 & 47.3 \\
\hline $\mathrm{H}$ & 5.6 & 6.8 \\
\hline $\mathrm{O}$ & 43.3 & 38.8 \\
\hline $\mathrm{N}$ & 0.6 & 0.8 \\
\hline Ash & 6.0 & 6.3 \\
\hline HHV, MJ/kg dry & 17.4 & 17.7 \\
\hline
\end{tabular}
each case, the product is called torrefied biomass, reflecting the lack of an agreed quantitative definition of torrefaction.

For our simulation, we have chosen to use the data for torrefaction at $250^{\circ} \mathrm{C}$. The resulting mass and energy balance for production of torrefied biomass is shown in Figure 4. The input biomass is corn stover with a moisture content of $20 \%$. It is dried to $4.1 \%$ moisture (to maintain consistency with Bridgeman et al.'s data). The energy extracted from burning of the torrefaction gases in the combustor are sufficient to heat the recycled portion of torrefaction gases and also to dry the biomass from $20 \%$ to $4.1 \%$ moisture content, so no solid biomass is required in the combustor. The dryer temperature is maintained sufficiently high $\left(110^{\circ} \mathrm{C}\right)$ to guarantee that the flue gases leave without becoming saturated with moisture, but sufficiently low to minimize devolatilization of the biomass. The combustor is operated with $150 \%$ of the theoretical stoichiometric amount of air for complete combustion. This value was chosen to ensure that the flame temperature stays below about $1370^{\circ} \mathrm{C}$, which minimizes NOx emissions. The majority of the torrefaction gases are circulated back to the torrefaction reactor after heating to $300^{\circ} \mathrm{C}$. The exact amount recirculated is set by the heat demand of the torrefier. After heating the recirculated torrefaction gases, the combustion flue gases are directed back to the dryer. 
The overall process depicted in Figure 4 has a mass yield, defined as the mass of torrefied biomass divided by the mass of input biomass (both on a dry, ash-free basis), of $83 \%$ and an overall energy yield $\left(\mathrm{HHV}_{\mathrm{dry}}\right.$, ash-free of torrefied biomass divided by $\mathrm{HHV}_{\mathrm{dry}}$, ash-free of input biomass) of $88 \%$.

\begin{tabular}{|c|c|c|c|c|c|}
\hline 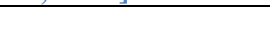 & \multirow{2}{*}{$\begin{array}{l}\text { Biomass input } \\
(\text { dry wt } \%)\end{array}$} & \multicolumn{4}{|c|}{ Torrefied Biomass (with indicated reaction temperature) } \\
\hline & & $230^{\circ} \mathrm{C}$ & $250^{\circ} \mathrm{C}$ & $270^{\circ} \mathrm{C}$ & $290^{\circ} \mathrm{C}$ \\
\hline $\mathrm{C}$ & 47.3 & 48.7 & 49.6 & 51.9 & 56.4 \\
\hline $\mathrm{N}$ & 6.8 & 6.3 & 6.1 & 5.9 & 5.6 \\
\hline $\mathrm{H}$ & 0.8 & 0.7 & 0.9 & 0.8 & 1.0 \\
\hline $\mathrm{O}$ & 37.7 & n.a. & 35.6 & 33.2 & 27.6 \\
\hline Ash & 6.3 & n.a. & 7.4 & 8.4 & 10.2 \\
\hline Moisture (wet wt\%) & 4.1 & 1.5 & 0.9 & 0.3 & 0.8 \\
\hline $\mathrm{HHV}, \mathrm{MJ} / \mathrm{kg}$ daf & 18.9 & 19.4 & 19.8 & 20.7 & 22.6 \\
\hline
\end{tabular}

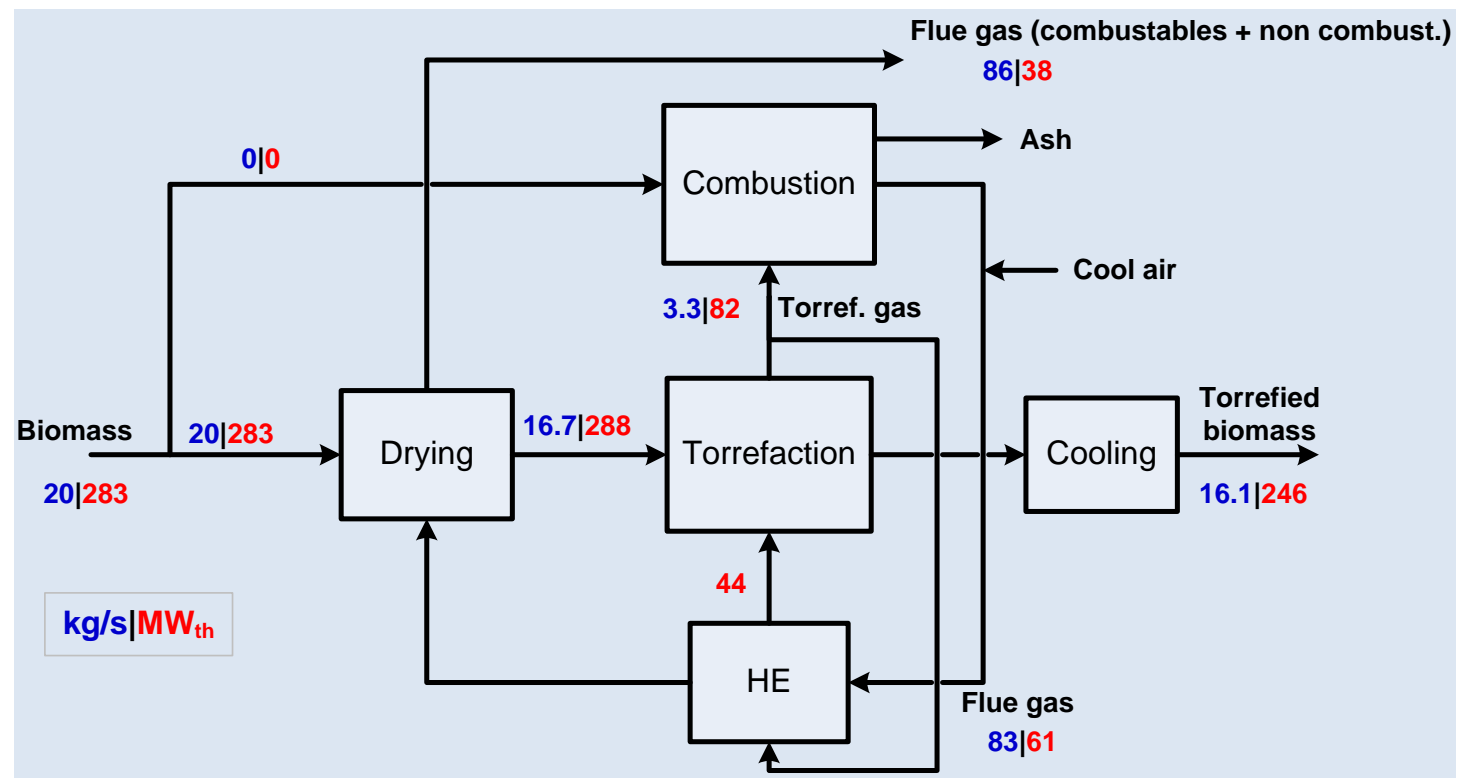

Figure 4. Aspen Plus simulation results for corn stover torrefaction.

\subsection{Pelletizing torrefied biomass}

A torrefaction system could be co-located with a co-gasification facility, in which case opportunities for heat and material integration between the torrefaction plant and the conversion plant can be exploited. Alternatively, the torrefied biomass can be produced remotely and transported to the gasification plant. For this alternative, pelletization would likely be required before transport. The higher volumetric energy density and hydrophobicity of pelletized torrefied biomass compared with raw biomass facilitates transporting it from remote locations, but opportunities for heat and material integration with the co-gasification facility would be lost. The decision was taken to assume as a baseline scenario the off-site production of torrefied pellets that are subsequently delivered to the conversion facility for cofeeding with coal. This provides a conservative estimate of overall system performance, compared with integrating torrefaction at the conversion facility. The literature suggests that pelletizing torrefied biomass, which would be required for efficient transport from the torrefaction facility to the gasification facility, is readily achievable (Bergman, 2005). 


\subsection{Uncertainties with slurrying behavior of torrefied biomass}

An important question we were not able to definitively answer in our project is how well torrefied biomass will behave in a slurry, as required for the GE gasifier. Available research suggests that it may be challenging to achieve a $64 \mathrm{wt} \%$ solids fraction in coal/torrefied-biomass slurries, as we have assumed, especially when the biomass fraction is high. Additional research is recommended to determine the feasibility of operating with coal/torrefied-biomass slurries, especially high-solids slurries. We briefly review some salient literature here.

Dooher and Castaldi (2010) have calculated the achievable solids fraction with milled torrefied beech wood using a theoretical model (Dooher, 2003) that correlates viscosity with particle packing density. (No empirical work was done, and no analysis of coal/biomass mixtures was done.) Their analysis predicts pumpable slurries, which we assume to mean with viscosity $<0.7 \mathrm{~Pa}-\mathrm{s}$, when the wt $\%$ solids loading is between $39 \%$ and $50 \%$, depending on the distribution of torrefied biomass particle sizes. However, their work does not appear to have taken into account the potential for swelling of torrefied material in water, which has been demonstrated by Felix, et al (2011) to be of some concern. In some preliminary experimental work, Whitty (2012) was unable to get a slurry of water and torrefied pine powder to flow when the solids loading exceeded about $15-20 \%$. He speculates that additives might improve the flowability, but the extent to which they would help is unclear without additional experiments.

In another study, He et al. (2009) have empirically measured the maximum solids fraction for a pumpable slurry of coal and pretreated biomass to be about $45 \%$. In this study, pretreatment of woody biomass was by a hydothermal process involving heating of a $20 \mathrm{wt} \%$ biomass-water slurry for 30 minutes at $230^{\circ} \mathrm{C}$ in a pressurized ( 7 bar) hydrogen-rich environment. The resulting product was combined with a $25 \mathrm{wt} \%$ coal slurry, yielding an overall solids fraction of $45 \%$ for the coal/biomass slurry, with a corresponding biomass weight fraction of $20 /(20+25)=44 \%$. We do not know if the hydrothermal processing used by He et al. would produce behavior of a biomass/coal slurry comparable to that for a torrefied-biomass/coal slurry. Felix, et al. (2011) suggests that swelling of torrefied biomass in water would be far greater than swelling of hydrothermally-treated biomass. Thus, hydrothermal pretreatment, in lieu of torrefaction, may be worth further investigation. A shortcoming of the hydrothermal process is a lower energy conversion efficiency than torrefaction. Measurements (Yan et al., 2009; Hoekman et al., 2011) indicate that 70 to $80 \%$ of the energy content of the input biomass to a hydrothermal process would be retained in the treated solid product. Additionally, some energy inputs

may be required to drive the process, which would lead to an overall energy efficiency well below that for torrefaction.

\section{Front-end process simulations}

We developed simulations for each of the three front-end configurations based on the torrefaction model discussed above and on two gasifier designs calibrated against data in the literature on coal-only operation. Our simulation of the slurry-feed gasifiers follows closely simulations of this technology reported by Liu, et al. (2011). Our simulation of the dry-feed technology is based largely on prior work by Chiesa et al (2005) and Kreutz et al (2005). Literature data for co-gasification of coal and biomass are essentially non-existent, so we have extrapolated from our coal-only simulations. Table 4 summarizes our input design parameter values for the simulations.

A key metric of performance for the three front-end systems that we examined is cold gas efficiency (CGE). We define this as the chemical energy in the syngas leaving the gasifier (high heating value basis) divided by the higher heating value energy content of the input coal plus biomass. In cases using torrefaction, the input biomass is the input prior to torrefaction.

$$
\mathrm{CGE}=\mathrm{m}_{\text {syn }} * \mathrm{HHV}_{\text {syn }} /\left(\mathrm{m}_{\text {coal }} * \mathrm{HHV}_{\text {coal }}+\mathrm{m}_{\text {biomass }} * \mathrm{HHV}_{\text {biomass }}\right)
$$


where $\mathrm{HHV}$ is given in $\mathrm{MJ} / \mathrm{kg}, \mathrm{m}_{\mathrm{syn}}$ is the syngas mass flowrate $(\mathrm{kg} / \mathrm{s})$, and $\mathrm{m}_{\text {biomass }}$ is the input biomass mass flowrate, $\mathrm{kg} / \mathrm{s}$.

Figure 5 shows the calculated CGE values for our three front-end process configurations as a function of the biomass input fraction. In all three cases, the CGE decreases as the biomass fraction increases. The basic reason for this is the lower energy content per unit mass for biomass compared with coal (Table 1). With increasing biomass fraction, a larger portion of the input energy content must be oxidized (rather than gasified) to keep the gasifier operating at its design temperature.

Figure 5 also shows that the front-end configuration utilizing the dry-feed gasifier with coal plus torrefied biomass has a CGE nearly 10 percentage points higher than for the system utilizing the slurryfeed gasifier with torrefied biomass. The lower CGE for the slurry-feed design arises from $i$ ) the lower carbon conversion achievable with a slurry-feed gasifier and ii) additional feedstock oxidation required to evaporate slurry water and heat it to reaction temperature.

Finally, Figure 5 shows that for the dry-feed gasifier, the difference in CGE for using dried biomass rather than torrefied biomass grows with the biomass fraction, reaching about 5 percentage points when biomass accounts for $100 \%$ of the input feedstock. The reduction in efficiency can be linked largely to the energy lost during torrefaction. ${ }^{1}$

Table 4. Gasifier design parameter assumptions for Aspen Plus simulations.

\begin{tabular}{l|l}
\hline $\begin{array}{l}\text { Entrained-flow, slurry-fed, } \\
\text { integral-quench gasifier }\end{array}$ & $\begin{array}{l}\text { Slurry wt } \% \text { solids }=64 ; \text { Carbon conversion }=96 \% \text { for coal; } 100 \% \text { for torrefied } \\
\text { biomass; } \mathrm{T} \text { gasifier }=1371^{\circ} \mathrm{C} \text { by adjusting } \mathrm{O}_{2} \text { in; Heat loss }=1 \% \text { of coal/biomass } \\
\text { HHV; } \mathrm{P}_{\text {reactor }}=75 \text { bar; } \Delta \mathrm{p}=3.5 \text { bar. }\end{array}$ \\
\hline $\begin{array}{l}\text { Entrained-flow, dry-fed, } \\
\text { Shell gasifier }\end{array}$ & $\begin{array}{l}\text { Coal dried to } 2 \% \text { moisture; biomass dried to } 4.1 \% \text { moisture; Carbon conversion }= \\
99.6 \% \text { for coal and biomass; T gasifier }=1427^{\circ} \mathrm{C} ; \text { Heat loss }=0.3 \% \text { of } \\
\text { coal/biomass } \mathrm{HHV} ; \mathrm{P}_{\text {reactor }}=40 \text { bar; } \Delta \mathrm{p}=3.5 \text { bar; steam input varies with } \\
\text { biomass fraction. }\end{array}$ \\
\hline
\end{tabular}

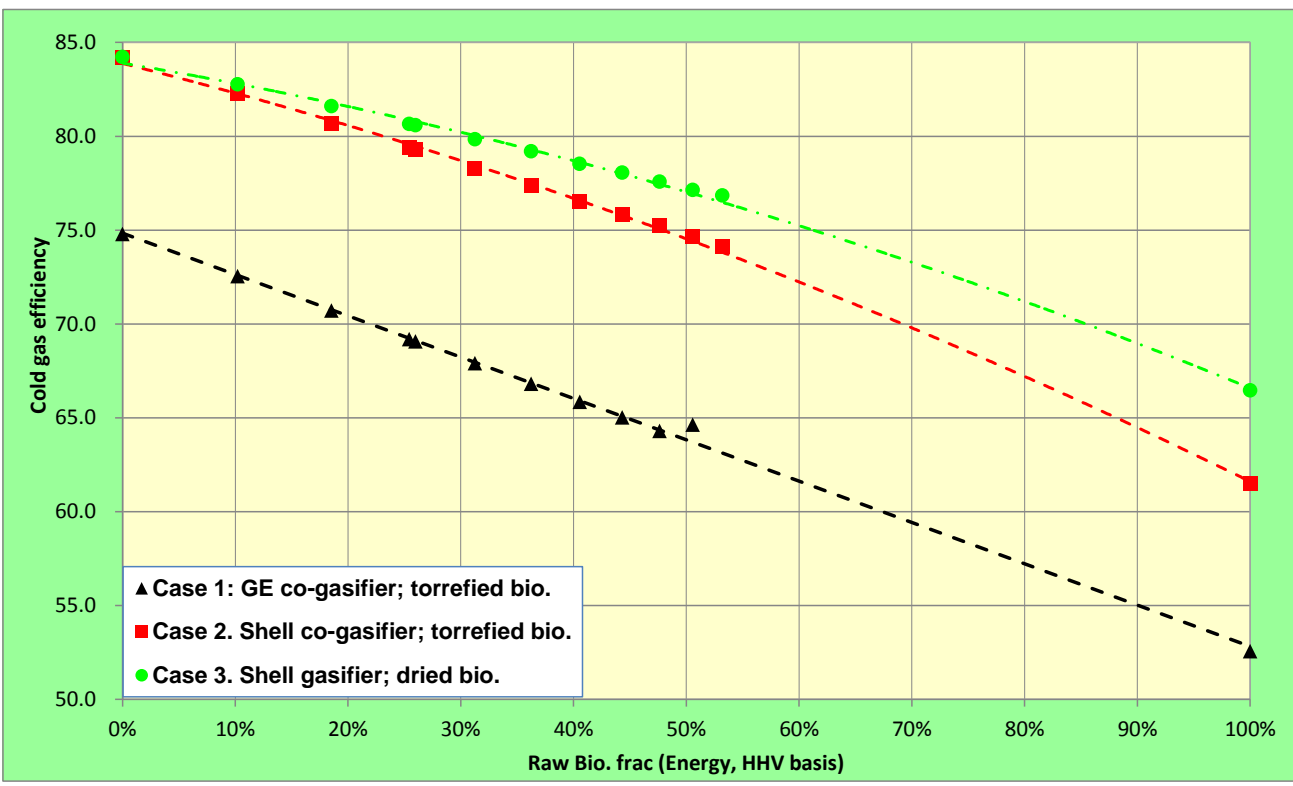

Figure 5. Cold gas efficiency (see definition in text) for biomass/coal cogasification as a function of the fraction of the input energy (HHV basis) that is biomass. The three curves are for the three front-end process configurations in Figure 1. For cases involving torrefaction, the input energy is measured prior to torrefaction.

\footnotetext{
${ }^{1}$ In our simulation of torrefaction, the final torrefied product contains $88 \%$ of the HHV energy input as biomass. Partially offsetting the $12 \%$ energy loss is an improvement in gasification efficiency when using torrefied material rather than raw, dry biomass. The net effect, when using $100 \%$ biomass feed, is approximately a $5 \%$ reduction in cold gas efficiency of converting biomass to syngas, as shown in Figure 5.
} 


\section{Capital cost estimation}

We developed capital cost estimates for all three of the front-end configurations in Figure 1, building on our prior database of component-level capital cost estimates (Liu et al., 2011). Our torrefaction cost parameter values (see Table 5 in Appendix B) are based on estimates by Uslu (2005) for a system design including all elements shown in Figure 4.

Costs for each of our two gasifier designs are based on coal gasifier cost estimates of NETL (2010). An appropriate gasifier cost scaling parameter for coal-only systems is the coal energy input rate. We have used this parameter to scale costs for slurry-feed gasification of coal, as well as of coal plus biomass. However, we recognized after completing our analysis of cases using slurry-fed gasification that the product gas volume flow is a more appropriate scaling parameter when coal plus biomass feeds are considered. With volume flow as the cost scaling parameter the gasifier capital cost estimates are $20 \%$ to $25 \%$ higher than if input energy is used as the scaling parameter, which converts to a few percent lower total plant cost. Thus, our plant capital cost estimates for the slurry-fed systems are probably a few percent lower than they should be. To remedy this underestimate in our analysis of cases using dry-feed gasifers, we adopted product gas volume flow rate as the cost scaling parameter for these cases.

For coal drying, we adopt a cost estimate for a fluidized-bed drying process with internal waste heat utilization, specifically costs estimated for the commercial WTA technology, a registered trademark of RWE Power AG (Schoff, et al., 2009).

Appendices B, C, D, and E report total plant costs for the alternative coproduction and poweronly systems analyzed in our work.

\section{$6 \quad$ Key Findings}

Two important findings emerged from our work on the front-end configurations: 1) the significant decline in gasifier cold-gas efficiency that accompanies increasing biomass/coal ratio of input feedstock, and 2) the much higher cold gas efficiency achievable with dry-feed gasifiers relative to slurryfeed gasifiers.

These findings, together with unanswered questions about the feasibility of pumping a coal/biomass slurry with solids concentration as high as $64 \%$ and the fact that the only entrained flow coal+biomass co-gasification system proven in commercial operation today (at Buggenum in the Netherlands) uses dry-feed gasification, led us to focus much of our subsequent design and simulation work on systems using dry-feed gasification. We nevertheless carried forward analysis of several system designs with the slurry-fed gasification to have an understanding of the costs and benefits of this option should the high solids content slurry-feeding of torrefied biomass ultimately prove feasible.

\section{References}

Arias, B., C. Pevida, J. Fermoso, M. G. Plaza, F. Rubiera, et al., "Influence of torrefaction on the grindability and reactivity of woody biomass," Fuel Processing Technology 89(2): 169-175, 2008.

Uslu, A., "Pre-treatment technologies, and their effects on the international bioenergy supply chain logistics: technoeconomic evaluation of torrefaction, fast pyrolysis and pelletisation," Masters thesis, Utrecht University, The Netherlands, 2005.

Bergman, P.C.A., "Combined torrefaction and pelletisation: The TOP process," ECN-C-05-073, The Energy Research Center of the Netherlands, 2005.

Bergman, P., A. Boersma, J. Kiel, M. Prins, K. Ptasinski, et al., "Torrefaction for entrained-flow gasification of biomass," Acknowledgement/Preface: 78, 2004.

Bergman, P., A. Boersma, R. Zwart and J. Kiel, "Torrefaction for biomass co-firing in existing coal-fired power stations," BIOCOAL, ECN-C-05-013, The Energy Research Center of the Netherlands, 2005. 
Bergman, P.C.A and Kiel, J.H.A., "Torrefaction for Biomass Upgrading," 14th European Biomass Conference and Exhibition, Paris, 2005.

Bridgeman, T.G., Jones, J.M., Shield, I., and Williams, P.T., "Torrefaction of reed canary grass, wheat straw and willow to enhance solid fuel qualities and combustion properties," Fuel, 87 (2008) 844-856.

Chiesa, P., Consonni, S., Kreutz, T., and Williams, R., "Co-production of hydrogen, electricity and $\mathrm{CO}_{2}$ from coal with commercially ready technology: PartA, performance and emissions," International J Hydrogen Energy, 30: 747-767, 2005

Deng, J., G.-j. Wang, J.-h. Kuang, Y.-1. Zhang and Y.-h. Luo. "Pretreatment of agricultural residues for cogasification via torrefaction," J Analytical and Applied Pyrolysis, 86(2): 331-337, 2009.

Dooher, J., "Physio-Chemical Modeling of Coal and Coal/Biomass Slurries for Gasification and Direct Combustion Applications," Proceedings, $28^{\text {th }}$ International Technical Conference on Coal Utilization and Fuel Systems, Clearwater, FL, 10-13 March 2003.

Dooher, J.P. and Castaldi, M.J., "Slurry Fed Biomass Gasifier: Feedstock Preparation Techniques and Performance Results," Proceedings, $35^{\text {th }}$ International Technical Conference of Coal Utilization and Fuel Systems, Clearwater, FL, 6-10 June 2010.

Felix, L., Farthing, B., Irvin, J. Snyder, T., Hoekman, S.K., and Coronella, C., "Employing Hydrothermal Carbonization for the Production of Energy-Dense Fuels from Lignocellulosic Biomass," presentation at the GTI TCBiomass Conference, Chicago, IL, 27-30 September 2011.

He, W., Park, C.S., and Norbeck, J.M., "Rheological Study of Comingled Biomass and Coal Slurries with Hydrothermal Pretreatment," Energy and Fuels, 23: 4763-4767, 2009.

Hoekman, S.K., Broch, A., and Robbins, C., "Hydrothermal Carbonization (HTC) of Lignocellulosic Biomass," Energy \& Fuels, 25: 1802-1810, 2011.

Kreutz, T., Williams, R., Consonni, S., and Chiesa, P., "Co-production of hydrogen, electricity and $\mathrm{CO}_{2}$ from coal with commercially ready technology: Part B, economic analysis," International J Hydrogen Energy, 30: 769-784, 2005 .

Larson, E.D., Fiorese, G., Liu, G., Williams, R.H., Kreutz, T.G., and Consonni, S., "Co-production of decarbonized synfuels and electricity from coal + biomass with $\mathrm{CO} 2$ capture and storage: an Illinois case study," Energy and Environmental Science, 3(1): 28-42, 2010.

Lau, F.S., Bowen, D.A., Dihu, R., Doong, S., Hughes, E.E., Remick, R., Slimane, R., Turn, S.Q., and Zabransky, R., "Techno-economic analysis of hydrogen production by gasification of biomass," final technical report for the period 15 Sept 2001 - 14 Sept 2002, contract DE-FC36-01GO11089 for US Dept. of Energy, Gas Technology Inst., Des Plaines, IL, June (rev.), 2003, 145 pp.

Liu, G., Larson, E.D., Williams, R.H., Kreutz, T.G., and Guo, X., "Making Fischer-Tropsch Fuels and Electricity from Coal and Biomass: Performance and Cost Analysis," Energy and Fuels, 2011, 25, 415-437 :

DOI: $10.1021 / \mathrm{ef} 101184 \mathrm{e}$.

Katofsky R.E., "The production of fluid fuels from biomass," CEES Rpt 279, Center for Energy and Environmental Studies, Princeton University, 1993.

Matchak T.A., Rao A.D., Ramanathan V. and Sander M.T., "Cost and Performance for Commercial Application of Gasification-Combined-Cycle Plants," Report AP-3486, Electric Power Research Institute, April 1984.

NETL (National Energy Technology Laboratory), Cost and Performance Baseline for Fossil Energy Plants: Volume 1: Bituminous Coal and Natural Gas to Electricity, DOE/NETL-2010/1397, (Rev. 2), November 2010.

Peng, X.D., Toseland, B.A., and Tijm, P.J.A., "Kinetic understanding of the chemical synergy under LPDME conditions -- once-through applications", Chemical Engineering Science, 54, pp. 2787-2792, 1999.

Prins, M.J., "Thermodynamic analysis of biomass gasification and torrefaction," PhD dissertation, Eindhoven University, The Netherlands, 2005. 
Prins, M.J., K.J. Ptasinski and F.J.J.G. Janssen, “Torrefaction of wood: Part 1. Weight loss kinetics," J Analytical and Applied Pyrolysis, 77(1): 28-34, 2006.

Schoff, R., et al., "Gasification of lignite coal: technology research and screening," Report 1018137, Electric Power Research Institute (in collaboration with Arkansas Electric Cooperative Corp., BP Alternative Energy, Great River Energy, Luminant, and the Southern Company), Palo Alto, CA, 2009.

Supp, E., How to produce methanol from coal, Springer-Verlag, Berlin, 1990.

Teco Energy, "Polk Power Station IGCC, presentation at the International Conference on Co-utilization of Domestic Fuels (ICCDF), Gainesville, Florida, 6 February, 2003.

Van der Drift, A., H. Boerrigter, B. Coda, M. Cieplik, K. Hemmes, et al., "Entrained flow gasification of biomass," ECN-C-04-039, Energy Research Centre of Netherlands, 2004.

van Dijk KM, van Dijk R, van Eekhout VJL, van Hulst H, Schipper W and Stam JH, "Methanol from natural gas conceptual design and comparison of processes," Delft U of Technology, The Netherlands, 1995, 286 pp.

Whitty, K., personal communication, Department of Chemical Engineering, University of Utah, February 22, 2012.

Yan, W., Acharjee, T.C., Coronella, C.J., and Vasquez, V.R., "Thermal Pretreatment of Lignocellulosic Biomass," Environmental Progress \& Sustainable Energy, 28(3): 435-440, 2009. 


\title{
Appendix B
}

\section{Process Design and Analysis for Co-Production of Electricity and Synthetic Gasoline via Co- Gasification of Coal and Biomass with CCS}

\author{
Guangjian Liu \\ Eric D. Larson \\ Robert H. Williams
}

\section{Contents}

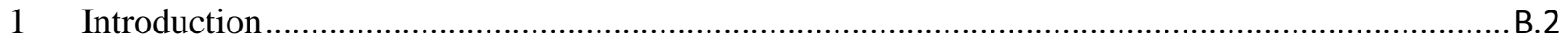

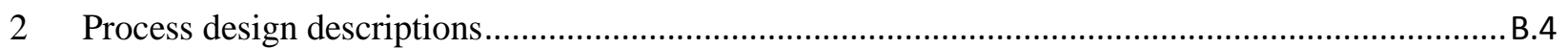

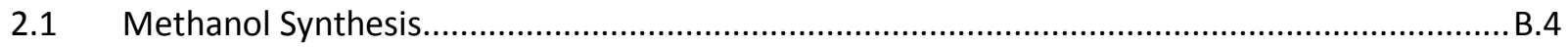

2.2 Methanol to Gasoline (MTG) Synthesis .............................................................................. B.5

3 Process Simulation and Economic Modeling Results................................................................. B.9

3.1 Key Design Parameters and Performance Metrics -- Definitions .........................................9.9

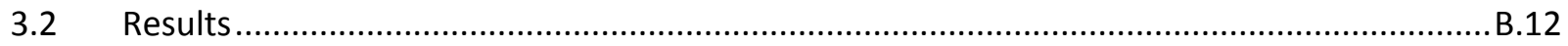

3.2.1 Dried biomass versus torrefied biomass - torrefied is favored.................................... B.12

3.2.2 Dry-feed gasifiers versus slurry-feed gasifiers ...............................................................15

3.2.3 Gas phase vs. liquid phase methanol synthesis ........................................................17

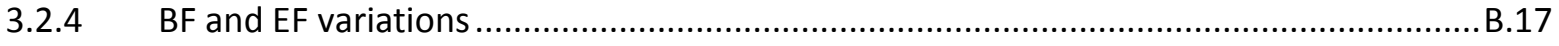

3.2.5 Economics with captured $\mathrm{CO}_{2}$ sold for EOR ............................................................20

3.2.6 Economics of co-production vs. liquids-only production under a carbon mitigation policy B.21 


\section{Introduction}

Two commercially demonstrated routes for converting solids to transportation fuels through gasification are the Fischer-Tropsch process (FT) and an alternative route through methanol to gasoline (MTG). The Fischer-Tropsch process produces a broad spectrum of straight chain olefins and paraffins that require upgrading to produce finished gasoline, diesel fuel and lubricants ${ }^{1,2}$ The MTG process produces primarily a finished-grade gasoline, with most of the remainder being propane and butane (LPG). ${ }^{3,4}$

Many systems studies of coal and/or biomass conversion to liquid fuels based on FT synthesis have been done e.g. ${ }^{5,6,7,8,9,10}$. Few studies have been published on biomass based MTG processes, ${ }^{11,12}$ and none that examine MTG with CCS. Moreover, there have been no studies that compare FT and MTG processes using a self-consistent analytical framework. Using the same analytical approach as for our prior analyses of FT processes, ${ }^{13}$ our objectives in the work reported in this Appendix are to quantify the energy, environmental, and economic performance of facilities that coproduce electricity and synthetic gasoline from mixtures of coal and biomass via co-gasification, with capture and storage of byproduct $\mathrm{CO}_{2}$ (CCS). Plant designs that exhibit the most promising economics, have superior environmental footprints, and have the potential to be deployed at scale are sought.

${ }^{1}$ X. Zhao, R.D. McGihon and S.A. Tabak, "Coal to clean gasoline,” Hydrocarbon Engineering, 2008.

${ }^{2}$ A.P. Steynberg and M.E. Dry, Fischer-Tropsch Technology, Elsevier, 2004.

${ }^{3}$ Tabak, S., and Zhao, X., "An alternative route for coal to liquid fuel," Presented at First World Coal-to-Liquids Conference, 3-4 April 2008, Paris, France.

${ }^{4}$ James Katzer. Coal (and Biomass) to Liquid Fuels. Environmental and Energy Study Institute (EESI) Energy Briefing. 1310 Longworth House Office Bld, 18 Mar. 2009.

${ }^{5}$ Bechtel Corporation, 1999, "Baseline Design/Economics For Advanced Fischer-Tropsh Technology,” DOE report No. De-Aczz-91pcgo027.

${ }^{6}$ Bechtel Corp., Global Energy Inc., and Nexant Inc., Gasification Plant Cost and Performance Optimization, Task 2 Topical Report: Coke/Coal Gasification with Liquids Coproduction, USDOE contract DE-AC26-99FT40342, September 2003.

${ }^{7}$ Van Bibber, L., Shuster, E., Haslbeck, J., Rutkowski, M., Olsen, S., and Kramer, S., Technical and Economic Assessment of Small-Scale Fischer-Tropsch Liquids Facilties, DOE/NETL-2007/1253, National Energy Technology Laboratory, February 2007.

${ }^{8}$ Van Bibber, L., Shuster, E., Haslbeck, J., Rutkowski, M., Olsen, S., and Kramer, S., Baseline Technical and Economic Assessment of a Commercial Scale Fischer-Tropsch Liquids Facility, DOE/NETL-2007/1260, National Energy Technology Laboratory, April 2007.

${ }^{9}$ Hamelinck C.N., Faaij, A.P.C., den Uil, H., and Boerrigter, H., "Production of FT Transportation Fuels from Biomass; Technical Options, Process Analysis and Optimisation, and Development Potential," Energy, 29:17431771, 2004.

${ }^{10}$ Mark Anders. Techno-economic modeling of coal conversion processes for liquid fuel production. The University of Aston, Birmingham. May 1991.

${ }^{11}$ Jones, S.B. and Zhu, Y.B., "Techno-economic Analysis for the Conversion of Lignocellulosic Biomass to Gasoline via the Methanol-to-Gasoline (MTG) Process," PNNL-18481, Pacific Northwest National Laboratory, US Department of Energy, April 2009.

${ }^{12}$ Phillips, S.D, Tarud, J.K., Biddy, M.J. and Dutta, A., "Gasoline from Woody Biomass via Thermochemical Gasification, Methanol Synthesis, and Methanol-to-Gasoline Technologies: A Technoeconomic Analysis," Ind. Eng. Chem. Res., 50: 11734-11745, 2011.

${ }^{13}$ Liu, G., Larson, E.D., Williams, R.H., and Kreutz, T.G., "Fischer-Tropsch Fuels from Coal and Biomass: Performance and Cost Analysis," Energy and Fuels, 25: 415-437, 2011. 
Underpinning our results are Aspen Plus mass and energy balance simulations that were developed for 16 process designs. Capital costs and overall economics were estimated for each design using a self-consistent capital cost database and analytical framework. Systems incorporating two different gasifier designs were studied. Figure 1 shows a simplified block diagram for systems co-feeding dried crushed biomass with crushed coal into a dry-feed gasifier (Shell design). Figure 2 shows the system design when torrefied biomass and coal are the feedstocks for either a dry-feed or a slurry-feed gasifer. The latter is based on a GE Energy quench-gasifier design.

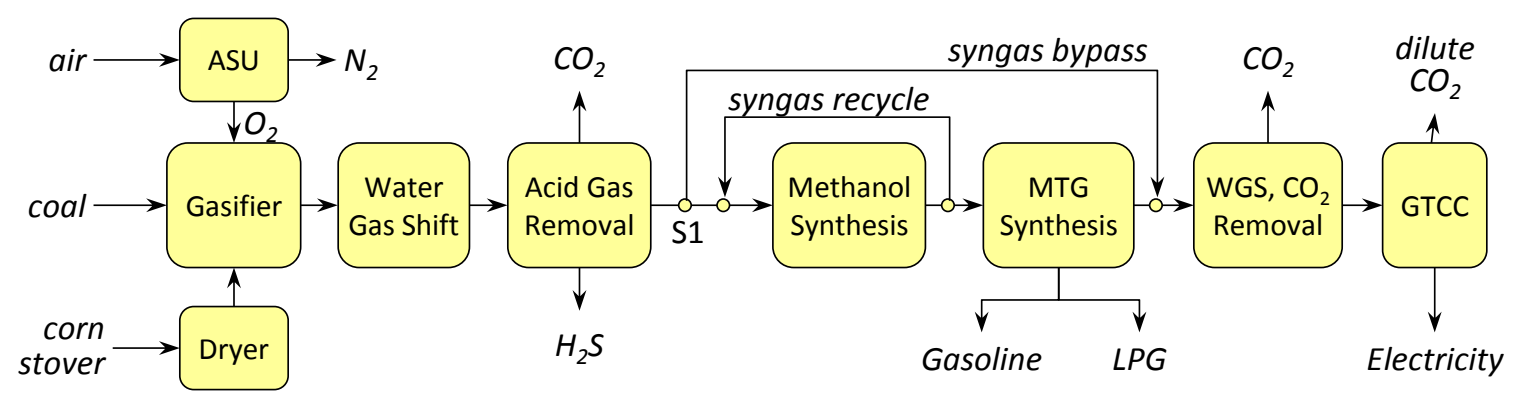

Figure 1. Simplified process diagram for co-production of electricity and gasoline via co-gasification of coal and dried biomass in a dry-feed gasifier. Grinding of the feedstocks (to $<1 \mathrm{~mm}$ for the dried corn stover and $<0.1 \mathrm{~mm}$ for the coal) is not shown.

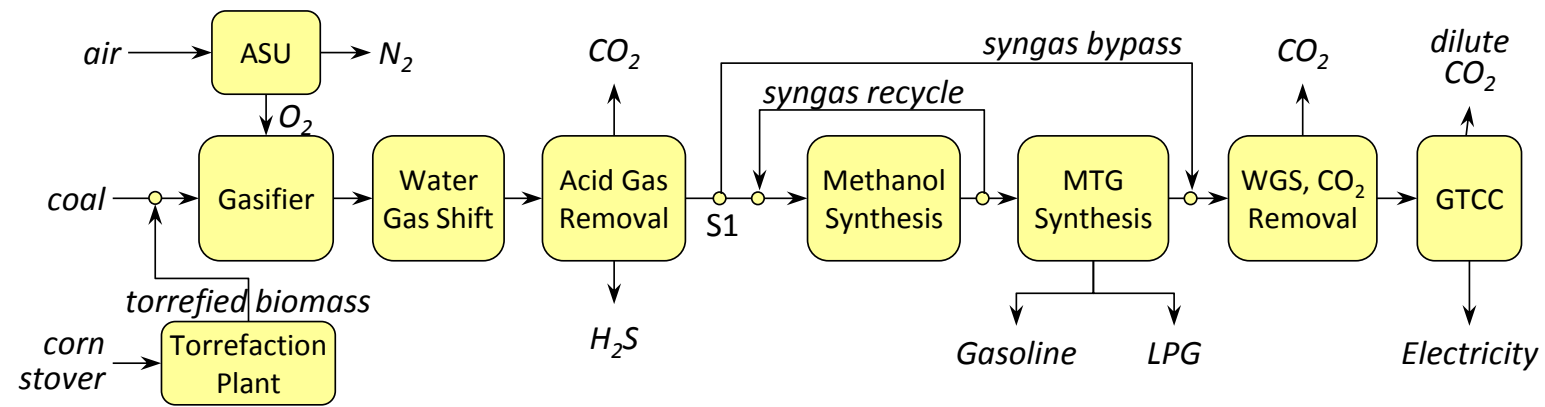

Figure 2. Simplified process diagram for co-production of electricity and gasoline via co-gasification of coal and torrefied biomass. Both dry-feed and slurry-feed gasifiers were examined.

With either gasifier design, the coal and biomass feedstocks are co-gasified with oxygen from a stand-alone cryogenic air separation unit, and the resulting syngas is cooled and cleaned via wet scrubbing before passing to a water gas shift (WGS) reactor used to tune the $\mathrm{H}_{2} / \mathrm{CO}$ content of the syngas to the desired level of approximately 2 at the entrance to the methanol synthesis island. Most of the $\mathrm{CO}_{2}$ is then removed from the syngas utilizing a Rectisol system, and the resulting gas is sent to methanol synthesis. The removed $\mathrm{CO}_{2}$ is compressed to 150 bar for pipeline delivery to an underground storage site. The methanol is delivered to the gasoline production area (MTG synthesis reactor), which produces a finished gasoline blendstock and a byproduct LPG-like stream. To further reduce the carbon footprint of the plant, any unconverted syngas leaving the synthesis area, along with some light gases produced during synthesis, is subjected to additional water gas shift, followed by $\mathrm{CO}_{2}$ removal, before going to a gas turbine combined cycle power island that generates sufficient power to meet onsite requirements and export power to the grid. The amount of power generated can be adjusted by changing the amount of recycle of unconverted syngas back to methanol synthesis and/or by changing the syngas bypass around the synthesis reactors.

Table 1 summarizes the key distinguishing features for each of the 16 cases. Collectively, the 16 designs enable system performances and costs to be compared for use of

- dried biomass versus torrefied biomass as the co-feed with coal,

- dry-feed gasifiers versus slurry-feed gasifiers,

- gas-phase methanol synthesis vs. liquid-phase synthesis, 
- different input biomass-to-coal ratios (characterized by the biomass fraction, BF),

- different electricity-to-liquids output ratios (characterized by the electricity fraction, $\mathrm{EF}$ ).

Table 1. Process designs for which simulation results were generated.

\begin{tabular}{|c|c|c|c|c|c|}
\hline Case \# & Gasifier & Biomass & $\mathrm{BF}^{*}$ & $\mathrm{EF}^{* *}$ & MeOH Synthesis \\
\hline 1 & Dry-feed & coal only & 0 & 0.50 & Liquid Phase \\
\hline 2 & Dry-feed & dried & 0.30 & 0.50 & Gas Phase \\
\hline 3 & Dry-feed & dried & 0.30 & 0.50 & Liquid Phase \\
\hline 4 & Dry-feed & torrefied & 0.05 & 0.26 & Liquid Phase \\
\hline 5 & Dry-feed & torrefied & 0.05 & 0.45 & Liquid Phase \\
\hline 6 & Dry-feed & torrefied & 0.28 & 0.28 & Liquid Phase \\
\hline 7 & Dry-feed & torrefied & 0.28 & 0.45 & Liquid Phase \\
\hline 8 & Dry-feed & torrefied & 0.28 & 0.02 & Liquid Phase \\
\hline 9 & Dry-feed & torrefied & 0.30 & 0.50 & Liquid Phase \\
\hline 10 & Dry-feed & torrefied & 0.30 & 0.50 & Gas Phase \\
\hline 11 & Slurry feed & coal only & 0 & 0.50 & Liquid Phase \\
\hline 12 & Slurry feed & torrefied & 0.05 & 0.21 & Liquid Phase \\
\hline 13 & Slurry feed & torrefied & 0.05 & 0.44 & Liquid Phase \\
\hline 14 & Slurry feed & torrefied & 0.26 & 0.21 & Liquid Phase \\
\hline 15 & Slurry feed & torrefied & 0.26 & 0.44 & Liquid Phase \\
\hline 16 & Slurry feed & torrefied & 0.26 & 0.03 & Liquid Phase \\
\hline \multicolumn{6}{|c|}{$\begin{array}{l}* \mathrm{BF} \text { is the fraction of energy input to the system that is biomass: } \\
\mathrm{BF} \equiv \mathrm{HHV}_{\text {biomass }} /\left(\mathrm{HHV}_{\text {biomass }}+\mathrm{HHV}_{\text {coal }}\right) \text {. For cases using torrefied biomass, the } \mathrm{BF} \\
\text { is calculated on the basis of } \mathrm{HHV} \text { of the biomass prior to torrefying it. } \\
* * \mathrm{EF} \text { is the fraction of the product mix that is electricity: } \\
\mathrm{EF} \equiv \mathrm{MW}_{\text {electric }} /\left(\mathrm{MW}_{\text {electric }}+\mathrm{MW}_{\text {gasoline } \mathrm{LHV}}+\mathrm{MW}_{\mathrm{LPG}, \mathrm{LHV}}\right) \text {. }\end{array}$} \\
\hline
\end{tabular}

\section{Process design descriptions}

The focus here is on describing the design and simulation of the syngas to MTG conversion portion of the plant designs. The other major areas of the plant configurations have been previously described by Liu, et al. ${ }^{13}$ The syngas to MTG process consists of syngas conversion to methanol followed by methanol conversion to gasoline and an LPG-like coproduct.

\subsection{Methanol Synthesis}

Methanol synthesis can be represented the following reactions:

$$
\begin{gathered}
\mathrm{CO}+2 \mathrm{H}_{2} \leftrightarrow \mathrm{CH}_{3} \mathrm{OH} \\
\mathrm{CO}_{2}+3 \mathrm{H}_{2} \leftrightarrow \mathrm{CH}_{3} \mathrm{OH}+\mathrm{H}_{2} \mathrm{O}
\end{gathered}
$$

In practice, a catalyst is required to make these reactions go, and methanol catalysts are well-established in the market. The synthesis reactions are highly exothermic, and heat is removed to maintain the reaction environment as close to isothermal as possible so as to maximize methanol production while protecting the catalyst from damage due to overheating. A small fraction of the produced methanol $(\sim 0.3 \%)$ reacts further to form side products such as dimethyl-ether, formaldehyde and/or higher alcohols. ${ }^{14}$ The stoichiometry of the overall synthesis is satisfied when the volumes of the constituents in the feed gas are such that the relationship among them, defined as $R$, has a value of $2.03:^{15}$

\footnotetext{
${ }^{14}$ van Dijk, K.M., van Dijk, R., van Eekhout, V.J.L., van Hulst, H., Schipper, W. and Stam, J.H., "Methanol from natural gas -conceptual design and comparison of processes," Delft University, The Netherlands, 1995,286 pp.

${ }^{15}$ Katofsky R.E., "The production of fluid fuels from biomass," CEES Rpt 279, Center for Energy and Environmental Studies, Princeton University, 1993.
} 


$$
R=\left(\mathrm{H}_{2}-\mathrm{CO}_{2}\right) /\left(\mathrm{CO}+\mathrm{CO}_{2}\right) \text {. }
$$

Our plant designs considered two different methanol synthesis reactor design concepts: gas-phase methanol synthesis $(\mathrm{GPMeOH})$ and liquid-phase methanol synthesis (LPMeOH).

$\mathrm{GPMeOH}$, the methanol industry standard today, involves flow of syngas over a fixed catalyst bed. Maintaining isothermal conditions can be difficult due to low gas-phase heat transfer coefficients. To limit temperature rise, the synthesis reactions typically are staged, with cooling between reactor stages. Also, by limiting the initial concentration of CO entering the reactor (to 10-15\% by volume) the extent of the exothermic reactions is further controlled. Control of the $\mathrm{CO}$ fraction is achieved in practice by maintaining a sufficiently high recycling of unconverted $\mathrm{H}_{2}$-rich syngas back to the reactor. The recycling leads to a typical actual value of the parameter $\mathrm{R}$ for the combined synthesis reactor feed (fresh plus recycle feeds) of 3 to 4 . Two GPMeOH reactor types predominate in commercial plants. The ICI lowpressure process is an adiabatic reactor with cold unreacted gas injected between the catalyst beds. The resulting heating and cooling involves an inherent efficiency penalty, but the process can be operated very reliably. The Lurgi system, in which catalyst-loaded tubes contain the reacting gases while a cooling medium circulates on the outside of the tubes, allows for better reactor temperature control. Our $\mathrm{GPMeOH}$ simulation is based on the Lurgi design. ${ }^{16}$

The LPMeOH process involves bubbling syngas through an inert mineral oil containing powdered catalyst in suspension. The inert fluid moderates the temperature rise very effectively by enhancing heat transfer rates to boiler tubes immersed in the fluid. Much higher heat release rates can be accommodated without excessive temperature rise than in a gas-phase reactor. Because of this, best advantage of the good temperature control can be taken with a CO-rich syngas, ${ }^{17}$ such as that produced by coal gasification. With such feed gases, high conversion of $\mathrm{CO}$ is possible in a single pass of the gas through a relatively small reactor. The LPMEOH process was invented in the late 1970s and further developed and demonstrated with support from the US DOE in the 1980s by Air Products and Chemicals. Since the 1990s a commercial-scale unit has been operating at Eastman Chemical's Kingsport, Tennessee, facility where chemicals are manufactured from coal. Following a successful demonstration phase, this unit has operated commercially for many years. Our LPMeOH synthesis modeling is based on the Air Products design. ${ }^{18}$

\subsection{Methanol to Gasoline (MTG) Synthesis}

Two companies offer MTG processes today: Exxon-Mobil and Halder Topsoe. A key distinction between the two systems is that the Exxon-Mobil process involves a partial conversion of methanol to $\mathrm{DME}$ in a separate reactor, followed by conversion of the DME/methanol mixture into gasoline in a separate fixed-bed reactor. The Haldor Topsoe process, called TIGAS, utilizes an initial single-step conversion of syngas into DME/methanol, followed by conversion to gasoline in a separate reactor. ${ }^{19}$ The TIGAS process has been demonstrated at a pilot plant level in Houston, Texas in 1983-1986 operating with synthesis gas produced from natural gas. ${ }^{20}$ We have chosen to base our simulations on the Exxon

\footnotetext{
${ }^{16}$ Supp, E., How to produce methanol from coal. Springer-Verlag Berlin, Heidelberg. 1990.

${ }^{17}$ Peng, X.D., Toseland, B.A., and Tijm, P.J.A., “'Kinetic understanding of the chemical synergy under LPDME conditions -- once-through applications', Chemical Engineering Science, 54, pp. 2787-2792, 1999.

${ }^{18}$ Larson, E.D. and Ren, T., "Synthetic fuel production by indirect coal liquefaction," Energy for Sustainable Development, VII(4), 2003.

${ }^{19}$ http://www.topsoe.com/Business_areas/Gasification-based/Processes/Gasoline TIGAS.aspx.

${ }^{20}$ Thomas Rostrup-Nielsen, Poul Erik Højlund Nielsen, Finn Joensen, Jørgen Madsen. Polygeneration - Integration of Gasoline Synthesis and IGCC Power Production Using Topsoe's TIGAS Process. Website: www.risoe.dk/rispubl/reports/ris-r-1608_56-68.pdf
} 
Mobil process because it is the only one that has been operated at commercial scale, ${ }^{21}$ and more details of that process are available in the literature.

In the 1970 's, researchers at Mobil ${ }^{22,23,24}$ synthesized a zeolite catalyst, known as ZSM-5, ${ }^{25}$ that promotes the formation of gasoline range molecules $\left(\mathrm{C}_{4}-\mathrm{C}_{10}\right)$ from a mixture of DME and methanol. Practically no hydrocarbons larger than $\mathrm{C}_{10}$ form because of the shape-selective nature of the zeolite. The MTG process was implemented on an industrial scale (15,000 barrels per day production) in New Zealand starting in the mid-1980s until poor economics caused by declining oil prices caused the plant to be converted to produce only methanol after ten years of MTG operation. However, several new MTG projects are now under construction or have recently started operation: a pilot MTG plant in Jincheng, Shanxi started up in 2008, with a production capacity of about $270 \mathrm{bbl} /$ day of gasoline; a commercialscale MTG plant is planned for Medicine Bow, Wyoming, to produce 15,000 bbl/day of gasoline; and Synthesis Energy Systems (SES) plans to utilize MTG technology at coal gasification projects under development in West Virgina, Mississippi, and North Dakota. Collectively, these projects would produce approximately 20,000 bbl/d of gasoline.

A block flow diagram of our simulated MTG system is shown in Figure 3. The methanol (96\% methanol by mass and the remainder primarily water) is pumped to 22.7 bar and then vaporized and superheated (to $297^{\circ} \mathrm{C}$ ) by heat exchange with reactor effluent before entering the fixed-bed dehydration (DME) reactor. The DME reactor is assumed adiabatic, and the output is assumed to be at chemical equilibrium at $409^{\circ} \mathrm{C}$. Following Kam, et al. ${ }^{24}$ the small amount of $\mathrm{CH}_{4}$ and $\mathrm{C}_{2} \mathrm{H}_{6}$ dissolved in the feed methanol are assumed inert in the DME reactor and the subsequent MTG reactor. The MTG product is cooled and then light gases, water, and raw liquids are separated in a flash step. A large recycle of light gases is used to limit the adiabatic MTG reactor outlet temperature to $400^{\circ} \mathrm{C}$. (The molar ratio of recycle gas to fresh feed is assumed to be 7.5, the design value for the New Zealand commercial unit. ${ }^{24}$ ) The recycle loop includes a small purge of fuel gas. The liquid hydrocarbon product is sent to a refining area for finishing, resulting in three output streams: high octane gasoline blendstock, a fuel gas resembling LPG, and light gases.

One undesirable component of the MTG gasoline is durene (1,2,4,5-tetramethyl benzene), which can cause carburetor "icing" because of its high melting point. Synthetic gasoline from the MTG process contains a higher concentration of durene (about 3-6 wt.\%) than is normally present in conventional gasoline (about 0.2-0.3 wt.\%). ${ }^{26}$ In the finishing process, the durene undergoes isomerisation, disproportionation and demethylation in the presence of hydrogen to convert it to isodurene, which eliminates potential carburetor icing issues. Hydrogen could be provided from a slipstream of syngas subjected to water-gas shift and PSA hydrogen separation. We have not included this in our simulation because we estimate the total hydrogen requirement for durene treatment to be small. ${ }^{27}$

${ }^{21}$ Clarence D. Chang. The New Zealand gas-to-gasoline plant: an engineering tour de force. Catalysis Today. 1992(13): 103-111.

${ }^{22}$ Meisel, S. L., J. P. McCullough, C. H. Lechthaler, P. B. Weisz. Gasoline from Methanol- In one step. Chemtech, Vol. 6, 1976.

${ }^{23}$ Clarence D. Chang, James C. W. Kuo, William H. Lang, Solomon M. Jacob, John J. Wise, Anthony J. Silverstrl. Process studies on the conversion of methanol to gasoline. Ind. Eng. Chem. Process Des. Dev. 1978, 17(3):255-260.

${ }^{24}$ A.Y. Kam, M. Schreiner, S. Yurchak, "Mobil Methanol-to-Gasoline Process," chapter 2-3 in Handbook of Synfuels Technology, R.A. Meyers (ed.), McGraw-Hill, 1984.

${ }^{25}$ Kokotailo, G. T., S.L. Lawton, D.H.Olson, W. M.Meir. Structure of Synthetic Zeolite ZSM-5. Nature, Vol. 272, 1978. p437.

${ }^{26}$ Frerich J. Keil. Methanol-to-hydrocarbons: process technology. Microporous and Mesoporous Materials. 1999(29): 49-66.

${ }^{27}$ Our estimate is that between 1.3 and $1.8 \mathrm{~kg} \mathrm{H}_{2}$ are needed per tonne of gasoline (durene) treated. Also, approximately one-third of the raw gasoline from the MTG reactors would undergo this hydrogen treatment, so the $\mathrm{H} 2$ requirements are 0.43 to $0.6 \mathrm{~kg} \mathrm{H} 2$ per $\mathrm{t}$ total gasoline produced. By diverting the amount of syngas needed to 


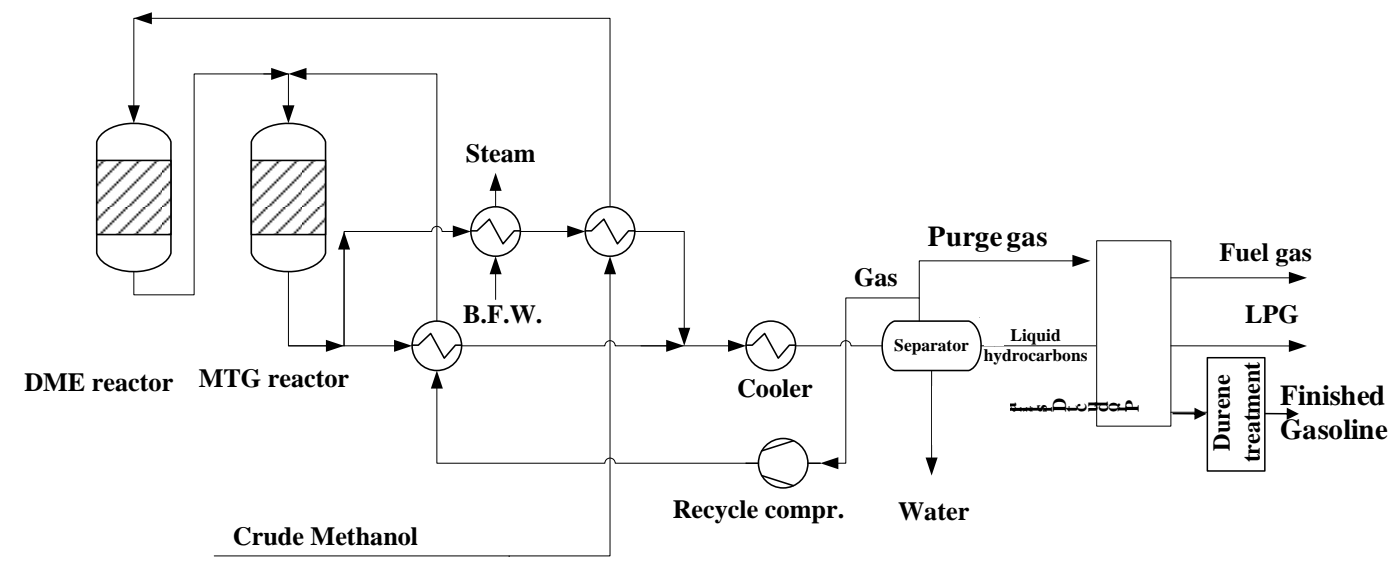

Figure 3. Schematic of the simulated MTG process. ${ }^{25}$

Table 2. Comparison of fixed-bed MTG yield structures (per kg of pure methanol input to DME reactor) published by Barker et al ${ }^{28}$ and Schreiner. ${ }^{30}$ The last column is the yield structure assumed for the simulation work reported here.

\begin{tabular}{|c|c|c|c|c|c|}
\hline & & & Barker $^{28}$ & Schreiner ${ }^{30}$ & This work \\
\hline Component & Formula & Molar mass & kmol & kmol & kmo \\
\hline Hydrogen & $\mathrm{H}_{2}$ & 2.02 & 0.0000124 & 0.0000126 & 0.00001049 \\
\hline Water & $\mathrm{H}_{2} \mathrm{O}$ & 18.02 & 0.03141444 & 0.03135 & 0.03137749 \\
\hline Carbon monoxide & $\mathrm{CO}$ & 28.01 & 0.00000536 & 0.00000536 & 0.00000446 \\
\hline Carbon dioxide & $\mathrm{CO}_{2}$ & 44.01 & 0.0000167 & 0.0000167 & 0.00001390 \\
\hline Methane & $\mathrm{CH}_{4}$ & 16.04 & 0.00023524 & 0.00023525 & 0.00019586 \\
\hline Ethene & $\mathrm{C}_{2} \mathrm{H}_{4}$ & 28.05 & 0.00000567 & 0.00000568 & 0.00000473 \\
\hline Ethane & $\mathrm{C}_{2} \mathrm{H}_{6}$ & 30.07 & 0.00006086 & 0.00006086 & 0.00005067 \\
\hline Propene & $\mathrm{C} 3 \mathrm{H} 6-2$ & 42.08 & 0.00002018 & 0.00002018 & 0.00002055 \\
\hline Propane & $\mathrm{C} 3 \mathrm{H} 8$ & 44.1 & 0.00028503 & 0.0004648 & 0.00042752 \\
\hline 1-Butene & $\mathrm{C} 4 \mathrm{H} 8-1$ & 56.11 & 0.00001783 & 0.00008514 & 0.00008593 \\
\hline n-Butane & $\mathrm{C} 4 \mathrm{H} 10-1$ & 58.12 & 0.00012767 & 0.0002097 & 0.00019381 \\
\hline i-Butane & $\mathrm{C} 4 \mathrm{H} 10-2$ & 58.12 & 0.00042703 & 0.0006796 & 0.00062811 \\
\hline Cyclopentane & $\mathrm{C} 5 \mathrm{H} 10-1$ & 70.13 & 0.00001468 & 0.00001482 & 0.00001514 \\
\hline 1-Pentene & $\mathrm{C} 5 \mathrm{H} 10-2$ & 70.13 & 0.00001426 & 0.0001372 & 0.00014015 \\
\hline N-pentane & $\mathrm{C} 5 \mathrm{H} 12-1$ & 72.15 & 0.0000845 & 0.00008451 & 0.00008633 \\
\hline I-pentane & $\mathrm{C} 5 \mathrm{H} 12-2$ & 72.15 & 0.00084042 & 0.000742 & 0.00075797 \\
\hline Gasoline $^{a}$ & $\mathrm{C} 7 \mathrm{H} 16-1$ & 100.2 & 0.00311861 & 0.002775 & 0.00283472 \\
\hline
\end{tabular}

(a) Barker represented gasoline as n-heptane $\left(\mathrm{C}_{7} \mathrm{H}_{16}-1\right)$, which has a molar mass of $100.2 \mathrm{~kg} / \mathrm{kmol}$. Schreiner indicates gasoline is a mix of $\mathrm{C}_{6}$ to $\mathrm{C}_{10}$ hydrocarbons for which the average molar mass is $104.4 \mathrm{~kg} / \mathrm{kmol}$. For the simulation results in this paper, gasoline is assumed to be represented as nheptane $\left(\mathrm{C}_{7} \mathrm{H}_{16}-1\right)$.

Our process simulation work has been done using Aspen Plus ${ }^{\circledR}$ software. We adopted Aspen's REquil block for simulating the DME reactor, assuming that the methanol dehydration reaction is at chemical equilibrium, which is a good approximation to reality. ${ }^{24,28,29,30}$ Because of the proprietary nature of the MTG process, very little has been published about the details of the MTG synthesis reactor itself, complicating our process simulation efforts. We chose to use an Aspen RYield block to simulate the MTG reaction, and we assumed a detailed product yield structure based on Barker, et al. ${ }^{28,29}$ and

produce this hydrogen, and also considering added parasitic electricity demand from the PSA unit, we estimate that net power output of the plant would be reduced by less than $1 \%$.

${ }^{28}$ E. Barker, J.M. Begovich, J.H. Clinton, P.J. Johnson, Aspen Modeling of the Tri-State Indirect Liquefaction Process," Oak Ridge National Laboratory contract No. W-7405-eng-6. October 1983. 
Schreiner $^{30}$ (see Table 2). We scrutinized these literature sources to develop the final yield structure used in our simulation (last column of Table 2). Using this yield structure, we were able to come very close to reproducing the most recently reported aggregated product distributions (Zhao, et al. in Table 3): 88.8\% gasoline, $10.9 \%$ LPG and $1.1 \%$ fuel gas.

With the above-described approach, our energy and carbon balance around the MeOH-to-DMEto-gasoline island is as shown in Table 4. To complete a basic mass/energy balance analysis for the area requires knowledge of the parasitic power and steam consumption. We assumed electricity consumption of $1.5 \mathrm{~kW}$ per BPD gasoline ${ }^{24}$ and, for simplicity, we assumed that waste heat recovered in the finishing area would enable production of the steam needed in that area, resulting in no net parasitic steam demand for this area.

\begin{tabular}{|c|c|c|c|c|c|}
\hline & Wise ${ }^{31}$ & Schreiner ${ }^{30}$ & $\begin{array}{l}\text { Tabak and } \\
\text { Yurchak }^{32}\end{array}$ & $\begin{array}{l}\text { Tabak \& Zhao, } \\
\text { Zhao, et } a l^{1}(\mathrm{a})\end{array}$ & $\begin{array}{l}\text { This } \\
\text { work }\end{array}$ \\
\hline \multicolumn{6}{|c|}{ Yield, wt\% of Methanol Charged } \\
\hline Methanol + DME & 0 & 0 & 0 & NA & 0 \\
\hline Hydrocarbons & 43.66 & 43.45 & 43.66 & NA & 43.35 \\
\hline Water & 56.15 & 56.45 & 56.15 & NA & 56.47 \\
\hline $\mathrm{CO}, \mathrm{CO}_{2}$ & 0.04 & 0.09 & 0.04 & NA & 0.07 \\
\hline Coke, oxygenates & 0.15 & 0.05 & 0.15 & NA & 0.1 \\
\hline Total & 100 & 100.0 & 100 & NA & 100 \\
\hline \multicolumn{6}{|c|}{ Hydrocarbon Product, wt\% } \\
\hline light gas & 1.4 & 1.42 & 1.3 & 1.1 & 1.13 \\
\hline propane & 5.5 & 4.67 & 4.6 & 4.3 & 4.38 \\
\hline propylene & 0.2 & 0.19 & 0.2 & 0.2 & 0.20 \\
\hline isobutane & 8.6 & 9.01 & 8.8 & \multirow[t]{2}{*}{10.9} & 8.48 \\
\hline n-butane & 3.3 & 2.78 & 2.7 & & 2.61 \\
\hline butylenes & 1.1 & 1.09 & 1.1 & 1.1 & 1.12 \\
\hline C5+ gasoline & 79.9 & 80.84 & 81.3 & 82.3 & 82.05 \\
\hline Total & 100 & 100.0 & 100 & 99.9 & 100.0 \\
\hline \multicolumn{6}{|l|}{ Fuel products, wt\% } \\
\hline Gasoline & 85 & 86.13 & 86 & 88.8 & 88.8 \\
\hline LPG & 13.6 & 11.65 & 12.7 & 10.0 & 10.0 \\
\hline Fuel gas & 1.4 & 2.22 & 1.3 & 1.1 & 1.2 \\
\hline
\end{tabular}

(a) Hydrocarbon product distribution based on 1. Fuel products distribution as given in 3 .

Table 4. Energy and carbon balance for fixed-bed MTG area.

\begin{tabular}{|l|r|r|r|}
\hline & MW, HHV & MW, LHV & kgC/sec \\
\hline Methanol in & 1681 & 1478 & 27.85 \\
\hline Outputs & \multicolumn{3}{|c|}{} \\
\hline Fuel gas & 26.2 & 3.4 & 0.44 \\
\hline LPG & 159.8 & 147.5 & 2.65 \\
\hline Gasoline & 1370.6 & 1269.9 & 23.81 \\
\hline Water, coke & 2.4 & 2.4 & 0.07 \\
\hline
\end{tabular}

${ }^{29}$ Tri-State Synfuels Co., Tri-State Synfuels Project Review, Volumes 1A, 1B, 2, 3, and 11A, June 1982.

${ }^{30}$ M. Schreiner, Research guidance studies to assess gasoline from coal by methanol-to-gasoline and SASOL-type Fischer-Tropsch Technologies, Final report to DOE under contract no. EF-77-C-01-2447, August 1978.

${ }^{31}$ J.J. Wise and A.J. Silvestri. "Mobil Process for the Conversion of Methanol to Gasoline," presented at 3rd Annual International Conference on Coal Gasification and Liquefaction, University of Pittsburgh, Pittsburgh, PA, 3-5 August 1976.

${ }^{32}$ S. A. Tabak and S. Yurchak, "Conversion of Methanol over ZSM-5 to Fuels and Chemicals," Catalysis Today, 6(3): 307-327, 1990. 


\section{Process Simulation and Economic Modeling Results}

\subsection{Key Design Parameters and Performance Metrics -- Definitions}

Three key parameters used to characterize each of the 16 process designs are the overall scale of the facility, the biomass fraction (BF), and the electricity fraction (EF).

The overall scales of facilities, as defined by total feedstock input, were selected assuming that the maximum biomass input rate for any facility would be one million dry metric tonnes per year, ${ }^{33} \mathrm{a}$ plausible level for truck-delivered biomass in the longer term. ${ }^{34}$ We also assumed that the maximum coal input rate would be 8,000 metric tonnes per day (as-received), which corresponds to the rate of coal use at a large coal-fired power plant in the U.S. today. Neither the maximum biomass input rate nor the maximum coal input rate are necessarily practical maxima, since rail or barge transport of biomass would enable larger supply rates, and coal facilities could presumably be larger. Our capital cost model (discussed below) enables us to make cost estimates as a function of scale.

The biomass fraction, BF, is defined as the higher heating value energy content of the input biomass divided by the higher heating value energy content of the input biomass plus coal. (The biomass energy content is measured prior to torrefaction for cases where torrefaction is included.) The range of BF values examined was zero (coal only) to 0.30 .

The electricity fraction, EF, is defined as the electricity output (MW) divided by the sum of electricity, gasoline and LPG outputs, the latter two quantities expressed on a lower heating value basis. Values of EF that are examined range from 0 to 0.50 .

Key performance metrics include energy, environmental, and economic figures of merit.

Plant energy efficiencies provide a basis for comparing overall energy performance. This efficiency is defined as the higher heating value of the products (electricity, gasoline, and LPG) divided by the higher heating value of the coal and biomass input. (The biomass energy content is measured prior to torrefaction for cases where torrefaction is included.)

Environmental performance is characterized using several metrics that provide different perspectives and insights. Metrics include the greenhouse gas emissions index (GHGI), the greenhouse gas emissions avoided (GHGA), the biomass input index (BII), and the zero-emissions fuel index (ZEFI). Each of these is briefly explained here.

With a coproduction system, how one allocates the lifecycle GHG emissions of the system to each of the coproducts is arbitrary. We have chosen to express emissions for each co-product as an identical percentage of emissions for supplying the same products using a conventional, business-as-usual (fossil fuel) approach. We calculate this percentage as:

$$
G H G I=\frac{\text { Lifecycle } \mathrm{CO}_{2} \text { eq emissions }}{\text { Business as usual emissions }}
$$

The numerator comprises all greenhouse gas emissions associated with the co-production facility, including emissions from mining and delivering coal, from producing and delivering biomass, from converting the coal and biomass to fuels and electricity, from delivery of the liquid fuels to end users, and from combustion of the liquid fuels by end users. Since carbon in the biomass arriving at the plant gate has been extracted from the atmosphere during plant growth, this carbon is counted as a negative emission in the lifecycle accounting, assuming that the biomass is grown on a sustainable basis (1 GJ/year of new biomass is grown for each GJ/year consumed). The "business as usual" emissions in the denominator of the GHGI are estimated lifecycle GHG emissions associated with producing the same amount of electricity and fuels as the co-production plant, but doing so at separate stand-alone facilities:

\footnotetext{
${ }^{33}$ When operating with $90 \%$ capacity factor.

${ }^{34}$ Larson, E.D., Fiorese, G., Liu, G., Williams, R.H., Kreutz, T.G., and Consonni, S., "Co-production of decarbonized synfuels and electricity from coal + biomass with $\mathrm{CO}_{2}$ capture and storage: an Illinois case study, Energy Env Sci, 3: 28-42, 2010.
} 
electricity from a supercritical pulverized coal plant $\left(831 \mathrm{kgCO}_{2}\right.$-eq/MWh), gasoline from crude oil (91 $\mathrm{kgCO}_{2}$-eq/GJ $\left.\mathrm{LHV}_{\mathrm{LHV}}\right)$, and $\mathrm{LPG}$ from crude oil $\left(86 \mathrm{kgCO} \mathrm{K}_{2}-\mathrm{eq} / \mathrm{GJ}_{\mathrm{LHV}}\right) .{ }^{35}$

The GHGA is one measure of how effectively the biomass input is being used to avoid GHG emissions. The GHGA is calculated as the emissions avoided per unit of biomass input to a coproduction system, assuming the coproducts displace emissions from electricity and fuels in the business as usual reference system:

$$
G H G A=\frac{(1-G H G I) \times \text { Business as usual emissions }}{\text { Biomass input }(\text { dry basis })}
$$

The BII is the amount of input biomass energy needed to make a unit of liquid fuel energy when the liquid fuel has zero (or negative) net lifecycle GHG emissions. BII is the input biomass energy divided by the liquid fuel energy produced. Lower heating values are used for dry biomass and for the liquid fuels in this calculation. The BII implicitly charges all of the input biomass energy against the liquid fuel product, even when some electricity coproduct is also produced. The BII is a convenient measure for assessing the effectiveness with which energy in the biomass is converted into low-carbon liquid fuel. In particular, BII values for systems cofeeding biomass and coal can be compared with BII values for "pure" biofuel systems, such as cellulosic ethanol. A projected BII value for the latter is approximately $2.5 \mathrm{GJ}_{\text {biomass }} / \mathrm{GJ}_{\text {ethanol. }}{ }^{13}$ An alternative set of units for BII that is commonly used in the biofuels community is volume of liquid fuel produced per tonne of dry biomass feedstock input. We have calculated this metric in units of liters of gasoline equivalent per dry metric tonne of biomass input.

Finally, the ZEFI indicates how much zero-net lifecycle GHG emission liquid fuel is available per unit of biomass energy input to a co-production system. For coproduction systems that have net negative lifecycle GHG emissions, the liquid fuel counted in the numerator of the ZEFI includes petroleum-derived fuels whose GHG emissions are considered to be offset by negative emissions associated with the coproduction system. Lower heating values are used for dry biomass and for the liquid fuels in the calculation of ZEFI.

We assess the economics of co-production on the basis of capital cost estimates (in constant 2007\$) made using equipment capacities taken from our Aspen Plus simulation results. We scale reference component costs in our equipment cost database to the calculated capacities using scaling exponents that vary with the type of equipment. We have strived to make our reference component costs consistent, where possible, with estimates made by NETL engineers. ${ }^{36}$ An earlier publication ${ }^{13}$ gives a detailed description of our reference cost database and plant capital cost estimating methodology. Table 5 shows additional component capital costs developed in this work to assess plant costs for MTG (and methanol to olefins described in Appendix C).

For all of our economic analyses for aquifier storage cases, $\mathrm{CO}_{2}$ transport and storage costs are treated as variable operating costs ( $\$ / \mathrm{t}$ of $\mathrm{CO}_{2}$ basis) evaluated via a model that includes capital and operating cost estimates for transporting $\mathrm{CO}_{2}$ via pipeline $100 \mathrm{~km}$, and injecting it into a saline aquifer 2.5 $\mathrm{km}$ underground for long-term storage. We use a $\mathrm{CO}_{2}$ transport and injection model developed by Ogden. ${ }^{37}$ Pipeline and injection costs vary with $\mathrm{CO}_{2}$ mass flow rate. The capital and operating and maintenance costs of compressing the captured $\mathrm{CO}_{2}$ to 150 bar prior to sending to the pipeline are included in the economics of the conversion facility.

\footnotetext{
${ }^{35}$ See note 13 for source of these lifecycle GHG emission estimates.

${ }^{36}$ National Energy Technology Laboratory, "Cost and Performance Baseline for Fossil Energy Plants, Volume 1: Bituminous Coal and Natural Gas to Electricity", U.S. Department of Energy, DOE/NETL-2007/1281, Final Report, May 2007. (Also, DOE/NETL-2010/1397, (Rev. 2), November 2010.)

${ }^{37}$ Ogden, J., "Modeling infrastructure for a fossil hydrogen energy system with $\mathrm{CO} 2$ sequestration," in Gale, J., Kaya, Y, Eds.; Proceedings 6th International Conf. on GHG Control Technologies, Elsevier Science: Oxford, 2003; pp 1069-1074.
}

Also, Ogden, J. M., "Conceptual Design of Optimized Fossil Energy Systems with Capture and Sequestration of Carbon Dioxide," UCD-ITS-RR-04-34, Institute of Transportation Studies, University of California Davis, 2004. 


\begin{tabular}{|c|c|c|c|c|c|}
\hline Plant component & Scaling parameter & $\begin{array}{c}\text { Unit } \\
\text { capacity }\end{array}$ & $\begin{array}{l}\text { Max unit } \\
\text { capacity }\end{array}$ & $\begin{array}{c}\text { Scaling } \\
\text { exponent }\end{array}$ & $\begin{array}{c}\text { Total overnight } \\
\text { capital cost } \\
\text { (2007 M\$) }\end{array}$ \\
\hline Torrefaction system $^{\mathrm{a}}$ & Torrefied biomass, $\mathrm{MW}_{\mathrm{LHV}}$ & 150 & 200 & 0.65 & 11.5 \\
\hline Dry-feed gasifier $^{b}$ & Cooled syngas(wet), $\mathrm{Nm}^{3} / \mathrm{hr}$ & 207,067 & 207,067 & 0.67 & 160.45 \\
\hline Slurry-feed gasifier ${ }^{c}$ & As-received coal, MW (LHV) & 815 & 815 & 0.67 & 86.5 \\
\hline Coal dryer $^{\mathrm{d}}$ & Water removed, metric $\mathrm{t} / \mathrm{d}$ & 1,767 & 2,400 & 0.85 & 43.81 \\
\hline Gas phase $\mathrm{MeOH}$ synthesis $^{\mathrm{e}}$ & Methanol output, metric $\mathrm{t} / \mathrm{d}$ & 5,500 & 5,500 & 0.65 & 172.8 \\
\hline \multirow[t]{3}{*}{ Liquid phase $\mathrm{MeOH}$ synth. $^{\dagger}$} & Syngas feed rate, $\mathrm{kmol} / \mathrm{s}$ & 10.82 & 11 & 0.65 & 11.04 \\
\hline & Fuel grade $\mathrm{MeOH}$ output, $\mathrm{kg} / \mathrm{s}$ & 26.36 & 30 & 0.65 & 3.25 \\
\hline & Recycle comp. feed rate, actual lit/s & 3402 & not est. & 0.65 & 7.15 \\
\hline $\mathrm{LP}_{\mathrm{MeOH}}$ distillation ${ }^{\dagger}$ & Fuel grade $\mathrm{MeOH}$ output, metric $\mathrm{t} / \mathrm{d}$ & 2202.3 & 5500 & 0.2909 & 3.75 \\
\hline MTG-1: DME reactor ${ }^{\mathrm{g}}$ & Gasoline output, bbl/day & 16,667 & 16,667 & 0.70 & 57.3 \\
\hline MTG-2: MTG reactors ${ }^{g}$ & Gasoline output, bbl/day & 16,667 & 16,667 & 0.70 & 128.0 \\
\hline MTG-3: Gasoline finisher ${ }^{\mathrm{g}}$ & Gasoline output, bbl/day & 5,556 & 5,556 & 0.70 & 10.4 \\
\hline Olefins synthesis from $\mathrm{MeOH}^{\mathrm{h}}$ & Olefins output, metric $t /$ day & 1,688 & not est. & 0.77 & 66.1 \\
\hline Olefins product separation $^{\text {h }}$ & Olefins output, metric t/day & 1,688 & not est. & 0.75 & 91.0 \\
\hline \multicolumn{6}{|c|}{$\begin{array}{l}\text { (a) This estimate is based on work of Uslu. }{ }^{38} \text { It includes all components of the system pictured in Fig. } 3 \text { of Appendix A. } \\
\text { (b) This is based on the Shell gasifier with radiant syngas cooling. }{ }^{36} \text { The maximum unit size is somewhat larger than the size of the } \\
\text { Buggenum Shell gasifier in the Netherlands (which operates on a co-feed of biomass and coal). That unit, which is sized to } \\
\text { provide the fuel gas for a Siemens/Kraftwerk Union V- } 94.2 \text { combustion turbine, has a bituminous coal-handling capacity of } \\
1,633 \text { tonnes/day and produces dry gas at a rate of } 158,575 \mathrm{Nm}^{3} / \mathrm{hr} \text { with an energy content of about } 1,792 \mathrm{GJ} / \mathrm{hr} \mathrm{HHV} \text {. } \\
\text { (c) Estimated cost for a General Electric type quench gasifier, including syngas cooler, black water handling, sour gas treatment, gas } \\
\text { scrubbing and low temperature cooling. NETL }{ }^{36} \text { provides a cost estimate for a GE radiant-quench gasifier. We have multiplied } \\
\text { the NETL estimate by } 0.583 \text {, the ratio of installed costs (i.e. material, labor, indirects, and contingencies) for a quench gasifier + } \\
\text { ash handling to the installed cost for a radiant-quench gasifier + ash handling, according to Matchak, et al. } \text {. }^{39} \\
\text { (d) This is for a WTA drying technology, based on Schoff } \text { et al. }{ }^{40} \\
\text { (e) Based on Gallaspy, et al. } \\
\text { (f) The liquid phase methanol synthesis and distillation capital costs, based on Larson and Ren, }{ }^{18} \text { are a build-up of four components } \\
\text { (including one for distillation). } \\
\text { (g) The MTG island cost estimate, based on discussion with engineers at ExxonMobil familiar with the MTG process, is a build-up } \\
\text { of } 3 \text { components. Approximately one-third of the raw gasoline from the MTG reactors is processed through the finisher. } \\
\text { (h) These estimates are based on Wan }{ }^{42} \text { for an ethylene:propylene production ratio of } 1: 1 \text {. The maximum unit capacity was not } \\
\text { estimated. }\end{array}$} \\
\hline
\end{tabular}

Our cost model allows capital costs to be estimated for a given plant design at different scales, assuming no change in unit performance of plants with scale. Assumed plant scales were discussed earlier in this Section.) We characterize the economics of plant designs using three main figures of merit:

- Levelized cost of fuel (LCOF), calculated for gasoline (in \$/GJ) assuming \$60/MWh revenues from the sale of coproduct electricity (the US average grid wholesale price in 2007), as well as

\footnotetext{
${ }^{38}$ Xx Uslu (2009).
}

${ }^{39}$ Xx Matchak, et al. (1984).

${ }^{40}$ Xx Schoff et al., 2009

${ }^{41}$ Gallaspy, D., Aycock, J., and Trapp, B., "Gasification-Based Production of Chemicals from Illinois Coal, Standalone and IGCC Coproduction modes - Phase 1b," final technical report on ICCI project DEV04-3 to the Illinois Clean Coal Institute, 2006.

${ }^{42}$ Wan, V., "Methanol to Olefins,” PEP report 261, SRI Consulting, Menlo Park, CA, November 2007,198 pages. 
revenues from sale of LPG at a price corresponding to the wholesale price of conventional LPG when the crude oil price is $\$ 90$ per barrel. The LCOF can be equivalently expressed as a cost per gallon of gasoline equivalent or as a breakeven oil price (BEOP), the crude oil price at which the cost to produce gasoline from crude oil matches the LCOF for the coproduction facility.

- Levelized cost of electricity (LCOE), calculated assuming revenues from sale of co-product gasoline and LPG at prices corresponding to the wholesale prices of conventional gasoline and LPG when the crude oil price is $\$ 90$ per barrel.

- Internal rate of return on equity (IRRE), calculated assuming revenues for electricity and liquid fuels as described in the previous two bullets.

Relevant financial parameters for calculating these metrics are 55/45 debt/equity coverage of the overnight capital cost; $4.4 \% / \mathrm{yr}$ real cost of debt; $10.2 \% / \mathrm{yr}$ required real rate of return on equity (for LCOF and LCOE calculations); a 20-year book life; MACRS depreciation schedule; $2 \%$ property tax and insurance; and 39\% federal and state income tax. The resulting capital charge rate (for LCOF and LCOE calculations) is $14.4 \% / \mathrm{yr}$. This is applied to total plant investment, which is the overnight capital cost plus $7.2 \%$ interest during construction. An operating capacity factor of $90 \%$ is assumed for all plants. Coal and biomass prices delivered to the plant gate are assumed to cost $\$ 2.04 / \mathrm{GJ}_{\mathrm{HHV}}$ and $\$ 5 / \mathrm{GJ}_{\mathrm{HHV}}$, respectively. Some comparisons are included here with natural gas power plants, for which we assume a delivered gas price of $\$ 6.35 / \mathrm{GJ}_{\mathrm{HHV}}$.

\subsection{Results}

Table 6 summarizes the detailed mass/energy balance simulations that were developed for each of our 16 designs, and Table 7 shows capital investment estimates and associated economic results. These tables provide the basis for the subsequent sections that discuss comparisons of performance and cost for

- dried biomass versus torrefied biomass as the co-feed with coal,

- dry-feed gasifiers versus slurry-feed gasifiers,

- gas-phase methanol synthesis vs. liquid-phase synthesis,

- different input biomass-to-coal ratios, i.e., different biomass fractions, BF,

- different electricity-to-liquids output ratios, i.e., different electricity fractions, EF.

\subsubsection{Dried biomass versus torrefied biomass - torrefied is favored.}

Torrefying the biomass, which provides benefits for biomass storage, transport and handling, was found to also provide overall performance and cost benefits in coal/biomass coproduction systems relative to the use of non-torrefied biomass. This latter judgment was reached for systems using dry-feed gasification. (Slurry-feed gasification of non-torrefied biomass was not considered, as discussed in Appendix A.) The benefits can be seen in comparing results for case 2 against case 10 or, similarly, case 3 against case 9 . All four of these cases are designed with the same coal and biomass inputs $(\mathrm{BF}=0.3)$ and same EF (0.50). Two of the cases ( 2 and 3 ) use dry ground biomass, while the other two ( 9 and 10$)$ torrefy the biomass before gasification. Table 8 shows salient results for these four cases. 
Table 6. Mass and energy balances for 16 process designs for coproduction of electricity and gasoline from coal and/or biomass feedstocks. See Table 1.

\begin{tabular}{|c|c|c|c|c|c|c|c|c|c|c|c|c|c|c|c|c|}
\hline CASE \# (see Table 1) > > & 1 & 2 & 3 & 4 & 5 & 6 & 7 & 8 & 9 & 10 & 11 & 12 & 13 & 14 & 15 & 16 \\
\hline \multirow{3}{*}{$\begin{array}{r}\text { Gasifier design } \gg> \\
\text { Biomass (corn stover) preparation } \gg> \\
\mathrm{MeOH} \text { synthesis technology } \gg> \\
\end{array}$} & \multicolumn{10}{|c|}{ Dry-Feed Gasifier } & \multicolumn{6}{|c|}{ Slurry-Feed Gasifier } \\
\hline & \multirow{2}{*}{$\begin{array}{c}\text { None } \\
\text { LP } \\
\end{array}$} & \multicolumn{2}{|c|}{ Dry } & \multicolumn{7}{|c|}{ Torrefy } & \multicolumn{6}{|c|}{ Torrefy } \\
\hline & & GP & LP & \multicolumn{6}{|c|}{ Liquid Phase (LP) } & GP & LP & \multicolumn{5}{|c|}{ Liquid Phase (LP) } \\
\hline \multicolumn{17}{|l|}{ Feedstocks } \\
\hline Coal input, AR metric t/day III. \#6 bit. & 8,000 & 4,639 & 4,639 & 8,000 & 8,000 & 5,050 & 5,050 & 5,050 & 4,639 & 4,639 & 8,000 & 8,000 & 8,000 & 5,622 & 5,622 & 5,622 \\
\hline Coal input, MW (HHV) & 2,511 & 1,456 & 1,456 & 2,511 & 2,511 & 1,585 & 1,585 & 1,585 & 1,456 & 1,456 & 2,511 & 2,511 & 2,511 & 1,764 & 1,764 & 1,764 \\
\hline Biomass input, AR metric t/day (a) & 0 & 3,805 & 3,805 & 806 & 806 & 3,805 & 3,805 & 3,805 & 3,805 & 3,805 & 0 & 806 & 806 & 3,805 & 3,805 & 3,805 \\
\hline Biomass input rate, MW (HHV) & 0 & 624 & 624 & 132 & 132 & 624 & 624 & 624 & 624 & 624 & 0 & 132 & 132 & 624 & 624 & 624 \\
\hline Biomass Fraction, HHV basis & 0.00 & 0.30 & 0.30 & 0.05 & 0.05 & 0.28 & 0.28 & 0.28 & 0.30 & 0.30 & 0.00 & 0.05 & 0.05 & 0.26 & 0.26 & 0.26 \\
\hline \multicolumn{17}{|l|}{ Electricity balance, $\mathrm{MW}_{\mathrm{e}}$} \\
\hline Gross production & 792 & 657 & 652 & 603 & 786 & 506 & 630 & 254 & 619 & 624 & 726 & 488 & 705 & 433 & 614 & 252 \\
\hline Gas turbine & 469 & 389 & 379 & 306 & 450 & 256 & 357 & 80 & 365 & 371 & 406 & 224 & 383 & 193 & 328 & 71 \\
\hline Expander(s) & 12 & 7 & 10 & 9 & 12 & 7 & 8 & 3 & 9 & 6 & 12 & 7 & 12 & 6 & 10 & 1 \\
\hline Steam turbine & 311 & 261 & 264 & 288 & 323 & 243 & 265 & 171 & 245 & 246 & 307 & 257 & 310 & 233 & 276 & 178 \\
\hline On-site consumption & 291 & 294 & 289 & 282 & 301 & 238 & 250 & 232 & 238 & 248 & 254 & 242 & 263 & 227 & 244 & 221 \\
\hline Net export to grid & 501 & 362 & 364 & 321 & 485 & 269 & 380 & 22 & 382 & 376 & 472 & 245 & 443 & 206 & 371 & 32 \\
\hline Electricity Fraction, LHV basis & 0.50 & 0.50 & 0.50 & 0.26 & 0.45 & 0.28 & 0.45 & 0.02 & 0.50 & 0.50 & 0.50 & 0.21 & 0.44 & 0.21 & 0.44 & 0.03 \\
\hline \multicolumn{17}{|l|}{ Liquid fuel production } \\
\hline Gasoline, barrels per day (b) & 7,814 & 5,583 & 5,678 & 14,064 & 9,317 & 10,558 & 7,226 & 16,301 & 5,924 & 5,848 & 7,322 & 14,116 & 8,849 & 11,896 & 7,445 & 15,794 \\
\hline Gasoline, MW (LHV) & 455 & 325 & 331 & 819 & 543 & 615 & 421 & 950 & 345 & 341 & 427 & 822 & 516 & 693 & 434 & 920 \\
\hline Gasoline, MW (HHV) & 488 & 349 & 355 & 879 & 582 & 660 & 452 & 1,019 & 370 & 365 & 458 & 882 & 553 & 743 & 465 & 987 \\
\hline LPG, metric tonnes per day & 88 & 62 & 64 & 158 & 105 & 118 & 81 & 179 & 67 & 65 & 82 & 157 & 99 & 132 & 83 & 170 \\
\hline LPG, MW (LHV) & 47 & 33 & 34 & 84 & 56 & 63 & 43 & 95 & 35 & 35 & 44 & 83 & 53 & 70 & 44 & 90 \\
\hline LPG, MW (HHV) & 51 & 36 & 37 & 91 & 61 & 68 & 47 & 103 & 38 & 38 & 47 & 90 & 57 & 76 & 48 & 98 \\
\hline \multicolumn{17}{|l|}{ Energy ratios } \\
\hline Liquids out (HHV) / Energy in (HHV) & 0.215 & 0.185 & 0.188 & 0.367 & 0.243 & 0.330 & 0.226 & 0.508 & 0.196 & 0.194 & 0.201 & 0.368 & 0.231 & 0.343 & 0.215 & 0.454 \\
\hline Net electricity / Energy in (HHV) & 0.200 & 0.174 & 0.175 & 0.122 & 0.184 & 0.122 & 0.172 & 0.010 & 0.183 & 0.181 & 0.188 & 0.093 & 0.168 & 0.086 & 0.155 & 0.013 \\
\hline First Law efficiency (HHV) & 0.414 & 0.359 & 0.363 & 0.488 & 0.427 & 0.451 & 0.398 & 0.518 & 0.380 & 0.375 & 0.389 & 0.461 & 0.398 & 0.429 & 0.370 & 0.468 \\
\hline \multicolumn{17}{|l|}{ Carbon accounting } \\
\hline $\mathrm{C}$ input in feedstock, $\mathrm{kgC} / \mathrm{sec}$ & 59.0 & 51.1 & 51.1 & 62.6 & 62.6 & 54.1 & 54.1 & 54.1 & 51.1 & 51.1 & 59.0 & 62.6 & 62.6 & 58.3 & 58.3 & 100.0 \\
\hline $\mathrm{C}$ stored as $\mathrm{CO}_{2}, \%$ of feedstock $\mathrm{C}$ & 75.4 & 79.2 & 78.6 & 63.9 & 73.2 & 65.1 & 72.7 & 51.9 & 74.4 & 75.0 & 74.2 & 61.5 & 71.9 & 63.6 & 73.0 & 51.9 \\
\hline C in char, $\%$ of feedstock $\mathrm{C}$ & 1.0 & 1.0 & 1.0 & 1.0 & 1.0 & 1.0 & 1.0 & 1.0 & 1.0 & 1.0 & 4.0 & 3.8 & 3.8 & 2.8 & 2.8 & 1.0 \\
\hline C vented to atm, \% of feedstock $C$ & 7.7 & 6.7 & 7.1 & 8.2 & 7.9 & 10.5 & 10.3 & 11.1 & 10.7 & 10.3 & 6.9 & 7.7 & 7.4 & 9.2 & 8.8 & 11.1 \\
\hline C in liquids, $\%$ of feedstock $C$ & 15.9 & 13.1 & 13.3 & 27.0 & 17.9 & 23.4 & 16.0 & 36.1 & 13.9 & 13.7 & 14.9 & 27.0 & 17.0 & 24.4 & 15.3 & 36.1 \\
\hline GHGI (c) & 0.37 & -0.13 & -0.12 & 0.50 & 0.34 & 0.12 & 0.00 & 0.42 & -0.05 & -0.06 & 0.37 & 0.55 & 0.34 & 0.17 & 0.00 & 0.42 \\
\hline GHGA, tCO2 avoided per t dry biomass & & 3.7 & 3.7 & 10.5 & 0.3 & 3.1 & 3.7 & 1.7 & 3.7 & -0.1 & & 0.6 & 0.3 & 0.2 & 3.6 & 1.7 \\
\hline \multicolumn{17}{|l|}{ Yield metrics for zero-GHG liquid fuels (d) } \\
\hline BII, GJ biomass per GJ gasoline (LHV, AR) & & 1.78 & 1.75 & & & & 1.38 & & 1.68 & 1.70 & & & & & 1.34 & \\
\hline ZEFI, GJ zero emission fuel per GJ biomass (LHV, AR) & & 1.6 & 1.6 & & & & 0.73 & & 0.6 & 0.6 & & & & & 0.75 & \\
\hline LGE, liters gasoline equiv per dry metric $t$ biomass & & 292 & 297 & & & & 377 & & 309 & 305 & & & & & 389 & \\
\hline
\end{tabular}


Table 7. Capital cost estimates and levelized production costs (for zero GHG emission price) for 16 coproduction systems with performance described in Table 6. (Costs in 2007\$.)

\begin{tabular}{|c|c|c|c|c|c|c|c|c|c|c|c|c|c|c|c|c|}
\hline CASE \# (see Table 1) $\gg \gg$ & 1 & 2 & 3 & 4 & 5 & 6 & 7 & 8 & 9 & 10 & 11 & 12 & 13 & 14 & 15 & 16 \\
\hline Gasifier design $\gg>$ & \multicolumn{10}{|c|}{ Dry-Feed Gasifier } & \multicolumn{6}{|c|}{ Slurry-Feed Gasifier } \\
\hline Biomass (corn stover) preparation $\gg>>$ & None & \multicolumn{2}{|c|}{ Dry } & \multicolumn{7}{|c|}{ Torrefy } & None & \multicolumn{5}{|c|}{ Torrefy } \\
\hline MeOH synthesis technology $\gg>$ & LP & GP & LP & \multicolumn{6}{|c|}{ Liquid Phase (LP) } & GP & $\mathrm{LP}$ & \multicolumn{5}{|c|}{ Liquid Phase (LP) } \\
\hline Overnight installed capital cost (million 2007\$) & 2,336 & 2,093 & 2,048 & 2,424 & 2,434 & 2,078 & 2,103 & 2,130 & 1,997 & 2,047 & 1,962 & 2,045 & 2,022 & 1,870 & 1,857 & 1,845 \\
\hline Torrefaction plant (a) & 0 & 0 & 0 & 12 & 12 & 43 & 43 & 43 & 43 & 43 & 0 & 12 & 12 & 43 & 43 & 43 \\
\hline ASU, $\mathrm{O}_{2} \& \mathrm{~N}_{2}$ compression & 282 & 275 & 275 & 286 & 292 & 268 & 272 & 256 & 263 & 263 & 299 & 301 & 308 & 296 & 302 & 289 \\
\hline Biomass preparation \& handling & 0 & 42 & 42 & 11 & 11 & 42 & 42 & 42 & 42 & 42 & 0 & 11 & 11 & 42 & 42 & 42 \\
\hline Coal preparation \& handling & 182 & 118 & 118 & 182 & 182 & 125 & 125 & 125 & 118 & 118 & 182 & 182 & 182 & 134 & 134 & 134 \\
\hline Coal drying (b) & 24 & 39 & 39 & 24 & 24 & 16 & 16 & 16 & 15 & 15 & 0 & 0 & 0 & 0 & 0 & 0 \\
\hline Gasification island & 742 & 644 & 649 & 790 & 790 & 666 & 666 & 666 & 610 & 610 & 386 & 396 & 396 & 330 & 330 & 330 \\
\hline Water gas shift reactors & 34 & 23 & 23 & 29 & 34 & 21 & 24 & 14 & 23 & 22 & 26 & 24 & 28 & 21 & 24 & 14 \\
\hline Rectisol acid gas removal & 287 & 257 & 255 & 277 & 290 & 245 & 255 & 227 & 250 & 251 & 302 & 273 & 303 & 252 & 279 & 227 \\
\hline Claus/SCOT & 61 & 36 & 36 & 61 & 61 & 38 & 38 & 38 & 36 & 36 & 61 & 61 & 61 & 41 & 41 & 41 \\
\hline CO2 compression & 33 & 32 & 32 & 30 & 33 & 28 & 31 & 24 & 29 & 30 & 32 & 30 & 33 & 29 & 32 & 26 \\
\hline Methanol synthesis & 68 & 96 & 57 & 149 & 75 & 110 & 64.9 & 292 & 57.8 & 99.3 & 0 & 146 & 0 & 118 & 0 & 201 \\
\hline MTG synthesis \& finishing & 144 & 114 & 115 & 217 & 163 & 178 & 136.3 & 241 & 119 & 117 & 138 & 218 & 157 & 193 & 139 & 236 \\
\hline Power island topping cycle & 257 & 229 & 219 & 184 & 247 & 151 & 207 & 64 & 212 & 220 & 223 & 130 & 214 & 116 & 189 & 54 \\
\hline Heat recovery and steam cycle & 223 & 189 & 188 & 172 & 220 & 149 & 182 & 83 & 180 & 181 & 313 & 262 & 318 & 255 & 303 & 209 \\
\hline $\begin{array}{l}\text { Levelized Cost of Fuel (LCOF), \$ per GJ LHV (c) } \\
\text { Capital charges }\end{array}$ & 27.9 & 34.9 & 33.6 & 16.1 & 24.3 & 18.3 & 27.1 & 12.2 & 31.4 & 32.6 & 25.8 & 13.5 & 22.0 & 14.6 & 24.0 & 10.9 \\
\hline O\&M charges ( $4 \%$ of overnight capex per yr) & 7.2 & 9.1 & 8.7 & 4.2 & 6.3 & 4.8 & 7.0 & 3.2 & 8.2 & 8.5 & 6.7 & 3.5 & 5.7 & 3.8 & 6.2 & 2.8 \\
\hline Coal (at $\$ 2.04 / G J ~ H H V)$ & 11.2 & 9.1 & 9.0 & 6.3 & 9.4 & 5.3 & 7.7 & 3.4 & 8.6 & 8.7 & 12.0 & 6.2 & 9.9 & 5.2 & 8.3 & 3.9 \\
\hline Biomass (at $\$ 5 / G J H H V)(a)$ & 0.0 & 9.6 & 9.4 & 0.8 & 1.2 & 5.1 & 7.4 & 3.3 & 9.0 & 9.2 & 0.0 & 0.8 & 1.3 & 4.5 & 7.2 & 3.4 \\
\hline GHG emissions charge (at $\$ 0 / \mathrm{tCO} 2 \mathrm{eq})$ & 0.0 & 0.0 & 0.0 & 0.0 & 0.0 & 0.0 & 0.0 & 0.0 & 0.0 & 0.0 & 0.0 & 0.0 & 0.0 & 0.0 & 0.0 & 0.0 \\
\hline $\mathrm{CO} 2$ transportation and storage & 2.2 & 2.9 & 2.9 & 1.2 & 1.9 & 1.4 & 2.1 & 0.8 & 2.6 & 2.6 & 2.3 & 1.1 & 1.9 & 1.3 & 2.3 & 0.9 \\
\hline Electricity revenue @ \$60/MWh & -18.3 & -18.6 & -18.3 & -6.5 & -14.9 & -7.3 & -15.0 & -0.4 & -18.4 & -18.4 & -18.4 & -5.0 & -14.3 & -4.9 & -14.2 & -0.6 \\
\hline LPG revenue@ @ 90\$/bbl crude & -1.9 & -1.9 & -1.9 & -1.9 & -1.9 & -1.9 & -1.9 & -1.9 & -1.9 & -1.9 & -1.9 & -1.9 & -1.9 & -1.9 & -1.9 & -1.8 \\
\hline LCOF, \$ per GJ LHV & 28.3 & 45.2 & 43.4 & 20.0 & 26.3 & 25.6 & 34.4 & 20.5 & 39.4 & 41.3 & 26.5 & 18.3 & 24.7 & 22.6 & 31.9 & 19.5 \\
\hline LCOF, \$ per gallon gasoline equivalent & 3.39 & 5.42 & 5.20 & 2.40 & 3.16 & 3.07 & 4.13 & 2.46 & 4.73 & 4.95 & 3.17 & 2.19 & 2.96 & 2.71 & 3.82 & 2.34 \\
\hline Breakeven crude oil price, $\$$ per barrel & 125 & 203 & 195 & 87 & 116 & 113 & 154 & 90 & 176 & 185 & 117 & 79 & 109 & 99 & 142 & 85 \\
\hline Levelized Cost of Electricity (LCOE), \$ per MWh (c,d) & 85 & 140 & 135 & 55 & 83 & 102 & 115 & n.a. & 121 & 128 & 79 & 32 & 77 & 84 & 108 & n.a. \\
\hline Internal Rate of Return on Equity, IRRE (c) & $3.9 \%$ & $0.0 \%$ & $0.0 \%$ & $11 \%$ & $4.9 \%$ & $3.9 \%$ & $0.0 \%$ & $10 \%$ & $0.0 \%$ & $0.0 \%$ & $5.1 \%$ & $13.6 \%$ & $6.1 \%$ & $7.2 \%$ & $0.0 \%$ & $12.1 \%$ \\
\hline
\end{tabular}

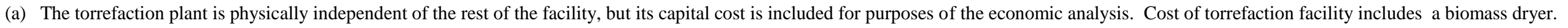

(b) For cases 2 and 3, this also includes the cost of biomass drying.

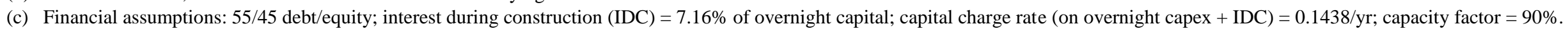

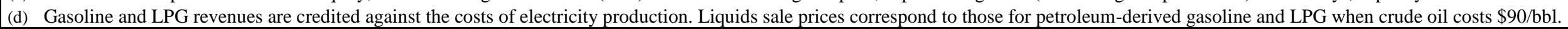


Table 8. Comparison of cases with dried biomass feed versus torrefied biomass feed. All four cases use a dry-feed gasifier and have the same biomass and electricity fractions.

\begin{tabular}{|l||c|c||c|c||}
\hline \multicolumn{1}{|c||}{} & Case 2 & Case 10 & Case 3 & Case 9 \\
\hline Biomass feed & Dry & Torrefied & Dry & Torrefied \\
\hline Methanol synthesis technology & Gas phase & Gas phase & Liquid phase & Liquid phase \\
\hline Biomass fraction & 0.3 & 0.3 & 0.3 & 0.3 \\
\hline Electricity fraction & 0.5 & 0.5 & 0.5 & 0.5 \\
\hline Gross electricity production, MW & 657 & 624 & 652 & 619 \\
\hline Onsite electricity use, MW & 294 & 248 & 289 & 238 \\
\hline Net electricity export, MW & 362 & 376 & 364 & 382 \\
\hline Gasoline production, bbl/day & 5,583 & 5,848 & 5,678 & 5,924 \\
\hline LPG production, tonnes/day & 62 & 65 & 64 & 67 \\
\hline Overall efficiency, \% HHV & 0.359 & 0.375 & 0.363 & 0.380 \\
\hline GHGI & -0.13 & -0.06 & -0.12 & -0.05 \\
\hline Overnight capital cost, million \$ & 2,093 & 2,047 & 2,048 & 1,997 \\
\hline Breakeven crude oil price, \$/bbl * & 203 & 185 & 195 & 176 \\
\hline Levelized Cost of Electricity, \$/MWh * & 140 & 128 & 135 & 121 \\
\hline
\end{tabular}

* For zero GHG emissions price.

Case 2 and Case 10 both use the same methanol synthesis technology and so have identical designs except that case 2 uses non-torrefied biomass and case 10 uses torrefied biomass. Case 10 requires about $15 \%$ less on-site electricity due to the large reduction in energy needed for grinding torrefied biomass compared with non-torrefied biomass and the reduced need for oxygen to feed the gasifier. (In case 10, less of the original input biomass makes it to the gasifier since some is lost during torrefaction, hence the smaller gasifier.) As a result, both the air separation unit and the gasifier are smaller and hence less costly when biomass is torrefied before gasification rather than used directly in the gasifier, and the overall energy efficiency of the plant using torrefied biomass is higher because losses associated with torrefaction are more than compensated by the reduced consumption of parasitic power.

The lower gasifier and ASU costs result in a slightly lower total plant capital cost for the system utilizing torrefied biomass (compare case 10 and case 2). This is despite the added cost that the torrefaction system imposes. With slightly lower capital cost and slightly higher conversion efficiency for the design using torrefaction, the levelized production cost is also lower for the case where torrefaction is used. However, in the absence of a greenhouse gas emissions price, neither of these particular cases provides compelling economics when compared against current technology options for electricity production (e.g., pulverized coal plant) or for liquid fuels supply (e.g., crude oil refining). Assuming the fuel co-products are sold at wholesale prices corresponding to those for the same fuels made from $\$ 90 / \mathrm{bbl}$ crude oil, the LCOE for case 2 and case 10 are $\$ 140 / \mathrm{MWh}$ and $\$ 128 / \mathrm{MWh}$, respectively. The breakeven oil prices are $\$ 203 / \mathrm{bbl}$ and $\$ 185 / \mathrm{bbl}$, respectively, assuming electricity is sold for \$60/MWh.

The economics would be improved if the $\mathrm{CO}_{2}$ were sold for use in enhanced oil recovery operations that result in the $\mathrm{CO}_{2}$ ultimately being permanently stored underground when the oil well is closed. Some preliminary estimates of the economics of this option are discussed in Sections 3.2.5 and 3.2.6.

\subsubsection{Dry-feed gasifiers versus slurry-feed gasifiers}

Three pairs of cases enable comparisons of systems built around dry-feed gasifiers with those built around slurry-feed gasifiers: case 5 vs. case 13 (pair A); case 7 vs. case 15 (pair B); and case 8 vs. case 16 (pair C). See Table 9. For any one of these pairs, the only design feature not shared between the two cases is the gasifier type. All other design elements are common between the two, including the use of torrefied biomass and the BF and EF values. Pair $\mathrm{C}$ has EF values close to zero. Pairs $\mathrm{A}$ and $\mathrm{B}$ have EF of 0.44 or 0.45 . These latter two pairs are true co-production systems and so we focus the discussion here on these. 
Table 9. Comparison dry-feed versus slurry-feed gasification. All designs use torrefied biomass and liquid-phase methanol synthesis.

\begin{tabular}{|l||c|c||c|c||c|c||}
\hline \multicolumn{1}{|c||}{} & \multicolumn{2}{c||}{ Pair A } & \multicolumn{2}{c||}{ Pair B } & \multicolumn{2}{c||}{ Pair C } \\
\hline \multicolumn{1}{|c|}{} & Case 5 & Case 13 & Case 7 & Case 15 & Case 8 & Case 16 \\
\hline Gasifier type & Dry & Slurry & Dry & Slurry & Dry & Slurry \\
\hline Biomass fraction & 0.05 & 0.05 & 0.28 & 0.26 & 0.28 & 0.26 \\
\hline Electricity fraction & 0.45 & 0.44 & 0.45 & 0.44 & 0.02 & 0.03 \\
\hline Gross electricity production, MW & 786 & 705 & 630 & 614 & 254 & 252 \\
\hline Onsite electricity use, MW & 301 & 263 & 250 & 244 & 232 & 221 \\
\hline Net electricity export, MW & 485 & 443 & 380 & 371 & 22 & 32 \\
\hline Gasoline production, bbl/day & 9,317 & 8,849 & 7,226 & 7,445 & 16,301 & 15,794 \\
\hline LPG production, tonnes/day & 105 & 99 & 81 & 83 & 179 & 170 \\
\hline Overall efficiency, \% HHV & 0.427 & 0.398 & 0.398 & 0.370 & 0.518 & 0.468 \\
\hline GHGI & 0.34 & 0.34 & 0.0 & 0.0 & 0.42 & 0.42 \\
\hline Overnight capital cost, million \$ & 2,434 & 2,022 & 2,103 & 1,857 & 2,130 & 1,845 \\
\hline Levelized Cost of Fuel, \$/GJ $_{\text {LHV }}^{*}$ & 26.3 & 24.7 & 34.4 & 31.9 & 20.5 & 19.5 \\
\hline Levelized Cost of Electricity, \$/MWh * $^{*}$ * & 83 & 77 & 115 & 108 & n.a. & n.a. \\
\hline
\end{tabular}

* For zero GHG emissions price.

For either pair $\mathrm{A}$ (with $\mathrm{BF}=0.05$ ) or pair $\mathrm{B}$ (with $\mathrm{BF}=0.26$ or 0.28 ), the case with dry-feed gasification in each pair (case 5 and case 7), has an overall efficiency advantage over its counterpart using slurry-feed gasification (case 13 and case 15) of nearly three percentage points (Table 9). This difference arises primarily because the cold gas efficiency of a slurry-feed gasifier is nearly 10 percentage points below that for a dry-feed gasifier using the same feedstock (Figure 4). As discussed in Appendix A, this result arises from the lower carbon conversion with slurry-feed gasification and the additional feedstock oxidation required with slurry gasification in order to evaporate the slurry water and heat it to the gasifier's operating temperature. A further comparison of pair A and B reveals that the overall system efficiency falls with increasing BF. This result is explained by the lower energy density of biomass compared to coal: as BF increases, a larger portion of the input feedstock must be oxidized to maintain the gasifier operating temperature at its design value. This is true for both a dry-feed or a slurry-feed design.

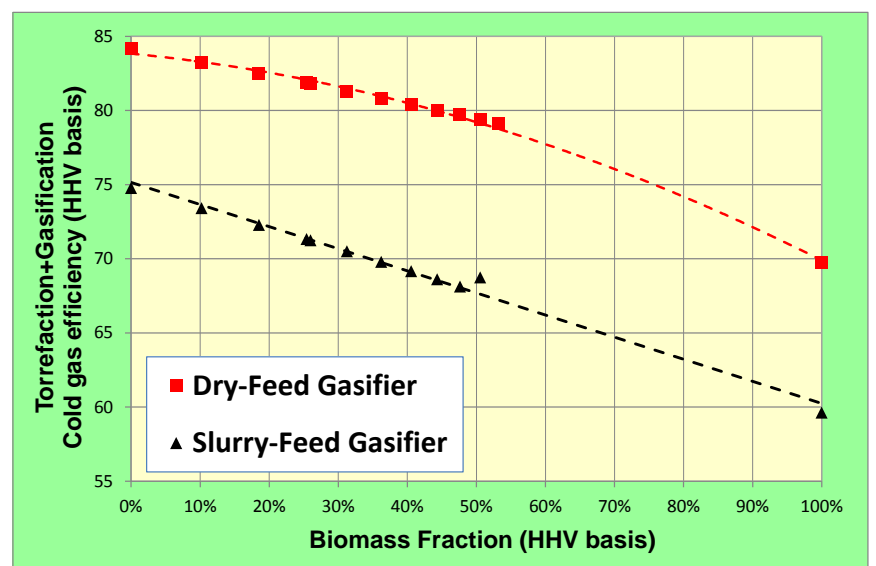

Figure 4. Our simulation results for cold-gas efficiency of syngas production (including torrefaction + gasification). The dry-feed system maintains an efficiency advantage of nearly 10 percentage points across the full range of BF values considered, and the efficiency of both systems falls with increasing BF. See additional discussion in Appendix A.

In any case, the better efficiency of dry-feed systems compared with slurry-feed systems comes with an added capital cost. This is evident from a comparison of the overnight installed capital cost for case 5 and case 13 (Table 9). With identical feedstock input rates, case 5 (with dry-feed gasifier) is 20\% more capital intensive. The differences in LCOF and LCOE between the two cases are only a few percent, however, because higher electricity and fuels production with the dry-feed system partially compensate the higher capital cost. The overall economics are not significantly different for the dry-feed system and 
the slurry-feed system, but considering that the results for the slurry-feed system assume a high solids fraction (that has yet to be verified as feasible), we chose to focus most of our analysis going forward on systems employing dry-feed gasification.

\subsubsection{Gas phase vs. liquid phase methanol synthesis}

A comparison of case 2 vs. 3 or case 9 vs. 10 (see Table 8) illustrates the modest benefits that come with liquid phase (LP) methanol synthesis over conventional gas-phase (GP) synthesis. The LP option provides for a small overall system efficiency advantage and also a small advantage in overnight capital cost, resulting in a few percentage points' advantage in levelized coproduct costs.

\subsubsection{BF and EF variations}

Results discussed in the prior three sections taken together suggest that the most promising coal/biomass systems for gasoline and electricity coproduction are those that use torrefied biomass, dryfeed gasification, and liquid phase methanol synthesis. For a system incorporating these technologies, Cases 4, 5, 6, and 7 (Table 10) provide a basis for examining the impact of different electricity fractions (EF) and biomass fractions (BF) on environmental and economic performance.

For these cases, the greenhouse gas emission index (GHGI) decreases with either increasing BF or increasing EF (Table 10).

An increase in EF lowers GHGI for two reasons: 1) the "business-as-usual" alternative used in the calculation of GHGI is coal-fired power generation, which is more carbon-intensive than production and use of petroleum-derived gasoline, the BAU alternative to the gasoline produced by the coal/biomass system; and 2) less of the carbon in the feedstock reaches the atmosphere via combustion of the liquid fuel produced and more of the carbon in the feedstock is captured and stored underground.

Table 10. Comparison of cases with high and low electricity fractions. One pair of cases are for a low BF and the second pair of cases are for high BF. All cases use dry-feed gasification of torrefied biomass and liquid-phase methanol synthesis. The low BF plants are sized for 8,000 t/day coal input. The high BF plants are sized to consume 1 million tonnes per year of biomass (at $90 \%$ capacity factor).

\begin{tabular}{|l||c|c||c|c||}
\hline \multicolumn{1}{|c||}{} & \multicolumn{2}{c||}{ Low BF } & \multicolumn{2}{c||}{ High BF } \\
\hline & Case 4 & Case 5 & Case 6 & Case 7 \\
\hline Biomass fraction, BF & 0.05 & 0.05 & 0.28 & 0.28 \\
\hline Electricity fraction, EF & 0.26 & 0.45 & 0.28 & 0.45 \\
\hline Coal input, AR metric t/day & 8,000 & 8,000 & 5,050 & 5,050 \\
\hline Biomass input, AR metric t/d & 806 & 806 & 3,805 & 3,805 \\
\hline Net electricity export, MW & 321 & 485 & 269 & 380 \\
\hline Gasoline production, bbl/day & 14,064 & 9,317 & 10,558 & 7,226 \\
\hline LPG production, tonnes/day & 158 & 105 & 118 & 81 \\
\hline Overall efficiency, \% HHV & 0.488 & 0.427 & 0.451 & 0.398 \\
\hline \% of input carbon stored & $65 \%$ & $74 \%$ & $66 \%$ & $74 \%$ \\
\hline Greenhouse Gas Emissions Index (GHGI) & 0.50 & 0.34 & 0.12 & 0.0 \\
\hline Overnight capital cost, million \$ & 2,424 & 2,434 & 2,078 & 2,103 \\
\hline Breakeven crude oil price, \$/bbl * & 87 & 116 & 113 & 154 \\
\hline Levelized Cost of Electricity, \$/MWh * & 55 & 83 & 102 & 115 \\
\hline
\end{tabular}

* For zero GHG emissions price.

An increase in BF lowers GHGI because carbon originating from photosynthesis is counted as an extraction of carbon from the atmosphere, offsetting some of the additions of carbon originating from the co-production system and the combustion of the liquid fuels produced. For Case 7, where BF is 0.28 and EF is 0.45 , GHGI is zero. For higher values of BF or EF than these values, the GHGI is negative (e.g., 
see Case 9 in Table 6). Even the low value of BF (0.05) provides for a 50\% reduction in emissions (GHGI $=0.5$ ) when the electricity fraction is 0.26 (case 4 in Table 10 ). ${ }^{43}$

The GHGI falls for systems with increasing EF or increasing BF, but the economics become less favorable in the absence of a greenhouse gas emissions price. For example, for a fixed BF of 0.28 , the levelized cost of electricity (LCOE) increases from $\$ 102$ per MWh to $\$ 115$ per MWh when the EF increases from 0.28 to 0.45 (compare cases 6 and 7 in Table 10). The breakeven crude oil price (BCOP) is even more sensitive to the EF for these cases. For the low BF cases (4 and 5 in Table 10), the LCOE and BCOP are reduced compared with the high BF cases. However, only case 4, with low BF and low EF appears to have an LCOE or BCOP value that might be plausibly competitive, in the absence of a GHG emissions price, with electricity generating costs or petroleum fuel costs prevailing today.

The introduction of a greenhouse gas emissions price dramatically alters the economics of $\mathrm{coal} / \mathrm{biomass}$ coproduction. Figure 5 shows the breakeven crude oil price for fuel production for the four cases in Table 10. [For this calculation, revenues for electricity co-product sales are assumed to be $\$ 60 / \mathrm{MWh}$ plus a GHG emissions charge corresponding to that for the U.S. grid-average emission rate (in 2007) of $636 \mathrm{kgCO}_{2}$-equivalent per MWh.] Because the GHGI is less than 1 for all of these cases, the BCOP falls with increasing GHG emission price. With zero GHG emissions price, case 4 (because of its low $\mathrm{BF}$ and relatively low $\mathrm{EF}$ ) provides the lowest $\mathrm{BCOP}$ - less than $\$ 90 /$ barrel. Case 4 continues to provide the lowest $\mathrm{BCOP}$ up to about $\$ 80 / \mathrm{tCO}_{2} \mathrm{e}$ emission price, beyond which the cases with higher $\mathrm{BF}$ (case 6 and case 7) have lower BCOP levels.

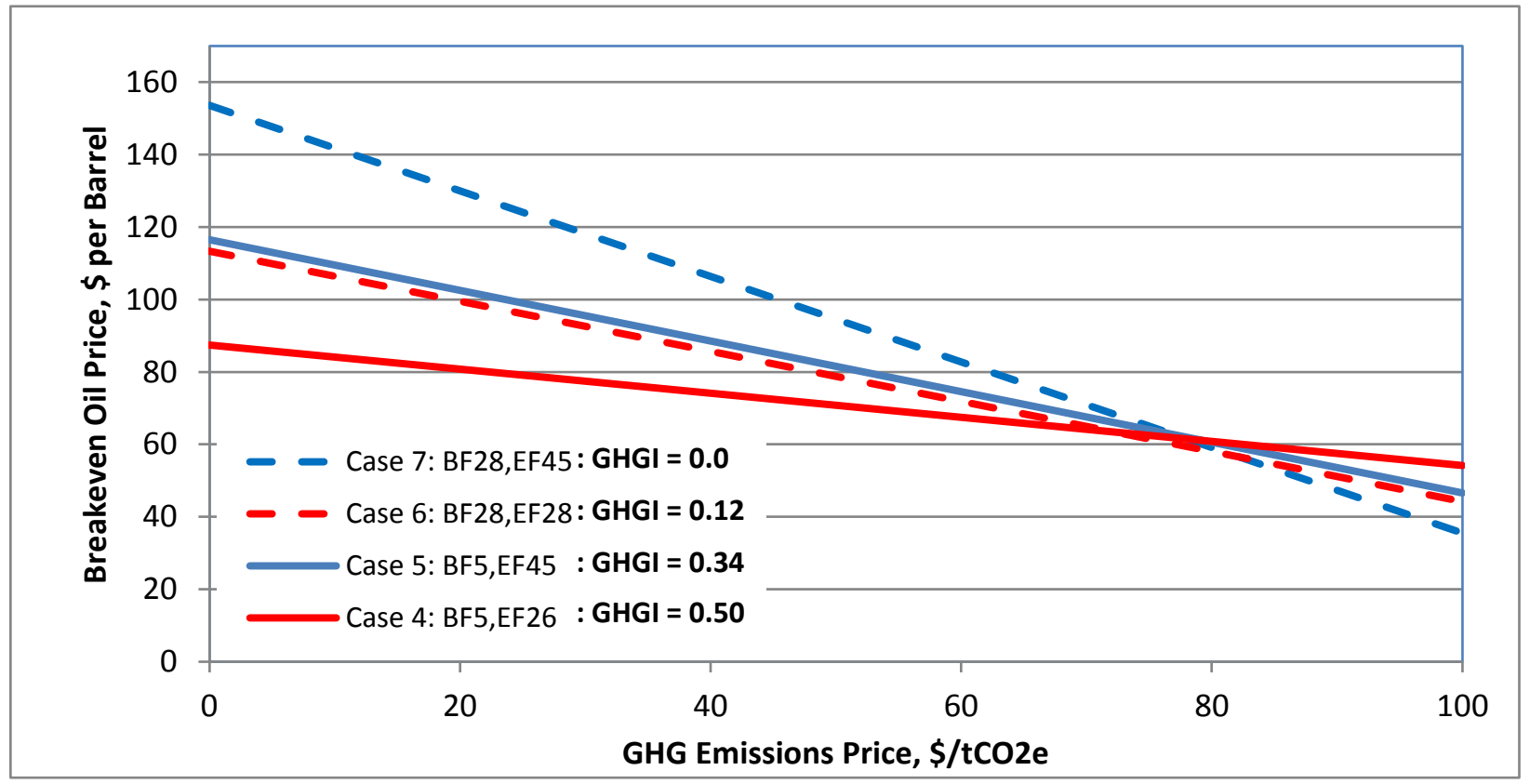

Figure 5. Breakeven crude oil price (BCOP) for cases 4, 5, 6, and 7 as a function of the GHG emissions price.

Figure 6 shows economics for the four cases from an electricity production perspective. Also shown for perspective is the LCOE for a new supercritical pulverized coal power plant that vents its $\mathrm{CO}_{2}$. To calculate the LCOE for the coproduction cases, the liquid fuel products are assumed to be sold at a price equivalent to the wholesale price of these products made from crude oil costing $\$ 90 / \mathrm{bbl}$ plus a greenhouse gas emission charge assuming $91 \mathrm{kgCO}_{2} \mathrm{e} / \mathrm{GJ}_{\mathrm{LHV}}$ for petroleum-derived gasoline. As in

\footnotetext{
${ }^{43}$ It may be noted that the co-production plant that uses only coal as feedstock with dry-feed gasification (case 1 in Table 6) has a GHGI of 0.37, which is lower than for either of the two low BF cases shown in Table 10. The relatively high EF value for case 1 (0.50) explains this observation, when one considers that in the extreme case of $\mathrm{EF}=1$, case 1 would essentially represent an IGCC with pre-combustion capture of $\mathrm{CO}_{2}$. Assuming $90 \%$ of the input carbon is captured, with such an IGCC, it would have a GHGI of about 0.16.
} 
Figure 5, the case with the lowest BF and EF (case 4) provides the lowest LCOE in the absence of a GHG emissions price, about $\$ 55 / \mathrm{MWh}$. The electricity produced in case 4 has $50 \%$ lower emissions than a conventional coal-fired power plant without CCS. The emission rate for case 4 is comparable to that for a natural gas combined cycle venting $\mathrm{CO}_{2}(\mathrm{NGCC}-\mathrm{V})$. (An LCOE of $\$ 55 / \mathrm{MWh}$ would be achieved for a new NGCC if the natural gas were $\$ 5.6 / \mathrm{GJ}_{\mathrm{HHV}}$, assuming a capacity factor of $85 \%$ and capital and operating and maintenance costs developed by NETL analysts. ${ }^{36}$ ) The LCOE for case 4 is roughly constant with increasing GHG emission price because the added revenue from fuel sales that accompanies the increasing GHG emissions price offsets the increased GHG emissions charges levied on the coproduction facility.

A higher BF than in case 4 (but with approximately the same EF) leads to a higher LCOE at low GHG emission prices. See case 6 in Figure 6. However, the LCOE falls with increasing GHG emission price due to the high biomass fraction. Beyond $\$ 80 / \mathrm{tCO}_{2} \mathrm{e}$, case 6 provides the lowest LCOE.

A final economic metric, the internal rate of return on equity (IRRE), is shown in Figure 7. For this calculation, electricity revenues and liquid fuel revenues are assumed to be as they were for the calculations behind Figure 5 and Figure 6 . As expected, case 4 provides the highest IRRE across a broad range of GHG emission prices. Beyond $\$ 80 / \mathrm{tCO}_{2} \mathrm{e}$, case 6 (with a much higher $\mathrm{BF}$ ) provides the highest return.

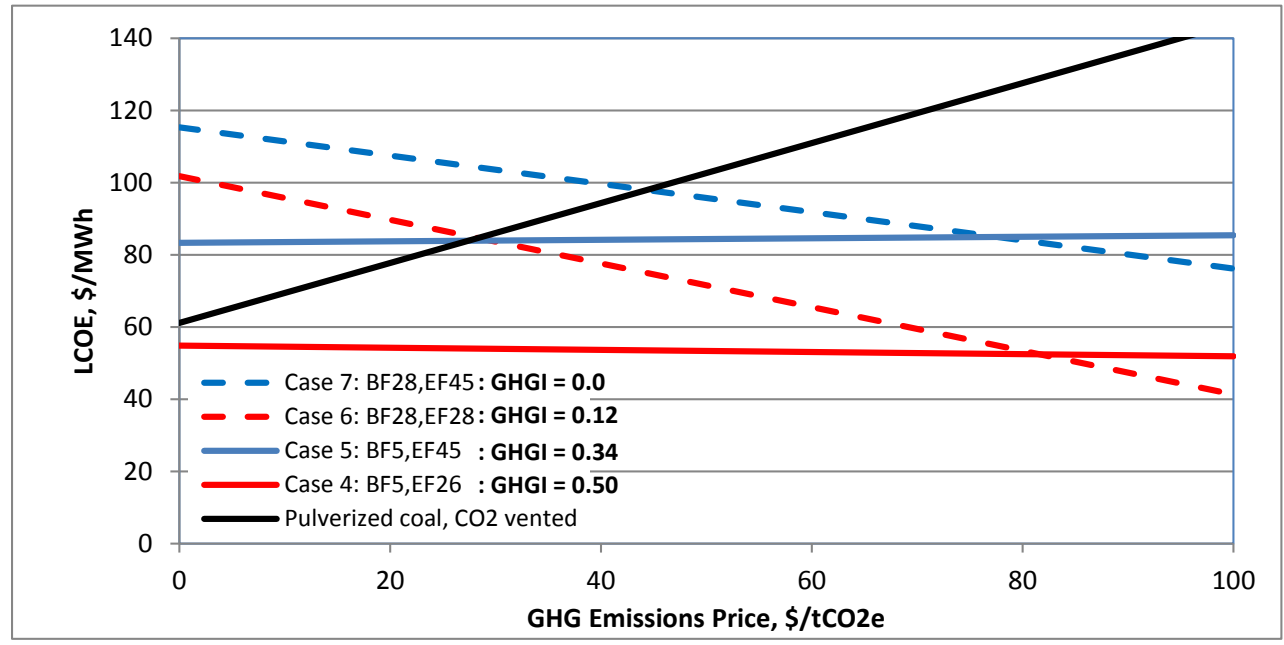

Figure 6. Levelized cost of electricity production for cases 4, 5, 6, and 7 as a function of the GHG emissions price. Also shown is the LCOE (based on NETL analysis ${ }^{36}$ ) for a new supercritical pulverized coal plant venting $\mathrm{CO}_{2}$.

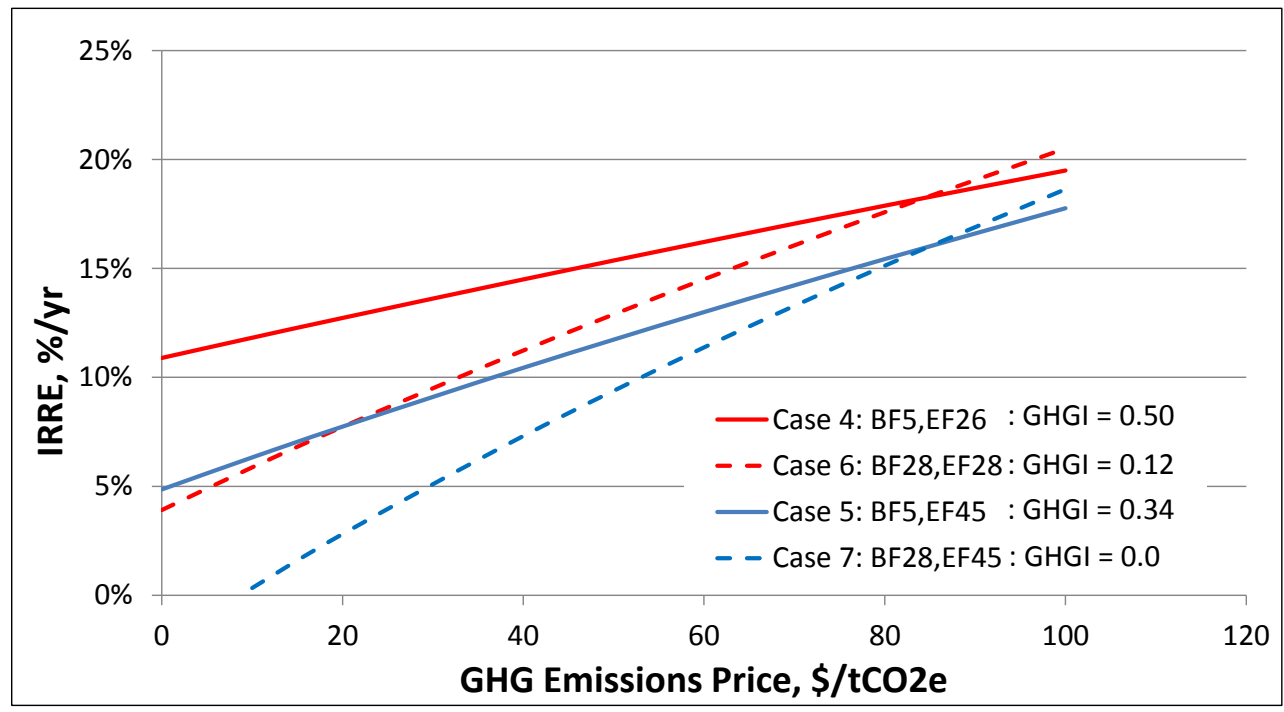

Figure 7. Internal rate of return on equity for cases 4, 5, 6, and 7. 


\subsubsection{Economics with captured $\mathrm{CO}_{2}$ sold for $\mathrm{EOR}$}

In all of the results discussed thus far, it was assumed that captured $\mathrm{CO}_{2}$ is compressed, transported by pipeline, and injected into a deep underground saline aquifer for long-term storage. An alternative means of storage would be injection into existing oil wells to promote enhanced oil recovery (EOR). With this option, the injected $\mathrm{CO}_{2}$ would ultimately be stored in the well reservoir once production of oil ended and the well was plugged. We have not evaluated this option in detail, but we have made some preliminary estimates of how the economics would change when a coproduction facility receives revenue for $\mathrm{CO}_{2}$.

Figure 8 shows our estimates of the $\mathrm{LCOE}$ as a function of the sale price of $\mathrm{CO}_{2}$ in the absence of any greenhouse gas emission price. (The earlier-discussed $\mathrm{LCOE}$ values with $\mathrm{CO}_{2}$ storage in aquifers are also indicated.) Results are shown for a $\mathrm{CO}_{2}$ sale price range from $\$ 20 / \mathrm{t}$ to $\$ 35 / \mathrm{t}$, considering that the current market price for $\mathrm{CO}_{2}$ sold for EOR ranges from $\$ 25 / \mathrm{t}$ to $\$ 40 / \mathrm{t} .{ }^{44}$ (As in earlier cost analyses, the liquid coproducts are assumed to be sold into a transportation fuels market characterized by a $\$ 90 / \mathrm{bbl}$ crude oil price.) Also shown in Figure 8, for reference, is the LCOE for a new supercritical pulverized coal (PC) plant venting $\mathrm{CO}_{2}$. Cases 3, 4, and 5 all have LCOE lower than for the PC plant across the full range of plotted $\mathrm{CO}_{2}$ selling prices. Case 4, with the lowest BF and EF values has a LCOE of $\$ 10$ per MWh when $\mathrm{CO}_{2}$ sells for $\$ 20 / \mathrm{t}$ and $\$ 0 / \mathrm{MWh}$ for $\mathrm{CO}_{2}$ selling for $\$ 27 / \mathrm{t}$. Case 7 , with high $\mathrm{BF}$ and high EF, has LCOE above that for the PC until the selling price of $\mathrm{CO}_{2}$ reaches $\$ 35 / \mathrm{t}$.

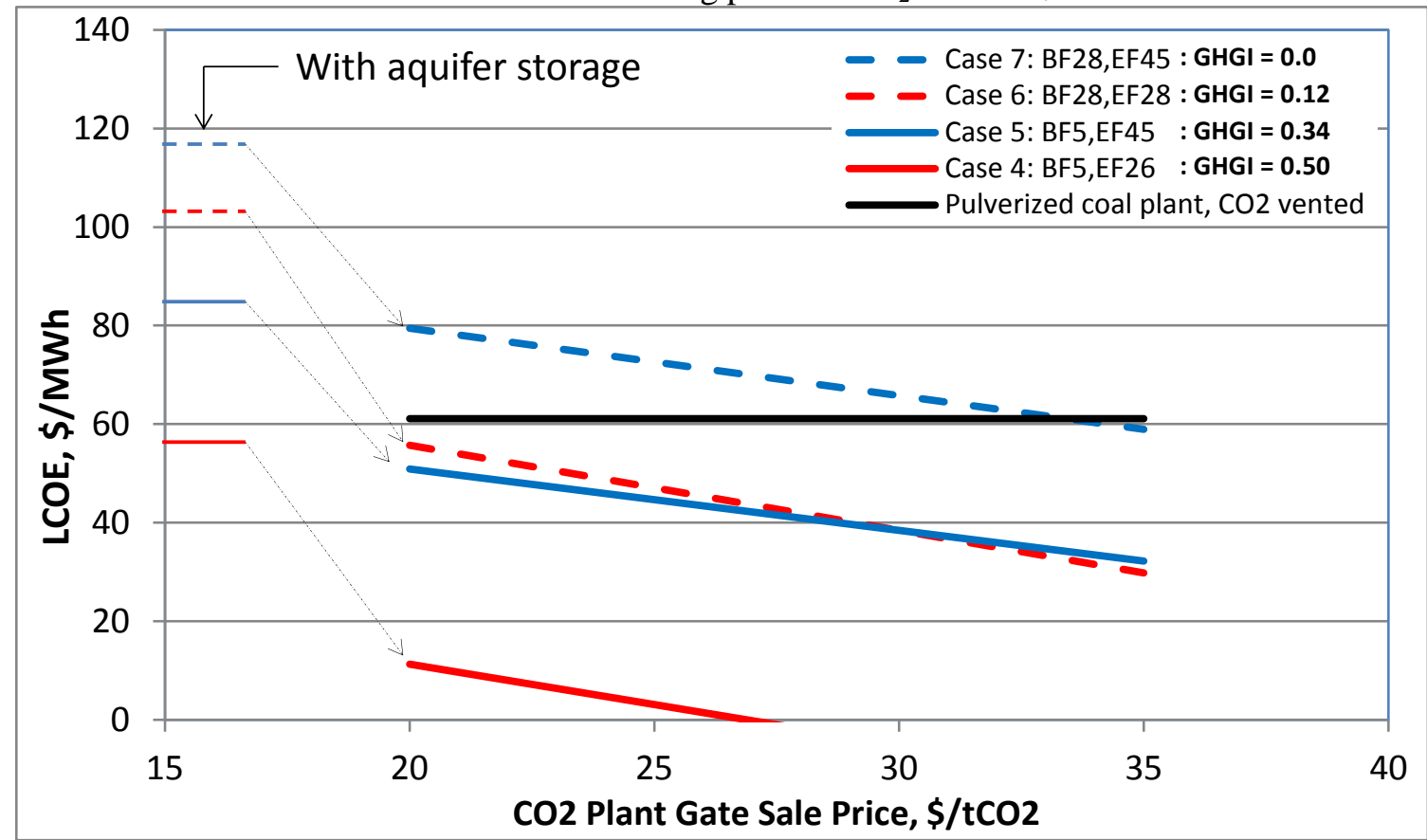

Figure 8. $\mathrm{LCOE}$ as a function of $\mathrm{CO}_{2}$ selling price for cases 4, 5, 6, and 7, assuming $\mathrm{CO}_{2}$ is sold for EOR. Also shown for reference is the LCOE (based on NETL analysis ${ }^{36}$ ) for a new supercritical pulverized coal plant venting $\mathrm{CO}_{2}$. $\mathrm{LCOE}^{\text {'s for }}$ these four cases with aquifer storage of $\mathrm{CO}_{2}$ (discussed earlier) are also shown.

Figure 9 shows how the LCOE for cases 6 and 7, each of which achieves large reductions in GHG emissions, change with GHG emissions price when $\mathrm{CO}_{2}$ is sold for EOR at a price of $\$ 27.5 / \mathrm{t}$ (the average of the range considered in Figure 8). Shown for comparison are LCOE values for two conventional power plants venting $\mathrm{CO}_{2}$ : a new supercritical pulverized coal plant $(\mathrm{GHGI}=1.0)$ and a new natural gas combined cycle $(\mathrm{GHGI}=0.51)$. With zero GHG emission price, the LCOE for Case 6 falls well below

\footnotetext{
${ }^{44}$ MIT Energy Initiative and Bureau of Economic Geology at UT Austin, Role of Enhanced Oil Recovery in Accelerating the Deployment of Carbon Capture and Sequestration, report of the 23 July 2010 symposium of the same title, May 2011.
} 
those for the coal and gas plants. For case 7, the LCOE falls below that for the PC plant (NGCC plant) when the GHG emissions price exceeds $\$ 5 / \mathrm{t}(\$ 10 / \mathrm{t})$.

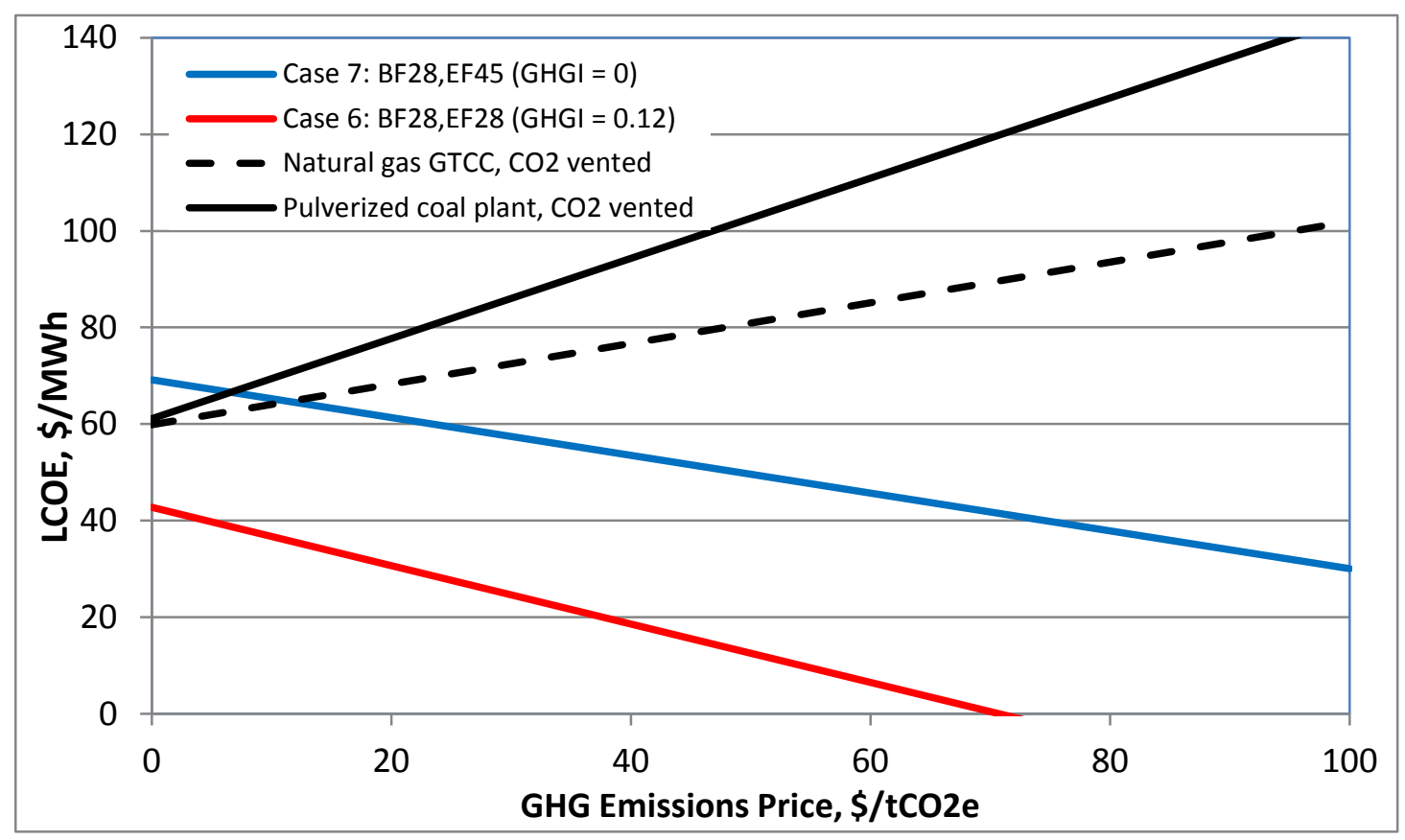

Figure 9. LCOE as a function of greenhouse gas emission price for coproduction case 6 (GHGI = 0.12) and case 7 (GHGI $=0$ ) when the facilities sell $\mathrm{CO}_{2}$ for EOR at a price of \$27.5/t. Shown for comparison are LCOE estimates (based on NETL analysis ${ }^{36}$ ) for a new supercritical pulverized coal plant and a new natural gas combined cycle, both venting $\mathrm{CO}_{2}$. Assumed fossil fuel prices are $\$ \mathbf{6 . 3 5} / \mathbf{G} \mathbf{J}_{\mathrm{HHV}}$ for natural gas and $\mathbf{\$ 2 . 0 4 / G} \mathbf{J}_{\mathrm{HHV}}$ for coal. The fossil fuel plants are assumed to operate with $85 \%$ capacity factor.

\subsubsection{Economics of co-production vs. liquids-only production under a carbon mitigation policy}

A comparison of Cases 6 and 8 shows that for systems coprocessing the same percentage of biomass in the feedstock, a much lower GHGI is realized for the coproduction option than for the option making mainly liquid fuels ( 0.12 for Case 6 vs 0.42 for Case 8$)$. Figure 10 provides a perspective on the relative profitability of these two options under a carbon mitigation policy: Case 8 offers a higher IRRE for low GHG emissions prices, but Case 6 is more profitable at high GHG emissions prices. The IRRE is the same for these two cases when the GHG emissions price is $\$ 82 / \mathrm{tCO}_{2} \mathrm{e}$ for aquifer storage applications and $\$ 57 / \mathrm{t}$ for $\mathrm{CO}_{2}$ EOR applications (with plant-gate $\mathrm{CO}_{2}$ selling price of $\$ 27.5 / \mathrm{t}$ ). In both cases the systems would be much more profitable than a coal IGCC-CCS option (based on the use of the same gasifier), for which GHGI is $0.16 .^{45,46}$ The latter comparison suggests the importance of examining the LCOE for Case 6 in relation to the LCOEs for alternative power only systems offering low GHGI values.

Figure 11 makes such a comparison for both aquifer storage and $\mathrm{CO}_{2} \mathrm{EOR}$ applications, again assuming in the latter case a plant-gate $\mathrm{CO}_{2}$ selling price of $\$ 27.5 / \mathrm{t}$ and including in the comparison NGCC options without and with CCS. This figure shows that not only is the LCOE for Case 6 lower than

\footnotetext{
${ }^{45}$ A 507 MWe IGCC-CCS unit for which the HHV efficiency is $31.3 \%$ and TPC is $\$ 2810 / \mathrm{kW}_{\mathrm{e}}$.

${ }^{46}$ A more appropriate comparison would be to an IGCC-CCS system coprocessing the same biomass percentage as for Cases 6 and 8. Such a comparison is made in a paper being prepared for peer-review journal submission (Liu, Larson, Williams, Kreutz, and Katzer, "Gasoline from Coal and/or Biomass with $\mathrm{CO}_{2}$ Capture and Storage" Princeton Environmental Institute, Princeton University, June 2012, in preparation). In this paper the MTG systems analyzed co-process coal and biomass in separate gasifiers (unlike the present analysis), but the relative ranking of profitability of power only, coproduction, and mainly liquid fuel production options is the same as in the present analysis.
} 
that for IGCC-CCS at all GHG emissions prices in both aquifer storage and $\mathrm{CO}_{2} \mathrm{EOR}$ applications, but also that Case 6 would be a strong competitor to NGCC systems.

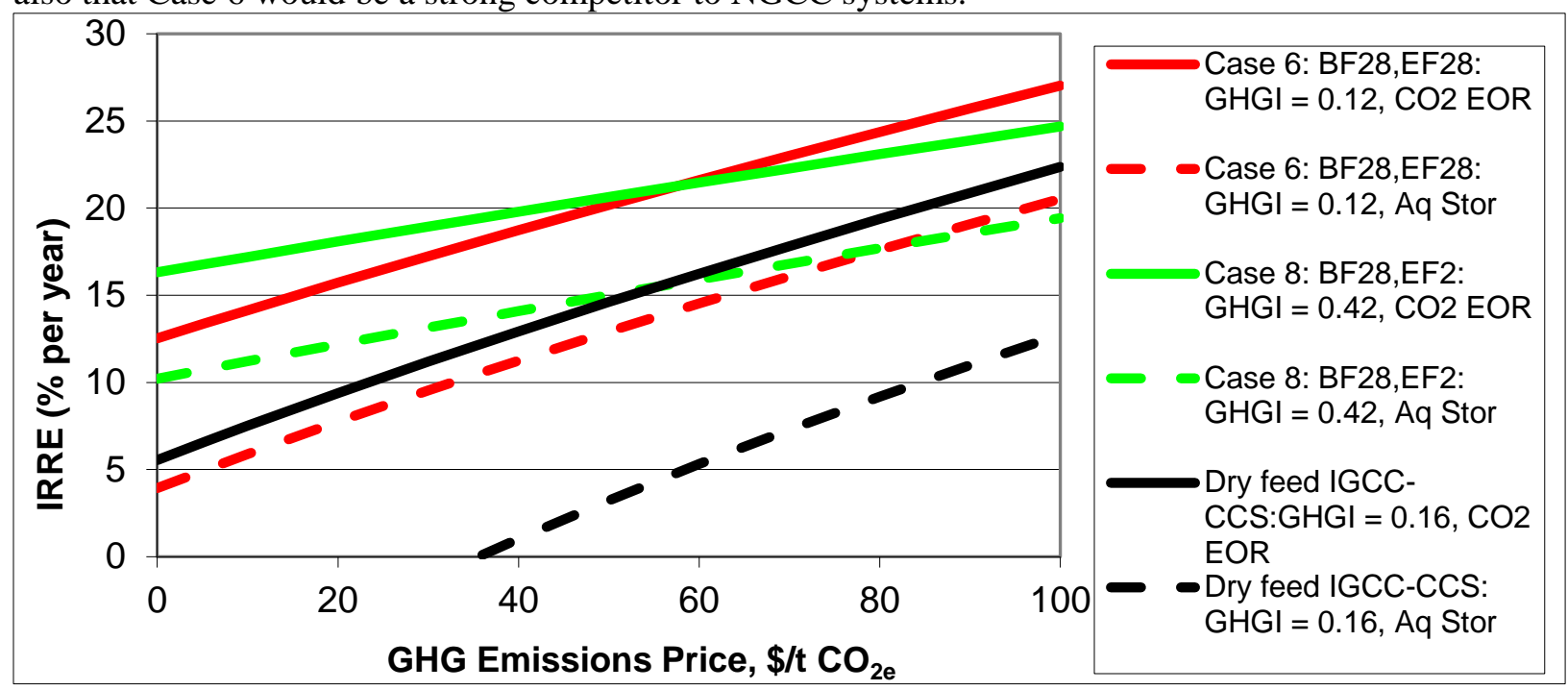

Figure 10. IRRE as a function of greenhouse gas emission price for Case 6 (Co-production with GHGI =0.12) and Case 8 (primarily liquids production with GHGI $=0.42$ ) and an IGCC using dry-feed (Shell) gasifier based on Princeton IGCC analysis (see Table 12 in the main text of this report). Two curves are shown for each case, one assuming aquifer storage of $\mathrm{CO}_{2}$ and one assuming $\mathrm{CO} 2$ storage via use for enhanced oil recovery. The assumed $\mathrm{CO}_{2}$ sale price for EOR is $\$ 27.5 / \mathrm{t}$. The assumed coal price is $\$ 2.04 / \mathrm{GJ}_{\mathrm{HHV}}$. The IGCC is assumed to operate with $85 \%$ capacity factor.

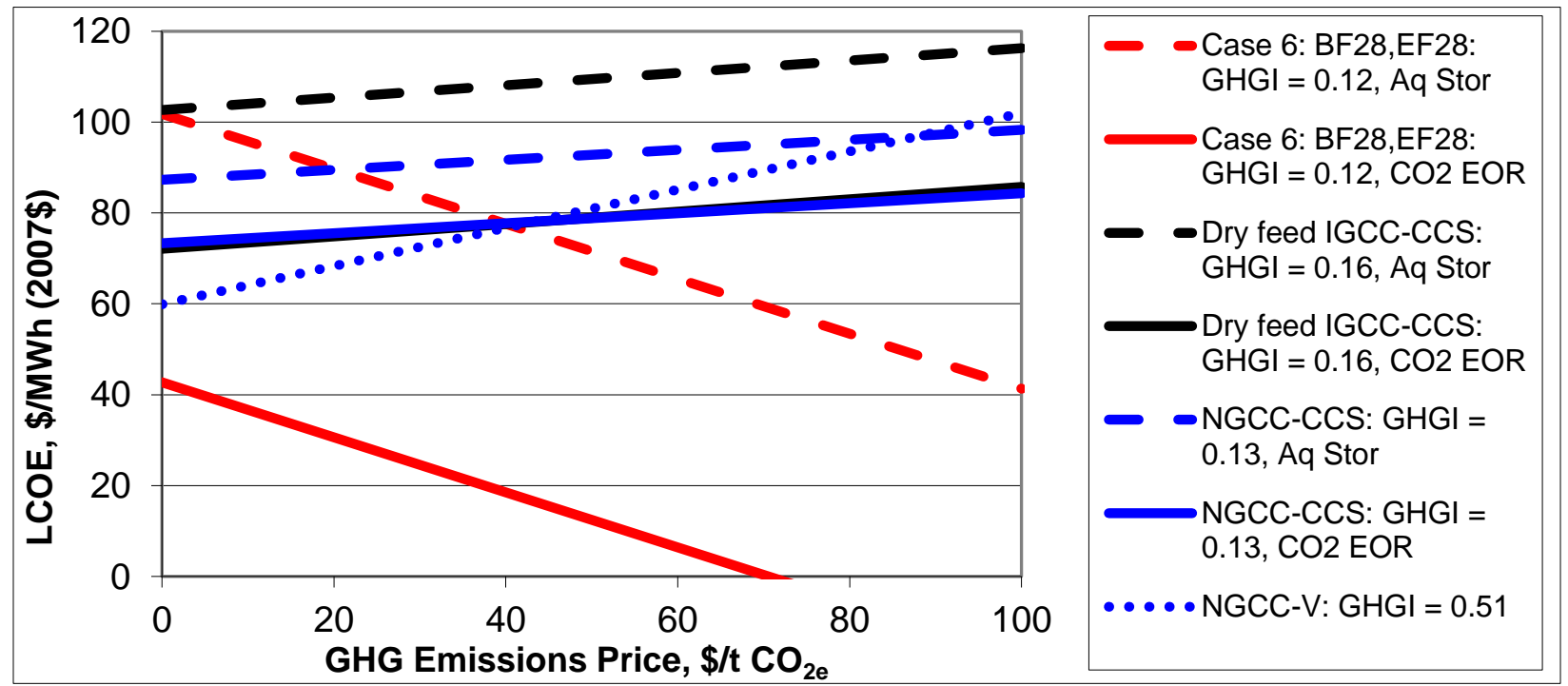

Figure 11. LCOE as a function of greenhouse gas emission price for Case 6 (Co-production with GHGI = 0.12), an IGCC using dry-feed (Shell) gasifier based on Princeton IGCC analysis (see Table 12 in the main text of this report), and for NGCC without with CCS. Two curves are shown for each case involving CCS, one assuming aquifer storage of $\mathrm{CO}_{2}$ and one assuming $\mathrm{CO}_{2}$ storage via use for enhanced oil recovery. The assumed $\mathrm{CO}_{2}$ sale price for EOR is $\$ 27.5 / t$. The assumed coal price is $\$ 2.04 / G J_{H H V}$. The IGCC and NGCC are assumed to operate with $85 \%$ capacity factor.

In the EOR application the Case $6 \mathrm{LCOE}$ is $\sim 2 / 3$ of the LCOE for a NGCC-V system at a zero GHG emissions price, and the LCOE gap between these options grows rapidly with GHG emissions price. In the aquifer storage application, the GHG emissions price at which Case 6 and the NGCC-CCS have the same LCOE is $\$ 20 / \mathrm{tCO}_{2} \mathrm{e}$. The breakeven between Case 6 and NGCC-V occurs at $\$ 41 / \mathrm{CO}_{2} \mathrm{e}$. At the $\$ 82 / \mathrm{t}$ GHG emissions price at which IRRE breakeven occurs between Case 6 and Case 8 options for aquifer storage (see Figure 10), the natural gas price would have to be less than $\$ 1.0 / \mathrm{GJ}$ in order for the least-costly NGCC option at this GHG emission price (NGCC-CCS) to have a lower LCOE value 
than that for Case 6. This shows that in the presence of a strong carbon mitigation policy coal-consuming coproduction options such as Case 6 would be strong competitors with natural gas.

The above analysis of the LCOE competition among NGCC, IGCC-CCS, and Case 6 options is based on the assumption that the NGCC and IGCC capacity factors are their design values of $85 \%$. In the real world the capacity factor is determined by economic dispatch competition on the electric grid. If there were a significant amount of coproduction capacity on the grid, the coproduction plants would tend to force down the capacity factors for NGCC and IGCC-CCS plants because of their much lower minimum dispatch costs ${ }^{13}$ - so that in the real world the Case 6 option would be even more competitive than is indicated above.

\section{Summary}

The key findings of our work on co-production of electricity and gasoline from coal and biomass can be summarized as follows:

- Systems with dry-feed and slurry-feed gasification show comparable economics when the biomass portion of the feed to the gasifier is torrefied. In the case of slurry-feed, torrefaction is probably essential for cogasification of biomass with coal, but it is not known how large a solids fraction can be used while maintaining pumpability of a coal/torrefied-biomass slurry. Our simulations have assumed $64 \mathrm{wt} \%$ (as is typical for coal slurries), but this assumption requires empirical confirmation. Since the overall economics of co-production with slurry gasification with this solids fraction were found to be not substantially different from those with dry-feed gasification, this suggests that dryfeed gasification is a more promising direction for at least first-generation technology.

- With dry-feed gasification, torrefaction of the biomass provides a slight economic benefit over the use of non-torrefied biomass, and technical challenges with feeding non-torrefied material to an entrained flow gasifier further increase the attractiveness of torrefaction.

- Advanced liquid-phase methanol synthesis provides only a modest cost benefit over the use of conventional gas-phase synthesis.

- The electricity fraction, $\mathrm{EF}$, and the biomass fraction, BF, are design parameters that significantly impact the environmental and economic performance of CBTG systems.

$\circ$ A 50\% reduction in greenhouse gas emissions (compared with a reference case of coal-fired electricity generation and petroleum-derived gasoline) is achieved with a small $\mathrm{BF}(0.05)$ and a modest EF (0.26). Greater GHG emission reductions can be achieved with higher EF values, but economics are less favorable. In the absence of a greenhouse gas emissions price, the levelized cost of electricity (LCOE) when EF is 0.26 ( $\$ 55 / \mathrm{MWh})$ is comparable to the $\mathrm{LCOE}$ for a new pulverized coal-fired power plant if the oil price is about $\$ 90$ per barrel. Selling the $\mathrm{CO}_{2}$ for enhanced oil recovery (ultimately resulting in the $\mathrm{CO}_{2}$ being stored underground when the well finishes production and is closed) would significantly improve the economics for the CBTG plant. This represents a strategic opportunity not only for early market launch of coproduction systems with CCS but also for launching lignocellulosic biomass supplies in the market, a process that is currently stalled by the slow pace of development of cellulosic ethanol technology.

$\circ$ With a higher biomass fraction $(\mathrm{BF}=0.30)$, larger reductions in greenhouse gas emissions (up to $100 \%$ reduction) can be achieved, but no CBTG design with this BF can provide competitive economics without a price on GHG emissions when the oil price is $\$ 90 / \mathrm{bbl}$. A GHG emission price of $\$ 30$ to $\$ 50$ per $\mathrm{tCO}_{2} \mathrm{e}$ would make the LCOE for some high BF systems competitive with a new pulverized coal plant that vents $\mathrm{CO}_{2}$. If $\mathrm{CO}_{2}$ could be sold into EOR markets, the required GHG emission price would be $\$ 10$ per $\mathrm{tCO}_{2} \mathrm{e}$ or less for a coproduction system achieving a GHGI of zero. No GHG emission price would be needed for coproduction systems that achieve GHGI of 0.1 or higher to compete. 
- In the presence of a strong carbon mitigation policy (high GHG emissions price) the use of coal in coproduction options has the potential to strongly compete in power generation markets with natural gas combined cycles. 


\title{
Appendix C
}

\section{Process Design and Analysis for Co-Production of Electricity and Light Olefins via Co- Gasification of Coal and Biomass with CCS}

\author{
Ilkka Hannula \\ Eric D. Larson \\ Guangjian Liu
}

\section{Contents}

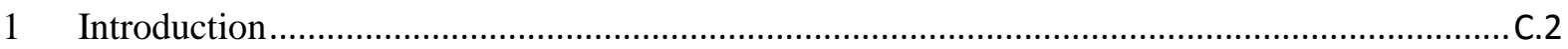

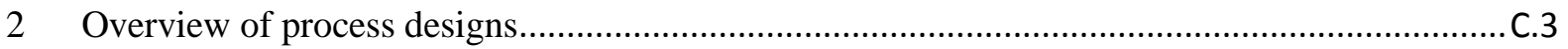

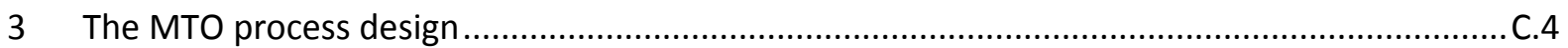

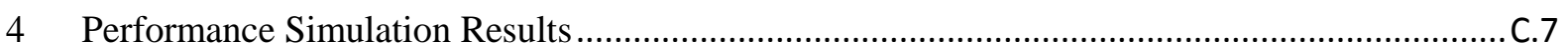

5 Capital Cost Estimates and Economic Analysis ......................................................................... 


\section{Introduction}

Light olefins (ethylene and propylene) are the basic building blocks for most of the petrochemical industry. They are mainly produced today by steam cracking hydrocarbon feedstocks and additionally from oil refinery upgrading processes and by catalytic dehydrogenation of paraffins. ${ }^{1}$ New capacity developments are presently focused in the Middle East and Asia due to feedstock costs and proximity to market, and expected continued strong consumption growth. ${ }^{2}$ Significant capacity expansion is expected to take place in the Middle East to supply the growing demand for olefins not only in the Asia Pacific, but also in Western Europe and North America. Polyolefins will remain the largest sector for olefins demand and also have the highest overall growth rate, while monomers and intermediates will form the second largest sector (see Figure 1).

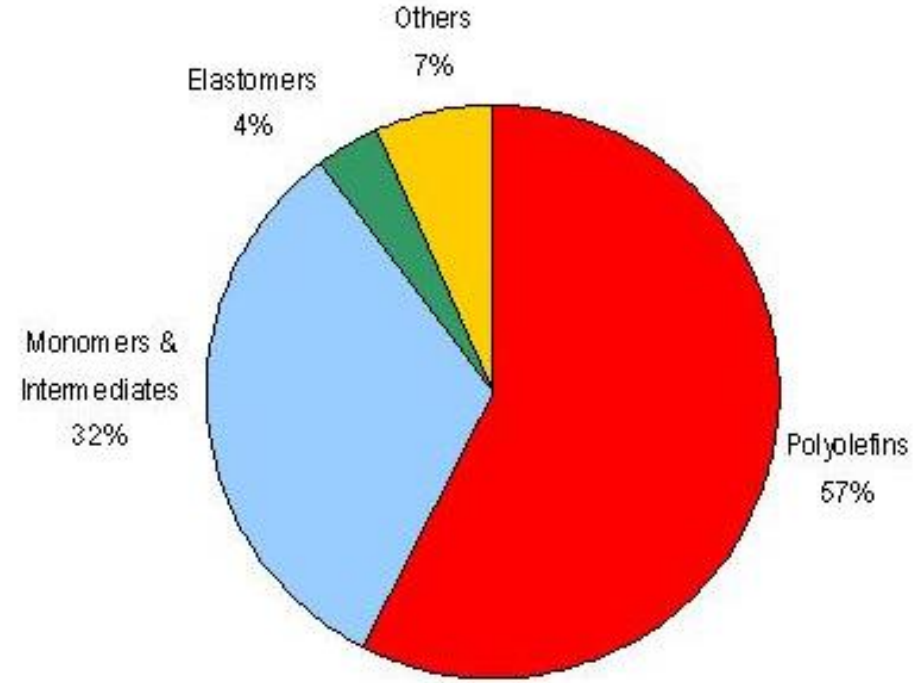

Figure 1. Global olefins consumption, $2007 .^{2}$

The rising prices of conventional petroleum feedstocks have driven technology development to enable olefin production from alternative feedstocks such as methanol. Because methanol can be made out of any gasifiable carbonaceous source including coal or biomass, this route opens up new alternatives to petroleum for olefins production. Two technologies based on catalytic conversion of methanol to olefins are currently available for licensing: UOP/Hydro's MTO (methanol-to-olefins) and Lurgi's MTP (methanol-to-propylene). Chinese technology is also available.

There are presently several coal-to-olefins (CTO) projects on-going in China and some plants already operating (Table 1). According to ASIACHEM, $6 \mathrm{Mt} / \mathrm{a}$ of new CTO capacity will come online in China during 2011-2015, necessitating 3.66 million $\mathrm{Nm}^{3} / \mathrm{h}$ of syngas capacity (19 gasifiers). ${ }^{3}$

Table 1. Key coal-to-olefins projects currently active in China. ${ }^{3}$

\begin{tabular}{|l|c|c|c|}
\hline Project type & $600 \mathrm{kt} / \mathrm{a}$ CTO & $500 \mathrm{kt} / \mathrm{a}$ CTO & $460 \mathrm{kt} / \mathrm{a}$ CTO \\
\hline Project owner & Shenhua & Shenhua Ningmei & Datang \\
Gasifier & GE Energy & Siemens GSP & Shell \\
Coal throughput & $7^{*} 1500 \mathrm{tpd} \mathrm{(5+2)}$ & $5^{*} 2000 \mathrm{tpd}$ & $3^{*} 2800 \mathrm{tpd}$ \\
Syngas capacity & $500,000 \mathrm{Nm}^{3} / \mathrm{h}$ & $520,000 \mathrm{Nm}^{3} / \mathrm{h}$ & $528,000 \mathrm{Nm}^{3} / \mathrm{h}$ \\
Final products* & $\mathrm{PE}, \mathrm{PP}$ & $\mathrm{PE}$ & $\mathrm{PE}$ \\
Start-up & 2010 & 2010 & 2011 \\
Location & Baotou, Inner Mongolia & Yinchuan, Ningxia & Duolun, Inner Mongolia \\
\hline
\end{tabular}

* $\mathrm{PE}=$ polyethylene, $\mathrm{PP}$ = polypropylene

\footnotetext{
${ }^{1}$ ChemSystems. “Olefins market report”, http://tinyurl.com/83uef7, Accessed 14 Jan 2011.

${ }^{2}$ ChemSystems, “Olefins outlook positive until 2009” http://tinyurl.com/7sr9rzg, Accessed 14 Jan 2011.

${ }^{3}$ Lei Xia, “China Gasification Market Outlook”. Presentation at the Gasification Technologies conference in San Francisco, CA, 10 Oct 2011. http://www.gasification.org.
} 


\section{Overview of process designs}

Performance and cost results were developed for co-production of electricity with light olefins (ethylene and propylene) from coal and coal/biomass mixtures in process designs utilizing $\mathrm{CO}_{2}$ capture for underground storage. We designed and analyzed five systems differentiated by type and quantities of feedstock, together with the electricity fraction of the products (Table 2). The specific biomass considered is corn stover. The coal in all cases is Illinois \#6 bituminous coal. Detailed compositional data for each of these feedstocks are given in Appendix A.

Table 2. Process designs considered for co-production of light olefins and electricity. $\mathrm{CO}_{2}$ capture and storage is included in all five designs.

\begin{tabular}{|l|c|c|c|c|c|}
\hline \multicolumn{1}{|c|}{ Process acronym>> } & $\begin{array}{l}\text { CTO- } \\
\text { EF50 }\end{array}$ & $\begin{array}{c}\text { CTO- } \\
\text { EF25 }\end{array}$ & $\begin{array}{c}\text { CBTO- } \\
\text { EF50HB }\end{array}$ & $\begin{array}{c}\text { CBTO- } \\
\text { EF25HB }\end{array}$ & $\begin{array}{c}\text { CBTO- } \\
\text { EF25LB }\end{array}$ \\
\hline $\begin{array}{l}\text { Biomass Fraction, BF } \\
\left(\mathrm{MW}_{\text {bio }} / \mathrm{MW}_{\text {coal+bio }}\right), \mathrm{HHV}\end{array}$ & \multicolumn{2}{|c|}{0} & \multicolumn{2}{|c|}{0.30} & 0.05 \\
\hline $\begin{array}{l}\text { Electricity Fraction, EF } \\
{\left[\mathrm{MW}_{\mathrm{e}} /\left(\mathrm{MW}_{\mathrm{e}}+\mathrm{MW}_{\text {olefins,LHV }}\right)\right.}\end{array}$ & 0.50 & 0.25 & 0.50 & 0.25 & 0.25 \\
\hline
\end{tabular}

The biomass is corn stover. The stover is torrefied prior to gasification, as discussed elsewhere in this report. The energy content of the biomass that is used in the calculation of the BF values corresponds to the energy in the biomass prior to torrefaction.

The scales for each of the facilities were selected to enable meaningful comparisons between cases:

- The CBTO-EF50HB case co-processes a large biomass fraction and produces half of its output as electricity ( $\mathrm{HB}=$ high biomass fraction). For this case, we set an annual biomass consumption of 1 million dry metric tonnes per year (at $90 \%$ capacity factor), a likely practical biomass supply limit under a variety of conditions. The coal input rate for this case is then set by the stipulated 30 $\%$ biomass input fraction. The biomass input rate at capacity for this design is 3,805 metric tonnes per day, as-received. The coal input rate at capacity is 4,639 metric tonnes per day, as-received. The electricity fraction (EF) for this plant, defined as the electricity output divided by the sum of electricity and olefin energy (LHV) output, for this plant is $50 \%$.

- The CBTO-EF25HB case maintains the same inputs of coal and biomass as CBTO-EF50HB, but the plant is designed with $\mathrm{EF}=25 \%$ instead of $50 \%$.

- For the CBTO-EF25LB (LB = low biomass fraction), the coal input rate was maintained as in the other two CBTO cases. The biomass fraction was set at 5\%, resulting in a biomass input rate at capacity of 467 metric tonnes per day, as-received. The EF for this case was set to $25 \%$.

- The CTO-EF50 case utilizes coal only, and half of its output is electricity. The coal input rate for this facility was set such that the olefins production rate was equal to the rate for the CBTOEF50HB case (705 metric tonnes per day, as described later).

- The CTO-EF25 case also utilizes only coal but has an electricity fraction of $25 \%$. For this case the coal input was fixed at the same level as for the CTO-EF50 case.

For purposes of describing the plant configurations, a simplified block diagram of a CTO system is shown in Figure 2. The process has a similar overall flow as for the coal-to-gasoline systems described in Appendix B. Following $\mathrm{CO}_{2}$ removal (using Rectisol technology), the syngas is split into two streams prior to methanol synthesis. Crude methanol is the feedstock for the olefin synthesis area and ethylene and propylene are produced there. Some fuel gases are also generated in the MTO process and these are mixed with syngas that bypasses the synthesis area. The mixture provides fuel for the gas turbine combined cycle power island. Heat is recovered from several places in the process and integrated into the heat recovery steam generator that feeds the steam turbine bottoming cycle in the power island. Bypassing some syngas around the synthesis area leads to higher output of electricity than without bypass. Within the synthesis area, syngas unconverted in the methanol synthesis reactor (a slurry-phase design discussed in Appendix B) can be recycled to the reactor to increase methanol production. Alternatively, it can be passed through the olefin synthesis area to the power island. A water gas shift unit is included following the synthesis area to convert $\mathrm{CO}$ to $\mathrm{CO}_{2}$ so that the latter can be removed to further reduce $\mathrm{CO}_{2}$ emissions from the process. $\mathrm{CO}_{2}$ is captured 
using a Rectisol absorption column, with regeneration of the Rectisol solvent integrated with the upstream Rectisol solvent regeneration to save some capital cost. Using different syngas bypass and syngas recycle ratios, designs with different ratios of olefins to electricity output can be achieved. Component technologies utilized in the process shown in Figure 2 have all been described in Appendix A or Appendix B, except for the olefins synthesis area. The latter is described next.

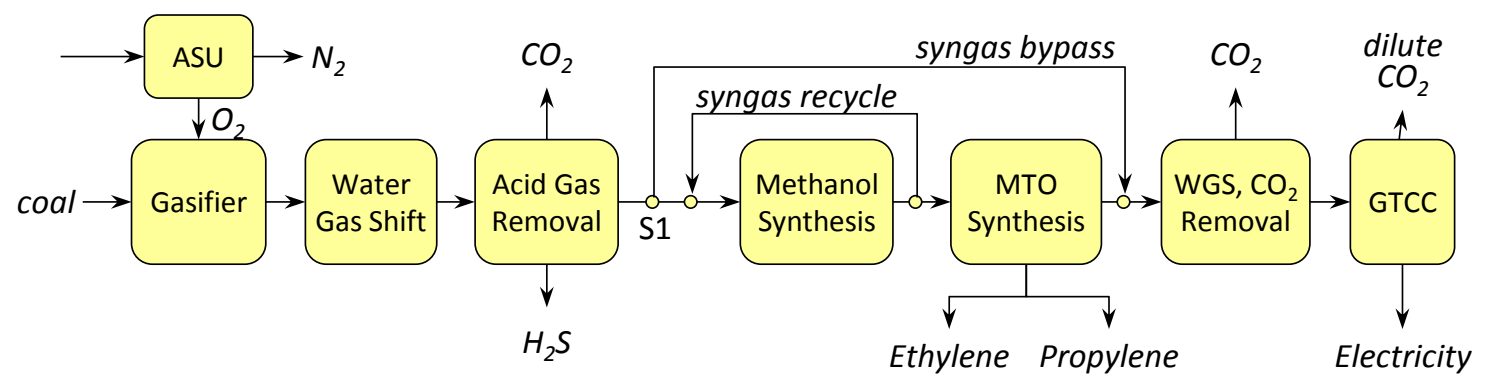

Figure 2. Simplified process diagram for coal conversion to light olefins and electricity.

Methanol-to-olefins technology (MTO) was first developed by Mobil (now ExxonMobil) in the mid-1980's as a spin-off of their methanol-to-gasoline process, but was not further developed at the time. In the mid-1990's UOP worked with Norsk Hydro to develop another version of the technology and build a pilot plant in Norway. A successful $100 \mathrm{bbl} / \mathrm{d}$ demonstration plant was later operated in Germany with U.S. and German government support ${ }^{4}$. Since then Lurgi has also developed its own version of this process, methanol-to-propylene (MTP), based on a fixed-bed reactor that preferentially produces propylene. The Chinese have also been active in this field: the Dalian Institute of Chemical Physics (DICP) has recently developed a similar process called DMTO. ${ }^{5}$

Each of these technologies has less and more attractive features, and it was not initially selfevident to us which would be the most appropriate option to consider in our plant designs. Some market analysts predict a growing need for on-purpose produced propylene in the future, which would be an argument in favour of considering the MTP process. On the other hand, process conditions with the MTO technology can be adjusted to favor propylene. Ultimately, the key deciding factor for which technology to include in our simulations was the apparent lack of available design information for both the Lurgi MTP process and the DICP DMTO process. As a consequence, we based our olefins synthesis designs on the UOP/Hydro technology, a fluidized-bed reactor that produces an ethylene-topropylene ratio that can be adjusted in response to changing market demands and pricing for ethylene and propylene. Our synthesis designs draw considerable inspiration from a detailed MTO study by Wan (2007). ${ }^{6}$

\section{The MT0 process design}

The MTO fluidized-bed reactor operates at $400-450^{\circ} \mathrm{C}$ and achieves $\sim 80 \%$ carbon selectivity to ethylene and propylene at near-complete methanol conversion. The mass ratio between ethylene and propylene can be varied from 0.75 to 1.5 by adjusting operating conditions, with higher temperatures leading to larger ethylene production. ${ }^{6}$ The highest overall yield of light olefins (ethylene plus propylene) is achieved with about equal amounts of both (see Figure 3 ). ${ }^{7}$ We have adopted a 1:1 ratio of ethylene to propylene production in our simulations.

A simplified depiction of our MTO process flowsheet is given in Figure 4. Compositions of the numbered streams are given in Table 3. The flowsheet has two distinct parts: the methanol conversion section and the product separation section.

\footnotetext{
${ }^{4}$ Wiley Critical Content: Petroleum Technology, Mar 2007, ISBN: 978-0-470-13402-3

${ }^{5}$ ChemSystems, "Ethylene PERP 08/09-5”, Report Abstract, Oct 2009, http://tinyurl.com/8278b3t, Accessed 15 Jan 2012

${ }^{6}$ Wan, V., "Methanol to Olefins," PEP report 261, SRI Consulting, Menlo Park, CA, November 2007, 198 pages.

${ }^{7}$ Meyers, R. (Ed.) Handbook of Petroleum Refining Processes ( ${ }^{\text {rd }}$ edition), The McGraw-Hill, New York, 2003.
} 
The core of the methanol conversion section is a fluidized-bed reactor/regenerator system that uses the proprietary MTO-100 catalyst (a modified SAPO-34 catalyst) to produce a mixture of hydrocarbons that are later separated into polymer-grade ethylene and propylene and various byproducts. The process feedstock is crude methanol (containing 97\% methanol and $3 \%$ water). Some steam (not shown in Figure 4) is added to the crude methanol to increase olefin selectivity and to decrease catalyst deactivation in the reactor. The crude methanol and steam feed is preheated, vaporized and mixed with recycled (unconverted) methanol vapor recovered from a downstream process. The combined stream (\#1 in Figure 4), containing now 27 mol\% water, is superheated to $310^{\circ} \mathrm{C}$ and fed to a fast-fluidized methanol-to-olefins reactor. The reactor produces an effluent (stream \#2) at 3 bar and $410^{\circ} \mathrm{C}$. The mass balance around the fluid-bed reactor in our simulation matches closely data presented by $\mathrm{Wan}^{6}$ for the UOP/Hydro technology, with ethylene and propylene produced in a mass ratio of 1 . Nearly complete conversion of methanol $(99.8 \%)$ is achieved in the reactor.

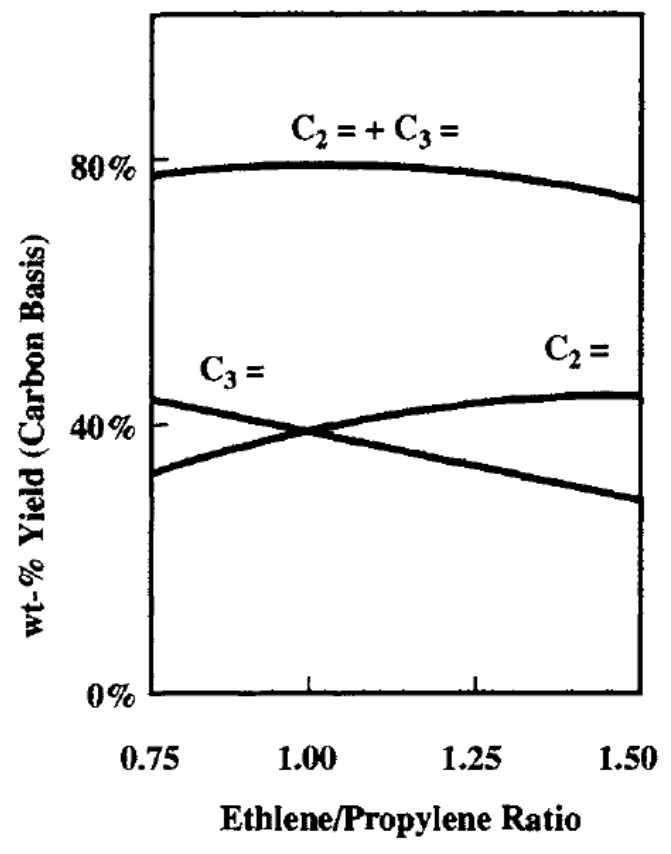

Figure 3. Light olefin yields of the MTO process ${ }^{7}$

Catalyst selectivity and methanol conversion gradually degrade over time due to coke buildup on the catalyst. Thus, to maintain good catalyst activity, a portion of the catalyst is continuously removed and sent to the regenerator (operating at 3.5 bar and $600^{\circ} \mathrm{C}$ ) where the coke is burned off in air. The carbon content of the catalyst is reduced from $5 \mathrm{wt} \%$ to $0.005 \mathrm{wt} \%$ before it is returned to the synthesis reactor. The $\mathrm{CO}_{2}$ formed during coke combustion is vented to atmosphere.

The fluid-bed reactor effluent is cooled to $125^{\circ} \mathrm{C}$, largely by exchanging heat with the reactor feed, and sent to a scrubber (labelled QUENCH) where water and unconverted methanol are separated from the stream. Methanol is then recovered in a stripper and returned to the reactor. The bottoms of this stripper contains mostly water that is sent to waste water treatment after exchanging heat with the reactor feed. The quench vapour is compressed in three stages to 25 bar and flashed at $38^{\circ} \mathrm{C}$ in a phase separator to produce a vapour stream (\#3) and a condensate with two liquid phases. The aqueous phase is separated from the condensate and sent together with scrubber water and methanol stream to the aforementioned stripper. The organic layer is stripped in a separate column and the produced organic concentrate is sent downstream to the depropanizer (labelled DE-C3).

Residual acid gases in stream \#3 are removed using a caustic wash operating with a $50 \mathrm{wt} \%$ aqueous caustic solution. The acid-free vapour is then cooled to $22^{\circ} \mathrm{C}$ and dried with a molecular sieve. The dried gas is further cooled to $10^{\circ} \mathrm{C}$ and sent to a de-ethanizer (DE-C2) where the majority of ethylene is recovered overhead and most of the propylene from the bottom (condenser temperature $-36^{\circ} \mathrm{C}$, boiler temperature $63^{\circ} \mathrm{C}$ ). After this point, the process separates into two downstream upgrading sections, one for the overhead stream and one for the bottom stream. 


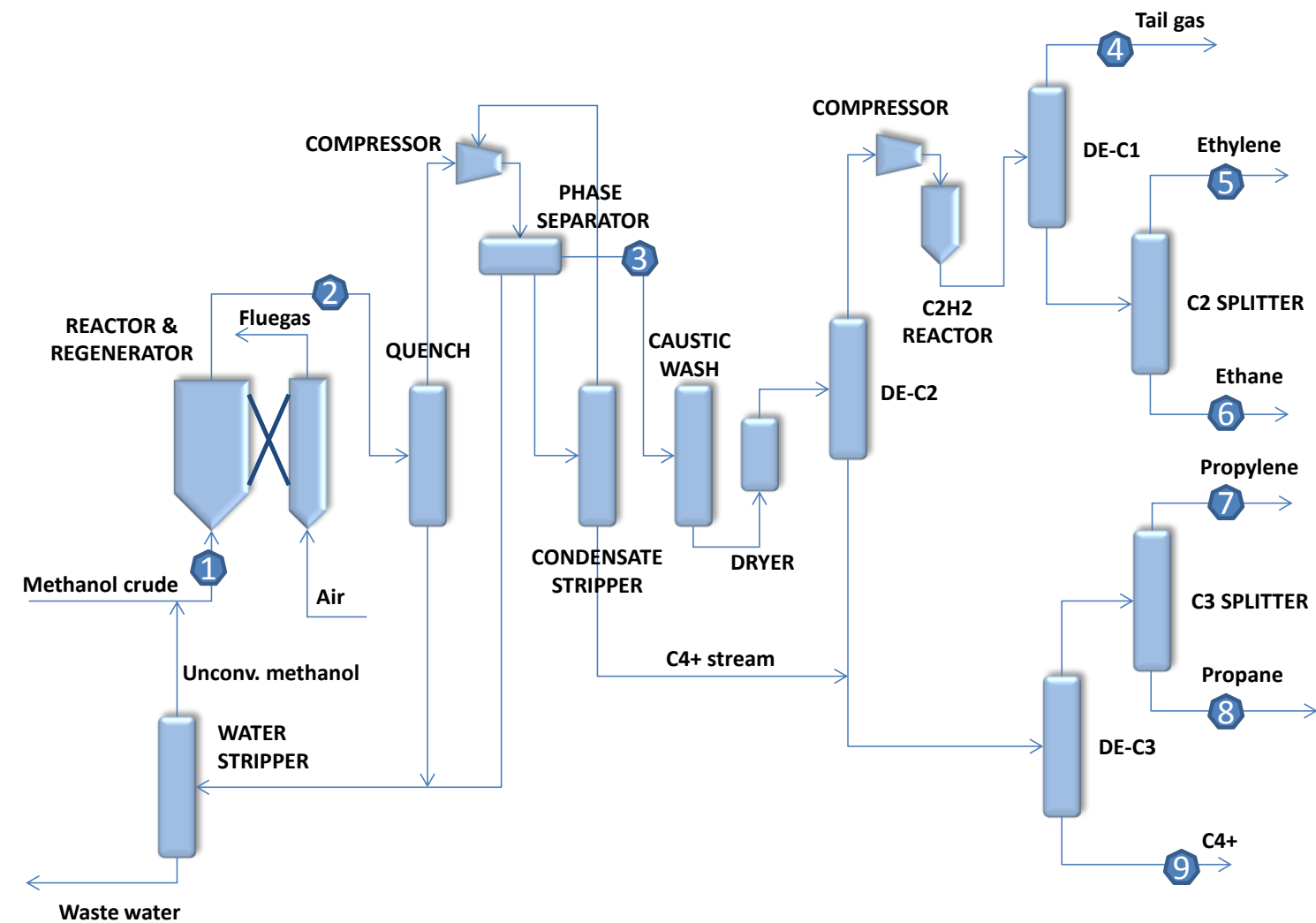

Figure 4. Simplified flowsheet of the MTO process.

Table 3. Simulation results of major MTO process streams as depicted in Figure 4. Compositions are given in mass fractions (residual concentrations smaller than $0.1 \%$ are omitted for the sake of readability).

\begin{tabular}{|l|c|c|c|c|c|c|c|c|c|}
\multicolumn{1}{l}{ Stream No: } & $\mathbf{1}$ & $\mathbf{2}$ & $\mathbf{3}$ & $\mathbf{4}$ & $\mathbf{5}$ & $\mathbf{6}$ & $\mathbf{7}$ & $\mathbf{8}$ \\
\hline $\mathrm{H}_{2}$ & & 0.5 & 1.3 & 26.9 & & & & & \\
$\mathrm{CO}$ & 0.9 & 0.2 & 0.5 & 6.1 & & & & & \\
$\mathrm{CO}_{2}$ & 1.0 & 0.1 & 0.2 & & & & & & \\
METHANE & & 0.7 & 2.2 & 43.7 & & & & & \\
ETHYLENE & & 14.4 & 42.0 & 4.3 & 99.8 & 17.3 & & & \\
ETHANE & & 0.3 & 0.9 & & 0.2 & 65.7 & & & \\
PROPYLEN & & 14.4 & 41.2 & & & 17.0 & 99.5 & 32.8 & 1.4 \\
PROPANE & & 0.2 & 0.6 & & & & 0.5 & 57.8 & 0.1 \\
BUTYLENE & & 4.2 & 8.7 & & & & & 9.4 & 78.0 \\
BUTANE & & & 0.1 & & & & & & 0.6 \\
C5+ & & 1.2 & 1.4 & & & & & & 19.7 \\
METHANOL & 80.8 & 0.2 & & & & & & & 0.2 \\
WATER & 17.0 & 63.2 & & & & & & & \\
NITROGEN & 0.2 & 0.2 & 0.6 & 13.1 & & & & & \\
ARGON & 0.1 & 0.1 & 0.3 & 5.9 & & & & & \\
\hline SUM & 100.0 & 100.0 & 100.0 & 100.0 & 100.0 & 100.0 & 100.0 & 100.0 & 100.0 \\
\hline Temp, C & 310 & 410 & 39 & -117 & -12 & 9 & 50 & 58 & 124 \\
Pres, bar & 3.5 & 3.3 & 25.2 & 31.4 & 31.0 & 31.0 & 20.7 & 20.7 & 24.1 \\
\hline
\end{tabular}

The overhead vapour is compressed to 33 bar and sent through an acetylene converter $(\mathrm{C} 2 \mathrm{H} 2$ REACTOR), which hydrogenates the small amount of acetylene produced in the MTO reactor to ethane over a palladium-based catalyst. The acetylene-free effluent is then cooled to $-20^{\circ} \mathrm{C}$ and fed to a de-methanizer (DE-C1) that produces methane rich vapour overhead (\#4) and a mixture of $\mathrm{C} 2$ hydrocarbons from the bottom. Very low temperatures (around $-60^{\circ} \mathrm{C}$ ) are needed to carry out this separation and ethylene refrigeration is thus required in the condenser.

The $\mathrm{C} 2$-stream from the bottom is directed to a $\mathrm{C} 2$-splitter column that produces a polymer-grade ethylene stream overhead (\#5) and an ethane rich (about $70 \mathrm{~mol} \%$ ) by-product stream from the bottom (\#6). The bottom stream from the de-ethanizer (DE-C2) is mixed with the bottoms from the 
aforementioned organic layer stripper (CONDENSATE STRIPPER) and sent to a de-propanizer (DE$\mathrm{C} 3$ ). The DE-C3 overhead stream goes to a large C3-splitter producing polymer-grade propylene (\#7) overhead and a propane-rich (around $50 \mathrm{~mol} \%$ ) by-product (\#8) from the bottom. The DE-C3 bottoms (stream \#9) consists of the heavy hydrocarbons formed in the MTO reactor and could be characterized as a ' $\mathrm{C} 4+$ stream'. The total propylene yield of the process could be further boosted by cracking this $\mathrm{C} 4+$ stream, but we have chosen not to include this option because of the interest in co-producing significant electricity fractions along with light olefins.

The light-gas by-product streams generated in the MTO process (steams 4, 6, 8, and 9) are collected and mixed with the purge gas stream (not shown in Figure 4) from the methanol synthesis recycle loop and with the syngas that bypasses the synthesis area altogether (see Figure 2). This collection of fuel gases is burned in the gas turbine combined cycle power island.

\section{Performance Simulation Results}

Mass and energy balance simulations based on flowsheets developed using Aspen Plus software are summarized in Table 4 for the five process designs identified in Table 2. Key performance metrics reported there include overall energy efficiency and the greenhouse gas emissions index (GHGI). As discussed in Appendix B, the GHGI is defined as the lifecycle GHG emissions for the process design under consideration divided by the lifecycle GHG emissions of a reference system. We define the latter to consist of a system that produces the same amount of electricity and olefin products as the co-production system, but using conventional resources and technologies. For conventional electricity generation, we assume GHG emissions of $636 \mathrm{kgCO}_{2} \mathrm{e} / \mathrm{MWh}$, the U.S. grid-average emissions rate in 2007 (based on the GREET model). Reliable studies that estimate GHG emissions for conventional olefins production could not be found in the literature, so we developed an independent estimate of the lifecycle GHG emissions for

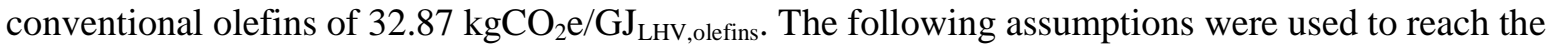
estimate of lifecycle $\mathrm{GHG}$ emissions for conventional olefins:

- An estimate, based on Ren et al. (2006), ${ }^{8}$ of $16.93 \mathrm{kgCO}_{2} \mathrm{e} / \mathrm{GJ}_{\text {olefins,LHV }}$ of process-related emissions for ethylene production by steam cracking of ethane derived from natural gas.

- Emissions associated with natural gas extraction and delivery to liquid fuels production plant of $15.94 \mathrm{kgCO}_{2} \mathrm{e} / \mathrm{GJ}_{\text {natural gas,LHV }}$ based on the GREET 2011 model. ${ }^{9} \mathrm{We}$ assumed this to be a good approximation for the upstream emissions associated with natural gas derived ethane.

- It is assumed that the end-products manufactured using the olefins are ultimately landfilled, effectively storing away from the atmosphere the contained carbon and thus yielding no additional emissions.

The CTO-EF50 design production capacities are 705 metric tonnes of olefins (half ethylene and half propylene) and $383 \mathrm{MW}$ of electricity exports, representing an EF of 50\%. With 6,039 metric tonnes per day of coal input, the overall efficiency of coal conversion to saleable products is $42 \%$. In this design, $72 \%$ of the input carbon is captured as $\mathrm{CO}_{2}$ and stored away from the atmosphere, and only $11 \%$ of the input carbon ends up in the atmosphere. The result is a surprisingly low GHGI of 0.31 , or nearly a $70 \%$ reduction in GHG emissions relative to the reference system.

For the CTO-EF25 design, the lower EF means more of the available syngas is converted to olefins than in the CTO-EF50 design. Since syngas conversion to olefins is intrinsically more efficient than conversion to electricity, the overall efficiency is several percentage points higher than for the CTO-EF50 case. A net of $14 \%$ of the input carbon is vented to the atmosphere. The GHGI for the CTO-EF25 case, 0.49, is higher than for the CTO-EF50 because the demoninator of the GHGI is much greater in the CTO-EF50 case (due to the relatively low GHG intensity we have assumed for conventional olefin production) while the numerator is not significantly different from that for the

\footnotetext{
${ }^{8}$ Ren, T., Patel, M., Blok, K., "Olefins from conventional and heavy feedstocks: Energy use in steam cracking and alternative processes,” Energy, 31(4): 425-451, March 2006.

${ }^{9}$ GREET model version 2011_1 downloaded from http://greet.es.anl.gov/ (October 2011).
} 
CTO-EF25 case. Nevertheless, the GHGI of 0.49 represents close to a $50 \%$ reduction in emissions relative to the reference system.

Table 4. Mass and energy balances for coproduction of electricity and olefins from coal and/or biomass feedstocks with capture and storage of byproduct $\mathrm{CO}_{2}$.

\begin{tabular}{|c|c|c|c|c|c|}
\hline \multirow[b]{2}{*}{ CASE } & \multicolumn{2}{|c|}{$\mathrm{BF}=0.0$} & \multicolumn{2}{|c|}{$\mathrm{BF}=0.30$} & \multirow{2}{*}{$\begin{array}{r}\mathrm{BF}=0.05 \\
\mathrm{CBTO} \\
\mathrm{EF} 25 \mathrm{LB}\end{array}$} \\
\hline & $\begin{array}{l}\text { CTO- } \\
\text { EF50 }\end{array}$ & $\begin{array}{l}\text { CTO- } \\
\text { EF25 }\end{array}$ & $\begin{array}{l}\text { CBTO- } \\
\text { EF5OHB }\end{array}$ & $\begin{array}{r}\text { CBTO- } \\
\text { EF25HB }\end{array}$ & \\
\hline \multicolumn{6}{|l|}{ Feedstocks } \\
\hline Coal input, AR mt/day Illinois \#6 bit. & 6039 & 6039 & 4639 & 4639 & 4639 \\
\hline Coal input, MW (HHV) & 1895 & 1895 & 1456 & 1456 & 1456 \\
\hline Biomass input, AR metric $t /$ day $^{a}$ & 0 & 0 & 3805 & 3805 & 467 \\
\hline Biomass input rate, $\mathrm{MW}(\mathrm{HHV})^{\mathrm{a}}$ & 0 & 0 & 624 & 624 & 77 \\
\hline \multicolumn{6}{|l|}{ Electricity balance, $\mathrm{MW}_{\mathrm{e}}$} \\
\hline Gross production & 591 & 405 & 618 & 435 & 332 \\
\hline Gas turbine & 352 & 219 & 356 & 225 & 176 \\
\hline Expander(s) & 8 & 4 & 8 & 4 & 3 \\
\hline Steam turbine & 231 & 182 & 254 & 206 & 153 \\
\hline On-site consumption & 207 & 189 & 229 & 223 & 162 \\
\hline Net exports to grid & 383 & 216 & 390 & 212 & 170 \\
\hline \multicolumn{6}{|l|}{ Olefins production } \\
\hline Ethylene/Propylene ratio (wt basis) & 1 & 1 & 1 & 1 & 1 \\
\hline Olefins, mt/day & 705 & 1226 & 705 & 1219 & 965 \\
\hline Olefins, MW (HHV) & 405 & 704 & 405 & 700 & 554 \\
\hline Olefins, MW (LHV) & 379 & 659 & 379 & 655 & 518 \\
\hline \multicolumn{6}{|l|}{ Energy ratios } \\
\hline Olefins out (LHV) / Energy in (LHV) & 0.210 & 0.365 & 0.196 & 0.338 & 0.356 \\
\hline Net electricity / Energy in (LHV) & 0.212 & 0.120 & 0.201 & 0.109 & 0.117 \\
\hline Total efficiency (HHV) & $42.2 \%$ & $48.4 \%$ & $39.7 \%$ & $44.8 \%$ & $47.3 \%$ \\
\hline Electricity fraction, LHV & 0.50 & 0.25 & 0.50 & 0.25 & 0.25 \\
\hline \multicolumn{6}{|l|}{ Carbon accounting } \\
\hline C input in coal, tonne/hr & 160 & 160 & 123 & 123 & 123 \\
\hline C input in biomass, tonne/hr & 0 & 0 & 61 & 61 & 7 \\
\hline C stored as $\mathrm{CO}_{2}, \%$ of feedstock $\mathrm{C}$ & 72 & 58 & 72 & 59 & 59 \\
\hline C in char, $\%$ of feedstock C & 1.02 & 1.02 & 0.97 & 0.97 & 1.01 \\
\hline C vented to atm, \% of feedstock C & 11 & 14 & 14 & 16 & 14 \\
\hline C in olefins, $\%$ of feedstock $C$ & 16 & 27 & 14 & 24 & 26 \\
\hline GHGI & 0.31 & 0.49 & -0.34 & -0.39 & 0.36 \\
\hline
\end{tabular}

(a) Biomass quantities and energy contents are prior to torrefaction.

The CBTO-EF50HB design produces the same electricity and olefin outputs but does so using a 30\% biomass input fraction. As discussed in Appendix A, the use of torrefied biomass in the entrained flow gasifier leads to a reduction in the cold gas efficiency of torrefaction + gasification, and this decrease propagates through the full system, resulting in an overall efficiency 2.5 percentage points lower than for the CTO-EF50 system. Substituting some biomass for coal results in a negative GHGI of -0.34 due to the sequestering from the atmosphere (either via underground $\mathrm{CO}_{2}$ storage or via ultimate landfilling of olefin-derived products) some photosynthetically derived carbon.

In the CBTO-EF25HB case, BF is kept at $30 \%$ but the electricity fraction is lowered to $25 \%$, which contributes to a $5 \%$ percentage point rise in total efficiency. A larger fraction of input carbon is locked up in the olefin product and less carbon is captured as $\mathrm{CO}_{2}$ at the plant. A net of $16 \%$ of input carbon is vented to the atmosphere. The GHGI for the CBTO-EF25HB is -0.39 .

Finally, in the CBTO-EF25LB design, both the output electricity fraction and the input biomass fraction are reduced. The inclusion of this case was motivated by a desire to better understand the effect of BF on the costs and performance characteristics of these co-production plants. The overall efficiency is increased by 7.5 percentage points compared with the CBTO-EF50HB case, and the GHGI increases to 0.36 . However, the GHGI is still $27 \%$ lower than the value for the CTOEF25 design, i.e. a notable decrease in emissions is achieved by feeding only $5 \%$ biomass in comparison to the coal-only case. 


\section{Capital Cost Estimates and Economic Analysis}

The Princeton capital cost database described in a prior publication ${ }^{10}$ was extended to include installed cost estimates for the UOP/Hydro MTO process, based on cost estimates published by Wan. ${ }^{6}$ Reference costs, capacities, and scaling exponents for the methanol conversion area and for the product separation area (see Table 5 in Appendix B) were integrated into the Princeton capital cost model to estimate total installed capital costs for the five plant designs (Table 5, below).

The capital cost estimates, together with operating and maintenance costs, feedstock costs, and $\mathrm{CO}_{2}$ storage costs were combined to estimate levelized costs of production assuming an annual average capacity factor of $90 \%$. Annual operating and maintenance costs are assumed to be $4 \%$ of the overnight installed cost (TPC in Table 5). Assumed coal and biomass prices are $\$ 2.04 / \mathrm{GJ}_{\mathrm{HHV}}$ and $\$ 5 / \mathrm{GJ}_{\mathrm{HHV}}$, respectively. The costs for pipeline transmission plus underground storage of $\mathrm{CO}_{2}$ are estimated as described in Appendix B.

Table 5. Total installed capital costs (million 2007 \$) for the coproduction systems in Table 4.

\begin{tabular}{|c|c|c|c|c|c|}
\hline \multirow[b]{2}{*}{ CASE } & \multicolumn{2}{|c|}{$\mathrm{BF}=0.0$} & \multicolumn{2}{|c|}{$B F=30 \%$} & \multirow{2}{*}{$\begin{array}{r}\text { BF }=5 \% \\
\text { CBTO- } \\
\text { EF25LB }\end{array}$} \\
\hline & $\begin{array}{l}\text { CTO- } \\
\text { EF50 }\end{array}$ & $\begin{array}{l}\text { CTO- } \\
\text { EF25 }\end{array}$ & $\begin{array}{r}\text { CBTO- } \\
\text { EF50HB }\end{array}$ & $\begin{array}{r}\text { CBTO- } \\
\text { EF25HB }\end{array}$ & \\
\hline Air separation unit & 244 & 238 & 265 & 259 & 167 \\
\hline Biomass drying, torrefaction, prep. & 0 & 0 & 84 & 84 & 16 \\
\hline Coal handling, drying, co-gasification & 613 & 613 & 636 & 636 & 543 \\
\hline Syngas cleanup & 339 & 316 & 334 & 313 & 274 \\
\hline $\mathrm{CO}_{2}$ compression & 26 & 23 & 29 & 25 & 20 \\
\hline Methanol synthesis & 83 & 287 & 84 & 316 & 245 \\
\hline Methanol to olefins plant & 81 & 123 & 81 & 123 & 103 \\
\hline Gas turbine topping cycle & 204 & 130 & 207 & 134 & 109 \\
\hline Heat recovery and steam cycle & 206 & 182 & 212 & 188 & 150 \\
\hline Total plant cost, TPC & 1796 & 1912 & 1932 & 2078 & 1626 \\
\hline Total plant investment, TPI (includes AFUDC) & 1925 & 2049 & 2070 & 2227 & 1743 \\
\hline
\end{tabular}

From the above performance and cost estimates, we calculated three metrics to assess the overall economics of the simulated designs: levelized cost of olefins (LCOO), levelized cost of electricity (LCOE), and internal rate of return on equity (IRRE). LCOO values were estimated by assuming revenues of $\$ 60 / \mathrm{MWh}$ from the sale of co-product electricity, the average sale price to the grid in the U.S. in 2007. LCOE values were estimated assuming average revenues of $\$ 0.52 / \mathrm{lb}$ from the sale of the co-product olefins, the average benchmark contract price for ethylene and propylene (in a 1:1 ratio) in 2010 (Table 6), expressed in 2007 dollars. A second set of results was generated assuming $\$ 0.75 / \mathrm{lb}$ for olefins, the projected price for 2015 (Table 6). Figure 5 provides a longer-term perspective on our assumed olefin prices. The forecast 2015 price in the case of propylene is relatively high in comparison to the past 20 years. Forecast ethylene prices seem representative of price levels observed in recent years.

Table 6. Current-dollar benchmark contract olefin prices in 2010 (actual) and in 2015 (projected), as reported by CMAI. ${ }^{11}$ The weighted average prices are for a 1:1 weight mix of ethylene and propylene.

\begin{tabular}{|l|cccc|}
\hline Year & $\begin{array}{c}\text { Ethylene } \\
\text { cents/lb }\end{array}$ & $\begin{array}{c}\text { Propylene } \\
\text { cents/lb }\end{array}$ & $\begin{array}{c}\text { Weighted avg. price } \\
\text { cents/lb }\end{array}$ & $\begin{array}{c}\text { Weighted avg. price } \\
\$ / \text { GJ }\end{array}$ \\
\hline 2010 & 49.9 & 59.58 & $\mathbf{5 4 . 7}$ & 25.6 \\
2015 & 67.4 & 81.6 & $\mathbf{7 4 . 5}$ & 34.8 \\
\hline
\end{tabular}

\footnotetext{
${ }^{10}$ Liu, G., Larson, E.D., Williams, R.H., Kreutz, T.G., and Guo, X., "Making Fischer-Tropsch Fuels and Electricity from Coal and Biomass: Performance and Cost Analysis," Energy and Fuels, 2011, 25, 415-437 : DOI:10.1021/ef101184e.

${ }^{11}$ Chemical Market Associates, Inc., "Monomers Market Report," No. 673, CMAI, Houston, TX, 31 March 2011. See also Chemical Market Associates, Inc., "Monomers Market Report Data Supplement," No. 55, CMAI, Houston, TX, 31 March 2011.
} 


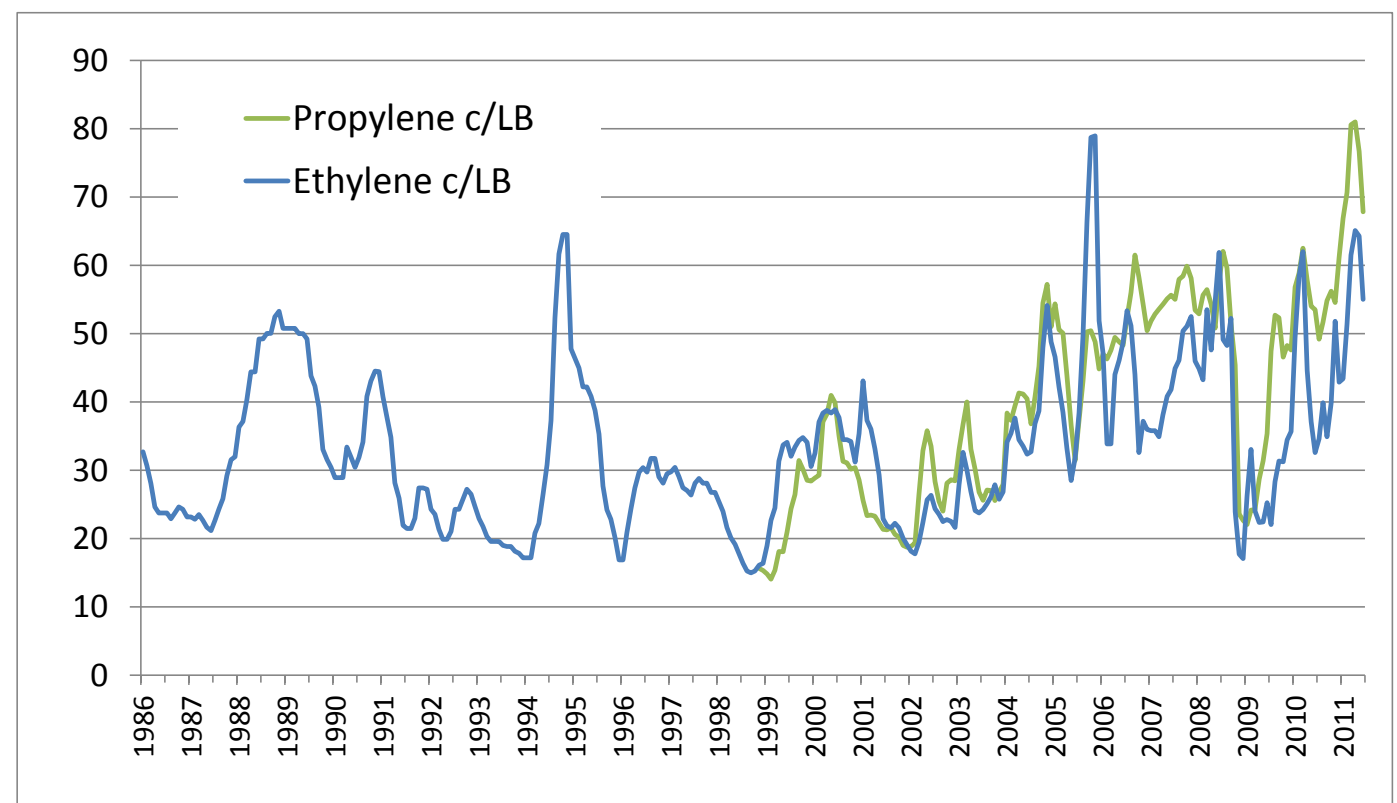

Figure 5. Constant-2007 dollar spot-market prices for ethylene and propylene (Datastream International 2011 ${ }^{12}$ ). These are prices in the U.S. for ethylene and in Europe for propylene. Current-dollar propylene prices were first converted from current-Euro prices using yearly average exchange rates. Current dollar prices for both olefins were then expressed in constant 2007 \$sing the API Producer Price index. ${ }^{13}$

Table 7 shows the cost components of LCOO for the five plant designs, assuming a zero greenhouse gas emissions price. Four important conclusions emerge from the LCOO estimates:

- The LCOO for a CBTO design is higher than for a CTO design having the same EF due largely to higher feedstock costs.

- Comparing CTO-EF50 and CTO-EF25, it can be seen that the lower EF provides for a considerably more competitive LCOO. The same is true for the cases co-processing coal and biomass, CBTO-EF50HB and CBTO-EF25HB.

- Comparing CBTO-EF25HB and CBTO-EF25LB, we notice that lower biomass fraction provides more competitive LCOO mainly due to lower feedstock costs.

- The process designs with EF of 0.25 have LCOO competitive with the average 2010 price of olefins produced conventionally $(\$ 0.52 / \mathrm{lb})$. Among the three EF25 cases the CTO-EF25 design has the lowest LCOO. The LCOO becomes less competitive as the biomass fraction rises. This is due to higher average feedstock costs for higher biomass input fractions. Additionally, in the case of the CBTO-EF25LB the overall plant scale is smaller, contributing reverse scale economy penalties.

Taking the perspective of an electricity generator, Table 7 also shows LCOE estimates. The conclusions parallel those for the LCOO:

- The LCOE for a CBTO design is considerably higher than for a CTO design having the same EF.

- Comparing CTO-EF50 and CTO-EF25, it can be seen that the electricity fraction has a very significant impact on the LCOE. The lower EF provides much lower cost electricity.

- The LCOE for the CTO-EF25 and CBTO-EF25LB designs are competitive with the 2007 gridaverage sale price $(\$ 60 / \mathrm{MWh})$. The LCOE for the CTO case is particularly competitive.

Finally, Table 7 also shows internal rates of return on equity with zero GHG emissions price. As might be expected based on the LCOO and LCOE results described above, the CTO-EF25 case shows the most favorable return (nearly 14\%).

\footnotetext{
${ }^{12}$ Datastream International. (July 22, 2011). Available: Datastream International.

${ }^{13}$ American Petroleum Institute (API), 2010 Basic Petroleum Data Book, API.
} 
Table 7. Levelized cost of olefins production, \$ per $\mathbf{G J}_{\mathrm{LHV}}$, assuming sale of co-product electricity (at \$60/MWh). Levelized cost of electricity production, $\$$ per $\mathrm{MWh}$, assuming sale of co-product olefins (at \$0.52/lb). Zero GHG emissions price assumed in each case. All costs and prices are given in $2007 \$$.

\begin{tabular}{|c|c|c|c|c|c|}
\hline & \multicolumn{2}{|c|}{$\mathrm{BF}=0.0$} & \multicolumn{2}{|c|}{$\mathrm{BF}=\mathbf{3 0} \%$} & \multirow{2}{*}{$\begin{array}{r}\text { BF = } 5 \% \\
\text { CBTO- } \\
\text { EF25LB }\end{array}$} \\
\hline & $\begin{array}{l}\text { CTO- } \\
\text { EF50 }\end{array}$ & $\begin{array}{l}\text { CTO- } \\
\text { EF25 }\end{array}$ & $\begin{array}{r}\text { CBTO- } \\
\text { EF50HB }\end{array}$ & $\begin{array}{r}\text { CBTO- } \\
\text { EF25HB }\end{array}$ & \\
\hline \multicolumn{6}{|l|}{ Levelized Cost of Olefins, LCOO } \\
\hline Installed capital (at $14.38 \%$ of TPI) & 25.72 & 15.74 & 27.67 & 17.22 & 17.02 \\
\hline O\&M (@ 4 \% of TPC per year) & 6.68 & 4.09 & 7.18 & 4.47 & 4.42 \\
\hline Coal (at $\left.2.04 \$ / G J_{H H V}\right)$ & 10.17 & 5.85 & 7.82 & 4.52 & 5.71 \\
\hline Biomass (at $5 \$ / \mathrm{GJ}_{\mathrm{HHV}}$ ) & 0.00 & 0.00 & 8.23 & 4.76 & 0.74 \\
\hline $\mathrm{CO}_{2}$ disposal (at $6.8 \$ /$ tonne $\mathrm{CO}_{2}$ ) & 2.25 & 1.27 & 2.61 & 1.49 & 1.48 \\
\hline Co-product electricity (@\$60/MWh) & -16.85 & -5.47 & -17.13 & -5.40 & -5.46 \\
\hline \multirow[t]{3}{*}{ Levelized cost of olefins $\quad \$ / G J_{L H V}$} & 27.97 & 21.48 & 36.37 & 27.06 & 23.91 \\
\hline & 1319 & 1014 & 1716 & 1277 & 1128 \\
\hline & 0.60 & 0.46 & 0.79 & 0.58 & 0.51 \\
\hline \multicolumn{6}{|c|}{ Levelized Cost of Electricity Production, LCOE } \\
\hline Olefin revenue (@ $\$ 0.52 / \mathrm{lb}), \$ / G J_{L H V}$ & 24.5 & 24.5 & 24.5 & 24.5 & 24.5 \\
\hline LCOE, \$/MWh & 72 & 27 & 102 & 88 & 54 \\
\hline IRRE, \%/yr & 7.1 & 13.8 & 0 & 6.7 & 10.6 \\
\hline
\end{tabular}

The results in Table 7 assume a zero greenhouse gas emissions price. The impact of a GHG price is shown in Figure 6. The left graph assumes an olefin sale price of $\$ 0.52 / \mathrm{lb}$, representing the average 2010 olefin price level (in $2007 \$$ ). The right graph assumes $\$ 0.75 / \mathrm{lb}$, representing olefin price levels that might be reached in the coming decade (Table 6). The CTO cases show only a modest change with GHG emission price due to the assumed end-of-life sequestering of the carbon contained in the olefins. The LCOE for the CTO-EF25 case is the lowest of all five cases until a GHG emissions price of about $\$ 70 / \mathrm{tCO}_{2} \mathrm{e}$ is reached. The CBTO cases with high biomass fraction (HB) (dashed lines) decline with GHG emissions price due to the negative emissions contributed by the use of biomass. The LCOE for the CBTO-EF25HB becomes the lowest among all cases at about $\$ 70 / \mathrm{tCO}_{2} \mathrm{e}$ and is below $\$ 20 / \mathrm{MWh}$ at a GHG emission price of $\$ 100 / \mathrm{tCO}_{2} \mathrm{e}$. Finally, a GHG price of about $\$ 20 / \mathrm{tCO}_{2} \mathrm{e}$ is sufficient to make all but the CBTO-EF50-HB case competitive with a new coal fired plant (PC-V). The CBTO-EF50HB case requires a still-modest $\$ 35 / \mathrm{tCO}_{2}$ e to be competitive with the PC-V plant.
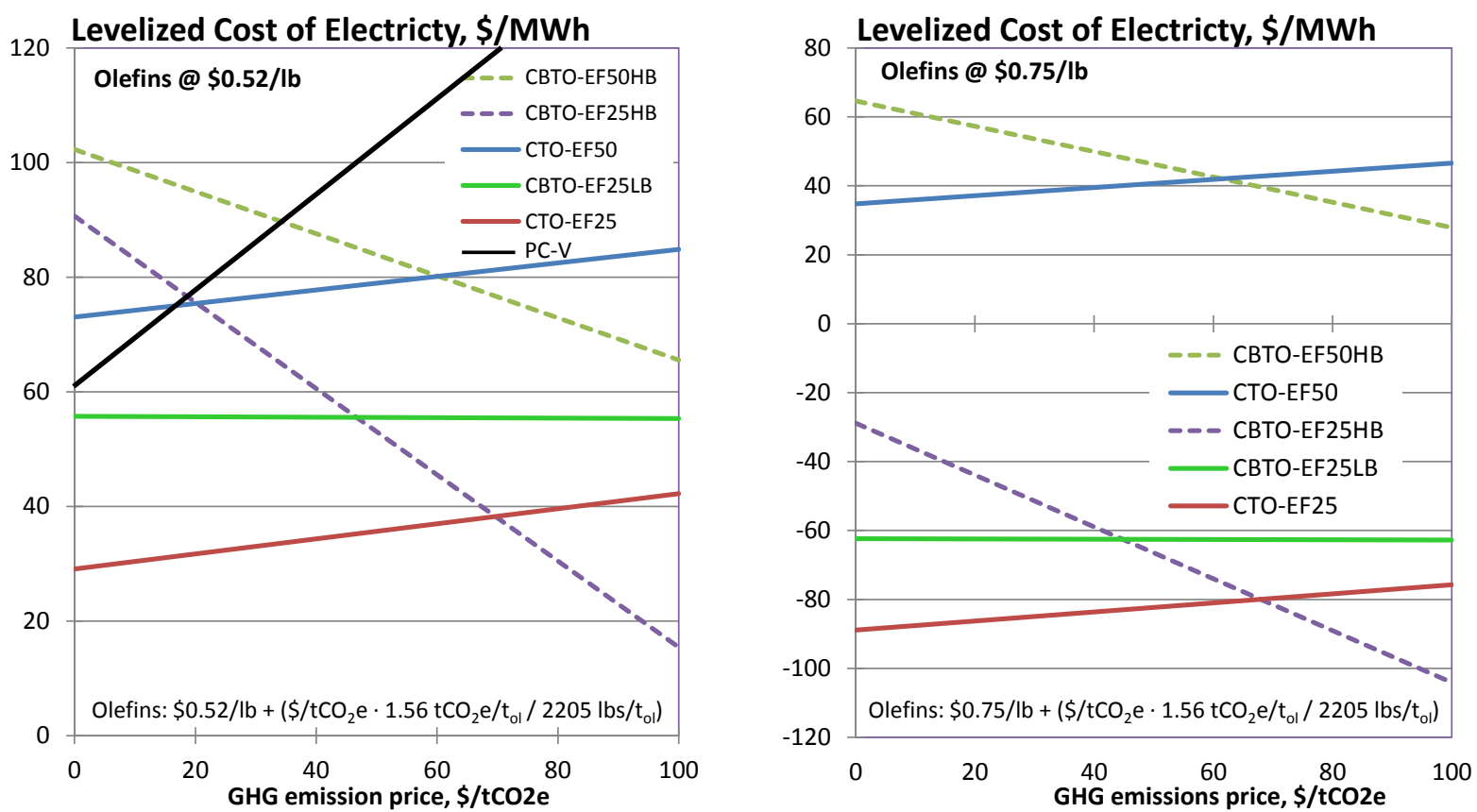

Figure 6. $\mathrm{LCOE}$ versus greenhouse gas emissions price for olefin sale price of $\$ 0.52 / \mathrm{lb}$ (left) and $\$ 0.75 / \mathrm{lb}$ (right) plus a GHG emissions charge of $32.87 \mathrm{kgCO}_{2} \mathrm{e} / \mathrm{GJ}_{\mathrm{LHV} \text {,olefins. }}$ Also shown on the left is the $\mathrm{LCOE}$ for a new supercritical pulverized coal plant with venting of CO2. The LCOE for the PC-V incurs a GHG emission charge of 831 $\mathrm{kgCO}_{2} \mathrm{e} / \mathrm{MWh}$, the estimated lifecycle emissions for a supercritical pulverized coal plant. 
The dramatically lower LCOE's in the right graph of Figure 6 indicate that LCOE's are quite sensitive to olefin price. This sensitivity is quantified in Figure 8. Not surprisingly, the cases with high olefin output fraction (CTO-EF25, CBTO-EF25HB, and CBTO-EF25LB) have LCOE's that are the most sensitive to olefin price. Also not surprisingly, changing the GHG price from zero to $\$ 100 / \mathrm{tCO}_{2} \mathrm{e}$ shifts the LCOE most significantly for the high biomass cases (CBTO-EF50HB and CBTO-EF25HB).

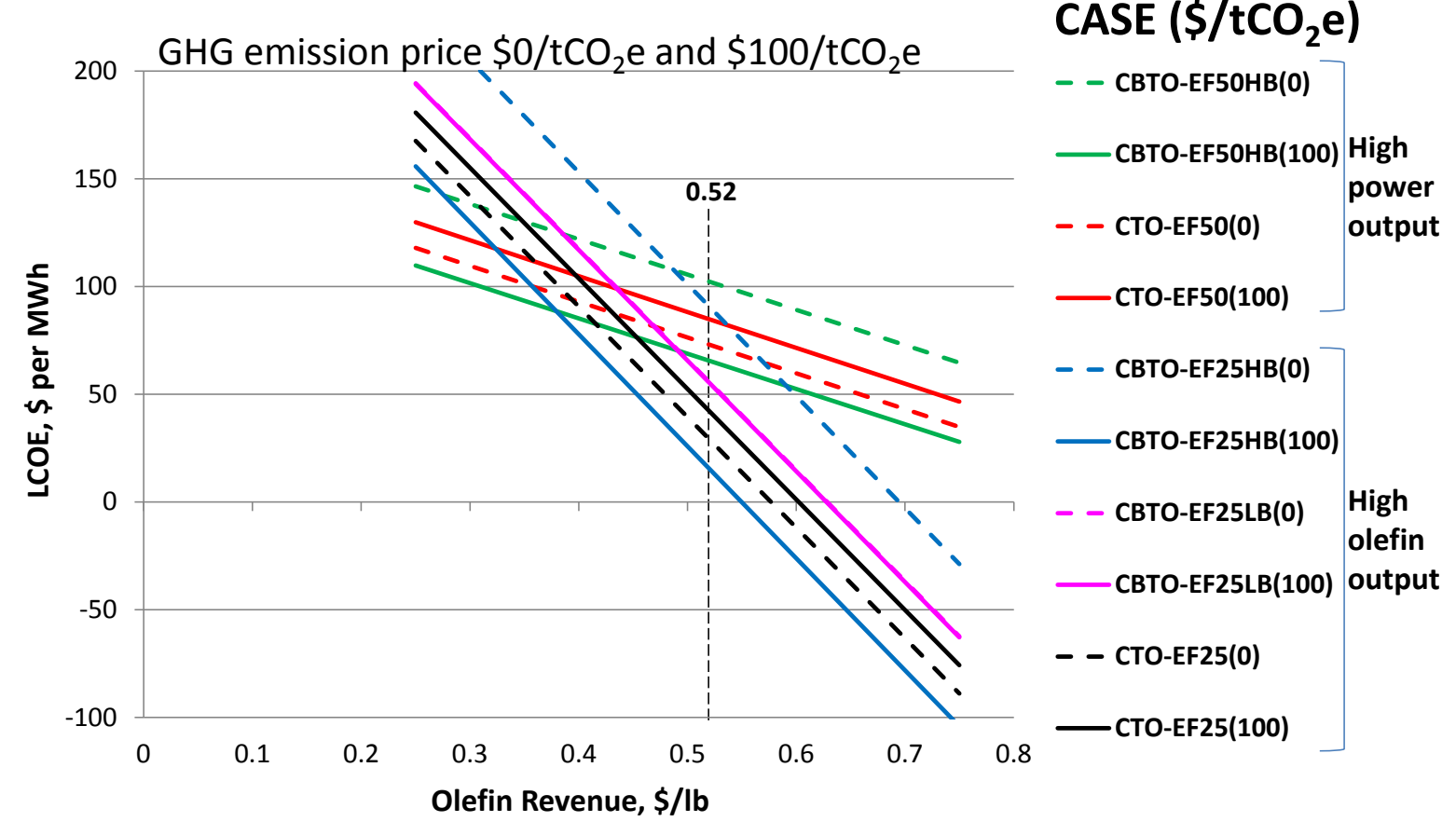

Figure 7. LCOE as a function of olefin price for zero greenhouse gas emissions price (dashed lines) and for $\$ 100 / \mathrm{CO}_{2} \mathrm{e}$ emissions price.

Figure 8 shows levelized costs of olefins production, considering a credit for electricity coproduct sales. Somewhat surprisingly, the LCOO in all cases decreases with increasing GHG emission price. This result comes about because the value of the electricity coproduct is strongly dependent on the GHG emission charge due to the relatively high U.S. grid-average emissions intensity (636 $\mathrm{kgCO}_{2} \mathrm{e} / \mathrm{MWh}$ ), reaching $\$ 124 / \mathrm{MWh}$ at $\$ 100 / \mathrm{tonCO}_{2} \mathrm{e}$. And because the electricity co-product in our process designs is highly decarbonised, the emissions charge for the co-production plants rises much more slowly with GHG emissions price than the revenues from electricity sales. This phenomenon is most clearly evident in the case with high electricity and biomass fractions (CBTO-EF50HB): the LCOO is uncompetitive at zero GHG emission price, but becomes the lowest among all cases for a GHG emissions price above $\$ 60 / \mathrm{tCO}_{2} \mathrm{e}$.

Finally, Figure 9 shows internal rates of return as a function of the olefin selling price and for two different GHG emission prices $\left(\$ 0\right.$ and $\$ 100 / \mathrm{tCO}_{2} \mathrm{e}$ ). With zero GHG emission price (dashed lines), the cases with the highest olefin output fraction and lowest biomass input fractions give the highest returns. With $\$ 100 / \mathrm{tCO} 2 \mathrm{GHG}$ price (solid lines), the IRRE increases in all cases, and the ordering of IRREs changes with the olefin price. The biggest increases in IRRE in going from $\$ 0$ to $\$ 100 / \mathrm{CO}_{2} \mathrm{e}$ are seen in the two high-biomass cases (CBTO-EF50HB and CBTO-EF25HB), the blue and green pairs of lines in Figure 9. 


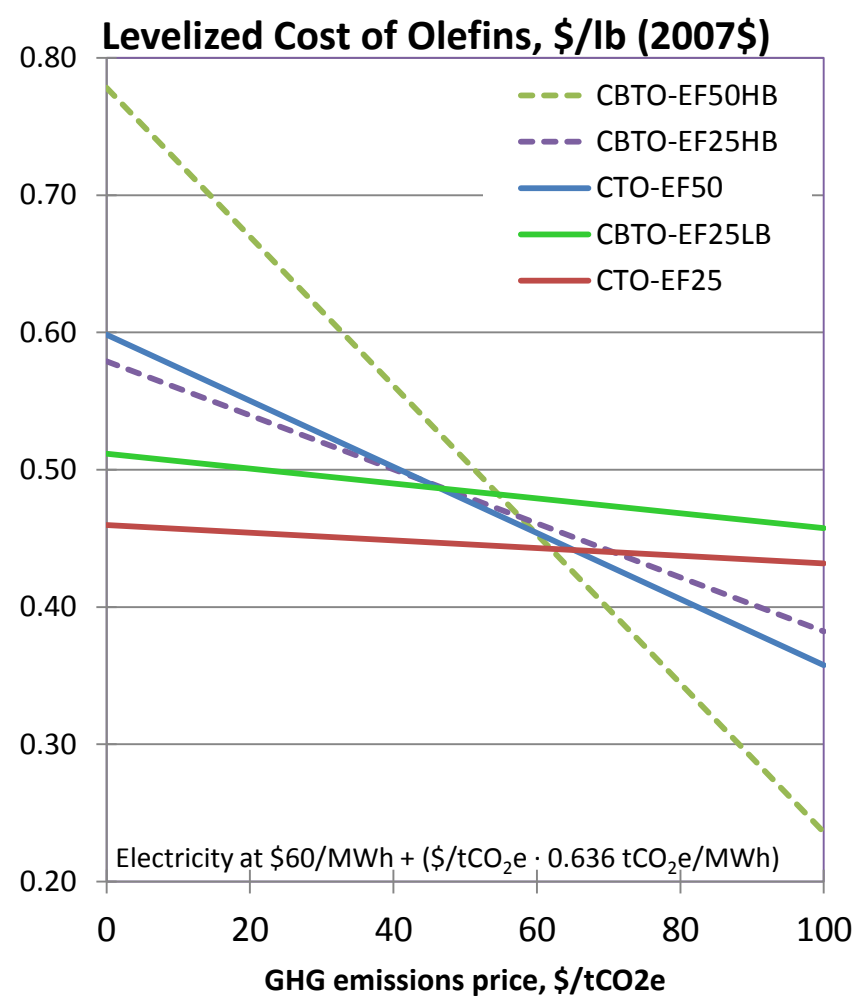

Figure 8. Levelized average olefin costs calculated assuming by-product electricity is sold for $\$ 60 / \mathrm{MWh}$ plus a GHG emissions charge of $636 \mathrm{kgCO}_{2} \mathrm{e} / \mathrm{MWh}$, the grid-average lifecycle GHG emissions rate for electricity generators in the U.S. in 2007.

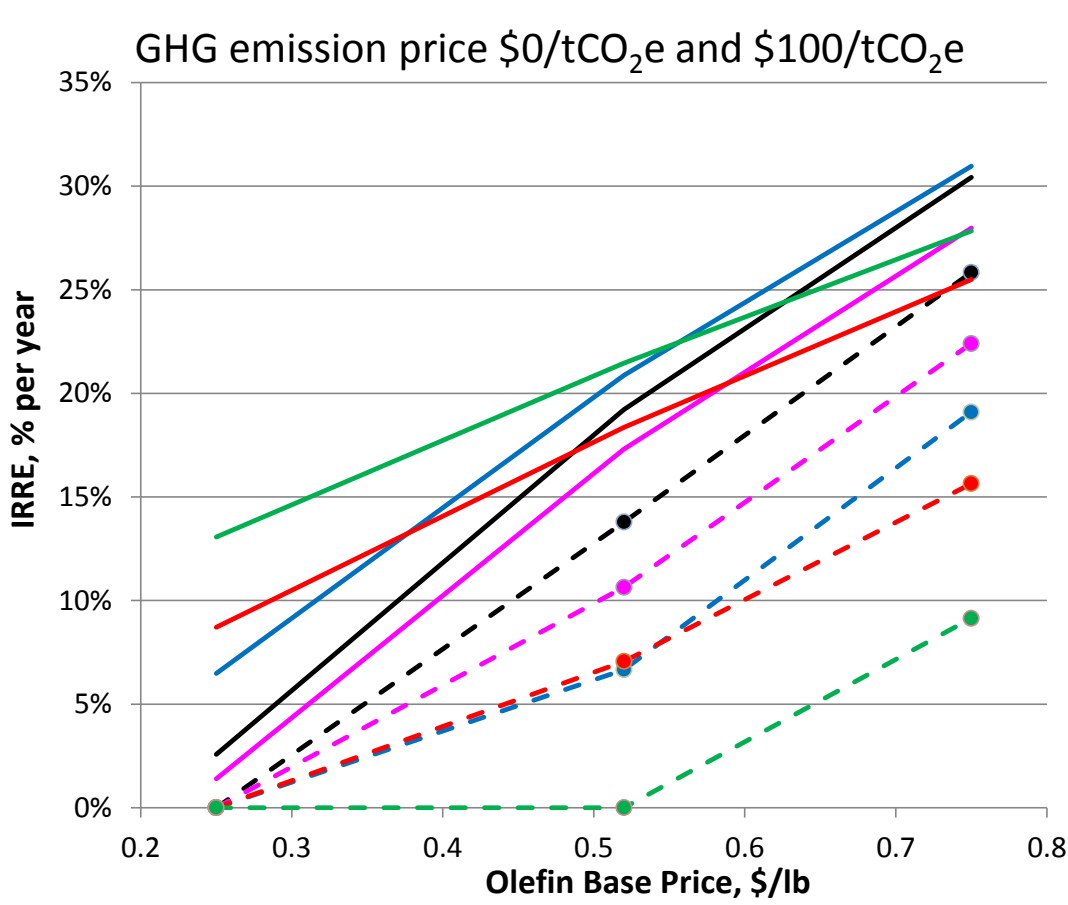

CASE $\left(\$ / \mathrm{tCO}_{2} \mathrm{e}\right)$

-๑- CTO-EF25(0)

_CTO-EF25(100)

-o- CBTO-EF25LB(0) High

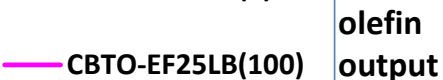

-๑- CBTO-EF25HB(0)

—CBTO-EF25HB(100)

-๑- CTO-EF50(0)

—CTO-EF50(100)

High

power

-๑- CBTO-EF50HB(0) output

Figure 9. Internal rates of return on equity for olefin-electricity co-production for zero and $\$ 100 / \mathrm{tCO}_{2} \mathrm{e} \mathrm{GHG}$ emissions price. IRRE is shown as a function of the olefin base price (to which a GHG emissions charge is added in the case with $\$ 100 / \mathrm{tCO}_{2} \mathrm{e}$ GHG emissions price). 


\title{
Appendix D
}

\section{Preliminary Assessments of: Coal to Electricity plus Ammonia with CCS, and Coal to Electricity plus Hydrogen with CCS}

\author{
Thomas G. Kreutz
}

\section{Contents}

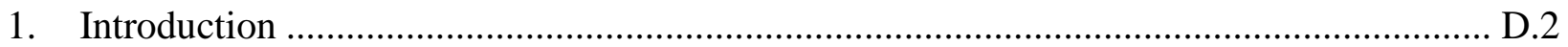

2. Conversion of Coal to Electricity and Ammonia with CCS ........................................... D.2

2.1 Electricity and $\mathrm{NH}_{3}$ Coproduction, Steady-State ............................................... D. 3

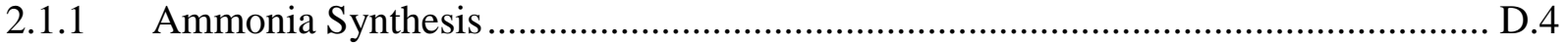

2.1.2 Modeling the Ammonia Synthesis Loop ............................................................ D.6

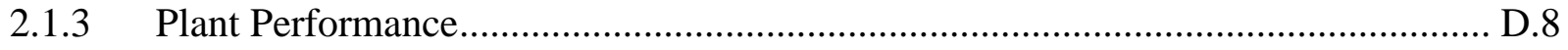

2.1.4 Co-Product Values........................................................................................... D.

2.1.5 Plant Economics .................................................................................... D. 10

2.2 Time-Dependent ("Flexible") Co-Product Generation ......................................... D. 12

2.2.1 Background........................................................................................... D. 12

2.2.2 A "Flexible" Ammonia + Electricity "Hybrid" Plant.......................................... D.13

2.2.3 “Threshold” Electricity Price ............................................................................. D.14

2.2.4 Economic Analysis: 2-State "Square Wave” Electricity Price Model .................. D.16

2.2.5 Economic Analysis: "Sine Wave” Electricity Price Model................................. D.18

2.2.6 Economic Analysis using Raw Electricity Prices........................................... D.20

2.2.7 Peak Power Generation Using Incremental Equipment ................................... D.21

3. Conversion of Coal to Electricity and $\mathrm{H}_{2}$ with $\mathrm{CO}_{2}$ Capture and Storage ..................... D.22

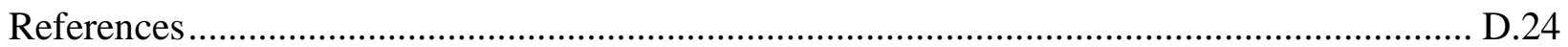




\section{Introduction}

This appendix describes two sets of preliminary performance and cost evaluations relating to the coproduction of electricity and ammonia from coal with CCS and one set of analyses relating to coproduction of electricity and hydrogen from coal with CCS. The electricity/ammonia analyses include one set of cases for steady-state plant operation and a second set that examines the potential impacts of time-varying production rates aimed at capitalizing on higher electricity sale prices during peak electricity demand periods to improve overall plant economics. The electricity/hydrogen analysis considers only steady-state plant operation.

\section{Conversion of Coal to Electricity and Ammonia with CCS}

Our simulation and analysis of electricity/ammonia co-production from coal with CCS is based on a design developed from an underlying process design we developed for a coal-IGCC system with CCS. The latter is shown in Fig. 1a and described in detail (as case "SE") in Martelli (2011). In brief, bituminous coal is milled, dried to a moisture level of $2 \% \mathrm{wt}$, and fed via lockhopper into an O2-blown, pressurized, entrained flow, dry-feed (Shell-type) gasifier, using $\mathrm{N}_{2}$ for pressurization and coal transport. The coal is gasified in the presence of medium pressure (MP) steam and 95\% oxygen from a stand-alone cryogenic air separation unit (ASU).

Gasification is modeled using full chemical equilibrium at 38.5 bara and $1390^{\circ} \mathrm{C}$. Steam-to-oxidant flows are set by maximizing the LHV of the raw synthesis gas exiting the gasifier while fixing the heat

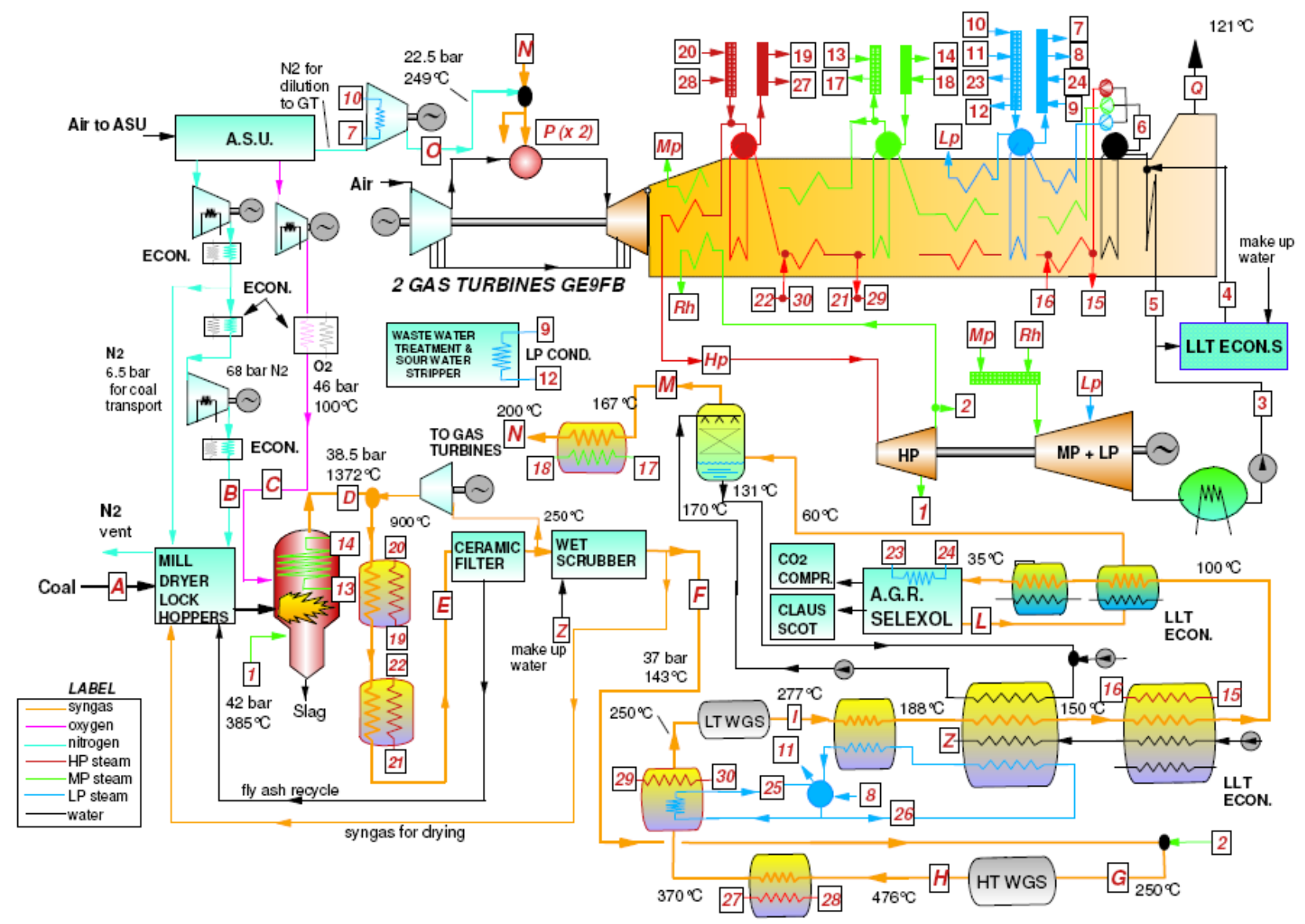

Fig. 1a. Plant schematic for a standard Shell IGCC+CCS with a conventional WGS. (From Martelli, 2011) 
loss to the membrane wall at $1.4 \%$ of the input coal HHV. The single-pass carbon conversion is $97.3 \%$, and by recycling the fly ash (minus $5 \%$ bleed), the overall carbon conversion is $99.8 \%$. Much of the input mineral matter (34.5\%) exits the bottom of the gasifier as a vitreous slag; the remainder is captured as fly ash (after syngas cooling) by a ceramic filter and recycled back to the coal milling/drying unit. Heat for drying is provided by burning $1 \%$ of the scrubbed syngas. Gasifier island parameters were "tuned" to closely match the detailed data on syngas flow and composition from the gasification island provided by Shell [IEA, 2003].

The raw syngas exiting the gasifier is first quenched to $900^{\circ} \mathrm{C}$ (to solidify molten ash) by a stream of recycled, cooled, ash-free syngas and is then cooled to $250^{\circ} \mathrm{C}$ in syngas coolers that economize and evaporate high pressure (HP) feedwater to generate HP steam for the bottoming cycle. Dry particulate filters remove fly ash from the syngas, which is then divided ( $45 \%$ is sent to the recycle compressor for the gas quench) and sent to a countercurrent flow wet scrubber that removes trace particulate matter and water soluble contaminants. The scrubbed syngas is preheated and sent to a water gas shift reactors. The plant shown in Fig. 1 employs a conventional two-stage WGS. For our ammonia-related analysis, we incorporated instead an advanced WGS (Martelli, 2011) consisting of four sequential, adiabatic sour shift reactors, each of which is fed a fraction of the original syngas stream plus the requisite amount of either MP steam (to reactor 1 ) or $160^{\circ} \mathrm{C}$ water (to reactors 2-4) needed to provide a minimum steam-to-CO (S/CO) ratio of 2.5 at the input of each reactor in order to avoid carbon formation on the catalyst. The WGS unit is designed to provide $98 \%$ CO conversion, leading to an overall carbon capture fraction of 93.0\%.

The shifted syngas is cooled to $38^{\circ} \mathrm{C}$, sent to a Selexol acid gas removal (AGR) process for separate removal of $\mathrm{H} 2 \mathrm{~S}$ and $\mathrm{CO} 2$, saturated with water, diluted with $\mathrm{N} 2$, heated to $200^{\circ} \mathrm{C}$, and burned in two GE 9FB gas turbines. The captured $\mathrm{CO} 2$ stream exiting the AGR is dehydrated and compressed from 1.8 to 150 bar for pipeline transport and storage in geologic formations; the H2S-rich stream is treated in a conventional Claus unit followed by a Shell Claus Offgas Treating (SCOT) process. NOx emissions from the GT are limited to 25 ppmv $(15 \%$ O2) by diluting the syngas with all the available N2 and some steam in order to lower the stoichiometric flame temperature to $2027^{\circ} \mathrm{C}$. Heat is efficiently recovered from the turbine exhaust in a 3 pressure level (plus reheat) heat recovery steam generator (HRSG) coupled to a single steam turbine. A high degree of heat integration is employed between the syngas train and the steam cycle, and design of the waste heat recovery system is rigorously optimized using the novel methodology of Martelli (2010) to achieve maximum efficiency.

\subsection{Electricity and $\mathrm{NH}_{3}$ Coproduction, Steady-State}

A facility that co-produces electricity and $\mathrm{NH}_{3}$ (with $\mathrm{CO}_{2}$ capture) is a simple modification of the IGCC-CCS plant described above. As shown in Fig. 1b, after exiting the AGR, the $\mathrm{H}_{2}$-rich syngas is split into two streams; a certain fraction, $f$, is sent to the $\mathrm{NH}_{3}$ synthesis island, and the remainder is sent to the power island. The $\mathrm{NH}_{3}$ synthesis island produces purge gas from the pressure swing adsorption (PSA) unit within, which is compressed and combined with the remaining syngas $(f-1)$ going to the power island. This fuel gas is humidified, diluted, and heated prior to combustion in the gas turbine(s). In addition, the $\mathrm{NH}_{3}$ synthesis island produces high quality waste heat, e.g. to raise steam, which is integrated with the waste heat recovery steam bottoming cycle.

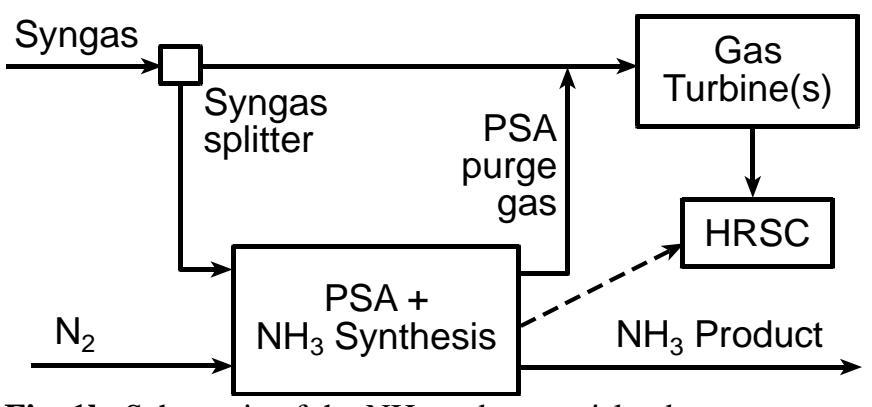

Fig. 1b. Schematic of the $\mathrm{NH}_{3}$ and power islands. 


\subsubsection{Ammonia Synthesis}

Ammonia synthesis is a mature technology whose commercial market is dominated by five licensors: Haldor Topsøe, M.W. Kellogg, Uhde, ICI, and Brown \& Root; among these, Topsoe is the leader, having supplied technology to more than half of all new ammonia plants since 1990 [Chemlink, 2011; Topsoe, 2011b]. Topsøe has long been a leading developer of cutting edge of chemical catalysis and process technologies, publishing extensively in the open literature and often notably forthcoming with detailed thermodynamic and economic data on their processes. For these reasons we have chosen to adopt Haldor Topsøe's S-300 process [Christensen, 2001] as the basis for our plant modeling. Topsøe graciously provided performance and cost estimates for this study [Han; 2011]; this preliminary report uses only Topsøe's cost estimates, which are significantly lower than those reported in a recent NETL study of coal-to-substitute natural gas (SNG) and ammonia [NETL, 2011] that also assumed Topsøe's S-300 technology. Preliminary performance estimates are taken from NETL (2011).

Industrially, ammonia is synthesized from hydrogen and nitrogen:

$$
\mathrm{N}_{2}+3 \mathrm{H}_{2} \rightarrow 2 \mathrm{NH}_{3} \quad\left(\Delta \mathrm{H}_{298}^{\mathrm{o}}=-92.44 \mathrm{~kJ} / \mathrm{mol} \mathrm{N}_{2}\right)
$$

using the Haber-Bosch process [Appl, 1999; Twigg, 2006; Dybkjaer, 1995; Hooper, 1991]. As an exothermic reaction accompanied by a decrease in volume at constant pressure, the equilibriumcontrolled production of $\mathrm{NH}_{3}$ is favored at low temperatures and high pressures (typically $350-550^{\circ} \mathrm{C}$ and 100-250 bara). Typically synthesis reactors employ multiple, quasi-adiabatic reactor beds within a pressure shell, with internal heat exchange between the relatively cool feed gas and the hot reaction products. The use of intercooled multiple stages enables the conversion to progress near (i.e. at temperatures and $\mathrm{NH}_{3}$ concentrations somewhat lower then dictated by full chemical) equilibrium, where the reaction rates are highest (Figs. 2 and 3). The Topsøe S-300 is a three bed, radial flow synthesis reactor. Radial flow allows for relatively small catalyst pellets (typically $1.5-3 \mathrm{~mm}$ ) with high activity that produce low pressure drop. [Hooper, 1991]

Equilibrium constraints typically prevent single-pass conversion rates of more
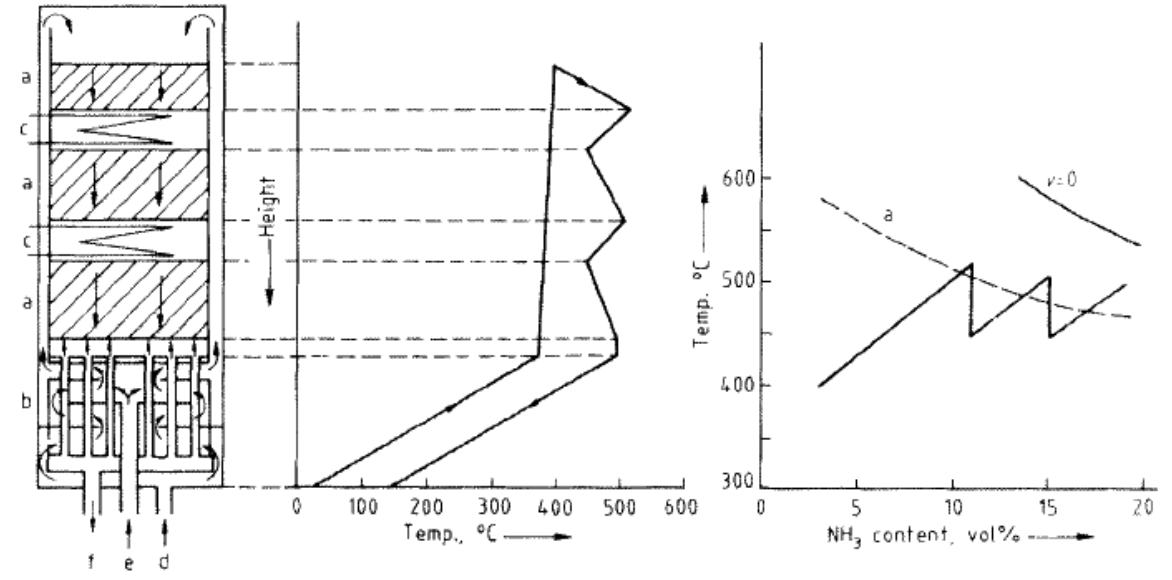

Fig. 3. In three intercooled synthesis beds, the reaction progresses in the vicinity of the line of maximum reaction rate. (From: Appl, 1999.) than $\sim 15 \%$ of the input feed. Thus, $\mathrm{NH}_{3}$ removal (by product gas cooling and $\mathrm{NH}_{3}$ condensation) and feed gas recompression + recycle are standard features in a $\mathrm{NH}_{3}$ synthesis loop. A typical layout - and the one followed here - is shown in Fig. 4. Note that make-up feed gas is injected into the loop prior to 
$\mathrm{NH}_{3}$ separation to avoid poisoning of the synthesis catalyst by entrained compressor oil and trace levels of water, carbon oxides, and sulfur-bearing compounds. Ammonia synthesis catalysts are easily poisoned [Højlund Nielsen, 1995], and significant efforts such as syngas methanation and pressure swing adsorption (PSA) are taken upstream to insure that the $\mathrm{NH}_{3}$ island feed stream is comprised essentially of only $\mathrm{H}_{2}$ and $\mathrm{N}_{2}{ }^{1}$.

The design of synthesis catalysts, reactors, and recycle loops have evolved significantly over the approximately 100 years that industrial ammonia synthesis has been practiced. A complex interplay between pressure, temperature, and $\mathrm{NH}_{3}$ concentration drive the overall plant economics, and the "optimal" configuration has changed over time as the technology and the values of exogenous variables such as feedstock price have evolved. Modern conditions lead to plants designed to efficiently utilize waste heat, and as a result can produce ammonia with as little as 32-35 GJ/tonne $\mathrm{NH}_{3}$. Note in Fig. 4 that high grade heat is recovered from the product gases leaving the synthesis reactor and used to meet process needs elsewhere in the plant.

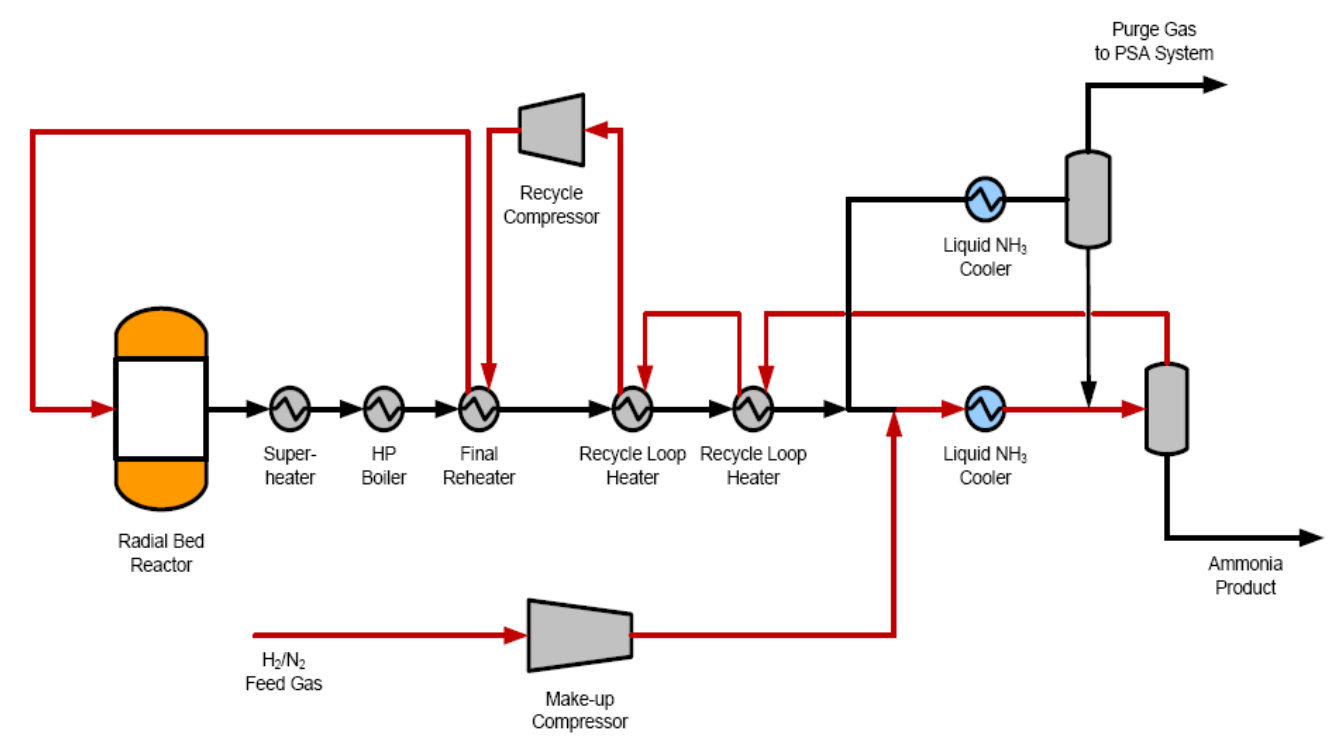

Fig. 4. Layout of the Topsøe S-300-based $\mathrm{NH}_{3}$ Synthesis Loop (From: NETL, 2011.)

\footnotetext{
${ }^{1}$ Argon also appears. In a natural-gas-based ammonia plant, $\mathrm{CH}_{4}$ is a common inert, requiring a purge stream to keep it's concentration at reasonable levels. In this system, a dedicated purge from the synthesis loop is not required.
} 


\subsubsection{Modeling the Ammonia Synthesis Loop}

Aspen Plus chemical process design software was used to reproduce the $\mathrm{NH}_{3}$ Synthesis Loop (Fig. 5) described in NETL (2011). The starting point for our model was an ammonia synthesis simulation provided by Aspen Technology, Inc. [Aspen, 2008], the creators of Aspen Plus. Although we chose not to use their chemical kinetics-based $\mathrm{NH}_{3}$ synthesis model, we retained the various modifications to ancillary models that describe the thermodynamic and thermophysical properties of the molecular species involved. In particular, quoting from Aspen Plus literature:

Equation-of-state models provide an accurate description of the thermodynamic properties of the high-temperature, high-pressure conditions encountered in ammonia plants. The Redlich-Kwong modification RKS-BM was chosen for this application. In most cases, the model parameters were taken from the Aspen physical property databanks. Special accuracy improvements were made to the RKS-BM model as follows:

- The pure-component properties of ammonia were modified to improve the vapor pressure and enthalpy of vaporization, which is important for the synthesis section.

- The binary interaction parameters of $\mathrm{H}_{2}, \mathrm{~N}_{2}, \mathrm{Ar}$ and $\mathrm{CH}_{4}$ with ammonia were modified in order to obtain accurate solubilities of these species in ammonia, which is important for the synthesis \& refrigeration sections.

- The binary parameters of the air system $\left(\mathrm{N}_{2}, \mathrm{O}_{2}, \mathrm{Ar}\right)$ were modified in order to enable an accurate simulation of the vapor-liquid equilibrium in the nitrogen plant.

Electrolyte NRTL method and RK equation of state are used to compute liquid and vapor properties respectively in the $\mathrm{CO}_{2}$ Removal Unit. The NRTL parameters for electrolyte pairs were regressed against VLE data from Maurer (1988). $\mathrm{NH}_{3}$ is selected as Henry-components to which Henry's law is applied and the Henry's constants are specified.

Rather than burden our simulation with the complexity of a kinetics-based synthesis model, Fig. 1 indicates that and temperature approach to equilibrium method might be an appropriate technique. In addition, modern plants are said to achieve near-equilibrium conversion efficiencies [Appl, 1999], which again suggests an equilibrium-based (rather than kinetics-based) approach. We simulated the S-300 reactor using three adiabatic equilibrium reactors (synthesis beds) and internal heat exchange (Fig. 5) and embedded this reactor in a synthesis loop (Fig. 6) patterned after and calibrated to the $\mathrm{NH}_{3}$ synthesis stream data in NETL (2011). As seen in Figs. 4 and 6, the synthesis loop contains the synthesis reactor, refrigeration units to cool and condense the $\mathrm{NH}_{3}$ product, knockout drums to separate the $\mathrm{NH}_{3}$ condensate from the unconverted feed gas, a recycle compressor, and various heat exchangers for both internal heat recovery and steam generation. The synthesis loop was fed $\mathrm{N}_{2}$ and $\mathrm{H}_{2}$ in a 3:1 ratio, and operated at 140 bar. A plot of $\mathrm{NH}_{3}$ concentration vs. temperature within the simulated synthesis reactor is shown in Fig.

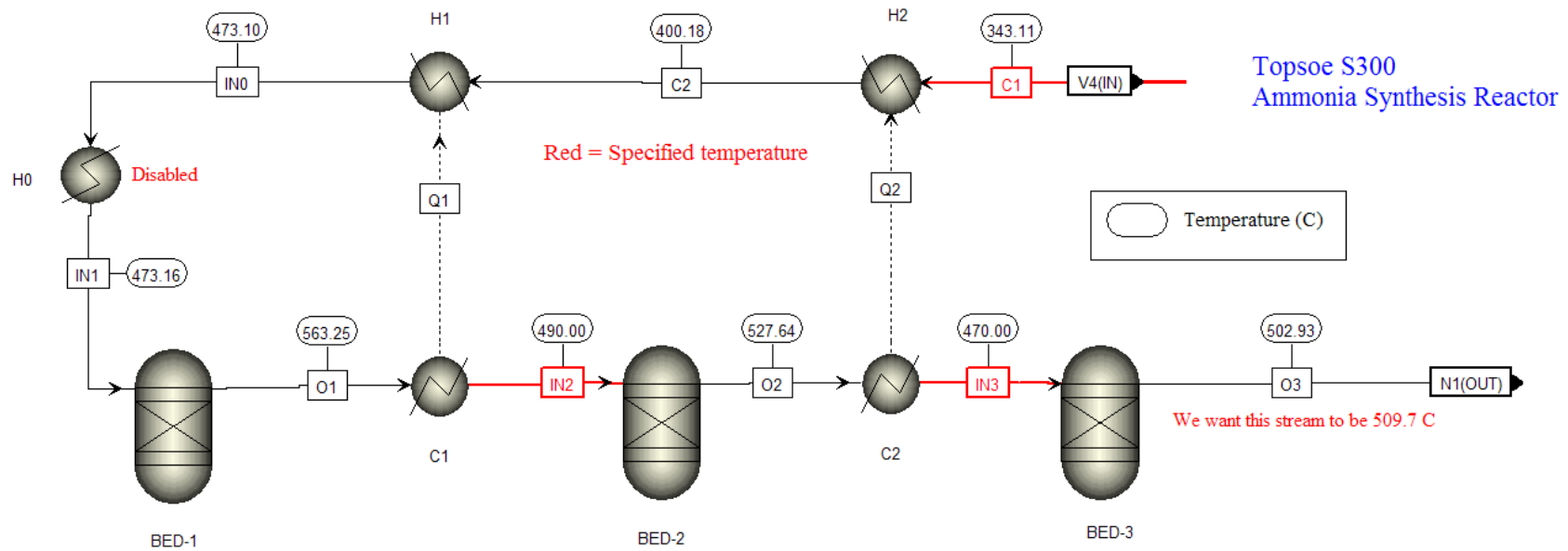

Fig. 5. Aspen Plus model of a Topsøe $\mathrm{S}-300 \mathrm{NH}_{3}$ synthesis reactor. 


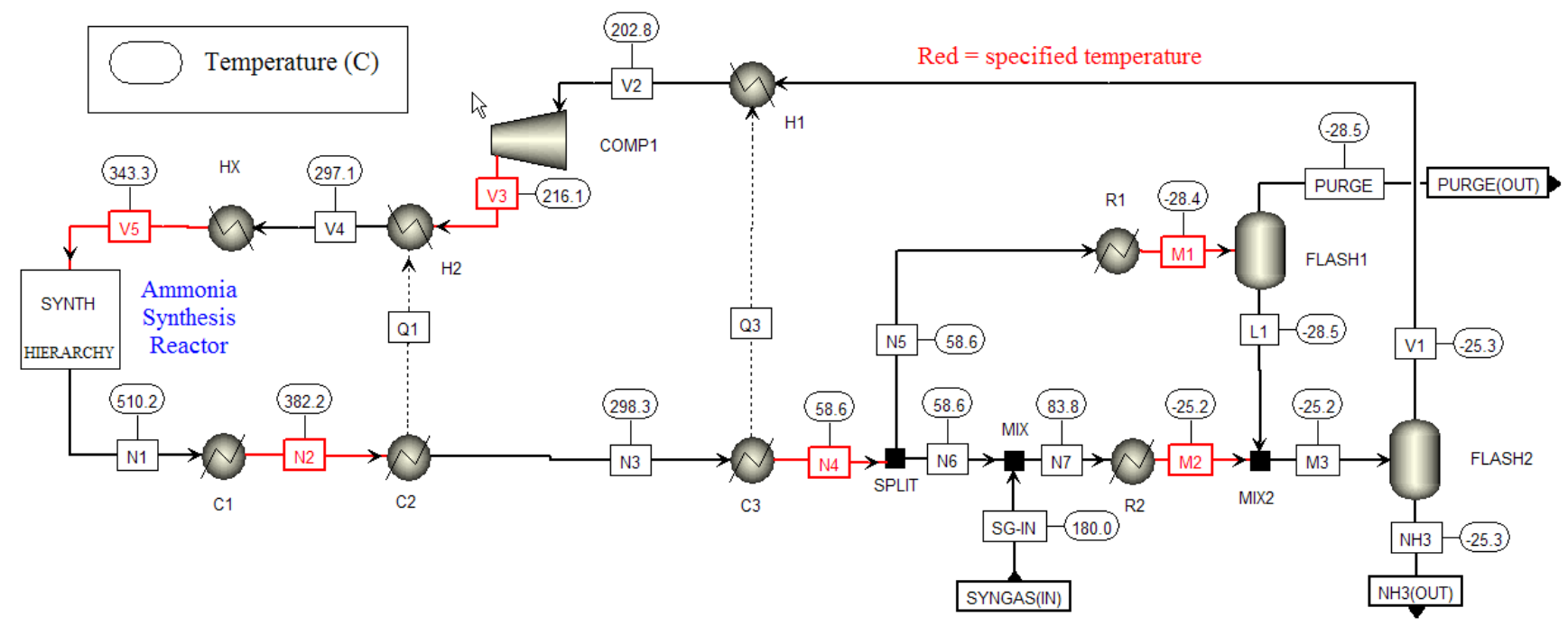

Fig. 6. Aspen Plus model of the Ammonia Synthesis Loop.

7. By adjusting the extent of internal heat exchange and equilibrium approach temperature ${ }^{2}$ to keep the catalyst within the manufacturer's specified temperature range of 340-550 C [Topsøe, 2011c], a "reaction path" is observed that mimics the behavior shown in Fig. 2. Note that the mole fraction of $\mathrm{NH}_{3}$ rises from $1.9 \%$ to $11.9 \%$ as it traverses the synthesis reactor.

The synthesis loop is part of the larger Synthesis Island (Fig. 8) whose overall function is to convert $\mathrm{N}_{2}$ and incoming $\mathrm{H}_{2}$-rich syngas into $\mathrm{NH}_{3}$, high quality process heat, and compressed PSA purge gas. Upstream of the synthesis loop, a PSA unit purifies the incoming $\mathrm{H}_{2}-$ rich syngas prior to synthesis, and compressors pressurize both $\mathrm{N}_{2}$ and the synthesis loop make-up feed. Downstream, a compressor enables the PSA purge gas to be combined with syngas bypassing the synthesis island, en route to humidification, heating, and dilution prior to

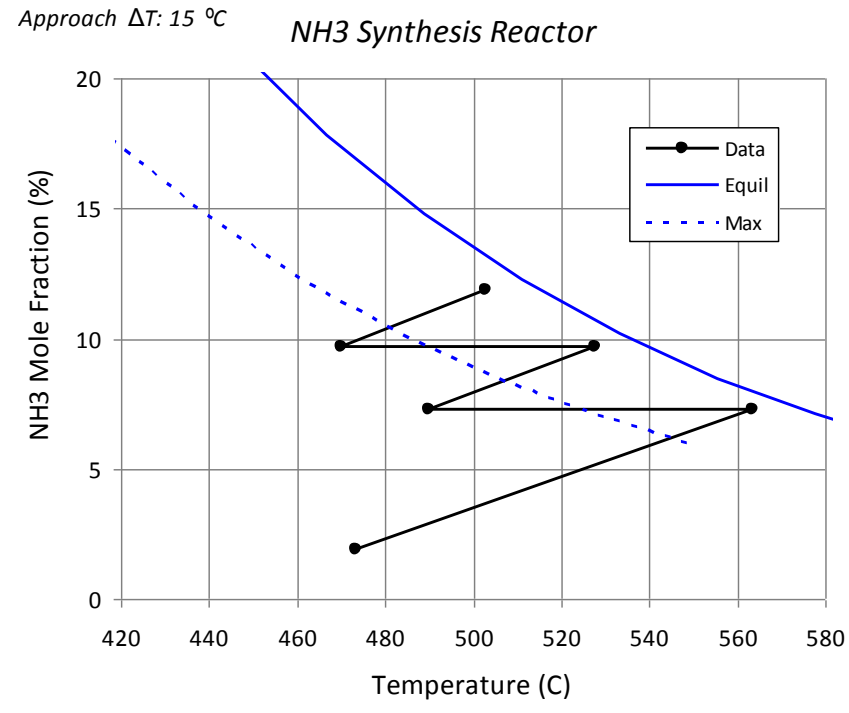

Fig. 7. Reaction path within the simulated S-300 reactor for a $15 \mathrm{C}$ approach to equilibrium. (Dotted line $=$ equilibrium 50 C.) combustion in the gas turbine(s). Because the PSA purge gas - pure $\mathrm{N}_{2}$ - is also an important component of $\mathrm{NH}_{3}$ synthesis feed stream, an unusually large fraction (e.g. 94\%) of the incoming $\mathrm{H}_{2}$ can be economically recovered by the PSA unit [Mak, 2004].

Key performance metrics for the synthesis island, derived from both our Aspen modeling and NETL (2011), include: a $\mathrm{H}_{2}-$ to- $\mathrm{NH}_{3}$ conversion efficiency of $91.3 \%$ ( $\mathrm{H}$ atom basis), production of 2.36 $\mathrm{MJ}_{\mathrm{th}} /$ tonne $\mathrm{NH}_{3}$ of waste heat between 380 and $500 \mathrm{C}$, and a parasitic electric load of $25.9 \mathrm{~kW} / \mathrm{MTPD}$ ["MTPD" = metric tonne of $\mathrm{NH}_{3}$ per day] for refrigeration and compression. NETL (2009) gives an overnight installed capital cost of 385.2 M\$ (2007 dollars) at a scale of 2000 MTPD. For reference, our

\footnotetext{
${ }^{2}$ The stream data of NETL (2011) suggest that full chemical equilibrium is achieved. However, we assume here a more conservative $15 \mathrm{C}$ approach to equilibrium.
} 
"standard" $\mathrm{NH}_{3}$ coproduction plant yields 2,824 MTPD (Table 1). This size is exactly in the economic "sweet spot" of modern ammonia plants, and is well matched to the Topsøe technology.

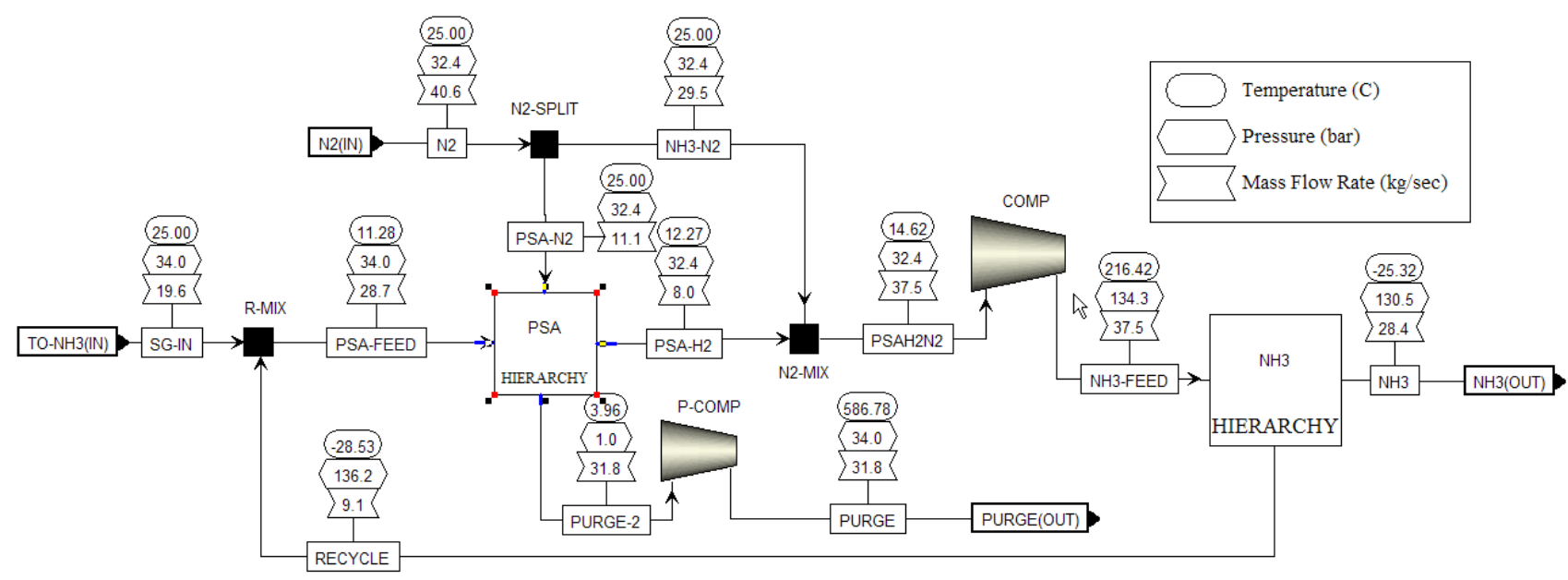

Fig. 8. Aspen Plus model of the $\mathrm{NH}_{3}$ Synthesis Island.

\subsubsection{Plant Performance}

In designing an $\mathrm{NH}_{3}$ coproduction plant, a value must be chosen for the fraction, $f$, of the $\mathrm{H}_{2}-$ rich syngas that is split off and sent to the $\mathrm{NH}_{3}$ synthesis island. A simple 50/50 split is one obvious possibility. However, we have discovered that $f=57.8 \%$ yields a fuel gas stream to the power island that exactly "satisfies" a single GE 9FB gas turbine operating at full load. Thus, while the IGCC-CCS $(f=0)$ employs two GT trains, the $f=57.8 \% \mathrm{NH}_{3}$ coproduction plant uses just one. Although other choices of $f$ are certainly possible, they complicate our estimates of GT performance and cost, which are by nature strictly quantized in the commercial GT market.

The performance of the reference IGCC-CCS $(f=0)$ and $\mathrm{f}=57.8 \% \mathrm{NH}_{3}$ coproduction plant are given in Table 1. Even though only about $42 \%$ of the original syngas goes directly to the power island in the $f=57.8 \%$ case, the output power of the plant drops by $76 \%$ compared with the IGCC $(f=0)$ case. This is due to the significant power required by the $\mathrm{NH}_{3}$ synthesis island, a feature of the process since its inception over a century ago.

\subsubsection{Co-Product Values}

Plant profitability can be assessed only in the context of the market value of its co-products. As discussed below in the section on flexible

Table 1. Plant performance, with breakdown of power consumption by unit.

\begin{tabular}{|l|cc|}
\hline & $f=0$ & $\boldsymbol{f}=\mathbf{5 7 . 8 \%}$ \\
\hline Power Consumption, $M W_{e}:$ & & \\
Coal handling, gasifier & 18.42 & 18.42 \\
ASU, $\mathrm{O}_{2} \& \mathrm{~N}_{2}$ compr., pumps & 128.69 & 128.69 \\
AGR, Claus, SCOT units & 19.75 & 19.75 \\
$\mathrm{CO}_{2}$ drying \& compression & 35.18 & 35.18 \\
Ammonia $\mathrm{N}_{2}$ compressor & 0 & 13.52 \\
Ammonia plant compressors & 0 & 37.59 \\
Ammonia refrigeration & 0 & 22.01 \\
PSA purge gas compressor & 0 & 26.82 \\
Auxiliary power, $M W_{e}$ & 202.04 & 301.98 \\
GT net power $(\mathrm{GE} 9 \mathrm{FB}), \mathrm{MW}$ & 593.92 & 296.56 \\
ST net power, $\mathrm{MW}_{\mathrm{e}}$ & 300.58 & 171.03 \\
Net electric power, $M W_{e}$ & 692.46 & 165.61 \\
Co-product $\mathrm{NH}_{3}$, tonne/day & 0 & $2,824.3$ \\
\hline Coal input, $\mathrm{MW}_{\text {th }} \mathrm{LHV}$ & $1,841.6$ & $1,841.6$ \\
Overall carbon capture, $\%$ & 93.09 & 93.09 \\
GHG emiss., $\mathrm{kg} \mathrm{CO}_{2 \_\mathrm{eq}}$ MWh & 101.39 & 423.96 \\
\hline
\end{tabular}
coproduction, the price of electricity is set by the operating cost of the marginal generator, which in the U.S is most often a natural gas combined cycle unit (NGCC). This is confirmed in Fig. 9, where the volatile history of natural gas (NG) prices for U.S. power producers is seen to be extremely well correlated with the historical prices for electric power at PJM's 
Eastern Hub. In order to quantify this relationship, this analysis assumes that the average price of electricity is equal to the operating cost of a F-class NGCC with a HHV efficiency of $48.5 \%$, fixed O\&M costs of 7.25 $\$ /(\mathrm{kW}-\mathrm{yr})$, and variable O\&M costs of 2.80 \$/MWh (NPCC, 2005). Given an average capacity factor of $40 \%$ (EIA, 2010), the price of electricity at zero $\mathrm{CO}_{2}$ emissions price, $E_{o}(N)$

(\$/MWh), can be expressed as:

$$
E_{o}(N)=\alpha_{1}+\alpha_{2} N
$$

where $\alpha_{1}=4.87 \$ / \mathrm{MWh}, \alpha_{2}=7.42$

GJ NG HHV/MWh, and $N$ is the price of natural gas (\$/GJ HHV). Since the operating cost will rise with $\mathrm{CO}_{2}$ emissions price, $P\left(\$ /\right.$ tonne $\left.\mathrm{CO}_{2 \mathrm{eq}}\right)$, the full price of electricity is given as:

$$
E(N, P)=E_{o}(N)+G_{E} P
$$

where $G_{E}=0.421$ tonne

$\mathrm{CO}_{2 \mathrm{eq}} / \mathrm{MWh}$ is the average carbon intensity NGCC power production. Figure 9 shows excellent correlation between the electricity prices predicted by Eq. 2 (with $P=$ 0 ) and those observed at PJM's

Eastern Hub.

The market price for ammonia (Fig. 10) has been subject to significant historical fluctuations. One cause is the underlying volatility in the price of natural gas (e.g. Fig. 9), the primary feedstock for global ammonia production. The tight historical correlation between the prices of natural gas and ammonia is demonstrated in Fig. 11. Mismatch between global supply and demand is the other key cause of variability in the market price of ammonia. This is highlighted in Fig. 12 , where the (often significant) difference between $\mathrm{NH}_{3}$ price and production cost are shown over the last two decades.

This analysis assumes that the market price of ammonia must reflect a future (global) price on GHG emissions. Industry experts estimate that the average carbon intensity of current global ammonia production is

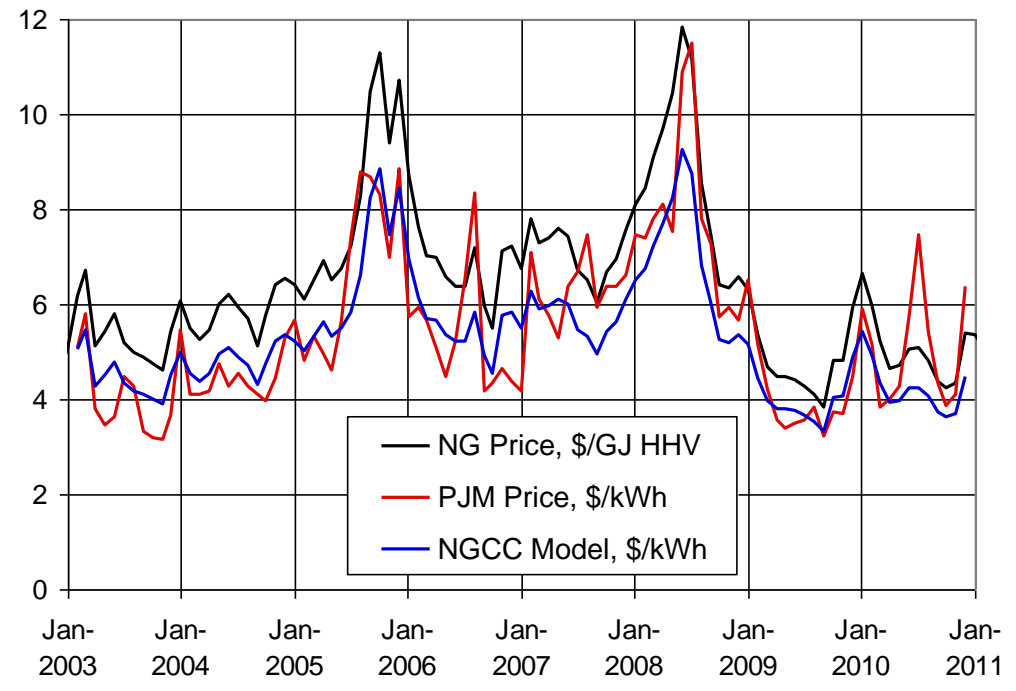

Fig. 9. Historical natural gas price to U.S. power producers (EIA, 2011), historical power prices at PJM's Eastern Hub (FERC, 2011), and the operating cost of generating NGCC-based power (NPCC, 2005) .

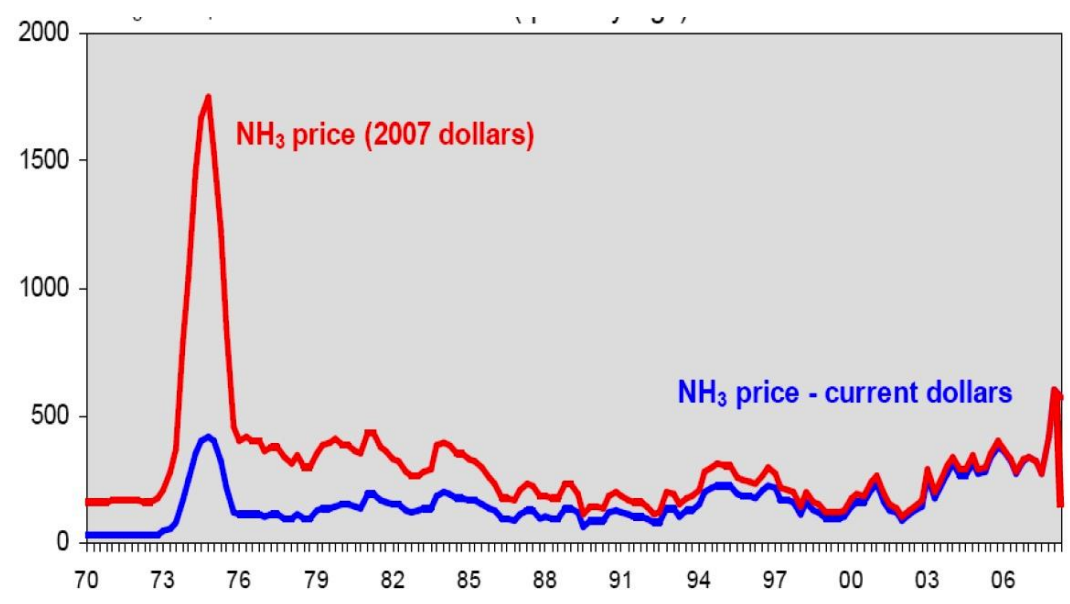

Fig. 10. Historical fob US/Caribbean $\mathrm{NH}_{3}$ prices (\$/ton). (Mann, 2009)

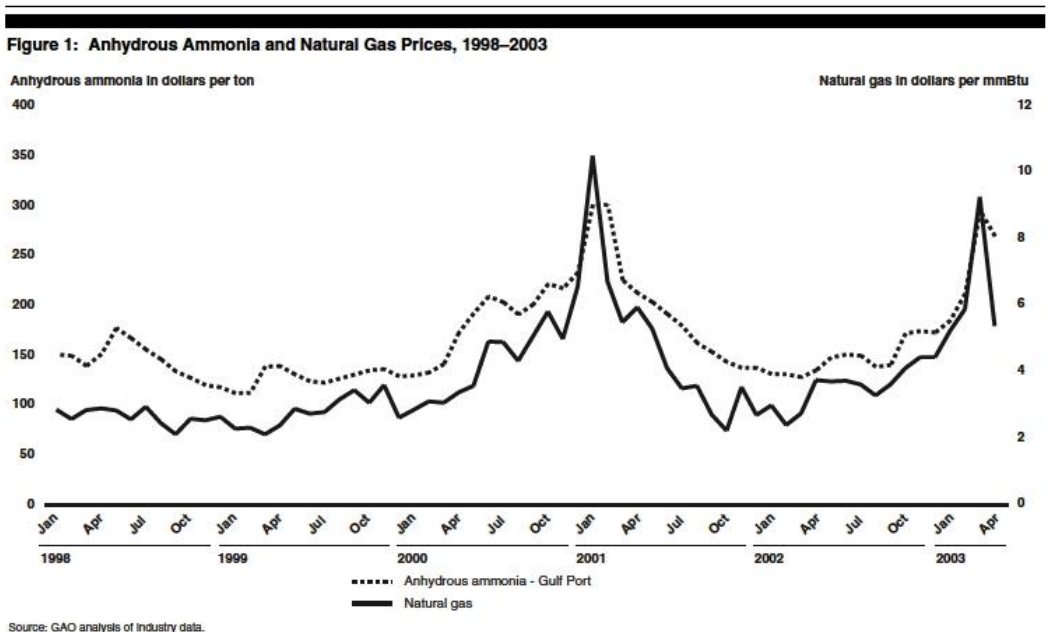

Fig. 11. Historical correlation between $\mathrm{NH}_{3}$ price and natural gas price. (From: GAO, 2003) 
2.1 tonne $\mathrm{CO}_{2} /$ tonne $\mathrm{NH}_{3}$ [IEA (2007)]; we assume here for simplicity that this value does not fall with increasing prices on $\mathrm{GHG}$ emissions.

The close correlation between the price of ammonia and the price of natural gas (NG), shown in Fig. 11, is expressed more quantitatively in Fig. 13, where the production cost of NG-based $\mathrm{NH}_{3}$ is disaggregated at four different gas prices. This yields an estimated market price for ammonia (at zero $\mathrm{CO}_{2}$ emissions price), $A_{o}(N)$ (\$/tonne), that can be written:

$$
A_{o}(N)=\beta_{1}+\beta_{2} N
$$

where $\beta_{1}=30 \$ /$ tonne $\mathrm{NH}_{3}, \beta_{2}=35$ GJ

$\mathrm{NG} \mathrm{HHV/tonne} \mathrm{NH}_{3}$, and $N$ is the price of natural gas (\$/GJ HHV). We assume that the future prospective market price of ammonia, $A(N, P)$ (\$/tonne), must reflect a future (global) price on $\mathrm{GHG}$ emissions:

$$
A(N, P)=A_{o}(N)+G_{A} P
$$

where $G_{A}$ is the average carbon intensity of current global ammonia production, estimated by industry experts to be 2.1 tonne $\mathrm{CO}_{2} /$ tonne $\mathrm{NH}_{3}$ (IEA, 2007), and $P$ is the price of $\mathrm{CO}_{2}$ emissions ( $\$ /$ tonne).

The volatile history of natural gas prices cautions against predicting its future. In light of prices seen during the last decade (Fig. 9), we use 6 \$/GJ HHV as a nominal value, and consider a range from $4-8 \$ / \mathrm{GJ}$. With a gas price of $N=6 \$ / \mathrm{GJ} H H V$ (and $P=0$ ), Eq. 4 yields an ammonia production cost of $240 \$ /$ tonne $\mathrm{NH}_{3}$; in light of the historical volatility shown in Fig. 10, the $\$ 6$ gas price appears to be a reasonable value to assume in the following economic analysis.

\subsubsection{Plant Economics}

The tradeoff between power and $\mathrm{NH}_{3}$ is explored in a comparative economic analysis, following that of Martelli (2011) and Kreutz (2005). Our approach employs the EPRI TAG revenue accounting method $^{3}$ [EPRI, 1993] and is intentionally transparent to facilitate the use of alternate economic assumptions (see Table 2). The coal price, $1.71 \$ / G J$ (LHV basis), was adopted from NETL (2007). Interest during construction (IDC) is taken to be $12.3 \%$ of overnight construction cost (or total plant cost, TPC), based on a 3-year construction schedule with equal, annual payments, and a real discount rate of $7.8 \% / \mathrm{yr}$. The 20 year levelized capital charge rate (CCR), applied to the total plant investment (TPI = TPC + IDC), is calculated to be $14.4 \% / \mathrm{yr}$. Operation and maintenance (O\&M) costs are estimated to be $4 \%$ of TPC per year. The capacity factor for all plants is assumed to be $85 \%$. At these plant sizes, $\mathrm{CO}_{2}$ removal rates are

\footnotetext{
${ }^{3}$ We assume a 55:45 debt:equity ratio for invested capital, a $4.4 \%$ real cost of debt, a $10.2 \%$ real cost of equity, a corporate income tax rate of $39.2 \%$, owner costs of $10 \%$ of TPC, a 3 yr construction time, a rate for property taxes and insurance of $2 \%$, a 20 year book and tax life for investment, and the MACRS depreciation schedule.
} 
Table 2. Economic assumptions employed here. ${ }^{4}$

\begin{tabular}{|l|l|}
\hline Coal price [1] & $1.71 \$ / \mathrm{GJ} \mathrm{LHV}$ \\
Capacity factor & $85 \%$ \\
Capital charge rate (CCR) $\mathrm{CO}_{2}$ & $14.4 \%$ per year \\
Interest during construction & $7.2 \%$ of overnight capital \\
Operation \& maintenance & $4 \%$ of overnight capital / yr \\
$\mathrm{CO}_{2}$ transport + storage costs & $7.1 \$$ tonne $\mathrm{CO}_{2}$ \\
\hline U.S. dollars valued in year & 2008 (mid-year) \\
\hline
\end{tabular}

high (565 tonnes/hr), and thus unit costs for $\mathrm{CO}_{2}$ transport and storage are potentially quite modest; using the simple engineering model of Ogden (2002), they are calculated here to be $7.0 \$ /$ tonne $\mathrm{CO}_{2}$. Lifecycle upstream greenhouse gas emissions for coal mining and delivery are taken to be $1.2 \mathrm{~kg} / \mathrm{GJ}$ LHV . Our model for estimating the capital costs of each major plant component is derived primarily from the detailed capital cost data for Shell IGCC plants given in NETL (2007). All capital costs are escalated to mid-2008 US dollars using the Chemical Engineering Plant Cost Index [CE (2011), Vavtuk (2002)]. The total plant costs given in Table 3 include engineering and overhead, general facilities, balance of plant (BOP), and both process and project contingencies (3.2 and $17 \%$ of the bare erected costs, respectively).

Levelized costs of electricity ( $L C O E$ ) and internal rates of return on equity (IRRe) are given in Table 4 for both the reference IGCC-CCS $(f=0)$ and the $f=57.8 \% \mathrm{NH}_{3}$ coproduction plant, at two $\mathrm{CO}_{2}$ emissions prices: $P=0$ and $100 \$$ tonne $\mathrm{CO}_{2}$. At the latter price, the market prices of the two co-products are expected to be: electricity: 91.5 \$/MWh (Eq. 2) and ammonia: $450 \$$ tonne $\mathrm{NH}_{3}$ (Eq. 4). The $\mathrm{CO}_{2}$ emissions price of $100 \$$ /tonne was chosen because it is close to the $111 \$$ /tonne break-even value at which the IGCC-CCS plant becomes profitable (i.e. when $L C O E=E(N, P)) . L C O E$ is also calculated and tabulated in Table 4 for the ammonia plant based on a credit for the sale of the $\mathrm{NH}_{3}$ co-product; however, it is unlikely that this metric has economic significance. Although the rise in $L C O E$ from $f=0$ to the $f=57.8 \%$ naively suggests a loss of economic viability, the increasing IRRe clearly demonstrates that the latter is the more profitable plant. Clearly, $L C O E$ is not a sensible metric when power becomes a minor plant byproduct. ${ }^{4}$ In any case, at $100 \$$ tonne $\mathrm{CO}_{2}$, neither plant is profitable because their IRRe are below the break-even value of $10.2 \% / \mathrm{yr}^{3}{ }^{3}$ If the price of natural gas is assumed to be 8 rather then $6 \$ / \mathrm{GJ} H \mathrm{HV}$ (see Tab. 4), both plants become profitable, but the IRRe of the ammonia plant still exceeds that of the power plant. This is because the market prices of both co-products are tied to the price and carbon

\footnotetext{
${ }^{4}$ Note that LCOE must rise to infinity as the electricity/ $\mathrm{NH}_{3}$ product ratio approaches zero.
}

Table 3. "Overnight" capital costs $(\mathrm{M} \$)$ for major plant components, and total plant cost (TPC) for each case.

\begin{tabular}{|c|c|c|}
\hline Plant component & $f=0$ & $f=57.8 \%$ \\
\hline Coal and sorbent handling & 43.8 & 43.8 \\
\hline Coal preparation \& feeding & 220.0 & 220.0 \\
\hline Ash handling & 51.5 & 51.5 \\
\hline Stand-alone ASU $+\mathrm{O}_{2}$ compressor & 204.0 & 204.0 \\
\hline Shell gasifier \& SG coolers & 385.6 & 385.6 \\
\hline LT heat recovery \& FG saturation & 37.5 & 37.5 \\
\hline Water-gas shift reactors & 2.3 & 2.3 \\
\hline Gas cleanup BOP & 12.3 & 12.3 \\
\hline AGR $\left(\mathrm{H}_{2} \mathrm{~S}\right.$ capture only $)$ & 49.8 & 49.8 \\
\hline AGR $2^{\text {nd }}$ stage $\left(\mathrm{CO}_{2}\right.$ capture $)$ & 116.8 & 116.8 \\
\hline Claus plant & 19.9 & 19.9 \\
\hline $\mathrm{CO}_{2}$ compression and drying & 50.9 & 50.9 \\
\hline GE F9B gas turbine(s) & 127.8 & 68.5 \\
\hline HRSG, ductwork, \& stack & 74.4 & 46.7 \\
\hline Steam turbine, condenser \& aux. & 78.6 & 53.9 \\
\hline Pressure Swing Adsorption (PSA) & 0.0 & 33.8 \\
\hline PSA purge gas compressor & 0.0 & 17.9 \\
\hline Ammonia production (minus PSA) & 0.0 & 140.7 \\
\hline Balance of plant & 269.6 & 284.4 \\
\hline Total Plant Cost (TPC), M\$ & 1,745 & 1,840 \\
\hline
\end{tabular}

Table 4. $L C O E$ and IRRe for each case. (Default NG price: $6 \$$ GJ HHV.)

\begin{tabular}{|c|c|c|}
\hline Cost component, mid $2008 \$ / M W h$ & $f=0$ & $f=57.8 \%$ \\
\hline Installed capital (at $14.4 \%$ of TPI) & 52.1 & 229.8 \\
\hline O\&M (at $4 \%$ of TPC per yr) & 13.5 & 59.7 \\
\hline Coal (at $1.71 \$ / G J, H H V)$ & 17.1 & 71.6 \\
\hline $\mathrm{CO}_{2}$ disposal (at $7.0 \$$ tonne $\mathrm{CO}_{2}$ ) & 5.7 & 23.7 \\
\hline Credit for $\mathrm{NH}_{3}$ (no carbon price) & 0 & -170.5 \\
\hline LCOE (no carbon price) & 88.4 & 214.3 \\
\hline $\mathrm{CO}_{2}$ emissions (at $100 \$ /$ tonne $\mathrm{CO}_{2}$ ) & 10.1 & 42.4 \\
\hline Credit for $\mathrm{NH}_{3}$ (at $100 \$ /$ tonne $\mathrm{CO}_{2}$ ) & 0 & -319.8 \\
\hline LCOE with $\mathrm{CO}_{2}$ price of $100 \$ /$ tonne & 98.6 & 107.4 \\
\hline IRRe $(P=100 \$ /$ tonne, $N=6 \$ / G J), \% / y r$ & 7.2 & 8.7 \\
\hline $\operatorname{IRRe}(P=100 \$ /$ tonne, $N=8 \$ / G J), \% / y r$ & 13.2 & 14.4 \\
\hline
\end{tabular}


intensity of natural gas, and thus are highly correlated. A more comprehensive view of the dependency of IRRe on $\mathrm{CO}_{2}$ emissions price and NG price is given in Fig. 14.

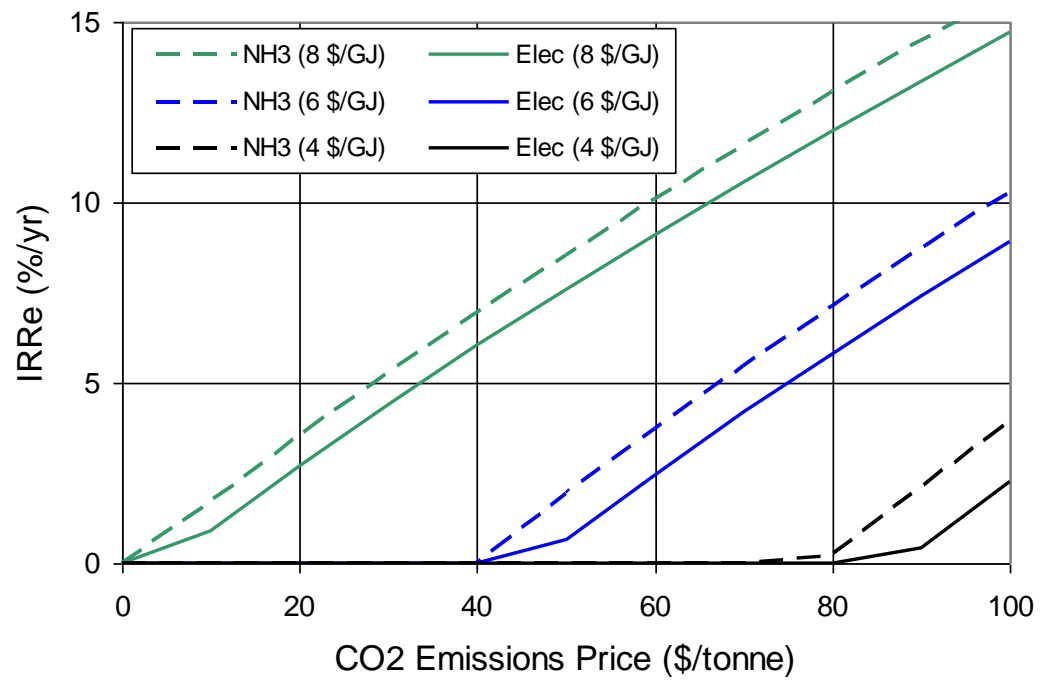

Fig. 14. Plant IRRe vs. $\mathrm{CO}_{2}$ emissions price and natural gas price.

\subsection{Time-Dependent ("Flexible") Co-Product Generation}

\subsubsection{Background}

The techno-economic analyses presented thus far have assumed that all plants operate at steady state with a high capacity factor (85-90\%), i.e. "baseload" operation. Accordingly, we have employed simple economic models of the market value of the various co-products, values that represent both spatial/locational and temporal averages. This approach neglects, however, price fluctuations that can potentially be exploited to improve overall plant profitability. Electric power is a prime example. Because large scale electricity storage is generally uneconomical and thus rare, electricity must be generated in response to demand, whose daily (and seasonal) fluctuations are often quite significant (Fig. 15). By design, the economic dispatch of power generators insures that the short run generating cost increases monotonically with increasing load, and as a result, the marginal (or market clearing) price of electric power at any given moment - paid to all participating generators - generally mirrors the temporal variation in load. However, the variability/volatility in power prices typically exceeds that of demand because of transient mismatches between demand and secure supply (most frequently caused by congestion in power transmission) which often impose higher than optimal costs due to generators being dispatched "out of economic merit order". Such extra variability can be seen in Fig. 16,

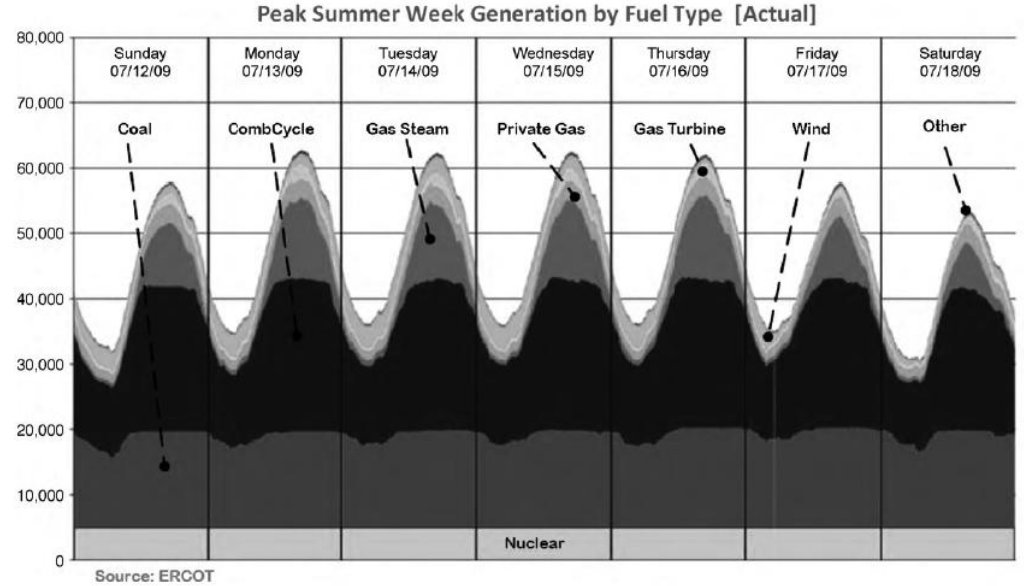

Fig. 15. Diurnal variation in ERCOT power generation, July 2009. As discussed in the text, the variation can be characterized by $\lambda \sim 0.3$. (From: Puga, 2010) 
where hourly real-time locational marginal prices (LMPs) at the PSEG node of PJM are graphed for the same time period shown in Fig. 15. By creating an average daily cycle in electricity prices (Fig. 17) by averaging three years worth of hourly LMPs, the variability is greatly reduced.

In contrast to the daily

fluctuations in power prices, market prices for more readilystored chemical co-products (such as liquid fuels, olefins, ammonia, etc.) are significantly more stable. In the following analysis, the price of chemical co-products are assumed to be time invariant - depending only on exogenous parameters such as market prices for crude oil, natural gas and $\mathrm{CO}_{2}$ emissions while the electricity price is assumed to vary cyclically and diurnally about an average value (that also depends upon the price of natural gas and $\mathrm{CO}_{2}$ emissions). As will be seen, if the daily variation in electricity prices is sufficiently high, and a coproduction facility has both the ability and flexibility to vary the relative output of its two coproducts, it can be economically advantageous to produce more power and less chemicals during times of high electricity prices, and the reverse during times of relatively low power prices. Offsetting to one degree or another the enhanced revenue from such "flexible" operation is the economic burden of extra capital equipment that is (by design) underutilized relative to traditional "inflexible" coproduction plants that operate steadily at their design points. This study seeks primarily to

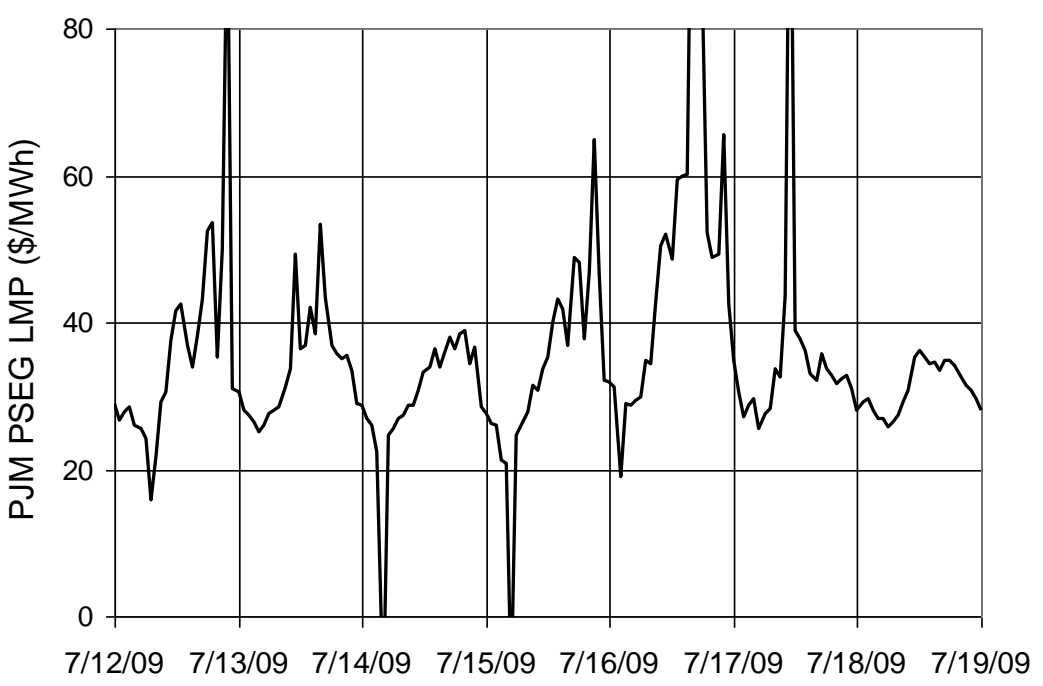

Fig. 16. Diurnal electricity price fluctuations at the PSEG node of PJM. (From: Borer, 2012)

Three Year Average (2009-2011)

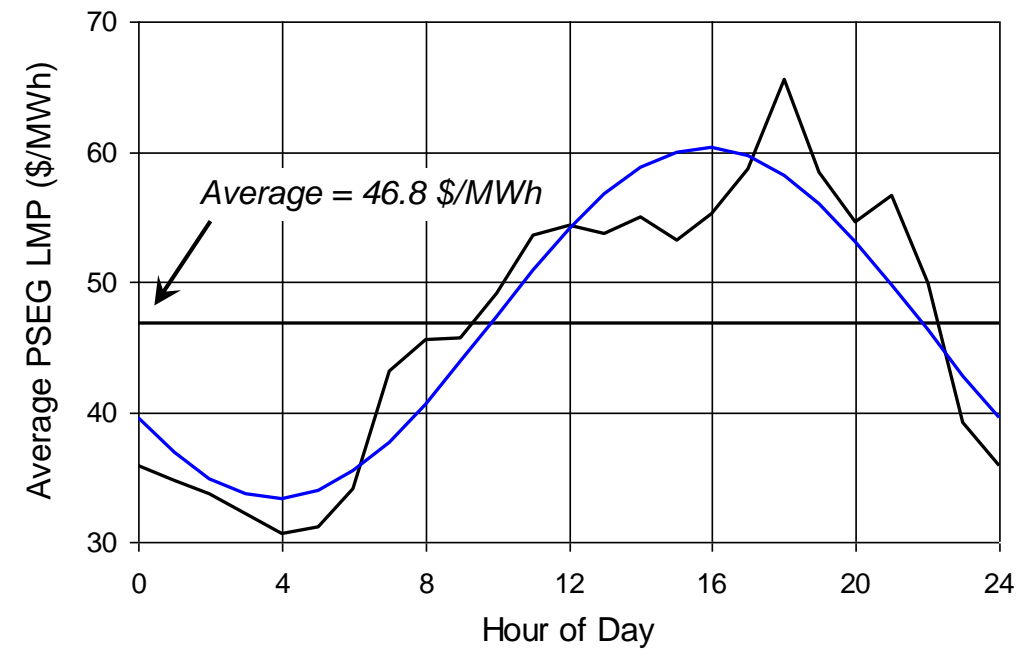

Fig. 17. Three-year daily average of real-time hourly LMPs from the PSEG node of PJM ISO. The best fit sine wave (blue) yields $\lambda=0.29$. quantify the potential economic benefits of flexible polygeneration; identifying practical considerations that constrain operational flexibility is deferred for future work. Various aspects of flexible polygeneration have been studied by Meerman (2011) and Chen (2011).

\subsubsection{A "Flexible" Ammonia + Electricity "Hybrid" Plant}

Here we will explore in a preliminary way the economics of flexible coproduction in the context of the coal gasification-based ammonia and electricity plants (with CCS) described in the earlier sections of 
this appendix. To make the analysis tractable, we will assume linear economics for a coproduction facility that is able to change its product mix over time. This assumption dictates that profit is maximized when the plant produces either $100 \%$ product $\mathrm{A}$ or $100 \%$ product $\mathrm{B}$, depending on market prices for each product. Analysis of Chiesa (2005) showed that for a co-production system co-producing $\mathrm{H} 2$ and electricity, this assumption of linearity was valid. Because ammonia/electricity production parallels $\mathrm{H}_{2}+$ electricity coproduction in some important ways, the assumption of linear economics for the $\mathrm{NH}_{3}$ +electricity system seems reasonable for a preliminary analysis.

Given the assumption of linear economics, a simplified framework is developed for investigating the economics of "time-of-day co-product selection" by considering a flexible "hybrid" coproduction plant that can switch between two distinct operating modes: 1) "chemicals" mode, where the primarily product is chemicals plus a relatively small electricity by-product, and 2) "electricity-only" mode. Cycling between operating modes on a diurnal timescale (or as dictated by market conditions) requires that the hybrid plant employ equipment that can be ramped up/down with enough speed that diurnal operation is feasible, e.g. a transition period less than 1-2 hours. For simplicity, this preliminary analysis neglects the transition period entirely, assuming that: 1) switching between modes is instantaneous (i.e. without partload operation), 2) equipment cycling brings no operational or durability penalties, and 3) idled equipment (e.g. the chemical synthesis reactor during electricity-only mode) can be maintained on "standby" at a negligible cost to overall plant efficiency.

This analytical framework is well matched our earlier analyses of $\mathrm{NH}_{3}+$ electricity coproduction options that considered two steady-states - or "modes"; thus, we adopt those plant configurations and analytical results as the basis for exploring flexible coproduction. (SCS Energy's proposed PUREGeN ONE coal gasification+CCS plant in Linden, $\mathrm{NJ}$ is similarly designed to produce both electric power and ammonia/urea, with the flexibility to dynamically alter its product slate in response to market signals.) Note that this "dual mode" analytical approach is a simplifying limiting case of the more general concept of flexible polygeneration, in which the plant can produce a continuous range of co-product ratios instead of just the two single product "end states".

Consider a flexible "hybrid" ammonia+electricity plant whose design is essentially a combination of the two plants $(f=0$ and $f=57.8 \%$ ) described above, with an ammonia synthesis island, two gas turbines, and a steam Rankine bottoming cycle sufficient for operating in either $\mathrm{NH}_{3}$ or electricity-only modes. The performance of the hybrid plant is exactly that given in Table 1 , where $f=57.8 \%$ is "mode 1 " $\left(\mathrm{NH}_{3}+\right.$ electricity) and $f=0$ is "mode 2" (power only). The estimated overnight capital cost of the hybrid plant, $1,972.5 \mathrm{M} \$$, is readily calculated from the disaggregated component costs given in Table 3.

\subsection{3 "Threshold" Electricity Price}

The economic motivation for a hybrid plant that can switch between two operating modes is illustrated in Fig. 18, where net revenue is plotted as a function of electricity price for three plants described above: 1) electricityonly (IGCC-CCS), 2) $\mathrm{NH}_{3}$ +electricity, and 3) hybrid (operating in both modes). Assume that the electricity price varies each day between 20 and 80 $\$ / \mathrm{MWh}$ around a mean of 50 $\$ /$ MWh (red lines). The net revenue of the electricity-only

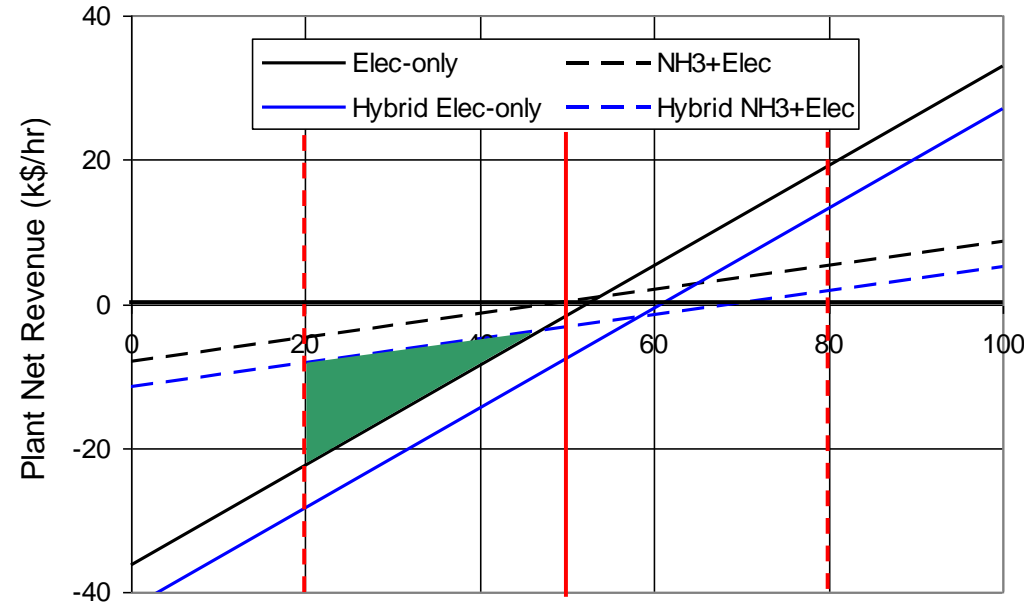

CO2 Price: 100 \$/tonne
NG: $6 \$ / G J H H V$

Fig. 18. Net Revenue vs. electricity price for three plants: 1) electricityonly, 2) $\mathrm{NH}_{3}+$ electricity, and 3) a "hybrid" version that can operate in either of the two previous modes. 
plant (black line) is naturally quite sensitive to the electricity price. The power plant is profitable during the day when prices are high, but those gains are lost each night as the electricity price falls. The same is true for the ammonia plant (black dashes); however, because of the plant's reduced power output, its net revenue is much less dependent on electricity price. In order to maximize revenue, one would like to take advantage of high daytime electricity prices by generating power during the day, but avoid nighttime losses by instead producing ammonia at night. As discussed above, constructing such a flexible hybrid requires extra (underutilized) capital. Its daytime (power-only) net revenue is shown with a blue line; at night it switches to ammonia production (blue dashes). Converting an electricity-only plant into a hybrid averts daily revenue losses shown conceptually by the area shaded green.

In the hybrid plant, both operating modes require the same amount of input coal, $\mathrm{CO}_{2}$ capture and storage, $\mathrm{CO}_{2}$ emissions, and other operating expenses. ${ }^{5}$ Thus, the decision to operate in one mode vs. the other depends only on which generates the most revenue. Since the market price of ammonia, $A(N, P)$ (\$/tonne), is assumed to be independent of time, there must be a "threshold" electricity price, $E^{*}$ $(\$ / \mathrm{MWh})$, above which it is more profitable to operate in electricity-only mode; at prices below $E^{*}$, ammonia production is most profitable. To simplify the following analytical development, we express $E^{*}$ in terms of the average market price for electricity, $\bar{E}(N, P)(\$ / \mathrm{MWh})$ as follows:

$$
E^{*} \equiv \bar{E}(N, P)(1+\lambda *)
$$

where $\lambda^{*}$ is the fractional difference in the mean electricity price. The time-dependent revenue during $\mathrm{NH}_{3}+$ electricity operation (mode 1$), R_{1}(N, P ; t)(\$ / \mathrm{hr})$, can be expressed as:

$$
R_{1}(N, P ; t)=a_{1} A(N, P)+e_{1} E(N, P ; t) .
$$

where $t$ is the time of day (hr), $a_{1}$ is the ammonia production rate (tonne/hr), $e_{1}$ is the coproduct power $\left(\mathrm{MW}_{\mathrm{e}}\right)$, and $E(N, P ; t)$ is the time-dependent market price of electricity $(\$ / \mathrm{MWh})$. The revenue $(\$ / \mathrm{hr})$ during power-only operation is expressed in a similar fashion:

$$
R_{2}(N, P ; t)=e_{2} E(N, P ; t) \text {. }
$$

(To increase legibility in the following development, we generally suppress the arguments: $N, P$ and $t$.) At threshold (i.e. when $\left.E=E^{*}\right), R_{1}=R_{2}$, or:

$$
a_{1} A=\left(e_{2}-e_{1}\right) E^{*} \text {. }
$$

In other words, at the threshold electricity price, revenue from ammonia production equals the loss of revenue from power production. Solving for $\lambda^{*}$ gives:

$$
\lambda *=\frac{a_{1} A}{\left(e_{2}-e_{1}\right) \bar{E}}-1 .
$$

Note that, when $\lambda^{*}>0$, ammonia production is more profitable than power-only generation under traditional (steady state) operation at $E=\bar{E}$, and vice versa. In Fig. 19, the value of $\lambda^{*}$ for this particular hybrid plant is plotted over a wide range of $\mathrm{NG}$ and $\mathrm{CO}_{2}$ emissions prices. Because both the market prices of both products - electricity and ammonia - are tied to the price and carbon intensity of natural gas, $\lambda^{*}$ is seen to be quite insensitive to these exogenous parameters, varying only between 0.08 and 0.11 ; in short, $\lambda^{*} \sim 10 \%$ is a good approximation. This confirms earlier results (Table 4) indicating than steady state ammonia production is slightly more profitable that power generation;

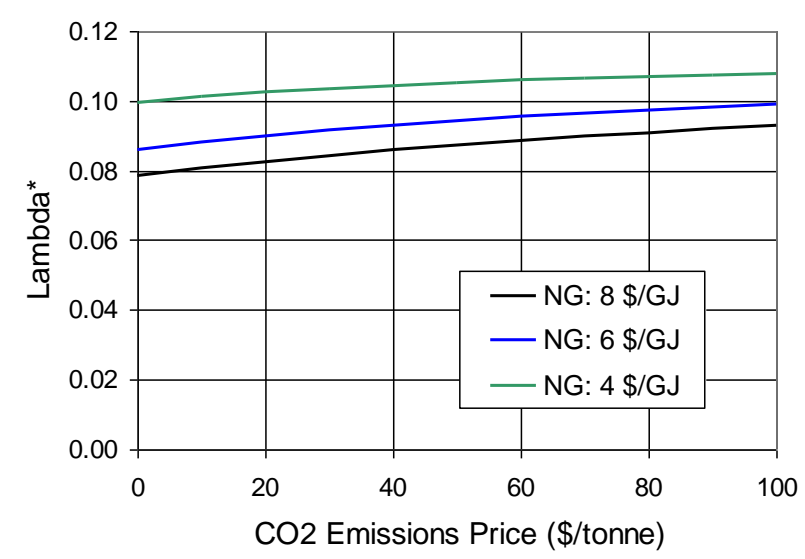

Fig. 19. $\lambda^{*}$ as a function of $\mathrm{NG}$ and $\mathrm{CO}_{2}$ emissions prices.

\footnotetext{
${ }^{5}$ In our simplified economic framework, O\&M costs are a fraction (4\% per yr) of the overnight capital cost. Presumably, operating both the power and $\mathrm{NH}_{3}$ synthesis islands simultaneously would be more costly than only the former.
} 
restated, at any given time electricity prices must be $\sim 10 \%$ higher than the average value, $\bar{E}(N, P)$, in order for power generation to be competitive with ammonia production.

\subsubsection{Economic Analysis: 2-State “Square Wave” Electricity Price Model}

In order to roughly quantify the potential magnitude of profitability enhancement via flexible coproduction, we begin with a simplified two-state "square wave" model in which the electricity price swings back and forth each day (Fig. 20) between a nighttime low price:

$$
E_{1} \equiv \bar{E}(1-\lambda)
$$

between the hours of $t=0$ and $t=T$ (for a duration, $d_{1}=T$, or fraction of the day, $f_{1}$ $\left.\equiv d_{1} / 24\right)$, and a daytime high electricity price:

$$
E_{2} \equiv \bar{E}\left(1+\frac{d_{1}}{d_{2}} \lambda\right)
$$

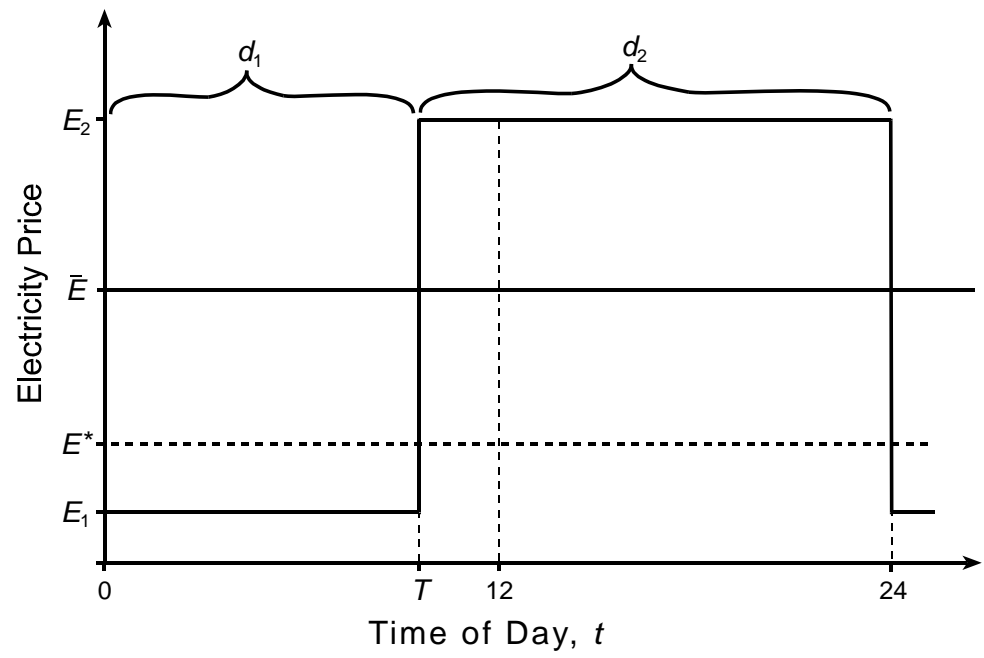

between the hours of $t=T$ and $t=24$ (for a duration, $d_{2}=24-T$, or fraction of the Fig. 20. Two-state "square wave" electricity price model, with an electricity price threshold, $E^{*}$, below the average value, $\bar{E}$. day, $\left.f_{2} \equiv d_{2} / 24\right){ }^{6}$ As expected, the average electricity price, $\langle E\rangle(\$ / \mathrm{MWh})$, is:

$$
\langle E\rangle=f_{1} E_{1}+f_{2} E_{2}=\frac{\left(d_{2}+d_{2}\right)}{24} \bar{E}=\bar{E} .
$$

We assume first that $\lambda^{*}<0$, i.e. $E^{*}<\bar{E}$, as indicated in Fig. 20 . When the daily electricity price excursion away from the mean is sufficiently large, i.e. $\lambda>\left|\lambda^{*}\right|, E_{1}<E^{*}$ and $\mathrm{NH}_{3}$ production (mode 1) is most profitable at nighttime (period 1), while power generation (mode 2) is preferred during the day (period 2). The average daily plant revenue, $R(\$ / \mathrm{hr})$, is given by

$$
R=f_{1}\left(e_{1} E_{1}+a_{1} A\right)+f_{2} e_{2} E_{2},
$$

which can be simplified using Eq. 8 and

$$
\rho \equiv \frac{e_{1}}{e_{2}}
$$

to:

$$
R=e_{2} E_{2}\left[1+f_{1}(1-\rho)\left(\lambda+\lambda^{*}\right)\right] .
$$

Re-writing Eq. 7 to identify the steady state revenue $(\$ / \mathrm{hr})$ from pure power generation:

$$
\bar{R}_{2} \equiv e_{2} \bar{E}
$$

and from ammonia production:

$$
\bar{R}_{1} \equiv\left(e_{1} \bar{E}+a_{1} A\right)=\bar{R}_{2}[1+(1-\rho) \lambda *] \approx \bar{R}_{2}(1+\lambda *)
$$

we define variable $\gamma$ as the fractional increase in plant revenue during flexible coproduction relative to that during pure power generation. With the simplifying assumption that $d_{1}=d_{2}=12 \mathrm{hr}$ (in order to streamline the following discussion), $\gamma$ can be expressed as:

$$
\gamma \equiv \frac{R-\bar{R}_{2}}{\bar{R}_{2}}=\frac{1}{2}(1-\rho)\left(\lambda+\lambda^{*}\right) \quad\left(\lambda \geq\left|\lambda^{*}\right| ; d_{l}=d_{2}=12 \mathrm{hr}\right) .
$$

\footnotetext{
${ }^{6}$ For analytical simplicity, the phase of the diurnal cycle has been arbitrarily shifted so that nighttime begins at $t=0$.
} 
It is readily seen from Fig. 20 that Eq. 18 applies to both positive as well as negative values of $\lambda *$. Note that, when the price excursion threshold is at a minimum $\left(\lambda^{*}=0\right), \gamma$ reaches a maximum of 0.5 (i.e. a $50 \%$ increase in plant revenue relative to power-only operation) when the price excursions are largest (we assume $\left.\lambda_{\max }=1\right)$ and the $\mathrm{NH}_{3}$ plant power generation is minimized $(\rho=0)$. This latter point is consonant with our discussion above; when market conditions favor product $\mathrm{A}$ over product $\mathrm{B}$, it is most profitable to produce only A, and vice versa.

When the price excursion is smaller then the threshold value, i.e. $\lambda<\left|\lambda^{*}\right|$, the value of $\gamma$ depends on the sign of $\lambda^{*}$. When $\lambda^{*}<0$ (as illustrated in Fig. 20), $R=\bar{R}_{2}$ and

$$
\gamma=0
$$

because $E$ always exceeds $E^{*}$, and ammonia production never occurs. On the other hand, when $\lambda^{*}>0$, as with the hybrid $\mathrm{NH}_{3}+$ electricity plant considered here $\left(\lambda^{*} \sim 0.1\right.$; see Fig. 19), $R=\bar{R}_{1}$ and

$$
\gamma=(1-\rho) \lambda *
$$

because $E$ never exceeds $E^{*}$ and ammonia production always occurs. The results of Eqs. 18-20 are plotted in Fig. 21 for $\rho=0.24$ and various artificially imposed values of $\lambda^{*}$; note that $\lambda^{*} \sim 10 \%$ for our hybrid plant (blue dashes). The horizontal sections of each line occur when $\lambda<|\lambda *|$, and only one mode is operative for the entire day: either $\mathrm{NH}_{3}$ production $(\lambda *>0)$ or power generation $(\lambda *<0)$. Also indicated in Fig. 21 is a realistic estimate for $\lambda$, i.e. $\lambda_{P J M} \sim 0.3$, based on the $\pm 30 \%$ diurnal oscillation observed in a 3-year historical average (2009-2011) of hourly real-time LMPs recorded at the PJM PSEG node (Fig. 9). Given this limitation on $\lambda$, the hybrid $\mathrm{NH}_{3}+$ electricity plant might expect a $\sim 15 \%$ enhancement in revenue relative to the power-only configuration $\left(\bar{R}_{2}\right)$, or a $\sim 6.7 \%$ enhancement relative to the ammonia production mode $\left(\bar{R}_{1}\right)$.

Extra capital is required to construct a flexible hybrid; thus, in Fig. 22 we plot the $\operatorname{IRR} e^{7}$ of this incremental investment as a function of $\lambda$. Since the flexible hybrid can be constructed from either the original IGCC-CCS or the original $\mathrm{NH}_{3}$ plant (which have different incremental capital requirements and revenue enhancements), the incremental IRRe is shown for both scenarios. The incremental IRRe for the IGCC-CCS case is non-zero when $\lambda<\lambda^{*}$ because here the (new) hybrid configuration operates all day in the more profitable ammonia mode. While the return on investment is $\left(\lambda<|\lambda *|: \lambda *<0: d_{1}=d_{2}=12 \mathrm{hr}\right)$

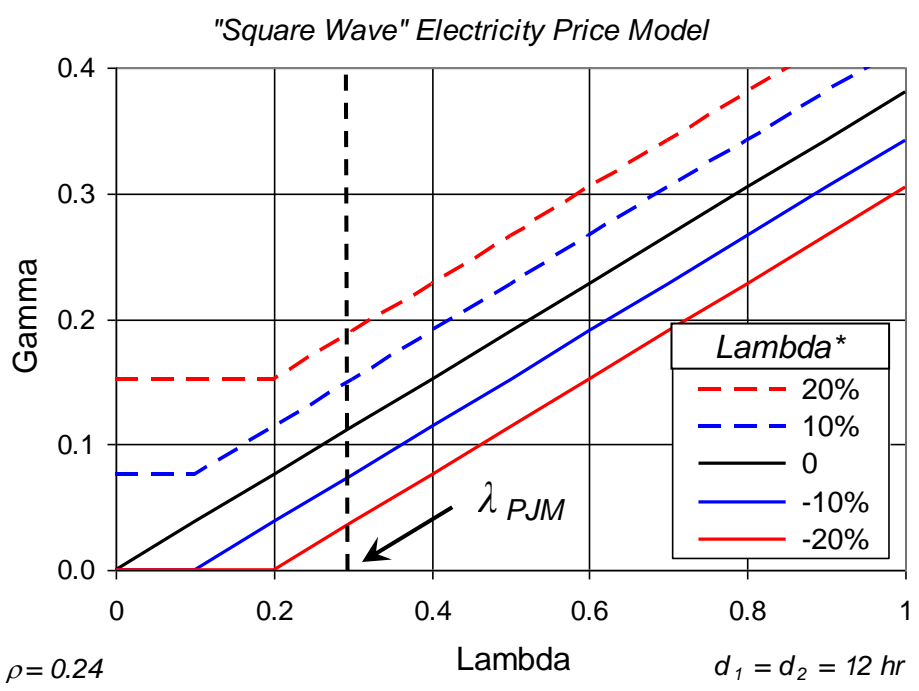

Fig. 21. Fractional revenue enhancement, $\gamma$, vs. fractional price deviation, $\lambda$, for various values of $\lambda^{*}$. The average daily variation in hourly real-time PJM PSEG node electricity prices shown in Fig. 16 $(\lambda=0.29)$ is indicated.

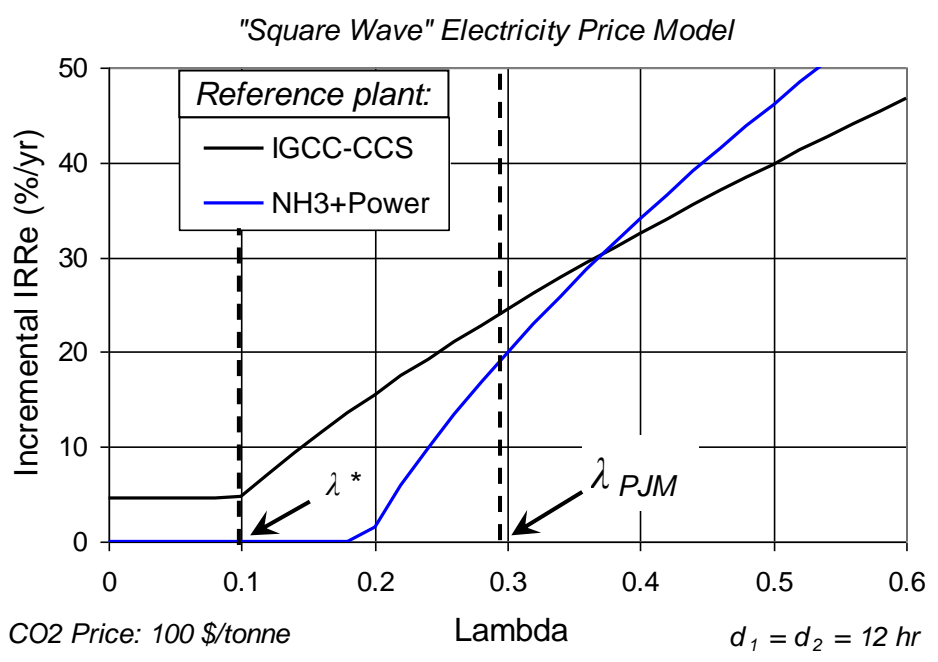

Fig. 22. IRRe on the extra capital required to create a flexible hybrid coproduction plant, starting from either the original IGCC$\mathrm{CCS}$ or the original $\mathrm{NH}_{3}+$ electricity plant.

\footnotetext{
${ }^{7}$ The debt/equity ratio for the "extra" capital is the same used above for the entire plant.
} 
impressive in Fig. 22, recall that it represents only the return on the incremental capital. In Fig. 23, which compares total plant IRRe for the three facilities (the two original plants and the flexible hybrid), it is clear that hybrid operation (black line) can increase the overall IRRe by only 1-2 percentage points.

\subsubsection{Economic Analysis: "Sine Wave" Electricity Price Model}

Having now developed the key concepts in our economic analysis of flexible coproduction, we now improve the accuracy of the analysis by replacing the two-state "square wave" electricity price model with a "sine wave" model that more realistically represents the average diurnal cycle (Fig. 17):

$$
E(N, P ; t)=\bar{E}(N, P)\left[1-\lambda \sin \left(\frac{\pi}{12} t\right)\right],
$$

oscillating between $E_{1} \equiv \bar{E}(1-\lambda)$ and $E_{2} \equiv \bar{E}(1+\lambda)$. In Fig. 24, the situation is illustrated for $\lambda^{*}<0$. At time $t=0$, the plant produces only power, and as the night progresses, $E(t)$ falls until it reaches the threshold price, $E^{*}=\bar{E}(1+\lambda *)$, at time $t=T$, where:

$$
T=-\frac{12}{\pi} \sin ^{-1}\left(\frac{\lambda^{*}}{\lambda}\right) .
$$

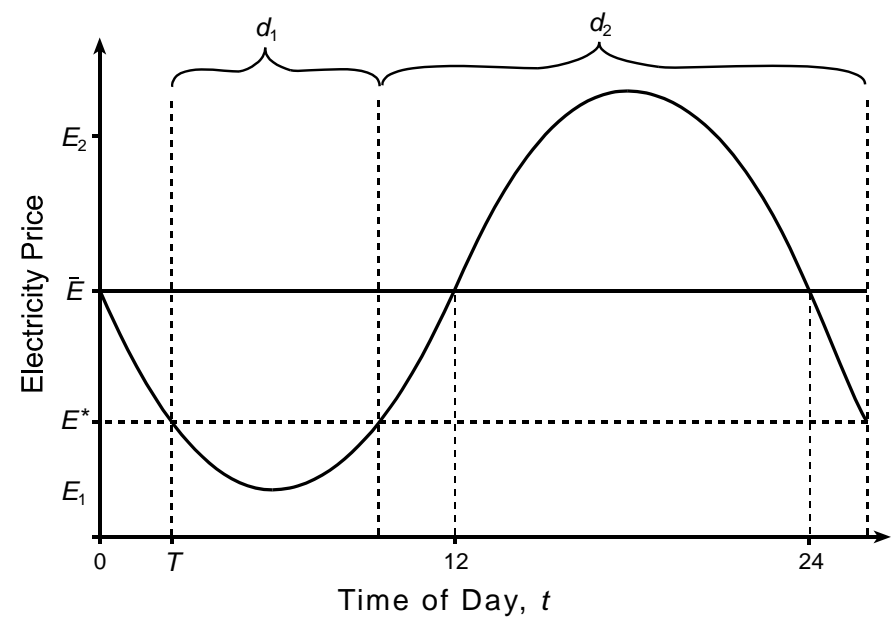

Fig. 24. The "sine wave" electricity price model, with an electricity price threshold, $E^{*}$, below the average value, $\bar{E}$.

At this point, the plant switches to ammonia production (mode 1), and remains thus until $t=12-T$, when power-only operation (mode 2 ) is again profitable. This cycle continues each day. The duration of the two operating modes are:

$$
d_{1}=12-2 T ; \quad d_{2} \equiv 24-d_{1} .
$$

and, as before, $f_{1} \equiv d_{1} / 24$ and $f_{2} \equiv d_{2} / 24$.

The average mode 1 electricity price from $t=T \rightarrow 12-T$ is:

$$
\langle E\rangle_{1}=\frac{1}{6-T} \int_{T}^{6} E(t) d t=\bar{E}\left[1-\frac{\lambda}{f_{1} \pi} \cos \left(\frac{\pi}{12} T\right)\right]=\bar{E}\left(1-\frac{\phi}{f_{1}}\right),
$$

where 


$$
\phi \equiv \frac{\lambda}{\pi} \cos \left(\frac{\pi}{12} T\right)=\frac{\lambda}{\pi} \cos \left[\sin ^{-1}\left(\frac{\lambda *}{\lambda}\right)\right] .
$$

As expected, when $T=0,\langle E\rangle_{1}=\bar{E}(1-2 \lambda / \pi)$, and as $T \rightarrow 6,\langle E\rangle_{1} \rightarrow \bar{E}(1-\lambda)$. The average daytime electricity price from $t=12 \rightarrow 24$ is:

$$
\langle E\rangle_{12 \rightarrow 24}=\frac{1}{12} \int_{12}^{24} E(t) d t=\bar{E}\left(1+\frac{2}{\pi} \lambda\right),
$$

and the average from $t=0 \rightarrow T$ (and also from $t=T \rightarrow 12$ ) is:

$$
\langle E\rangle_{0 \rightarrow T}=\frac{1}{T} \int_{0}^{T} E(t) d t=\bar{E}\left\{1+\frac{12 \lambda}{\pi T}\left[\cos \left(\frac{\pi}{12} T\right)-1\right]\right\}=\bar{E}\left[1+\frac{12}{T}\left(\phi-\frac{\lambda}{\pi}\right)\right] .
$$

As expected, at $T=0,\langle E\rangle_{0 \rightarrow T}=\bar{E}$, and at $T=6,\langle E\rangle_{0 \rightarrow T}=\bar{E}(1+2 \lambda / \pi)$. Thus, the average mode 2 electricity price is:

$$
\langle E\rangle_{2}=\frac{1}{d_{2}}\left[12\langle E\rangle_{12 \rightarrow 24}+2 T\langle E\rangle_{0 \rightarrow T}\right]=\bar{E}\left(1+\frac{\phi}{f_{2}}\right) \text {. }
$$

In analogy with Eq. 13, the daily plant revenue can be expressed as:

$$
R=f_{1}\left[e_{1}\langle E\rangle_{1}+a_{1} A\right]+f_{2} e_{2}\langle E\rangle_{2}=\bar{R}_{2}\left[1+(1-\rho)\left(\phi+f_{1} \lambda *\right)\right],
$$

and the fractional revenue enhancement as:

$$
\gamma=(1-\rho)\left(\phi+f_{1} \lambda *\right) \text {. }
$$

As with the "square wave" model, when the price excursion is smaller than the threshold value, i.e. $\lambda<\left|\lambda^{*}\right|$, then $\gamma=0$ if $\lambda^{*}$ $<0$, and $\gamma=(1-\rho) \lambda *$ if $\lambda^{*}>0$. Potential revenue enhancement using the "sine wave" price model is plotted as a function of $\lambda$ in Fig. 25 for $\rho=0.24$, and various artificially imposed values of $\lambda^{*}$; recall that $\lambda^{*} \sim 10 \%$ for our hybrid plant (blue dashes). The results are qualitatively similar to those seen for the "square wave" model in Fig. 20, but the slope of $\gamma$ (i.e. the ability of price variations to enhance revenue) is reduced by $36 \%$. This is, of course, because the "sine wave" (and actual) electricity prices cross the threshold price more "tentatively" (i.e. with a shorter duration) than in the crude "square wave" model. As a result, the rise in total hybrid

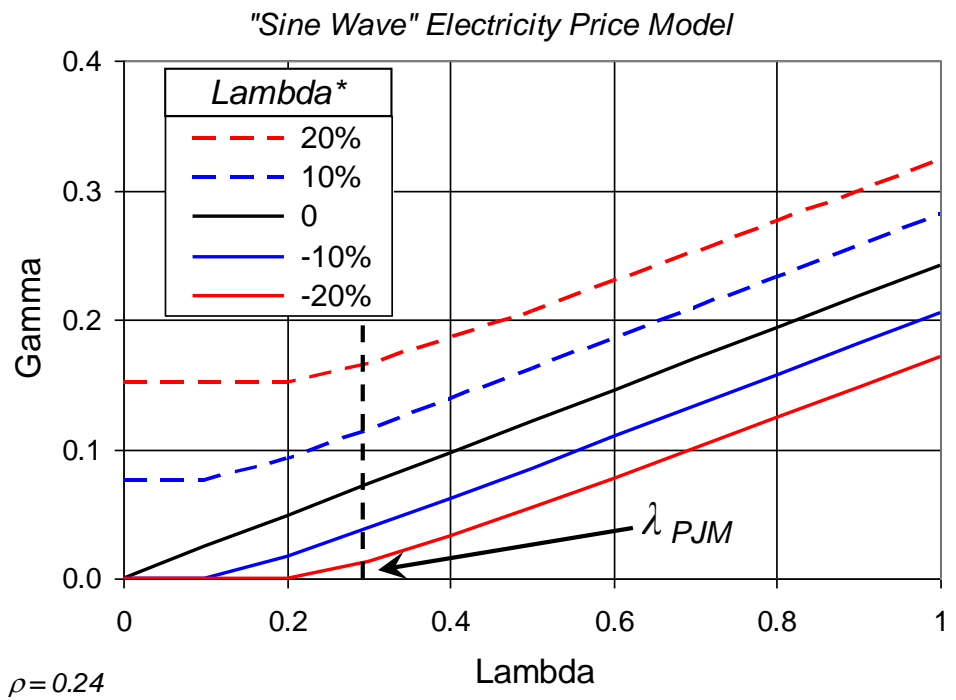

Fig. 25. Using the "sine wave" electricity price model, the fractional revenue enhancement, $\gamma$, is plotted versus $\lambda$, for various values of $\lambda^{*}$. plant IRRe with increasing $\lambda$ is seen in Fig. 23 (green line) to be significantly less dramatic than with the "square wave" model. In fact, at $\lambda_{P J M} \sim 0.3$, although the total plant IRRe for the flexible hybrid exceeds that of the dedicated IGCC-CCS by 0.83 $\% / \mathrm{yr}$, it is actually $0.51 \% / \mathrm{yr}$ lower than the IRRe of the dedicated ammonia plant. Thus, rather than commit to the additional capital and operational complexity for a flexible hybrid, it makes more economic sense to build a dedicated ammonia plant instead. Parenthetically, it is worth noting that, because the market prices of both ammonia and electric power are based on the price of natural gas, a hybrid plant does not offer any particular hedge against the possibility of falling gas prices. 


\subsubsection{Economic Analysis using Raw Electricity Prices}

Having developed a general, model for characterizing the diurnal variation in electricity prices and quantifying the revenue enhancement as a function of the magnitude of that variation, it is instructive to probe the underpinnings of this analysis. While the sine wave in Fig. 17 appears to adequately represent the average daily price excursion over three years, the raw (i.e. non-averaged) data (e.g. Fig. 16) varies much more significantly from the mean than does the sine wave. Since the hybrid plant is specifically designed to exploit price deviations, perhaps the averaging inherent in the sine wave model inhibits an accurate assessment of the plant's economic potential.

To test this hypothesis, we momentarily assume that the hybrid plant: 1) can switch operating modes instantaneously, and 2) chooses the most profitable mode each hour of the day based on the hourly LMP. As before, ammonia is produced (mode 2) when $E \leq E^{*}$, and only power is generated (mode 1) when $E>$ $E^{*}$. Given this scenario, it is sufficient to scan all 26,280 hourly LMPs underlying Fig. 17 and determine the average electricity prices in each mode, $\langle E\rangle_{1}$ and $\langle E\rangle_{2}$, and the fraction of time spent in each, $f_{1}$ and $f_{2}$. This enables a calculation of revenue, $R$ (via Eq. 29), and revenue enhancement, $\gamma$. [Instead of scaling the raw LMPs to their estimated values at a $\mathrm{CO}_{2}$ emission price of $100 \$$ tonne, we instead set the $\mathrm{CO}_{2}$ price to zero and shift the LMPs upward by $2.6 \$ / \mathrm{MWh}$ so that their mean value matches that in our electricity price model (Eq. 2)]. The results of this procedure, given in Table 5, indicates that the hybrid plant could achieve almost $18.9 \%$ enhancement in revenue (relative to pure power generation; $11.6 \%$ relative to $\mathrm{NH}_{3}$ production) if it were able to instantaneously switch back and forth on an hourly basis. This is significantly higher than the $10.6 \%$ enhancement (or $3.8 \%$ relative to $\mathrm{NH}_{3}$ production) given by the sine wave model, confirming that, by averaging out the "noise", the model hides the plant's theoretical economic potential, which is revealed by the raw LMP methodology.

Since it is clearly impractical for a real facility to switch modes on such a rapid time scale, we have replaced the hourly LMPs with rolling averages, assuming averaging "windows" that range from 1-6 hours. The results (Fig. 26 and Table 5) indicate that such averages reduce the revenue enhancement only slightly, even with averaging windows that are quite substantial. This appears to suggest that, even if operability constraints were to limit the minimum duration of each mode to, for example, 6 hours (unfortunately we do not have sufficient technical data to estimate these durations), it might be possible to achieve revenue enhancements much closer to those given by the raw LMP analysis than by the sine wave model. This raises the question: "How are such plants actually operated?" The sine wave analysis implicitly suggests that, based on historical diurnal cycles of electricity prices, one might operate a hybrid plant on a rigid schedule, switching between modes each day at fixed times. Instead, the raw LMP analysis allows the plant to respond directly to market signals, albeit at unrealistic rates. One could easily imagine developing and optimizing an algorithm for estimating/extrapolating very near-term future electricity prices (e.g. within the next 3-6 hours) based on immediately previous prices, historical prices and trends, current transmissions

Table 5. Raw LMP analysis, for two rolling averages.

\begin{tabular}{|l|cc|}
\hline & $\mathbf{1} \boldsymbol{h r}$ & $\mathbf{6} \boldsymbol{h r}$ \\
\hline$\langle E\rangle_{1}$ & 37.6 & 38.6 \\
$f_{1}$ & $76 \%$ & $74 \%$ \\
$\langle E\rangle_{2}$ & 87.4 & 79.6 \\
$f_{2}$ & $24 \%$ & $26 \%$ \\
$\gamma$ & $18.9 \%$ & $17.1 \%$ \\
\hline
\end{tabular}


congestion issues and other market data, and using those estimates to determine when to switch modes. Such an analysis is beyond the scope of this study, whose primary purpose is to quantify the magnitude of the gains that are possible by flexible coproduction.

\subsubsection{Peak Power Generation Using Incremental Equipment}

Closely related to the flexible hybrid plant is the concept of enhancing the economics of a gasification-based polygeneration plant by: 1) increasing its capacity to produce a gas turbine (GT) fuel (e.g. syngas, hydrogen, methanol, FT liquids, synthetic natural gas, etc.), 2) store the (continuously produced) incremental GT fuel during times of low electricity prices, and 3) generate electricity during times of peak power prices by burning the stored fuel in either a simple cycle GT or a combined cycle (perhaps integrated with the polygeneration plant's bottoming cycle). The primary competitor in this market is NGCC and NG-fired simple cycle GTs, which currently provide the bulk of the grid's peaking power and, as marginal generators, set the price of electricity (as discussed above). Thus, the economic viability of "incremental peak power generation" requires that the cost of incremental fuel production and storage be lower than the price of natural gas.

Estimates for the production cost of incremental fuel depend to a large degree on the assumptions made about the cost of the extra equipment required (e.g. incremental capacity in feedstock handling and preparation, gasification, syngas cleaning and processing, and fuel synthesis). Situations might occur in which "piggybacking" on a large polygeneration plant could lead to cost savings. However, in general, if the plant is already well designed and optimized to maximize profitability (without exogenous constraints that lead to underutilized capacity within the plant, or sub-optimal equipment sizing and training), incremental fuel cannot be produced at a cost that is significantly lower than the cost of the plant's primary fuel. [If this were possible, then the original plant was clearly not optimized, having failed to take advantage of this low cost fuel production capability.] Therefore, the cost of producing incremental fuels can be readily estimated by disaggregating the production costs of various intermediate fuels in polygeneration plants described elsewhere. For example, at zero $\mathrm{CO}_{2}$ emissions price, the coal gasification-based production cost (\$/GJ, LHV) of some typical fuels are: $\mathrm{H}_{2} \sim 10.5$, methanol $\sim 10$, and FTL 13. Neglecting the cost of incremental fuel storage, which is quite significant for gaseous fuels, these production costs are all significantly higher than the price of natural gas $(6 \$ / \mathrm{GJ} \mathrm{HHV}$ is the nominal price assumed here). Due to NG's relatively low carbon intensity ( $\sim 15.5 \mathrm{~kg} \mathrm{C} / \mathrm{GJ} \mathrm{LHV})$, the comparison becomes even less favorable with increasing $\mathrm{CO}_{2}$ emissions prices; for example, at 100 $\$$ /tonne $\mathrm{CO}_{2}$, the effective NG price rises by only $5.1 \$ / \mathrm{GJ} \mathrm{HHV}$, much less than the cost increase for other coal-based incremental fuels (except for $\mathrm{H}_{2}$ from coal with CCS, which is particularly difficult and costly to store). In short, until NG prices rise well into the double digits, incremental peak power generation does not appear to be an economically viable proposition; furthermore, if it is accompanied by high $\mathrm{CO}_{2}$ emissions prices, the incremental fuels must have a relatively low carbon signature to compete with gas. 


\section{Conversion of Coal to Electricity and $\mathrm{H}_{2}$ with $\mathrm{CO}_{2}$ Capture and Storage}

In analogy with our analysis in Section 1 on $\mathrm{NH}_{3}$ + electricity coproduction, we consider here both an IGCC-CCS and a $\mathrm{H}_{2}$ plant with a small electricity coproduct. This work draws heavily on the results of Chiesa (2005) and Kreutz (2005), cases EPQ and HPQ. Since the results of Kreutz (2005) indicate that coal gasification-based production of electricity and $\mathrm{H}_{2}$ is more economical when the raw syngas exiting the gasifier is cooled using a total water quench instead of radiative + convective heat exchange, we employ the former (with a GE gasifier) in this section. Otherwise, the IGCC design is very similar to that described above in Section 1. The power island is based on Siemens (instead of GE) gas turbines, model V94.3a ( 266 MWe on NG) when producing only power and model V64.3a $(\sim 67 \mathrm{MWe}$ on $\mathrm{NG}$ ) when producing $\mathrm{H}_{2}$.

The performance of two plants (with CCS), an IGCC and $\mathrm{H}_{2}$ production plant (with a small electricity co-product) are given in Table 6. In Table 7 we provide disaggregated component capital cost estimates obtained used the same capital costing model employed throughout this study.

In order to estimate the profitability of a coalbased $\mathrm{H}_{2}$ plant, a market value for $\mathrm{H}_{2}$ is required. Because $\mathrm{H}_{2}$ is not readily transported, a global market for $\mathrm{H}_{2}$ does not exist. However, like ammonia, the vast majority of $\mathrm{H}_{2}$ is produced from natural gas via steam reforming of methane (SMR) - primarily for ammonia production (Appl, 1997). Thus, we assume that the value of $\mathrm{H}_{2}$ equals the cost of producing $\mathrm{H}_{2}$ from NG via SMR, and adopt the economics in NRC (2004) for "central station" scale (110.2 tonne/day) $\mathrm{H}_{2}$ production using current SMR technology. This cost, (at zero $\mathrm{CO}_{2}$ emissions price), $H_{o}(N)$ (\$/tonne), can be written:

$$
H_{o}(N)=\delta_{1}+\delta_{2} N \text {, }
$$

where $\delta_{1}=329 \$ /$ tonne $\mathrm{H}_{2}, \delta_{2}=231 \mathrm{GJ}$ NG

$\mathrm{HHV} /$ tonne $\mathrm{H}_{2}$, and $N$ is the price of natural gas $(\$ / \mathrm{GJ}$ $\mathrm{HHV})$. We further assume that the cost/value of $\mathrm{H}_{2}$, $H(N, P)(\$ /$ tonne) rises with $\mathrm{GHG}$ emissions price, $P$ (\$/tonne), i.e.,

$$
H(N, P)=H_{o}(N)+G_{H} P, \quad \text { (32) }
$$

where $G_{H}$ is the carbon intensity of $\mathrm{H}_{2}$ production, 8.94 tonne $\mathrm{CO}_{2}$ / tonne $\mathrm{H}_{2}$, assuming an SMR conversion efficiency of $76.2 \%$ LHV (NRC 2004).

Plant economics, calculated using the same methodology as that employed in Section 1 above

Table 6. Plant performance, with breakdown of power consumption by unit.

\begin{tabular}{|l|cc|}
\hline & IGCC & H $_{2}$ Plant \\
\hline Power Consumption, MWe: & & \\
$\mathrm{O}_{2}$ production & 28.5 & 53.9 \\
$\mathrm{O}_{2}$ compression & 18.2 & 34.4 \\
$\mathrm{~N}_{2}$ compression & 28.5 & 0.0 \\
$\mathrm{CO}_{2}$ drying \& compression & 22.8 & 43.1 \\
PSA purge gas compressor & 0.0 & 11.7 \\
Auxiliaries (+ Selexol, PSA) & 23.0 & 36.3 \\
Auxiliary power, MWe & 120.9 & 179.4 \\
GT net power & 293.7 & 78.8 \\
ST net power & 179.3 & 139.5 \\
Syngas expander & 9.8 & 0.0 \\
Net electric power, $M W e$ & 361.9 & 38.9 \\
Co-product $\mathrm{H}_{2}$, tonne/day & - & 771.0 \\
\hline Coal input, MW $\mathrm{MH}_{\mathrm{th}} \mathrm{LHV}$ & 983.6 & $1,862.7$ \\
Overall carbon capture, \% & 91.3 & 91.3 \\
\hline
\end{tabular}

Table 7. "Overnight" capital costs (M\$) for major plant

\begin{tabular}{|c|c|c|}
\hline Plant component & $I G C C$ & $\mathrm{H}_{2}$ Plant \\
\hline Coal and sorbent handling & 29.6 & 45.4 \\
\hline Coal preparation \& feeding & 40.6 & 73.0 \\
\hline Ash handling & 37.4 & 57.3 \\
\hline Stand-alone ASU $+\mathrm{O}_{2}$ compressor & 127.2 & 231.0 \\
\hline Shell gasifier \& SG coolers & 86.0 & 154.8 \\
\hline LT heat recovery \& FG saturation & 22.9 & 41.1 \\
\hline Water-gas shift reactors & 10.6 & 19.0 \\
\hline Gas cleanup BOP & 6.9 & 12.4 \\
\hline AGR $\left(\mathrm{H}_{2} \mathrm{~S}\right.$ capture only $)$ & 72.0 & 129.6 \\
\hline AGR $2^{\text {nd }}$ stage $\left(\mathrm{CO}_{2}\right.$ capture $)$ & 64.0 & 115.2 \\
\hline Claus plant & 33.8 & 51.9 \\
\hline $\mathrm{CO}_{2}$ compression and drying & 38.0 & 68.4 \\
\hline Siemens V64.3A gas turbine & 0.0 & 45.2 \\
\hline Siemens V94.3A gas turbine & 107.4 & 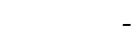 \\
\hline HRSG, ductwork, \& stack & 39.6 & 16.4 \\
\hline Steam turbine, condenser $\&$ aux. & 55.6 & 47.0 \\
\hline Pressure Swing Adsorption (PSA) & 0.0 & 38.1 \\
\hline PSA purge gas compressor & 0.0 & 12.1 \\
\hline Balance of plant & 141.0 & 211.6 \\
\hline Total Plant Cost (TPC), M\$ & 912.6 & 1,369 \\
\hline
\end{tabular}
components, and total plant cost (TPC) for each case. 
(e.g. Table 2), are summarized in Table 8. A NG price of $6 \$ / G J ~ H H V$ and a $\mathrm{CO}_{2}$ emissions price of $100 \$$ /tonne are generally assumed, except where indicated. Note that $\mathrm{CO}_{2}$ disposal costs vary between the two plants because of the different flow rates of stored $\mathrm{CO}_{2}$. The LCOE in Table 8 for the GE-quench-based IGCC is seen to be quite similar to (but slightly larger than) that of the Shell-based IGCC in Section 1 above, 100 \$/MWh. As in Section 1, at a gas price of $6 \$ / G J$ $\mathrm{HHV}$, the value of electricity ( $\sim 91$ $\$ / \mathrm{MWh}$ ) is somewhat smaller than the LCOE, leading an IRRe $<10.2 \%$, i.e. an unprofitable plant. However, the $\mathrm{H}_{2}$ plant has a levelized cost of $\mathrm{H}_{2}(\mathrm{LCOH})$ significantly smaller than that of SMRbased $\mathrm{H}_{2}$ (Eq. 32), yielding an IRRe of $27.7 \%$. Similar to the situation seen in Fig. 14, the profitability of the $\mathrm{H}_{2}$ plant always exceeds that of the IGCC throughout the space of $\mathrm{NG}$ price and $\mathrm{CO}_{2}$ emissions price, except that the difference is substantially larger than in the case of ammonia.
Table 8. $L C O E, L C O H$ and IRRe. (Default NG price: 6 \$/GJ HHV.)

\begin{tabular}{|c|c|c|}
\hline Cost component (mid-2008 US \$) & $\begin{array}{c}I G C C \\
(\$ / M W h)\end{array}$ & $\begin{array}{l}\mathrm{H}_{2} \text { Plant } \\
\left(\$ / \mathrm{kg} \mathrm{H}_{2}\right)\end{array}$ \\
\hline Installed capital (at $14.4 \%$ of TPI) & 52.16 & 0.882 \\
\hline O\&M (at $4 \%$ of TPC per yr) & 13.54 & 0.229 \\
\hline Coal (at $1.71 \$ / G J, H H V)$ & 17.62 & 0.376 \\
\hline $\mathrm{CO}_{2}$ disposal (at 8.4/6.9 \$/mt $\mathrm{CO}_{2}$ ) & 7.02 & 0.123 \\
\hline Electricity credit (at $49.4 \$ / \mathrm{MWh}$ ) & 0.00 & -0.060 \\
\hline LCOE, LCOH (no carbon price) & 90.33 & 1.550 \\
\hline $\mathrm{CO}_{2}$ emissions (at $100 \$ /$ tonne $\mathrm{CO}_{2}$ ) & 11.59 & 0.247 \\
\hline Electricity credit (at 91.5 $\$ / \mathrm{MWh}$ ) & 0 & -0.111 \\
\hline $\mathrm{LCOE}, \mathrm{LCOH}\left(\right.$ at $100 \$$ /tonne $\left.\mathrm{CO}_{2}\right)$ & 101.92 & 1.746 \\
\hline Market values of NG-based products & 91.45 & 2.609 \\
\hline $\operatorname{IRRe}(P=100 \$ /$ tonne, $N=6 \$ / G J), \% / y r$ & 5.7 & 27.7 \\
\hline $\operatorname{IRRe}(P=100 \$ /$ tonne, $N=8 \$ / G J), \% / y r$ & 11.9 & 35.9 \\
\hline
\end{tabular}




\section{References}

Aspen, 2008. “Aspen Plus Ammonia Model”, Aspen Technology, Inc., Version 7.0, July.

Appl, 1997, “Ammonia Methanol Hydrogen Carbon Monoxide - Modern Production Technologies”, Max Appl, Nitrogen. ISBN 1-873387-26-1.

Appl, M., 1999. “Ammonia: Principles and Industrial Practice”, Wiley-VCH, Weinheim, Germany, 1999

Barkley, N.E., 2006. "Petroleum Coke Gasification Based Ammonia Plant", AIChE $51^{\text {st }}$ Annual Safety in Ammonia Plants and Related Facilities Symposium, Vancouver, Canada.

Borer, E.T., 2012. Princeton University Energy Plant Manager, personal communication, Jan. 17.

Dybkjaer, I., 1995. “Ammonia Production Processes”, in “Ammonia Catalysis and Manufacture”, A. Nielsen (Ed.), New York, Springer-Verlag: 199-328.

CE, 2011. Chemical Engineering, http://www.che.com/pci/, accessed 28 Oct.

Chemlink, 2011. “Ammonia in Australia”, Chemlink Consultants, http://www.chemlink.co.au/ammoniasummary.htm, accessed 25 Oct.

Chen, 2011. "Optimal Design and Operation of Flexible Energy Polygeneration Systems”, Y. Chen, T.A. Adams II, and P.I. Barton, Ind. Eng. Chem. Res. $504553-4566$.

Chiesa, 2005. "Coproduction of Hydrogen, Electricity, and $\mathrm{CO}_{2}$ from Coal with Commercially Ready Technology. Part A: Performance and Emissions”, P. Chiesa, S. Consonni, T. Kreutz, and R. Williams, International Journal of Hydrogen Energy, 30 747-767.

Christensen, P.V., 2001. "Design and Operation of Large Capacity Ammonia Plants", Proceedings of the 4th Conference for Development and Integration of Petrochemical Industries in the Arab States, Bahrain, 7-8 May.

EIA, 2010. Electric Power Annual 2010, Energy Information Administration, http://www.eia.gov/electricity/annual/; accessed 14 Dec 2011.

EIA, 2011. Energy Information Administration, Natural Gas Prices: http://205.254.135.24/naturalgas/data.cfm\#prices, accessed 26 Oct.

EPRI, 1993. "TAG - Technical Assessment Guide (Electric Supply)", Electric Power Research Institute, EPRI Report TR-102275, Vol. 1 Rev. 7. Paolo Alto, CA, June.

FERC, 2011. "PJM Electric Market: Overview and Focal Points", Federal Energy Regulatory Commission, 6 Jan. http://ebookbrowse.com/01-2011-elec-pjm-archive-pdf-d273485506, accessed 4 Feb. 2012.

GAO, 2003. "NATURAL GAS - Domestic Nitrogen Fertilizer Production Depends on Natural Gas Availability and Prices", United States General Accounting Office (GAO) Report (\#GAO-03-1148) to the Ranking Democratic Member, Committee on Agriculture, Nutrition and Forestry, U.S. Senate, Sept.

Han, 2011. Dr. Pat Han, Technology Supervisor for Topsoe Ammonia Technology, personal communication, 14 Oct.

Højlund Nielsen, P.E., 1995. "Poisoning of Ammonia Synthesis Catalysts", in "Ammonia Catalysis and Manufacture”, A. Nielsen (Ed.), New York, Springer-Verlag: 191-198.

Hooper, C.W., 1991. “Ammonia Synthesis: Commercial Practice”, in "Catalytic Ammonia Synthesis: Fundamentals and Practice”, J.R. Jennings (Ed.), Plenum Press, New York.

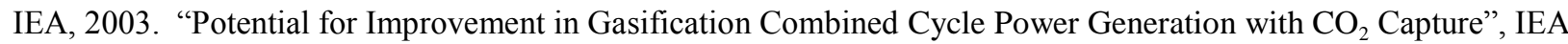
Greenhouse Gas R\&D Programme Report PH4/19, (cases A.1 and B.3), May.

IEA, 2007. "Tracking Industrial Energy Efficiency and $\mathrm{CO}_{2}$ Emissions", International Energy Agency, OECD Publishing.

IFA, 2010. International Fertilizer Industry Association - Fertilizer supply statistics http://www.fertilizer.org/ifa/Home-Page/STATISTICS/Fertilizer-supply-statistics, accessed 15 May. 
Kreutz, 2005. "Coproduction of Hydrogen, Electricity, and CO2 from Coal with Commercially Ready Technology. Part B: Economic Analysis", T. Kreutz, R. Williams, S. Consonni, and P. Chiesa, International Journal of Hydrogen Energy 30, 769-784.

Mak, 2004. "Synthesis Gas Purification in Gasification to Ammonia/Urea Complex", J.Y. Mak, D. Heaven, D. Kubek, C. Sharp, M. Clark, Proceedings of the 2004 Gasification Technologies Conference, Washington, DC, 3-6, Oct.

Mann, D., 2009. "Global Ammonia Market Update", KBR 2009 Technology Conference - Ammonia \& Syngas, Dubai, UAE, 5-6 Oct.

Martelli, 2011. "Shell Coal IGCCs with Carbon Capture: Conventional Gas Quench vs. Innovative Configurations", E. Martelli, T.G. Kreutz, M. Carbo, S. Consonni, and D. Jansen, Applied Energy 88, 3978-3989.

Maurer, 1988. "Vapor-Liquid Equilibrium in Aqueous Solutions of Ammonia and Carbon Dioxide at Temperatures Between 333 and 393 K and Pressure up to 7 MPa", Goppert U. and Maurer G., Fluid Phase Equilibrium 41, 153.

Maxwell, G.R., 2004. "Synthetic Nitrogen Products: A Practical Guide to the Products and Processes", Kluwer Academic Publishers, New York.

Meerman, 2011. "Performance of Simulated Flexible Integrated Gasification Polygeneration Facilities. Part A: A Technical-energetic Assessment", J.C. Meerman, A. Ramírez, W.C. Turkenburg, A.P.C. Faaij, Renewable and Sustainable Energy Reviews 15, 2563-2587.

NETL, 2007. Cost and Performance Comparison Baseline for Fossil Energy Power Plants, Volume 1: Bituminous Coal and Natural Gas to Electricity"”, DOE/NETL-401/053106, Final Report, May.

NETL, 2011. "Cost and Performance Baseline for Fossil Energy Plants, Volume 2: Coal to Synthetic Natural Gas and Ammonia", DOE/NETL-2010/1402, Final Report, 5 July.

Nexant, 2009. "Ammonia and Urea Strategic Business Analysis - 2009/10 Prospectus", Chemsystems/Nexant, http://tinyurl.com/42tndh7, accessed 27 Oct 2011.

NPCC, 2005. "The Fifth Northwest Electric Power and Conservation Plan", Northwest Power and Conservation Council, Jul. http://www.nwcouncil.org/energy/powerplan/5/Default.htm, accessed 4 Feb. 2012.

NRC, 2004. "The Hydrogen Economy: Opportunities, Costs, Barriers, and R\&D Needs", National Research Council (NRC), The National Academies Press, Washington, DC, 4 Aug 2004. http://www.nap.edu/catalog/10922.html, accessed 29 Mar 2012.

Ogden, J., 2002. "Modeling Infrastructure for a Fossil Hydrogen Energy System with $\mathrm{CO}_{2}$ Sequestration", Proceedings of the 6th International Meeting on Greenhouse Gas Control (GHGT-6), Kyoto, Japan, 1-4 Oct.

Puga, J.N., 2010. "The Importance of Combined Cycle Generating Plants in Integrating Large Levels of Wind Power Generation", The Electricity Journal 23(7), 33-44.

Tøpsoe, 2011. “Topsøe Ammonia Technology”, Haldor Topsøe, Inc.,

http://www.topsoe.com/business_areas/ammonia/ /media/PDF\%20files/Ammonia/topsoe_ammonia_technology.ash $\underline{\mathrm{x}}$, accessed 25 Oct.

Topsøe, 2011b. "Topsøe Technology: Radial Flow Ammonia Synthesis Converters", http://www.topsoe.com/business areas/ammonia/processes/ /media/PDF\%20files/Ammonia/Topsoe_radial_flow_c onverters.ashx, accessed 25 Oct.

Topsøe, 2011c. "KM1/KM1R - The Heart of the Ammonia Plant", http://www.topsoe.com/business areas/ammonia/processes/ /media/PDF\%20files/Ammonia/km1_ammonia_synthe sis_catalyst_april2011.ashx, accessed 25 Oct.

Twigg, M.V., 1996. “Catalyst Handbook, 2nd Edition”, Manson Publishing, London.

Vavatuk, W.M., 2002. "Updating the CE plant cost index”, Chemical Engineering, pp. 62-70, Jan. 


\title{
Appendix E
}

\section{Process Design and Analysis for Stand-Alone Solid Oxide Fuel Cell Power Generation}

\author{
Andrea Lanzini \\ Thomas G. Kreutz
}

\section{Contents}

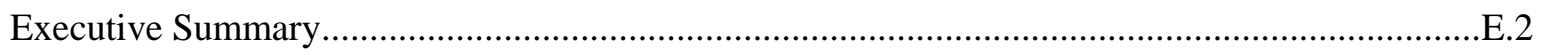

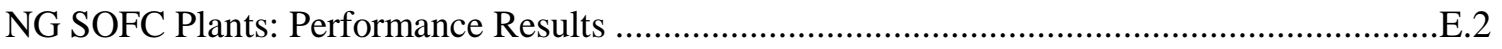

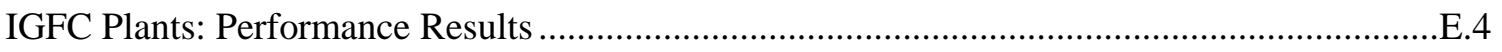

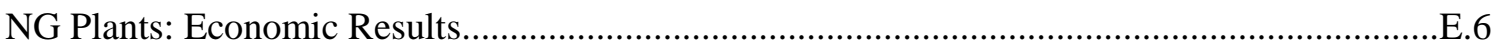

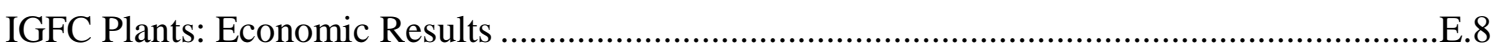

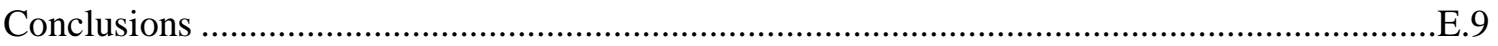

1 Introduction: High Temperature Fuel Cell Systems ......................................................... 10

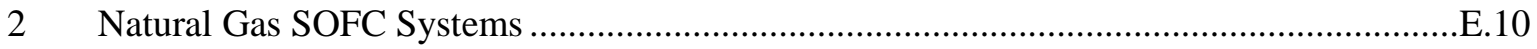

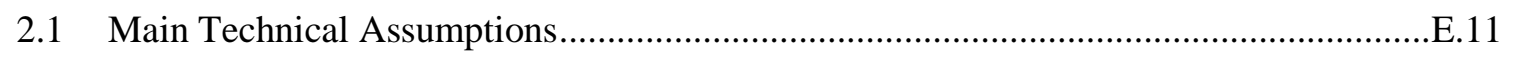

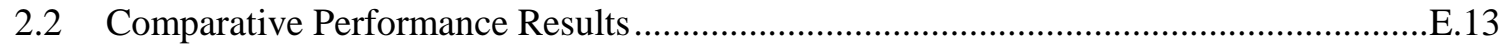

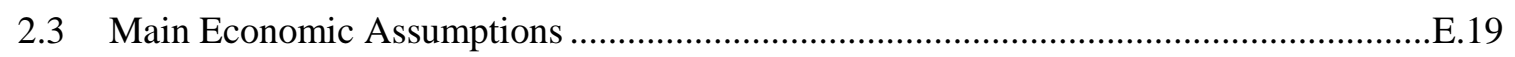

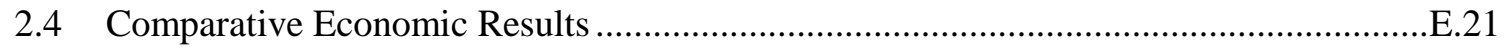

3 Integrated Coal Fuel Cell (IGFC) Systems …................................................................23

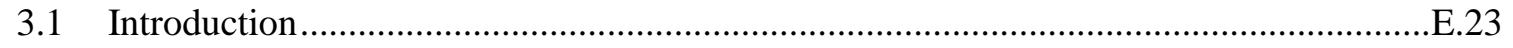

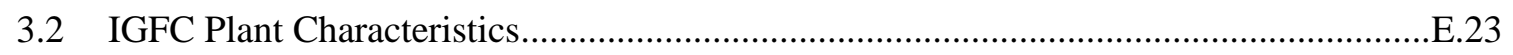

3.3 IGFC plants with Cryogenic Air Separation Unit .........................................................27

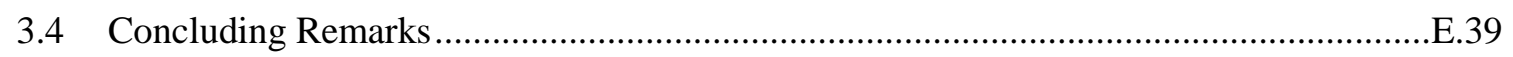

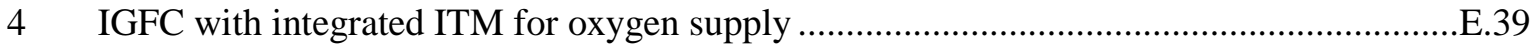

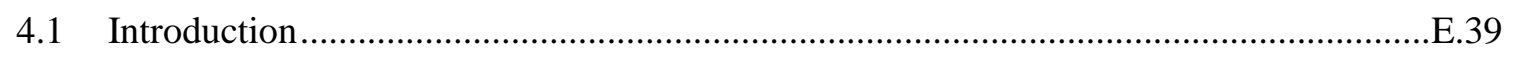

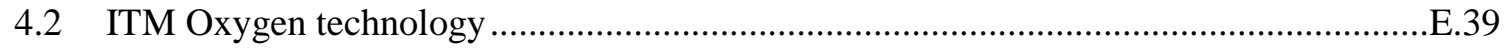

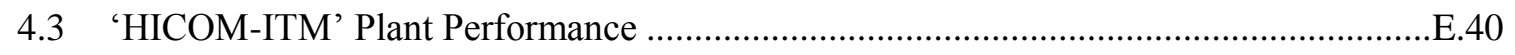

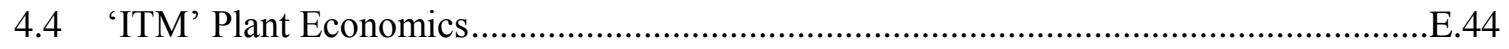

4.5 Additional Considerations on the Cost of ITM Reactors .................................................45 


\section{Executive Summary}

Techno-economic analyses of advanced power cycles based on Solid Oxide Fuel Cells (SOFCs) indicate their potential for high fuel-to-power conversion efficiency as well as competitive economic performance; these may ultimately lead to the widespread diffusion of SOFC as large base-load power generators. Market penetration of these electrochemical power generators will depend upon 1) achievement of the high efficiencies predicted by system analyses, 2) long lifetime and good reliability of the SOFC power island, and 3) cost reduction of the manufacturing processes for the fuel cell and fuel cell stack. In particular, the basic cost for the SOFC active area ${ }^{1}$ will have a large impact on future profitability of such plants.

This study compares the thermodynamic and economic performance of large scale (hundreds of MWe) SOFC-based plants fueled by bituminous coal or natural gas (NG).

Table 1. Main plant configurations analyzed in this study

\begin{tabular}{|c|c|c|}
\hline Natural gas (NG) & $\mathrm{CO}_{2}$ vented $(\mathbf{V})$ & $\mathrm{CO}_{2}$ captured $(\mathbf{C C S})$ \\
\hline Atmospheric (A) & NGSOFC-A-V & NGSOFC-A-CCS \\
\hline Pressurized to 20 bar $(\mathbf{P})$ & NGSOFC-P-V & NGSOFC-P-CCS \\
\hline \multicolumn{3}{|l|}{ Coal-syngas (IGFC) } \\
\hline Atmospheric $(\mathbf{A})$ & IGFC-A-V & IGFC-A-CCS \\
\hline Pressurized to 20 bar $(\mathbf{P})$ & IGFC-P-V & IGFC-P-CCS \\
\hline
\end{tabular}

In our study of Integrated Gasifier Fuel Cell (IGFC) plants, three different fuel cleaning \& processing strategies were assessed while quantifying the effect of different syngas composition on the performance of both the SOFC power island and overall plant. In particular, syngas methanation upstream of the SOFC was included in two of the three IGFC cases (HICOM and TREMP) in order to investigate the effect of increasing the methane content of the SOFC feed gas; the remaining plant (DIRECT) serves as the reference case without methanation. The IGFC plant with highest overall efficiency, HICOM, employed direct methanation of the syngas following syngas cleaning (to remove impurities and sulfur); $\mathrm{CO}_{2}$ was captured downstream of the SOFC via oxy-combustion of the anode exhaust, cooling and water condensation/knock-out. The other IGFC plant configuration with methanation, TREMP, was penalized by the energy intensive Rectisol process, used to capture both $\mathrm{H}_{2} \mathrm{~S}$ and $\mathrm{CO}_{2}$.

Finally, in the IGFC-HICOM plant, an Ion Transfer Membrane (ITM) integrated with the SOFC was studied as an alternative method for providing oxidant for the gasifier and the anode oxy-combustor, replacing the cryogenic air separation unit (ASU) used in some of our other designs.

\section{NG SOFC Plants: Performance Results}

Figure 1 shows the performance of NG fueled SOFC power cycles - both with and without carbon capture - for systems with and without SOFC pressurization. The HHV efficiency achieved ranges from $55.6 \%$ to almost $70 \%$ (or $65-76 \%$ LHV).

SOFC pressurization to 20 bar strongly improves plant performance. The benefits of pressurization are: 1) enhanced Nernst voltage, 2) enhanced cell (stack) polarization, and 3) better efficiency of the combined Brayton and Rankine bottoming cycles.

\footnotetext{
${ }^{1}$ The SOFC active area refers to the active area of the stack assembly, which essentially includes 'cell+sealant+interconnector'.
} 


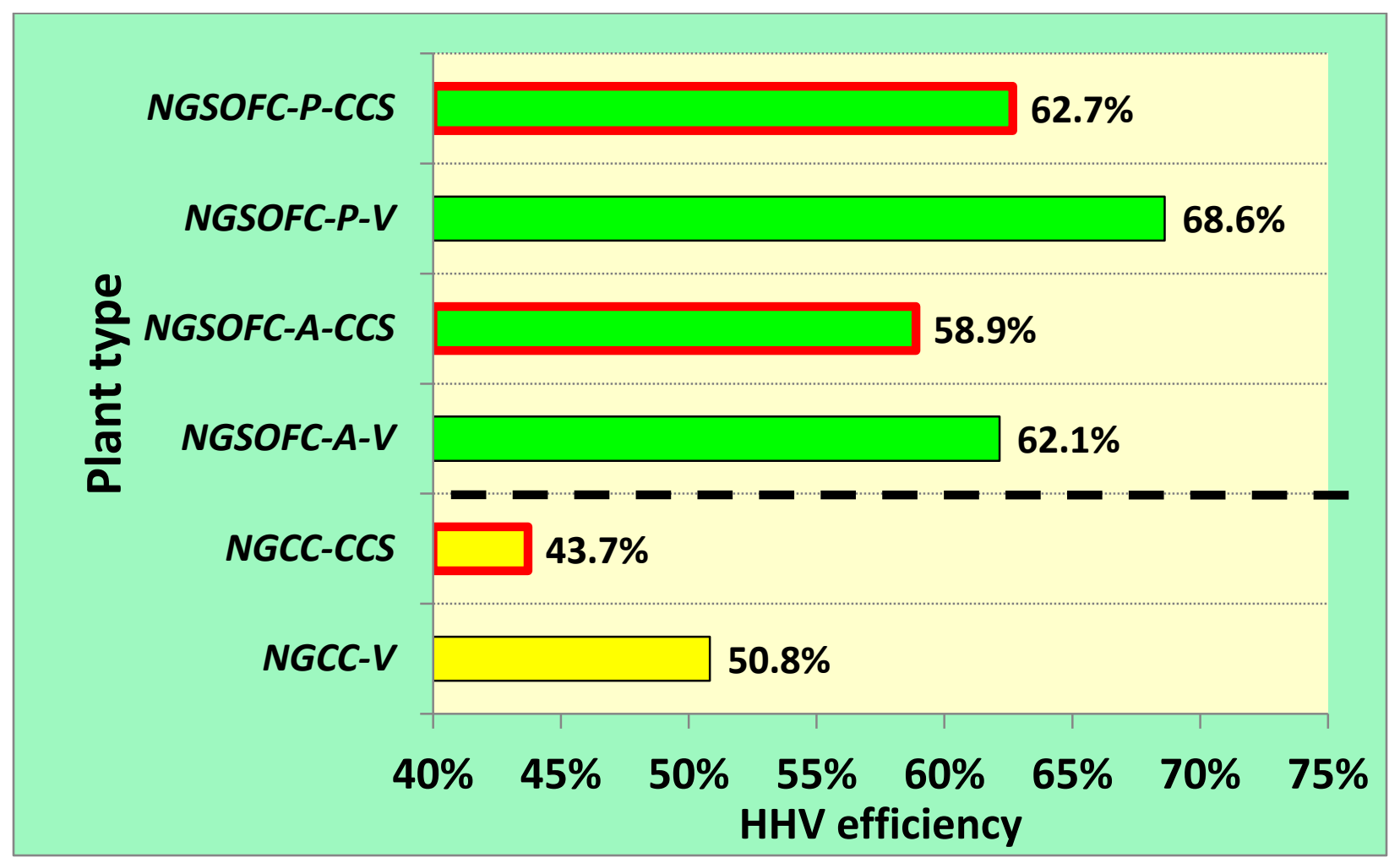

Figure 1. Performance results for natural gas SOFC power plants.

( $\mathrm{A}=$ atmospheric pressure. $\mathrm{P}=$ pressurized. $\mathrm{V}=\mathrm{CO} 2$ vented. $\mathrm{CCS}=\mathrm{CO} 2$ captured and stored.)

$\mathrm{CO}_{2}$ capture significantly reduces SOFC plant efficiency, but the loss is smaller than for $\mathrm{CO}_{2}$ capture in conventional NG-fired combined cycles (NGCC). The efficiency penalty is more pronounced in pressurized SOFC plants than in their atmospheric analogs. ${ }^{2}$ Figure 2 and Figure 3 show Sankey diagram for cases NGSOFC-P-V and NGSOFC-P-CCS, respectively.

${ }^{2}$ About half of the efficiency penalty of 6.6 percentage points for NGSOFC-P-CCS relative to the corresponding V-plant is due to oxygen production and $\mathrm{CO}_{2}$ compression duties. A less efficient bottoming cycle design also contributes. 
Net AC plant efficiency: $68,6 \%$ (HHV)

Auxiliaries: $20,4 \mathrm{MJ}$

Other parasitic losses: $5,7 \mathrm{MJ}$

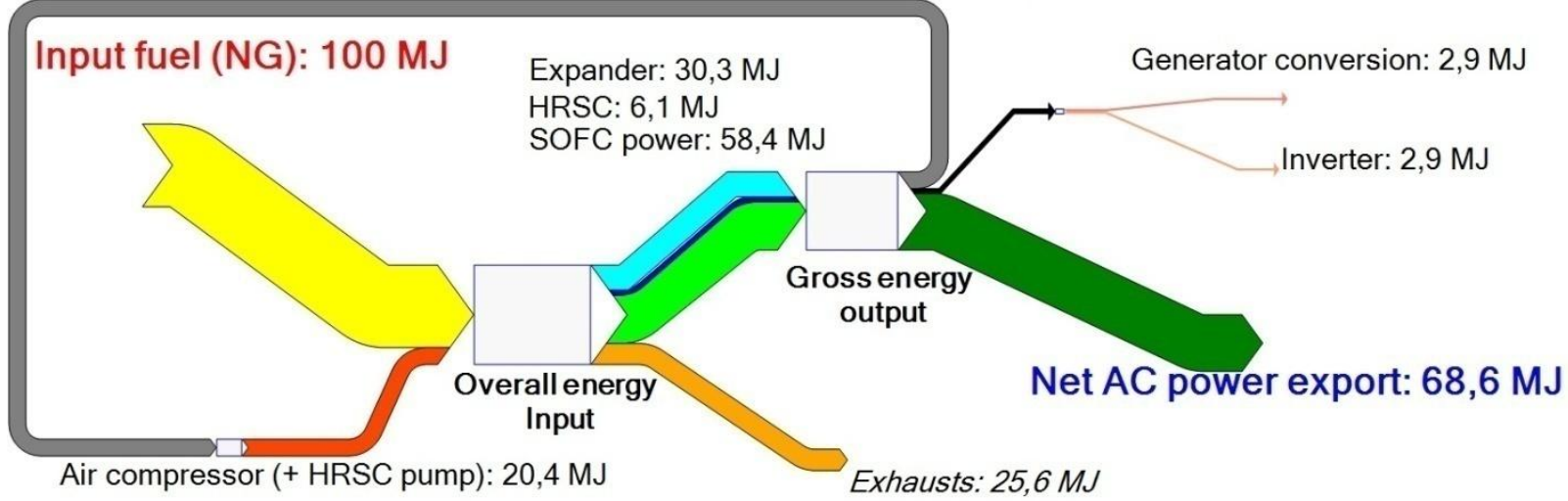

Figure 2. Sankey diagram for the NGSOFC-P-V case.

Net AC plant efficiency: 62,7\% (HHV)

Auxiliaries: $20,7 \mathrm{MJ}$

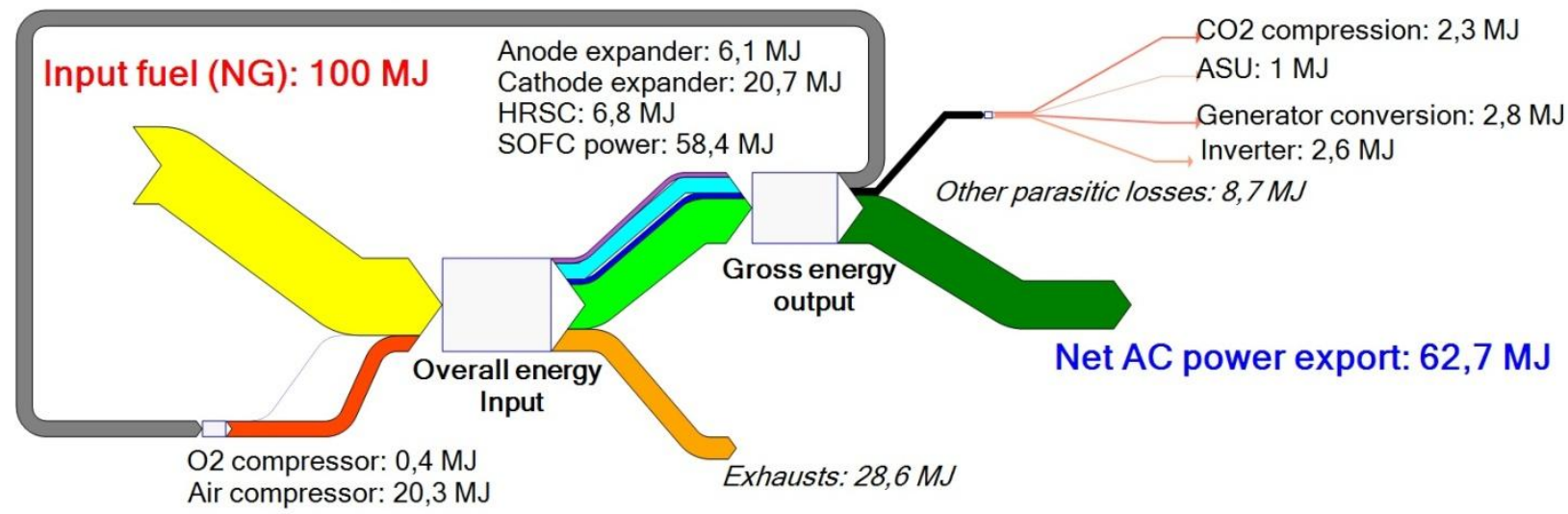

Figure 3. Sankey diagram for the NGSOFC-P-CCS case.

\section{IGFC Plants: Performance Results}

Figure 4 compares the HHV efficiency of three different IGFC plant configurations, two of which (TREMP and HICOM) employ methanation upstream of the SOFC power island by means of a single adiabatic catalytic methanation reactor and partial recirculation of the cooled (via steam generation) product stream. The HICOM case, whose methanation occurs in a high CO-tolerant reactor without upstream WGS and $\mathrm{CO}_{2}$ removal, has the highest overall plant efficiency. In contrast, the TREMP case employs both WGS and Rectisol-based $\mathrm{CO}_{2}$ capture upstream of methanation, both of which cause significant efficiency losses. 


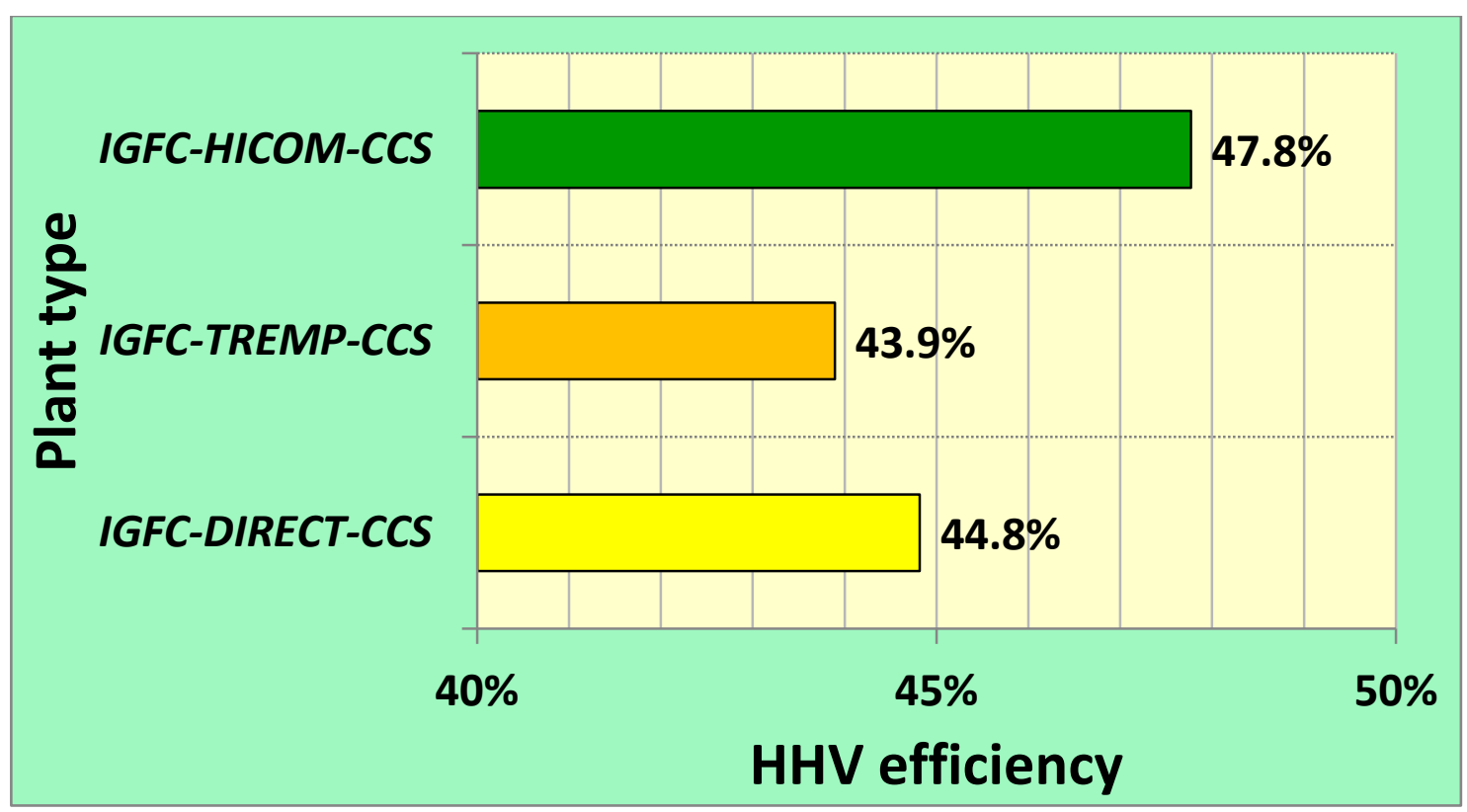

Figure 4. Comparison of different syngas processing strategies upstream of the SOFC in IGFC plants.

Figure 5 shows the efficiency of IGFC-HICOM power cycles with and without $\mathrm{CO}_{2}$ capture and with oxidant produced either by conventional ASU or by ITM integrated with the SOFC. The efficiency penalty for $\mathrm{CO}_{2}$ capture is $\sim 9$ percentage points for the IGCC, but only $\sim 4$ percentage points for the IGFC plants regardless of oxidant source.

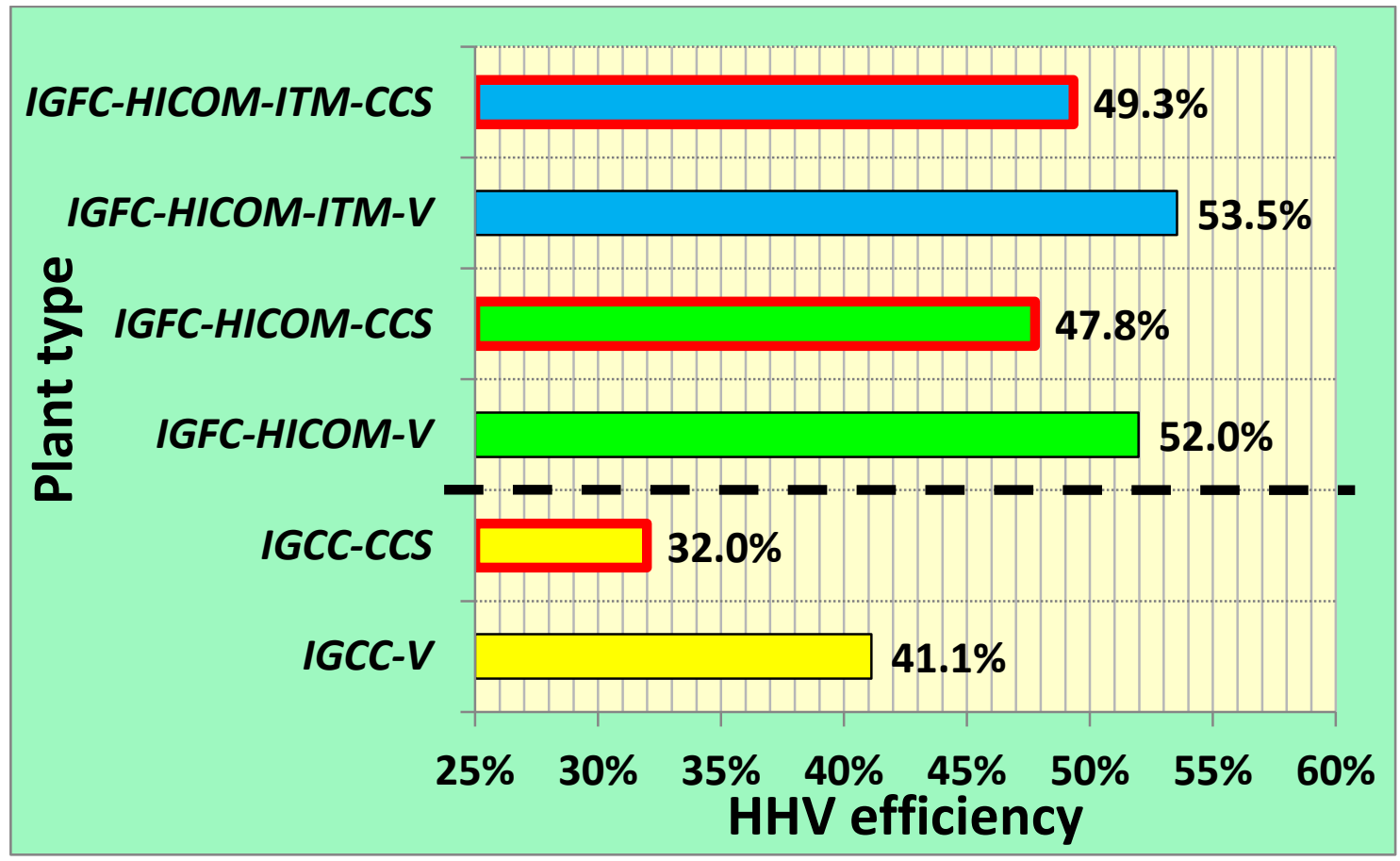

Figure 5. Performance results for IGFC power plants without and with carbon capture. 


\section{NG Plants: Economic Results}

Levelized costs of electricity (LCOE) for the NG-based power plants studied here are given in Figure 6 for various $\mathrm{CO}_{2}$ emission prices. The specific cost (per unit of active area) of the SOFC assumed in these results was based on the DOE-NETL target cost for 2010-2011. The assumed SOFC power density represents state-of-the-art performance achieved by planar cells ${ }^{3}$, and is believed by SOFC manufacturers to be the achievable performance of commercial cells within the next 3-5 years. In the pressurized cases, the cost of the SOFC active area is roughly one fifth of the total bare erected cost (BEC) of the SOFC module, which includes cell (and stack) active area, pressure vessel, insulation, piping, etc.

In Fig. 6, the breakeven $\mathrm{CO}_{2}$ emissions price for NGCC-CCS (where NGCC-V and NGCC-CCS lines cross) is seen to be relatively high, $\sim 90 \$ / \mathrm{tCO} 2 \mathrm{e}$, because of the large efficiency penalty and capital costs associated with $\mathrm{CO}_{2}$ capture. In SOFC systems (both atmospheric and 20 bar), both of these burdens are significantly reduced. $\mathrm{CO}_{2}$ capture via oxy-combustion of the $\mathrm{SOFC}$ anode exhaust is relatively straightforward and inexpensive. As a result, the CCS breakeven emissions price is $57 \$ / \mathrm{tCO} \mathrm{e}$ for atmospheric SOFC plants, and $46 \$ / \mathrm{tCO} 2 \mathrm{e}$ for pressurized systems.

Figure 7 shows a sensitivity analysis of the economics of the NG-P-CCS plant around two fundamental factors: 1) the SOFC power density, and 2) the SOFC bulk specific cost (i.e. the active area cost). At present, cost estimates from SOFC manufacturers are $~ 5,000 \$ / \mathrm{kWe}^{4}$. In Figure 7 , the DOENETL target cost for 2010 was increased by an order of magnitude in order to reach an SOFC module cost of $\sim 1,500-3,000 \$ / \mathrm{kWe}$, depending on the power density. The points that are circled and labeled 'market entry' represent what might be achieved now, i.e. current technology maturity, but scaled up to moderate production volumes.

\footnotetext{
${ }^{3}$ In single cell lab tests, SOFC planar cells can readily achieve $500-1000 \mathrm{~mW} \mathrm{~cm}^{-2}$ (with current densities up to $0.5-0.7 \mathrm{~A} \mathrm{~cm}^{-2}$ ); however, in real stacks, the current density is normally limited to $0.2-0.3 \mathrm{~A} \mathrm{~cm}^{-2}$ in order to limit polarization losses and thus achieve higher conversion efficiency.

${ }^{4}$ BloomEnergy (US) declared in 2010 (through is website news section) an SOFC module cost of 7000-8000 \$/kWe; while SOFCPower (IT/CH) declared that cost of around 3000-5000 \$/kWe could be achieved now if large production volumes would be available (talk of the SOFCpower CEO at the International Panel on Hydrogen and fuel cell Economy (IPHE) roundtable hold in Berlin in November 2011). In Japan, starting from November 2011, a well-established oil and gas company commenced the commercialization of SOFC units with a nominal output of $\sim 700 \mathrm{~W}$ for the residential sector. The single unit costs around 25,000-30,000 US-\$, but is planned to be reduced at 6,000 US-\$ once fully commercialized (JX Nippon Oil \& Energy Corporation, "Commercialization of SOFC micro-CHP in the Japanese market, keynote presentation at the Fuel Cells 2012 Science and Technology conference, 11-12 ${ }^{\text {th }}$ April, 2012, Berlin, Germany).
} 


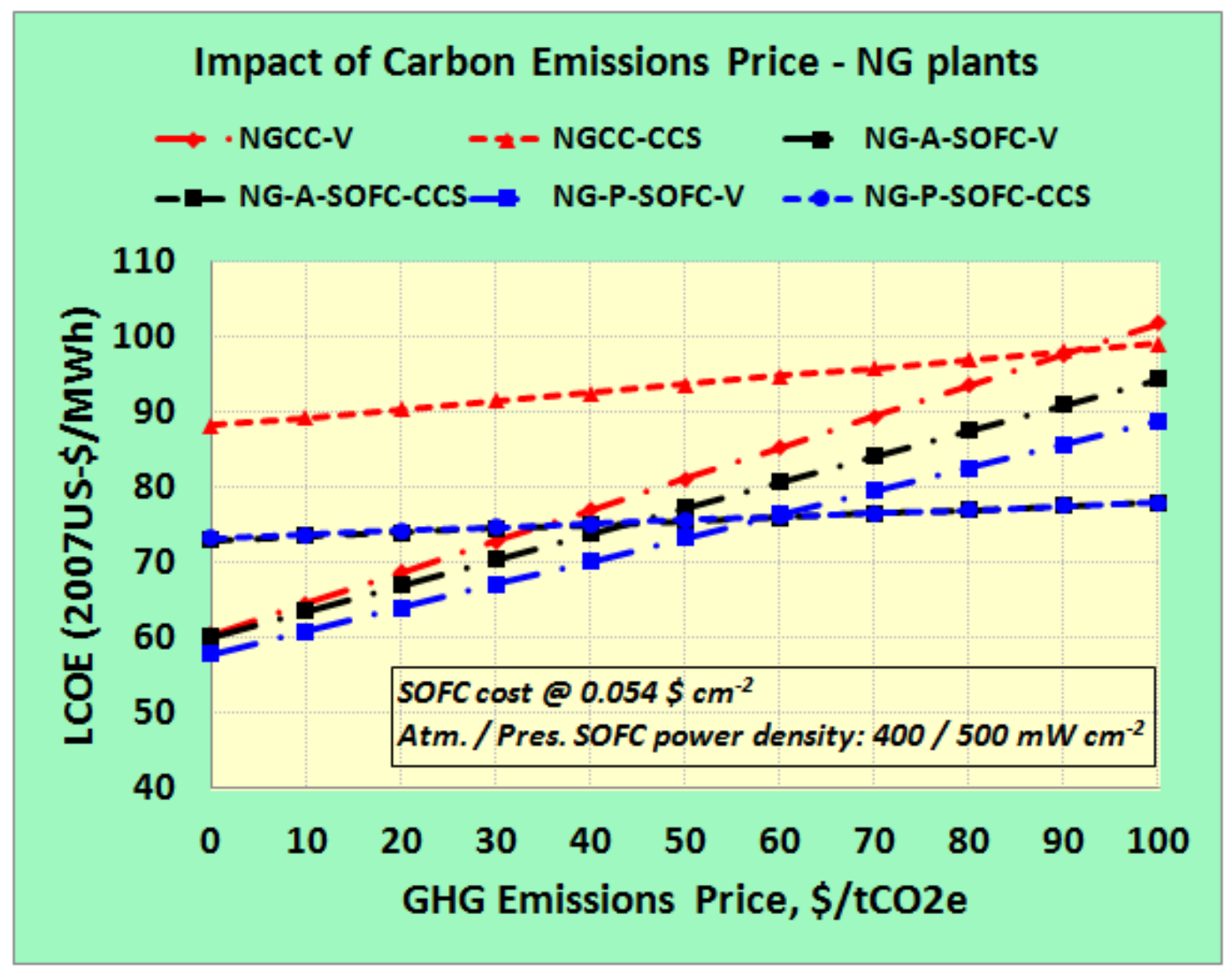

Figure 6. Impact of greenhouse gas emissions price on NG-plants.

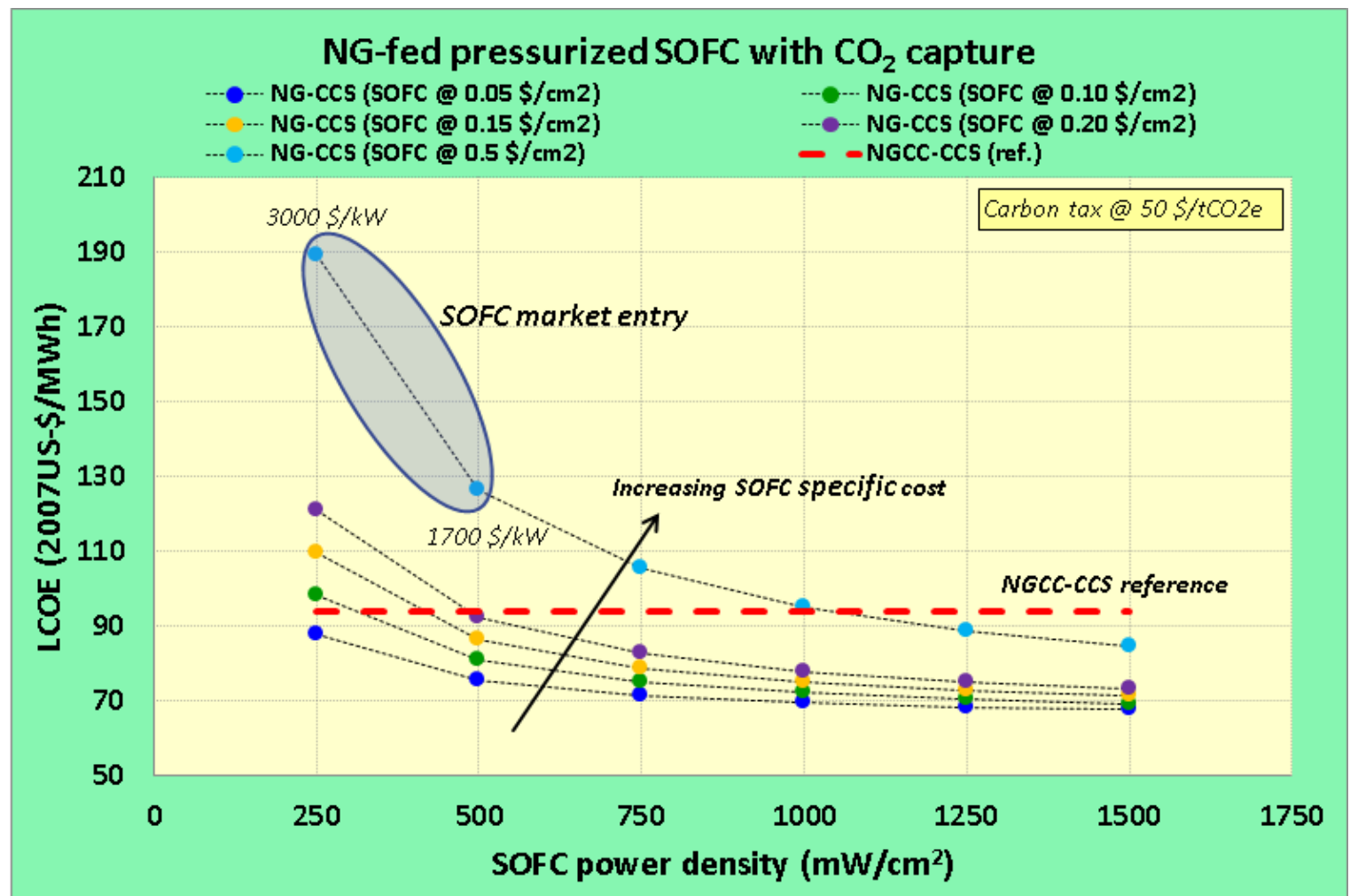

Figure 7. Impact of SOFC power density and SOFC bulk specific cost on the economics of the NG-PCCS plant. 


\section{IGFC Plants: Economic Results}

The economics of NG-SOFC plants is given in Figure 8; for reference, the IGFC plants are compared with pulverized coal (PC) plants as well as with integrated gasifier combined cycle (IGCC) plants. As seen before, inclusion of a SOFC power island significantly reduces the $\mathrm{CO}_{2}$ breakeven price for CCS.

As seen previously for NGCC plants, retro-fitting PC plants with CCS would require relatively high $\mathrm{CO}_{2}$ prices. For IGCC plants, the $\mathrm{CO}_{2}$ breakeven price is lower, but new IGCCs are less profitable investments that CCS retrofits to PC plants. For IGFC, with and without ITM, the breakeven $\mathrm{CO}_{2}$ price is significantly lower still.

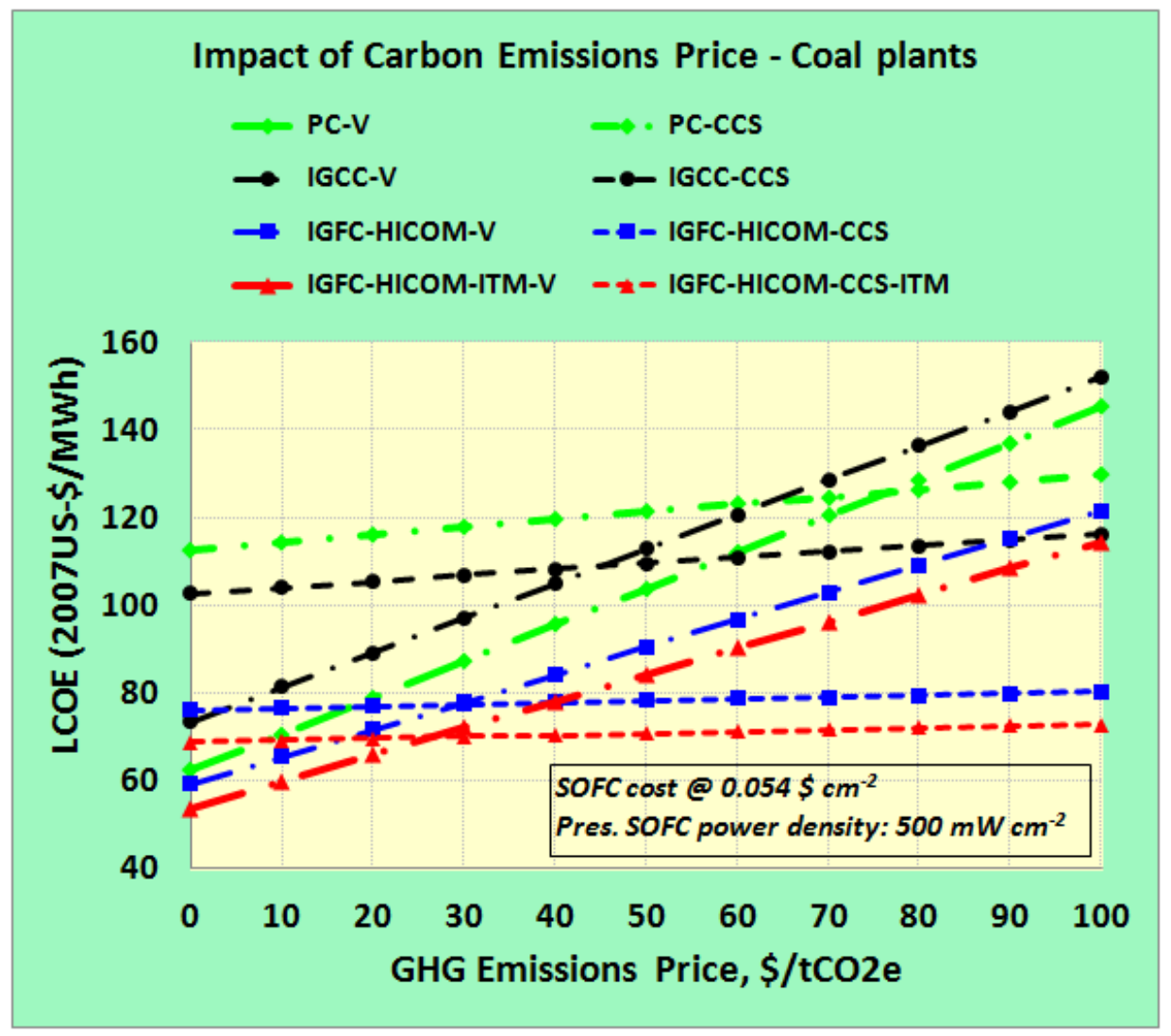

Figure 8. Impact of greenhouse gas emissions price on coal plants.

Similar to the Figure 7, Figure 9 shows the sensitivity of the LCOE for plant IGFC-HICOM-ITMCCS to the SOFC power density, and bulk specific cost. With an SOFC module cost of $\sim 1,500$ 2007 US $\$ / \mathrm{kWe}$, the IGFC-CCS plant would have a LCOE comparable to that of IGCC-CCS. 


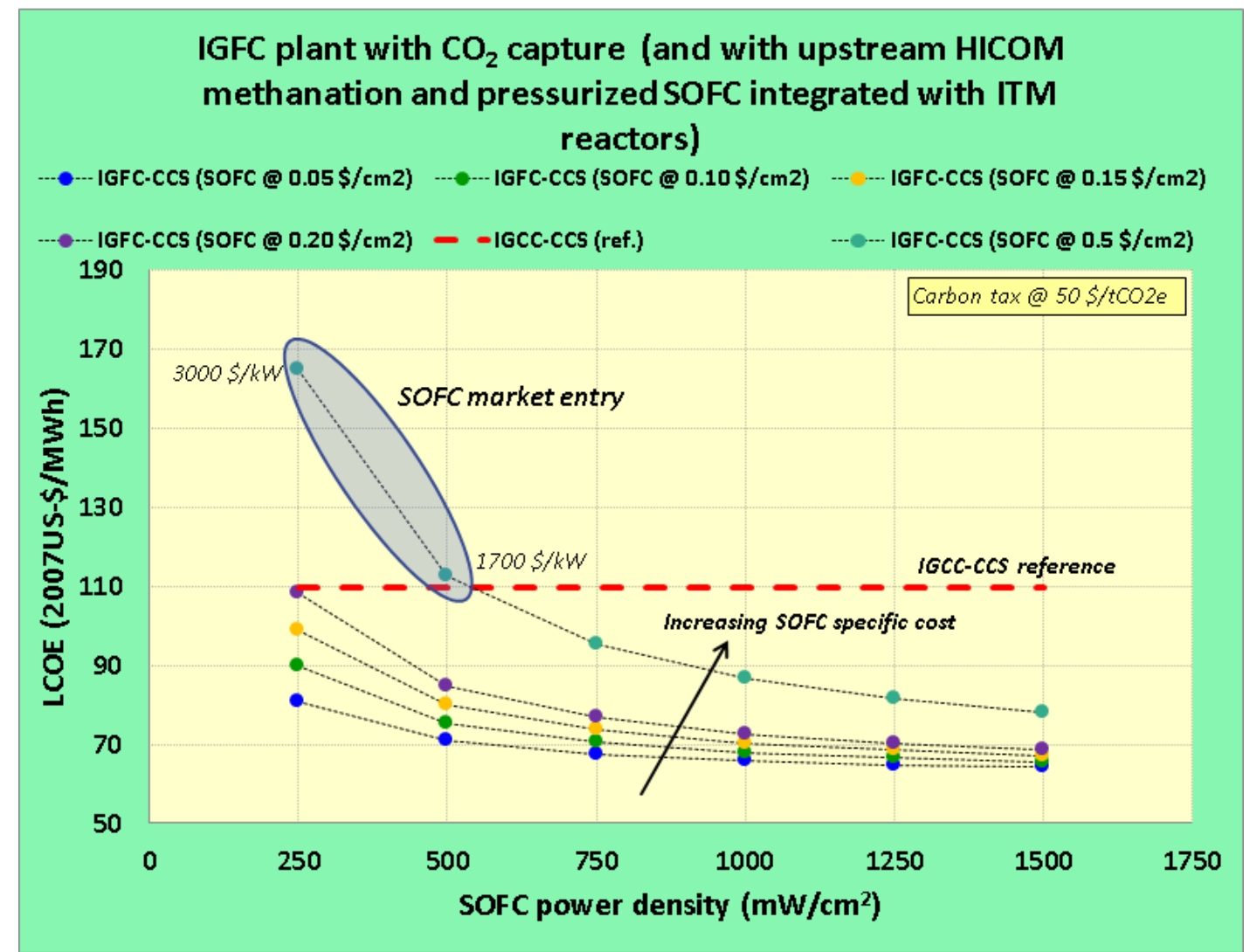

Figure 9. Impact of SOFC power density and SOFC bulk specific cost on the economics of the IGFCHICOM-ITM-CCS plant.

\section{Conclusions}

Main conclusions of this study are:

- Oxy-combustion of the SOFC anode exhaust appears to be a cost-effective method of $\mathrm{CO}_{2}$ capture in SOFC-based power cycles;

- If the cost and performance targets assumed here are met, the economics of both NG- and coal-based SOFC plants appear to be favorable against those of more conventional technologies;

- SOFC pressurization is highly beneficial to overall plant efficiency, and should be the subject of future R\&D. 


\section{Introduction: High Temperature Fuel Cell Systems}

SOFC technology has made great advances in the past few decades, and market maturity has finally been reached for micro-CHP (combined heat and power) systems (1-5 kWel) for the residential and light commercial building sectors. Commercial SOFC are presently operated at atmospheric pressure. Pressurization yields better stack polarization and enables its integration with efficient heat recovery bottoming cycles based on gas turbine plus Rankine cycles, as has been demonstrated at prototype scales 5 .

This study is focused on advanced power cycles based on integrated pressurized SOFC plant designs. All the integrated gasifier fuel cell (IGFC) plants studied here include an SOFC pressurized at 20 bar, a value well matched to conventional turbomachinery. (Conventional combined cycles operate with pressure ratios of 15-20.) This pressure was also used in a series of recent NETL techno-economic evaluations of IGFC and NG-SOFC.

Our simulations assume planar SOFC designs currently being developed by various manufacturers, e.g. TOPSOE Fuel Cells. The power island is configured as an SOFC hybrid system: a primary SOFC power generator coupled to a bottoming cycle to recover additional power from hot exhaust. Our atmospheric-pressure plant designs employ only a steam Rankine bottoming cycle, while our pressurized plants use a gas turbine/Rankine cycle in which heat from the SOFC exhaust gases replaces the gas turbine combustor. Waste heat is recovered for steam generation in all of our plant designs to augment power generation.

Since the SOFC converts hydrocarbons to electricity electrochemically, rather than via combustion in air, it naturally produces an anode exhaust stream with a high $\mathrm{CO}_{2}$ concentration, which facilitates $\mathrm{CO}_{2}$ capture. In our plant designs, $\mathrm{CO}_{2}$ capture (when included) occurs downstream of the SOFC. The anode exhaust is oxy-combusted to obtain a stream containing only steam and $\mathrm{CO}_{2}$, from which $\mathrm{CO}_{2}$ is separated by flashing, cooling and water condensation.

We first developing SOFC plant simulations using natural gas as fuel. One important feature of fueling with natural gas is that the operating temperature of the $\operatorname{SOFC}\left(800^{\circ} \mathrm{C}\right)$ corresponds well to the temperature needed for internal reforming of the natural gas at the anode of the SOFC. The corresponding endothermic reforming reactions help reduce the air cooling of the fuel cell stack that would otherwise be required by energy-intensive cathode air cooling. Since methane is typically present only in small concentrations in syngas from an entrained-flow gasifier, the ability of the SOFC to reform fuel gas internally is not immediately recognized as beneficial when operating on syngas. We explored the option of utilizing a syngas methanator upstream of the SOFC to increase the methane content of the syngas. The exothermic methanation reaction helps pre-heat the fuel gas (avoiding costly hightemperature heat exchangers) and also cools the SOFC by reforming at the anode. The Integrated Gasifier Fuel Cell (IGFC) plants have been analyzed with three different fuel processing options, two including an upstream methanator and a reference case without methanation.

\section{Natural Gas SOFC Systems}

We first modeled hybrid NG-based SOFC plants in order to: 1) understand and implement a realistic set of constraints on the SOFC plant design, 2) study the influence of relevant operating parameters on the system performances, and 3) eventually optimize the plant's electrical efficiency within

\footnotetext{
${ }^{5}$ Both Siemens Westinghouse and Rolls-Royce Fuel Cell Division has demonstrated in the past the conceptual and practical feasibility of SOFC-GT pressurized cycles in the 200-1000 kWel range. Currently, Rolls-Royce R\&D is still actively involved in developing a $1 \mathrm{MWe}$ pressurized SOFC module coupled with a micro-turbine.
} 
the given constraints. Then, with an in-depth understanding of the NG-based SOFC, we were able to confidently proceed with the more complex IGFC plants.

\subsection{Main Technical Assumptions}

SOFCs operating either at atmospheric pressure or 20 bar (a value chosen to facilitate integration with state-of-the-art gas turbine bottoming cycles) were considered in this study.

The plant size considered here is $\sim 500 \mathrm{MW}$ of net electricity export for the NG cases, and $~ 900$ MW for the IGFC cases discussed later; as such, we assume that a slightly modified commercially available gas turbine and compressor could be employed. An axial cathode air compressor is used to pressurize the SOFC vessel. Compressor inter-cooling is not used, since pre-heating of the air is required before feeding it to the cathode. Pressurizing to 20 bar obviates the need for air pre-heaters because partial recirculation of the cathode exhaust at $800^{\circ} \mathrm{C}$ provides the additional heat needed to boost the cathode inlet flow to the required $650^{\circ} \mathrm{C}$.

The main SOFC operating parameters are summarized in Table 2. The fuel inlet temperature is set to $800^{\circ} \mathrm{C}$ for all the $\mathrm{NG}$ cases; since steam-reforming of $\mathrm{CH}_{4}$ is assumed to take place directly on the fuel cell anode, and the reforming kinetics on Ni-catalyst are quite fast at the SOFC operating temperature, immediate cooling of the fuel stream is expected to occur in the anode inlet region. To compensate for this, in all simulations with NG fuel, the inlet fuel stream is pre-heated to the nominal SOFC operating temperature of $800^{\circ} \mathrm{C}$ instead of only $650{ }^{\circ} \mathrm{C}$ in the cathode stream. In contrast, in the IGFC cases where the fuel contains little to moderate amounts of $\mathrm{CH}_{4}$, the fuel is pre-heated to only $700{ }^{\circ} \mathrm{C}$.

The SOFC operating voltage is calculated as:

$$
V_{\text {cell }}=V_{\text {Nernst }}^{\text {average }}(T, p, \bar{y})-A S R \cdot j .
$$

In Eq. 1, the Nernst potential is given by the reversible thermodynamic potential generated by the (electrochemical) oxidation of $\mathrm{H}_{2}$ (and $\mathrm{CO}$ ) as a function of temperature, pressure and gas composition. Both anode and cathode recirculation are employed to provide a steam-to-carbon ratio of 2 at the inlet anode chamber and to heat the air up to $650{ }^{\circ} \mathrm{C}$ at the cathode inlet ${ }^{6}$. The anode stream is pre-heated to $700{ }^{\circ} \mathrm{C}$ prior to feeding the SOFC. To avoid significant reductions in Nernst voltage due to oxygen starvation, sufficient cathode air flow is provided such that the partial pressure of $\mathrm{O}_{2}$ in the cathode exhaust exceeds $10 \%$ vol.

For the atmospheric SOFC operation, a power density of $\sim 400 \mathrm{~W} / \mathrm{cm}^{2}$ is used, consistent with $\mathrm{NETL}^{12,13}$; this power density is based on independent calculations assuming the SOFC operates at a current density of $0.55 \mathrm{~A} \mathrm{~cm}^{-2}$ with an overall equivalent cell resistance of $0.68 \mathrm{~m} \Omega$ (corresponding to an area specific resistance, $A S R$, of $0.38 \Omega \mathrm{cm}^{2}$ ). For pressurized SOFC operation, a power density of $\sim 500$ $\mathrm{W} / \mathrm{cm}^{2}$ was instead used, again consistent with $\mathrm{NETL}^{12,13}$; the latter was calculated assuming a SOFC current density of $0.64 \mathrm{~A} \mathrm{~cm}^{-2}$ and an overall equivalent cell resistance a $25 \%$ lower than for the atmospheric case (resulting in an ASR of $0.28 \Omega \mathrm{cm}^{2}$ ).

The designated fuel is compressed natural gas from the grid at 30 bar; no NG compression work on the anode side of the SOFC is required. The NG must be deeply desulfurized prior to entering the SOFC. Impregnated active carbons, zeolites, or a combination of both can efficiently remove sulfur compounds down to concentrations acceptable for the SOFC. Although the desulfurizer is not shown in the plant layouts of Figure 10 and Figure 11, its cost is nevertheless accounted for in the economic analysis.

\footnotetext{
${ }^{6}$ When operating an SOFC with exhaust recirculation, it is instructive to express the reactants consumption (or their excess ratio, which is essentially the inverse number) in both global and local terms. For example, the global fuel utilization $(F U)$ is the one actually seen by the SOFC as a whole (i.e. with a control volume that includes the recirculation loop), while the local $F U$ refers to a control volume around only the SOFC module itself.
} 
Table 2. Baseline parameter values for the SOFC module.

\begin{tabular}{|l|c|}
\hline \multicolumn{1}{|c|}{ SOFC module } & \\
\hline SOFC temperature, ${ }^{\circ} \mathrm{C}$ & 800 \\
Operating pressure (atm. / pres.), bar & $1 / 20$ \\
Cell (stack) ASR (atm. / pres.), $\Omega \mathrm{cm}^{2}$ & 0.38 / 0.28 \\
Current density $j$ (atm. / pres.), A cm ${ }^{-2}$ & 0.55 / 0.64 \\
Approx. power density (atm. / pres.), $\mathrm{mW} \mathrm{cm}^{-2}$ & $400 / 500$ \\
Fuel inlet temperature, (NG / coal syngas), ${ }^{\circ} \mathrm{C}$ & 800 \\
Air inlet temperature in the SOFC, ${ }^{\circ} \mathrm{C}$ & 650 \\
Local (single-passage) / Global Fuel Utilization & $73 \% / 85 \%$ \\
(FU) factor & 2 \\
Steam to carbon factor (S/C) & variable \\
Global air excess ratio $(\lambda)$ & \\
\hline
\end{tabular}

In plant designs that vent $\mathrm{CO}_{2}$ (Figure 10), the anode exhaust is combined with the cathode exhaust and burned to recover the chemical energy of the unspent $\mathrm{H}_{2}$ and $\mathrm{CO}$. The resulting stream has a temperature between $1000-1050^{\circ} \mathrm{C}$, and is expanded in a turbine to both drive the air compressor and produce additional electric power.

In the CCS cases (Figure 11), power is recovered separately from both the cathode and anode exhausts, using two different expanders. For different plant designs, the cathode exhaust stream entering the turbine will be at different temperatures. The minimum temperature corresponds to the SOFC operating temperature, $800^{\circ} \mathrm{C}$; this case employs a turbine with un-cooled blades. When the cathode exhaust temperature is boosted, e.g. using heat from the products of oxy-combustion of the anode exhaust, a turbine with cooled blades is required. In CCS plants, heat provided by oxy-combusted anode exhaust is used to boost the temperature of the stack gas exiting the turbine and entering to the heat recovery stam cycle (HRSC). Alternatively, the very hot oxy-combusted stream can be directly integrated within the HRSC: the hot exhaust could exchange heat efficienctly with the MP or HP evaporator. Water evaporation would prevent the heat exchanger wall temperature from exceeding the maximum limit. In this way, a high-temperature (metal/ceramic) heat-exchanger can be avoided (Figure 11).

Table 3. Process design parameter assumptions for natural gas fed plants.

\begin{tabular}{|c|c|}
\hline Unit & \\
\hline Air Separation & $\begin{array}{l}\text { Cryogenic air separation with } 99.5 \% \text { vol. } \mathrm{O}_{2} \text { production; power }(\mathrm{kWh} / \mathrm{t} \text { pure } \\
\left.\qquad \mathrm{O}_{2} \text { at atmospheric bar }\right)=26.32\end{array}$ \\
\hline Fre & Air input (vol.): $\mathrm{O}_{2}, 21 \% ; \mathrm{N}_{2}, 79 \%$. \\
\hline $\mathrm{Na}$ & $\begin{array}{l}\text { Fuel input (vol.): } 90 \% \mathrm{CH}_{4} ; 6 \% \mathrm{C}_{2} \mathrm{H}_{6} ; 1 \% \mathrm{C}_{3} \mathrm{H}_{8} ; 0.5 \% \mathrm{C}_{4} \mathrm{H}_{10} ; 1 \% \mathrm{CO}_{2} ; 1.5 \% \\
\mathrm{~N}_{2} \text {. }\end{array}$ \\
\hline $\begin{array}{r}\text { Cathode } \\
\text { Catl }\end{array}$ & $\begin{array}{l}\eta_{i s}=0.825 ; \eta_{\text {mech }+e l}=0.95 \\
\quad \eta_{i s}=0.89 ; \eta_{\text {mech }+e l}=0.95\end{array}$ \\
\hline A & $\begin{array}{c}\text { Steam } / \mathrm{CO}_{2} \text { expander TIT max. set to } 850^{\circ} \mathrm{C}: \eta_{i s}=0.85 ; \eta_{\text {mech }+e l}= \\
0.95 .\end{array}$ \\
\hline Oxy & Oxygen excess st \\
\hline $\mathrm{CO}_{2}$ & $\begin{array}{c}4 \text { inter-cooled stages at } 30{ }^{\circ} \mathrm{C} \text { with liquid water knock-out. Pressure } \\
\text { ratio of each stage is } \beta=1.21 \text { and discharge pressure is of } 43 \text { bar. } \eta_{p o l}= \\
0.73 ; \eta_{\text {mech }+e l}=0.95 . \text { Last stage (from } 43 \text { to } 150 \text { bar): } \eta_{i s}=0.75 ; \eta_{\text {mech }+e l}= \\
0.95 .\end{array}$ \\
\hline $\begin{array}{l}\text { Heat recovery ste } \\
\text { (HRSC) }\end{array}$ & $\begin{array}{l}\text { Steam turbines: } \eta_{i s, L P}=0.88 ; \eta_{i s, M P}=0.94 ; \eta_{\text {is, HP }}=0.92 ; \eta_{\text {mech }+e l}= \\
\text { 0.95. BWF pumps: } \eta_{i s}=0.75 ; \eta_{\text {mech }+e l}=0.95 .\end{array}$ \\
\hline
\end{tabular}




\subsection{Comparative Performance Results}

With natural gas as fuel, we examined the performance impacts of several important design parameters including the configuration of anode and cathode exhaust recycle loops and the fuel cell operating pressure. Anode exhaust recirculation is an effective method of controlling the steam/carbon ratio at the fuel inlet. Cathode exhaust recirculation aids air pre-heating and thereby reduces fresh air intake requirements (and associated parasitic losses associated with cathode air compression).

Direct reforming of methane within the SOFC reactors is assumed. The Ni catalyst in the anodesupported fuel cells plays the dual role of: 1) catalyst for converting $\mathrm{CH}_{4}$ to $\mathrm{H}_{2}+\mathrm{CO}$, as well as 2) electro-catalyst for the electrochemical oxidation of $\mathrm{H}_{2}$ (and $\mathrm{CO}$ ) to $\mathrm{H}_{2} \mathrm{O}$ (and $\mathrm{CO}_{2}$ ).

We developed NG-based plant designs for an SOFC operating at both atmospheric pressure and 20 bar, and with and without $\mathrm{CO}_{2}$ capture. Design parameter values are given in Table 3. Our results indicate that the pressurization leads to improved performance. Figure 10 and Figure 11 show the plant layouts and simulation results for the pressurized systems with and without $\mathrm{CO}_{2}$ capture; Table 4 and Table 5 characterize the streams indicated in the plant layouts. Note that, although the reformer is shown as a component separate from the SOFC, in reality the SOFC module is both the chemical and electrochemical reactor for the anode fuel. The so-called 'hot-box' volume in Figure 10 and Figure 11 is physically what constitutes the SOFC reactor module.

Table 6 gives a detailed description of the SOFC main operating parameters as well as the electricity produced and consumed by the main plant components for the NG cases. Interestingly, if the extra power required for $\mathrm{CO}_{2}$ compression and oxygen production are neglected, the efficiency of plant NG-A-CCS is the same of that of NG-A-V. In other words, at atmospheric pressure, the $\mathrm{CO}_{2}$ capture plant is not inherently less efficient than the $\mathrm{CO}_{2}$ venting plant. However, when the SOFC is pressurized, there appear to be some inherent efficiency penalties related to the differences in plant configuration between $\mathrm{CO}_{2}$ venting and capture plants. It is possible that, with further optimization, these differences will disappear. 


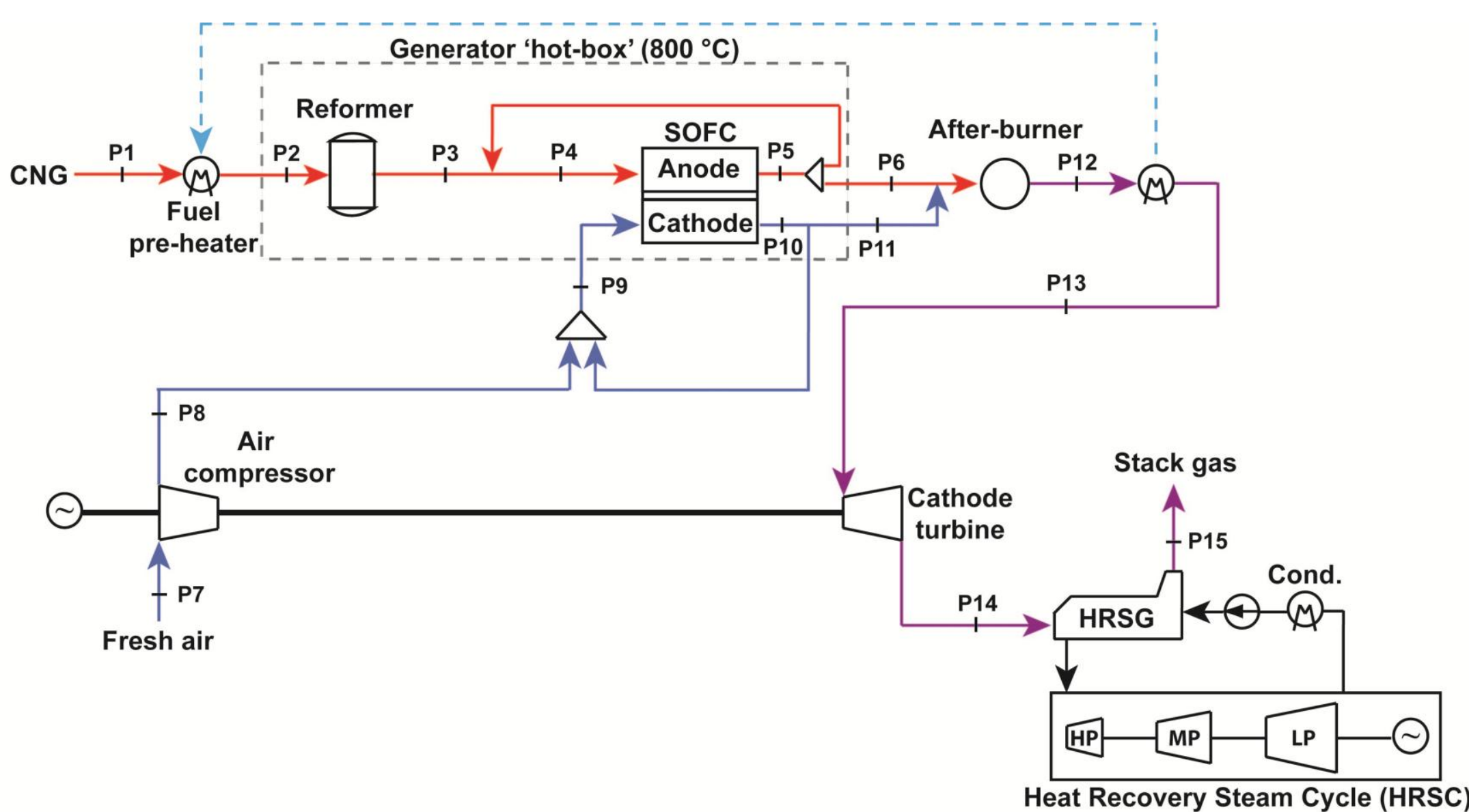

Figure 10. NG-P-V plant layout. See Table 4 for stream parameter values. 
Table 4. Stream table of plant NG-P-V. (See Figure 10.)

\begin{tabular}{|c|c|c|c|c|c|c|c|c|c|c|c|c|c|c|c|}
\hline Stream ID: & $\mathrm{P} 1$ & $\mathrm{P} 2$ & $\mathrm{P} 3$ & $\mathrm{P} 4$ & P5 & P6 & $\mathrm{P} 7$ & P8 & P9 & $\mathrm{P} 10$ & $\mathrm{P} 11$ & $\mathrm{P} 12$ & $\mathrm{P} 13$ & $\mathrm{P} 14$ & $\mathrm{P} 15$ \\
\hline \multicolumn{16}{|l|}{ Composition (vol.) } \\
\hline $\mathrm{CH} 4$ & $90.0 \%$ & $90.0 \%$ & $20.2 \%$ & $8.0 \%$ & $0.1 \%$ & $0.1 \%$ & $0.0 \%$ & $0.0 \%$ & $0.0 \%$ & $0.0 \%$ & $0.0 \%$ & $0.0 \%$ & $0.0 \%$ & $0.0 \%$ & $0.0 \%$ \\
\hline $\mathrm{CO} 2$ & $1.0 \%$ & $1.0 \%$ & $21.8 \%$ & $13.6 \%$ & $27.8 \%$ & $27.8 \%$ & $0.0 \%$ & $0.0 \%$ & $0.0 \%$ & $0.0 \%$ & $0.0 \%$ & $7.6 \%$ & $7.6 \%$ & $7.6 \%$ & $7.6 \%$ \\
\hline $\mathrm{CO}$ & $0.0 \%$ & $0.0 \%$ & $5.1 \%$ & $18.3 \%$ & $6.6 \%$ & $6.6 \%$ & $0.0 \%$ & $0.0 \%$ & $0.0 \%$ & $0.0 \%$ & $0.0 \%$ & $0.0 \%$ & $0.0 \%$ & $0.0 \%$ & $0.0 \%$ \\
\hline$H 2$ & $0.0 \%$ & $0.0 \%$ & $10.2 \%$ & $35.3 \%$ & $13.2 \%$ & $13.2 \%$ & $0.0 \%$ & $0.0 \%$ & $0.0 \%$ & $0.0 \%$ & $0.0 \%$ & $0.0 \%$ & $0.0 \%$ & $0.0 \%$ & $0.0 \%$ \\
\hline $\mathrm{H} 2 \mathrm{O}$ & $0.0 \%$ & $0.0 \%$ & $40.3 \%$ & $24.2 \%$ & $51.9 \%$ & $51.9 \%$ & $0.0 \%$ & $0.0 \%$ & $0.0 \%$ & $0.0 \%$ & $0.0 \%$ & $14.3 \%$ & $14.3 \%$ & $14.3 \%$ & $14.3 \%$ \\
\hline$O 2$ & $0.0 \%$ & $0.0 \%$ & $0.0 \%$ & $0.0 \%$ & $0.0 \%$ & $0.0 \%$ & $21.0 \%$ & $21.0 \%$ & $14.7 \%$ & $8.7 \%$ & $8.7 \%$ & $4.8 \%$ & $4.8 \%$ & $4.8 \%$ & $4.8 \%$ \\
\hline$N 2$ & $1.5 \%$ & $1.5 \%$ & $0.7 \%$ & $0.6 \%$ & $0.5 \%$ & $0.5 \%$ & $79.0 \%$ & $79.0 \%$ & $85.3 \%$ & $91.3 \%$ & $91.3 \%$ & $73.3 \%$ & $73.3 \%$ & $73.3 \%$ & $73.3 \%$ \\
\hline $\mathrm{C} 2 \mathrm{H} 6$ & $6.0 \%$ & $6.0 \%$ & $1.3 \%$ & $0.0 \%$ & $0.0 \%$ & $0.0 \%$ & $0.0 \%$ & $0.0 \%$ & $0.0 \%$ & $0.0 \%$ & $0.0 \%$ & $0.0 \%$ & $0.0 \%$ & $0.0 \%$ & $0.0 \%$ \\
\hline $\mathrm{C} 3 \mathrm{H} 8$ & $1.0 \%$ & $1.0 \%$ & $0.2 \%$ & $0.0 \%$ & $0.0 \%$ & $0.0 \%$ & $0.0 \%$ & $0.0 \%$ & $0.0 \%$ & $0.0 \%$ & $0.0 \%$ & $0.0 \%$ & $0.0 \%$ & $0.0 \%$ & $0.0 \%$ \\
\hline C4H1O (n-butane) & $0.5 \%$ & $0.5 \%$ & $0.1 \%$ & $0.0 \%$ & $0.0 \%$ & $0.0 \%$ & $0.0 \%$ & $0.0 \%$ & $0.0 \%$ & $0.0 \%$ & $0.0 \%$ & $0.0 \%$ & $0.0 \%$ & $0.0 \%$ & $0.0 \%$ \\
\hline Total Flow $\left(\mathrm{kmol} \mathrm{s}^{-1}\right)$ & 0.87 & 0.87 & 3.91 & 4.98 & 5.77 & 2.74 & 11.55 & 11.55 & 23.64 & 22.09 & 10.00 & 12.47 & 12.47 & 12.47 & 12.47 \\
\hline Total Flow $\left(\mathrm{kg} \mathrm{s}^{-1}\right)$ & 15.6 & 15.6 & 87.9 & 87.9 & 137.6 & 65.3 & 333.3 & 333.3 & 676.2 & 626.4 & 283.5 & 348.8 & 348.8 & 348.8 & 348.8 \\
\hline Temperature $\left({ }^{\circ} \mathbf{C}\right)$ & 15 & 800 & 800 & 800 & 800 & 800 & 15 & 490 & 650 & 800 & 800 & 1106 & 1019 & 464 & 80 \\
\hline Pressure (bar) & 22 & 22 & 22 & 22 & 22 & 22 & 1 & 22 & 22 & 22 & 22 & 20 & 20 & 1 & 1 \\
\hline
\end{tabular}




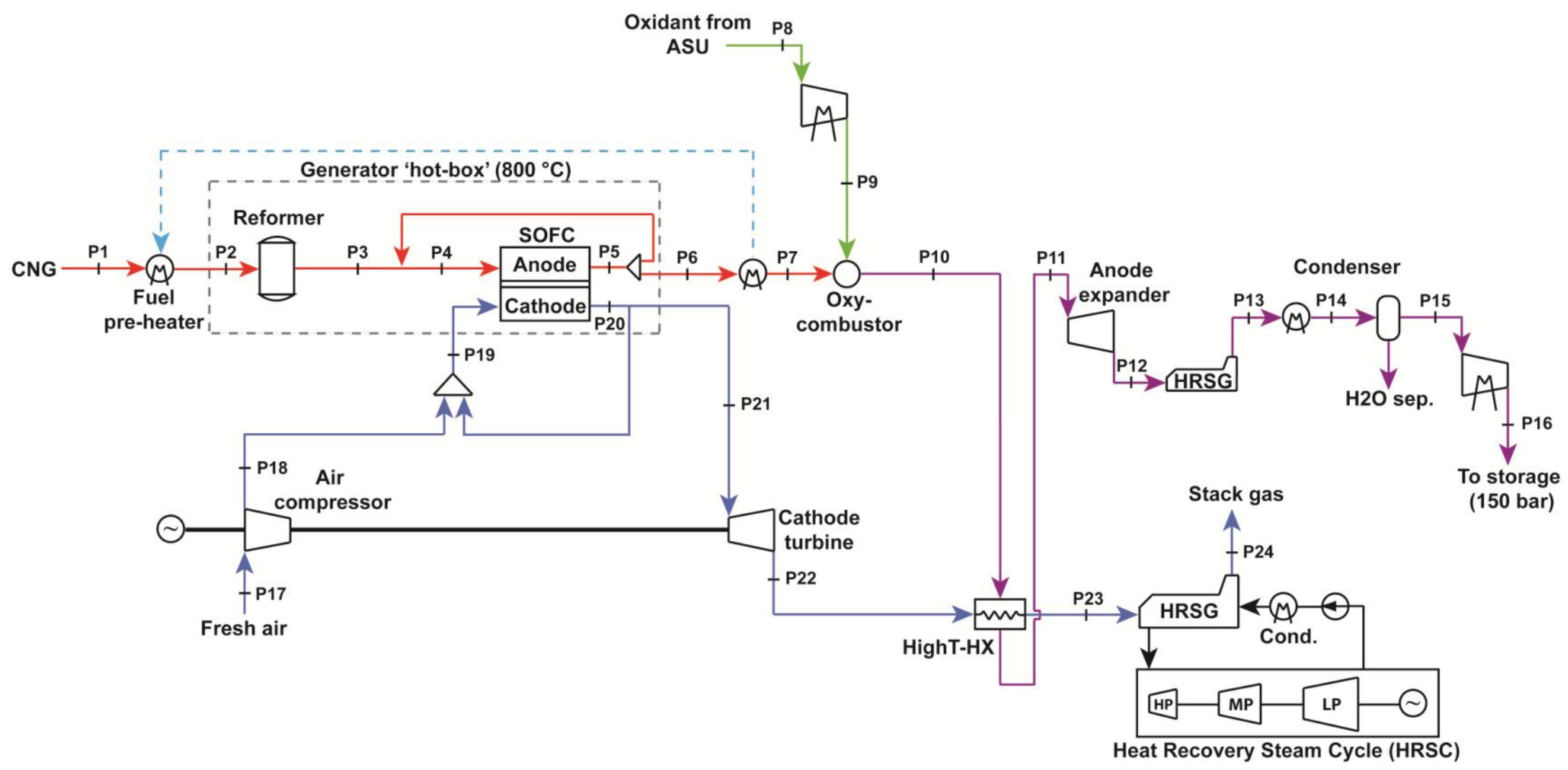

Figure 11. NG-P-CCS plant layout. See Table 5 for stream parameter values. 
Table 5. Stream table of plant NG-P-CCS. (See Figure 11.)

\begin{tabular}{|c|c|c|c|c|c|c|c|c|c|c|c|c|}
\hline Stream ID: & $\mathrm{P} 1$ & $\mathrm{P} 2$ & P3 & P4 & P5 & P6 & $\mathrm{P} 7$ & P8 & P9 & P10 & P11 & $\mathrm{P} 12$ \\
\hline \multicolumn{13}{|l|}{ Composition (vol.) } \\
\hline $\mathrm{CH} 4$ & $90.0 \%$ & $90.0 \%$ & $20.2 \%$ & $8.0 \%$ & $0.1 \%$ & $0.1 \%$ & $0.1 \%$ & $0.0 \%$ & $0.0 \%$ & $0.0 \%$ & $0.0 \%$ & $0.0 \%$ \\
\hline $\mathrm{CO} 2$ & $1.0 \%$ & $1.0 \%$ & $21.8 \%$ & $13.6 \%$ & $27.8 \%$ & $27.8 \%$ & $27.8 \%$ & $0.0 \%$ & $0.0 \%$ & $34.3 \%$ & $34.3 \%$ & $34.3 \%$ \\
\hline $\mathrm{CO}$ & $0.0 \%$ & $0.0 \%$ & $5.1 \%$ & $18.3 \%$ & $6.6 \%$ & $6.6 \%$ & $6.6 \%$ & $0.0 \%$ & $0.0 \%$ & $0.1 \%$ & $0.1 \%$ & $0.1 \%$ \\
\hline$H 2$ & $0.0 \%$ & $0.0 \%$ & $10.2 \%$ & $35.3 \%$ & $13.2 \%$ & $13.2 \%$ & $13.2 \%$ & $0.0 \%$ & $0.0 \%$ & $0.0 \%$ & $0.0 \%$ & $0.0 \%$ \\
\hline $\mathrm{H} 2 \mathrm{O}$ & $0.0 \%$ & $0.0 \%$ & $40.3 \%$ & $24.2 \%$ & $51.9 \%$ & $51.9 \%$ & $51.9 \%$ & $0.0 \%$ & $0.0 \%$ & $65.0 \%$ & $65.0 \%$ & $65.0 \%$ \\
\hline$O 2$ & $0.0 \%$ & $0.0 \%$ & $0.0 \%$ & $0.0 \%$ & $0.0 \%$ & $0.0 \%$ & $0.0 \%$ & $99.5 \%$ & $99.5 \%$ & $0.0 \%$ & $0.0 \%$ & $0.0 \%$ \\
\hline$N 2$ & $1.5 \%$ & $1.5 \%$ & $0.7 \%$ & $0.6 \%$ & $0.5 \%$ & $0.5 \%$ & $0.5 \%$ & $0.5 \%$ & $0.5 \%$ & $0.5 \%$ & $0.5 \%$ & $0.5 \%$ \\
\hline $\mathrm{C} 2 \mathrm{H} 6$ & $6.0 \%$ & $6.0 \%$ & $1.3 \%$ & $0.0 \%$ & $0.0 \%$ & $0.0 \%$ & $0.0 \%$ & $0.0 \%$ & $0.0 \%$ & $0.0 \%$ & $0.0 \%$ & $0.0 \%$ \\
\hline $\mathrm{C} 3 \mathrm{H} 8$ & $1.0 \%$ & $1.0 \%$ & $0.2 \%$ & $0.0 \%$ & $0.0 \%$ & $0.0 \%$ & $0.0 \%$ & $0.0 \%$ & $0.0 \%$ & $0.0 \%$ & $0.0 \%$ & $0.0 \%$ \\
\hline C4H1O-1 & $0.5 \%$ & $0.5 \%$ & $0.1 \%$ & $0.0 \%$ & $0.0 \%$ & $0.0 \%$ & $0.0 \%$ & $0.0 \%$ & $0.0 \%$ & $0.0 \%$ & $0.0 \%$ & $0.0 \%$ \\
\hline Total Flow $\left(\mathrm{kmol} \mathrm{s}^{-1}\right)$ & 0.87 & 0.87 & 3.91 & 4.98 & 5.77 & 2.74 & 2.74 & 0.27 & 0.27 & 2.75 & 2.75 & 2.75 \\
\hline Total Flow $\left(\mathrm{kg} \mathrm{s}^{-1}\right)$ & 15.6 & 15.6 & 87.9 & 87.9 & 137.6 & 65.3 & 65.3 & 8.8 & 8.8 & 74.1 & 74.1 & 74.1 \\
\hline Temperature $\left({ }^{\circ} \mathbf{C}\right)$ & 15 & 800 & 800 & 800 & 800 & 800 & 442 & 15 & 189 & 1484 & 850 & 439 \\
\hline Pressure (bar) & 22 & 22 & 22 & 22 & 22 & 22 & 22 & 1 & 20 & 20 & 20 & 1 \\
\hline Stream ID: & $\mathrm{P} 13$ & $\mathrm{P} 14$ & P15 & P16 & $\mathrm{P} 17$ & $\mathrm{P} 18$ & P19 & $\mathrm{P} 20$ & $\mathrm{P} 21$ & $\mathrm{P} 22$ & $\mathrm{P} 23$ & $\mathrm{P} 24$ \\
\hline \multicolumn{13}{|l|}{ Composition (vol.) } \\
\hline $\mathrm{CH} 4$ & $0.0 \%$ & $0.0 \%$ & $0.0 \%$ & $0.0 \%$ & $0.0 \%$ & $0.0 \%$ & $0.0 \%$ & $0.0 \%$ & $0.0 \%$ & $0.0 \%$ & $0.0 \%$ & $0.0 \%$ \\
\hline $\mathrm{CO} 2$ & $34.3 \%$ & $34.3 \%$ & $96.2 \%$ & $97.5 \%$ & $0.0 \%$ & $0.0 \%$ & $0.0 \%$ & $0.0 \%$ & $0.0 \%$ & $0.0 \%$ & $0.0 \%$ & $0.0 \%$ \\
\hline $\mathrm{CO}$ & $0.1 \%$ & $0.1 \%$ & $0.2 \%$ & $0.2 \%$ & $0.0 \%$ & $0.0 \%$ & $0.0 \%$ & $0.0 \%$ & $0.0 \%$ & $0.0 \%$ & $0.0 \%$ & $0.0 \%$ \\
\hline$H 2$ & $0.0 \%$ & $0.0 \%$ & $0.1 \%$ & $0.1 \%$ & $0.0 \%$ & $0.0 \%$ & $0.0 \%$ & $0.0 \%$ & $0.0 \%$ & $0.0 \%$ & $0.0 \%$ & $0.0 \%$ \\
\hline $\mathrm{H} 2 \mathrm{O}$ & $65.0 \%$ & $65.0 \%$ & $1.9 \%$ & $0.6 \%$ & $0.0 \%$ & $0.0 \%$ & $0.0 \%$ & $0.0 \%$ & $0.0 \%$ & $0.0 \%$ & $0.0 \%$ & $0.0 \%$ \\
\hline$O 2$ & $0.0 \%$ & $0.0 \%$ & $0.0 \%$ & $0.0 \%$ & $21.0 \%$ & $21.0 \%$ & $14.7 \%$ & $8.7 \%$ & $8.7 \%$ & $8.7 \%$ & $8.7 \%$ & $8.7 \%$ \\
\hline$N 2$ & $0.5 \%$ & $0.5 \%$ & $1.5 \%$ & $1.5 \%$ & $79.0 \%$ & $79.0 \%$ & $85.3 \%$ & $91.3 \%$ & $91.3 \%$ & $91.3 \%$ & $91.3 \%$ & $91.3 \%$ \\
\hline $\mathrm{C} 2 \mathrm{H} 6$ & $0.0 \%$ & $0.0 \%$ & $0.0 \%$ & $0.0 \%$ & $0.0 \%$ & $0.0 \%$ & $0.0 \%$ & $0.0 \%$ & $0.0 \%$ & $0.0 \%$ & $0.0 \%$ & $0.0 \%$ \\
\hline $\mathrm{C} 3 \mathrm{H} 8$ & $0.0 \%$ & $0.0 \%$ & $0.0 \%$ & $0.0 \%$ & $0.0 \%$ & $0.0 \%$ & $0.0 \%$ & $0.0 \%$ & $0.0 \%$ & $0.0 \%$ & $0.0 \%$ & $0.0 \%$ \\
\hline C4H1O-1 & $0.0 \%$ & $0.0 \%$ & $0.0 \%$ & $0.0 \%$ & $0.0 \%$ & $0.0 \%$ & $0.0 \%$ & $0.0 \%$ & $0.0 \%$ & $0.0 \%$ & $0.0 \%$ & $0.0 \%$ \\
\hline Total Flow $\left(\mathrm{kmol} \mathrm{s}^{-1}\right)$ & 2.75 & 2.75 & 0.98 & 0.97 & 11.56 & 11.56 & 23.64 & 22.09 & 10.00 & 10.00 & 10.00 & 10.00 \\
\hline Total Flow $\left(\mathrm{kg} \mathrm{s}^{-1}\right)$ & 74.1 & 74.1 & 42.3 & 42.0 & 333.4 & 333.4 & 676.2 & 626.4 & 283.6 & 283.6 & 283.6 & 283.6 \\
\hline Temperature $\left({ }^{\circ} \mathbf{C}\right)$ & 90 & 20 & 20 & 157 & 15 & 490 & 650 & 800 & 800 & 267 & 552 & 90 \\
\hline Pressure (bar) & 1 & 1 & 1 & 150 & 1 & 22 & 22 & 22 & 20 & 1 & 1 & 1 \\
\hline
\end{tabular}


Table 6. Performance results for the NG-SOFC plants. In the plant design names, A and P designate atmospheric and pressurized SOFC. $\mathrm{V}$ and $\mathrm{CCS}$ designate venting or capturing of $\mathrm{CO}_{2}$.

\begin{tabular}{|c|c|c|c|c|c|}
\hline & Plant design: & NG-A-V & NG-A-CCS & NG-P-V & NG-P-CCS \\
\hline \multicolumn{6}{|l|}{ Fuel input } \\
\hline NG feed & $\mathrm{kmol} \mathrm{s}^{-1}$ & 0.87 & 0.87 & 0.87 & 0.87 \\
\hline NG HHV & $\mathrm{MJ} \mathrm{kmol}^{-1}$ & 933 & 933 & 933 & 933 \\
\hline NG energy input (HHV & & & & & \\
\hline basis) & MWt & 815 & 815 & 815 & 815 \\
\hline \multicolumn{6}{|l|}{ SOFC power unit } \\
\hline Cell current / A & & 26 & 26 & 30 & 30 \\
\hline Overall number of cells ( $550 \mathrm{~cm}^{2}$ active area) & & $1.97 \mathrm{E}+06$ & $1.97 \mathrm{E}+06$ & $1.71 \mathrm{E}+06$ & $1.71 \mathrm{E}+06$ \\
\hline Cell ASR / $\Omega \mathrm{cm}^{2}$ & & 0.38 & 0.38 & 0.28 & 0.28 \\
\hline Global fuel utilization, $F U$ & & $85 \%$ & $85 \%$ & $85 \%$ & $85 \%$ \\
\hline Local fuel utilization, $F U^{*}$ & & $73 \%$ & $73 \%$ & $73 \%$ & $73 \%$ \\
\hline Operating voltage & $\mathrm{V}$ & 0.72 & 0.72 & 0.79 & 0.79 \\
\hline Inlet Nernst voltage & $\mathrm{V}$ & 0.99 & 0.99 & 1.02 & 1.02 \\
\hline Outlet Nernst voltage & $\mathrm{V}$ & 0.87 & 0.87 & 0.93 & 0.93 \\
\hline Average Nernst voltage & $\mathrm{V}$ & 0.93 & 0.93 & 0.97 & 0.97 \\
\hline SOFC power (DC) & MWe & 430.9 & 430.7 & 476.0 & 476.0 \\
\hline \multicolumn{6}{|l|}{ Additional power / cathode side } \\
\hline Air recirculation fraction & & $52 \%$ & $53 \%$ & $55 \%$ & $55 \%$ \\
\hline Global air utilization, $\lambda$ & & 2.21 & 2.17 & 1.56 & 1.56 \\
\hline Local air utilization, $\lambda^{*}$ & & 3.54 & 3.48 & 2.24 & 2.24 \\
\hline TIT (cathode turbine) & ${ }^{\circ} \mathrm{C}$ & - & - & 1018.8 & 800.0 \\
\hline Air turbine power & MWe & - & - & 234.7 & 160.5 \\
\hline Air compressor consumption & MWe & 9.1 & 8.9 & 174.5 & 174.6 \\
\hline GT net power & MWe & - & - & 60.1 & -14.1 \\
\hline \multicolumn{6}{|l|}{$\begin{array}{l}\text { Additional power / anode } \\
\text { side }\end{array}$} \\
\hline TIT (anode turbine) & ${ }^{\circ} \mathrm{C}$ & - & - & - & 850 \\
\hline Anode steam- $\mathrm{CO}_{2}$ expander & MWe & - & - & - & 47.5 \\
\hline $\mathrm{O}_{2}$ compressor & MWe & - & - & - & 3.2 \\
\hline ASU consumption (for the oxy-combustor) & MWe & - & 8.6 & - & 8.3 \\
\hline $\mathrm{CO}_{2}$ compression & MWe & - & 19.0 & - & 18.6 \\
\hline Heat-recovery-steam-cycle & MWe & 106.0 & 105.8 & 46.5 & 52.9 \\
\hline \multicolumn{6}{|l|}{ Summary } \\
\hline Power output (net, DC) & MWe & 527.8 & 500.1 & 582.7 & 532.3 \\
\hline Inlet fuel & MWt & 815.3 & 815.3 & 815.3 & 815.3 \\
\hline Inverter efficiency & & $96 \%$ & $96 \%$ & $96 \%$ & $96 \%$ \\
\hline AC electrical efficiency, $\eta_{A C}$ (HHV NG) & & $62.1 \%$ & $\mathbf{5 8 . 9 \%}$ & $68.6 \%$ & $62.7 \%$ \\
\hline$\eta_{A C}$ without $\mathrm{CO}_{2}$ compression & & - & $61.1 \%$ & - & $64.9 \%$ \\
\hline$\eta_{A C}$ without $\mathrm{CO}_{2}$ compression and ASU & & - & $62.1 \%$ & - & $66.2 \%$ \\
\hline $\mathrm{CO}_{2}$ captured post-SOFC & $\mathrm{kg} \mathrm{s}^{-1}$ & - & 42 & - & 42 \\
\hline
\end{tabular}




\subsection{Main Economic Assumptions}

\subsubsection{General Assumptions}

Consistent with the rest of this report, the economic viability of each plant was estimated using the EPRI TAG revenue requirement methodology ${ }^{7}$ in conjunction with the capital cost database based on Kreutz, et al. ${ }^{8}$ Economic parameters used to estimate the cost of producing electricity are given in Table 7. All capital costs are escalated to mid-2007 US dollars using the Chemical Engineering Plant Cost Index.

Table 7. Techno-economic assumptions for the SOFC in this study.

\begin{tabular}{|lc|}
\hline NG price, \$/GJ HHV & 6.35 \\
Capacity factor & $85 \%$ \\
Capital charge rate (CCR), \% per yr & $14.4 \%$ \\
Interest during construction, fraction of TPC & $11.4 \%$ \\
Construction period, yr & 3 \\
O\&M, fraction of TPC per yr & $4 \%$ \\
$\mathrm{CO}_{2}$ transport \& storage, \$/tonne & 6.1 \\
SOFC module lifetime, yr & 5 \\
SOFC degradation rate, ASR \% increase per 1000h & 0.2 \\
\hline Notes: & \\
- Interest during construction (IDC) is based on a 3-year construction schedule with equal, annual \\
- payments, and a discount rate of 10\%/yr. \\
\hline
\end{tabular}

\subsubsection{SOFC Power Island}

Costing of the SOFC core unit is a critical issue. It is difficult to accurately estimate (or to obtain from the manufacturers) the cost of technologies still under development, but the DOE-funded SECA (Solid State Energy Alliance) program has specified SOFC cost targets. In 2011, the SECA technology manager offered the following costs: ${ }^{9} 685 \$ / \mathrm{kW}(2007$ \$) as the actual cost for an IGFC power module, as compared with the 2010 target cost of $700 \$ / \mathrm{kW}$. Bloom Energy, a US-based SOFC manufacturer (not involved in the SECA) and vendor of $100 \mathrm{~kW}_{\mathrm{e}}$ power systems running either on NG or biogas notes on their website that their full SOFC system had an actual production cost $(2010 \$)$ of $\$ 7,000 / \mathrm{kW}$. Of course, Bloom Energy is not yet taking advantage of scale economies as, to date, only a few hundred units have been sold and installed. In addition, the CEO of SOFCpower (IT/CH) - one of Europe's most prominent SOFC producers - declared in Nov. 2011, at the International Panel on Hydrogen and fuel cell Economy (IPHE) roundtable in Berlin, that a cost of 3,000-5,000 \$/kWe could be achieved at present (i.e. with actual technology performance and manufacturing techniques) if large production volumes were available. In Japan, starting from November 2011, a well-established oil and gas company commenced the commercialization of SOFC units with a nominal output of $\sim 700 \mathrm{~W}$ for the residential sector. The

7 Electric Power Research Institute (EPRI). 'Technical Assessment Guide, Volume 1: Electricity Supply'. Report number TR102276-V1R7, 1993.

8 Kreutz, T.G., Larson, E.D., Liu, G., Williams, R.H. 'Fischer-Tropsch Fuels from Coal and Biomass'. 25th Annual International Pittsburgh Coal Conference, Pittsburgh (PA), USA, 2008.

9 Vora, D.S., 'Overview of DOE SECA Program', 12th Annual SECA Workshop XXII, National Energy Technology Laboratory, July 2011. (http://www.netl.doe.gov/publications/proceedings/11/seca/index.html). 
single unit costs around 25,000-30,000 US\$ and is planned to be reduced to 6,000 US\$ once fully commercialized. ${ }^{10,11}$

For this study, the design and capital cost of SOFC modules were calculated following NETL ${ }^{12,13}$; additional costs for piping and insulation were taken from Siemens Westinghouse ${ }^{14}$. The highly modular SOFC unit is configured as follows. Each pressurized module consists of 64 blocks of stacked planar cells with metallic interconnectors that serve as both bipolar plates and gas distributors. Each cell (i.e. the fundamental unit of a stack) has an active area of $550 \mathrm{~cm}^{2}$, and each block contains 96 cells, or $5.28 \mathrm{~m}^{2}$ of active cell area. A pressurized SOFC module of 64 blocks produces $\sim 1.7 \mathrm{MW}_{\mathrm{e}}$. Each module is enclosed in its own insulated pressure vessel, with an AC/DC inverter, turbomachinary and heat-exchangers.

Each module cost includes capital costs for the following equipment (Table 8):

- Blocks of planar-type cells stacked together with metallic interconnectors (acting both as bipolar plates as well as gas distributors); cell blocks are then arranged as stack modules;

- piping and insulation;

- $\quad$ an enclosure/pressure vessel;

- a DC-AC inverter.

As shown at the bottom of Table 8, the overall cost for a stack module is fundamentally related to the specific cost per unit of active cell surface area $\left(\$ / \mathrm{cm}^{2}\right)$. Note also that the area required to generate a fixed amount of power (i.e. the total number of single fuel cells required) is directly dependent on the specified power density.

Table 8. Pressurized SOFC module: cost breakdown.

\begin{tabular}{|c|c|}
\hline Integrated pres. SOFC blocks, $\$ / \mathrm{kWe}^{\dagger}$ & 112 \\
\hline Pressurized enclosure, $\$ / \mathrm{kWe}$ & 200 \\
\hline DC/AC Inverter, $\$ / \mathrm{kWe}$ & 82 \\
\hline Piping and insulation, $\$ / \mathrm{kWe}$ & 125 \\
\hline Transport and placement, $\$ / \mathrm{kWe}$ & 12 \\
\hline Foundations at the site, $\$ / \mathrm{kWe}$ & 37 \\
\hline Manufacturing cost, $\$ / \mathrm{kWe}$ & 30 \\
\hline Bare-Erected-Cost (BEC), \$/kWe & 568 \\
\hline Total-Plant-Cost (TPC) & 657 \\
\hline \multicolumn{2}{|c|}{ 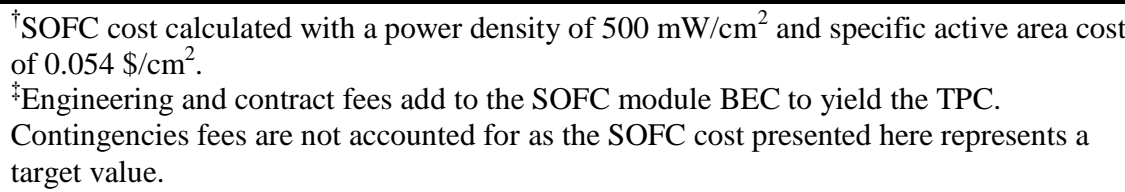 } \\
\hline
\end{tabular}

${ }^{10}$ JX Nippon Oil \& Energy Corporation, "Developments of Residential Fuel Cells in Japan”, Taipei, International Conferences on Green Trade 2011, August 4th, 2011.

${ }^{11}$ JX Nippon Oil \& Energy Corporation, "Commercialization of SOFC micro-CHP in the Japanese market, Keynote presentation at the Fuel Cells 2012 Science and Technology conference, 11-12th April, 2012, Berlin, Germany.

12 DOE/NETL-2011/1486 report 'Analysis of Natural Gas Fuel Cell Plant Configurations'.

${ }^{13}$ DOE/NETL-2011-1482 report 'Analysis of Integrated Gasification Fuel Cell Plant Configurations'.

${ }^{14}$ Lundberg, W.L., Israelson, G.A., Holmes, R.A., Zafred, P.R., King, J.E., Kothmann, R.E, 2000, "Pressurized solid oxide fuel cell/gas turbine power system", Siemens Westinghouse. 
The cost for high-temperature heat-exchangers was evaluated following Turton et al. ${ }^{15,16}$ and cost data reported in other relevant studies ${ }^{17,18}$; cost factors of 10 and 20 (relative to carbon steel heatexchangers) were used for heat-exchangers made of high-temperature alloys (for gas temperatures below $850^{\circ} \mathrm{C}$ ) and of metal/ceramic alloys (for gas temperatures $<1450{ }^{\circ} \mathrm{C}$ and with wall temperatures $<1050$ $\left.{ }^{\circ} \mathrm{C}\right)$, respectively.

\subsection{Comparative Economic Results}

Table 9 disaggegates estimated LCOE's, including showing " $\mathrm{N}^{\text {th }}$ plant" estimates for the cost of spare capacity (which have been annualized) and annual O\&M costs associated with module replacements. ${ }^{19}$ The main findings have been already discussed in the Executive Summary. Notably, at 50 $\$$ /tonne $\mathrm{CO}_{2}$ emissions price, theLCOE does not increase significantly when $\mathrm{CO}_{2}$ capture is included for either the atmospheric or pressurized SOFC designs. Table 10 gives detailed overnight costs of the main plant components in the NG-P-CCS plant; more than half of the total plant cost is due to the SOFC reactors.

Table 9. Levelized Cost of Electricity for NG-SOFC plants

\begin{tabular}{|c|c|c|c|c|}
\hline Electricity Cost Components, $2007 \$ / M W h$ : & $N G-A-V$ & $\begin{array}{c}N G-A- \\
C C S\end{array}$ & $\begin{array}{c}N G-P- \\
V\end{array}$ & $\begin{array}{c}N G-P- \\
C C S\end{array}$ \\
\hline Installed capital (at $14.38 \%$ of TPI) & 15.91 & 21.79 & 16.74 & 23.94 \\
\hline O\&M (at $4 \%$ of TPC per yr) & 3.97 & 5.44 & 4.18 & 5.98 \\
\hline O\&M SOFC module replacements & 3.53 & 3.72 & 3.53 & 3.86 \\
\hline Natural Gas (at 6.35 \$/GJ, HHV) & 36.78 & 38.82 & 33.32 & 36.47 \\
\hline $\mathrm{CO}_{2}$ emissions (at $50.0 \$ /$ tonne $\mathrm{CO}_{2}$ ) & 17.14 & 2.51 & 15.52 & 2.36 \\
\hline $\mathrm{CO}_{2}$ disposal (at $10.2 \$$ /tonne $\mathrm{CO}_{2}$ ) & 0.00 & 3.23 & 0.00 & 3.03 \\
\hline Levelized cost of electricity ( $L C O E)$ & 77.33 & 75.52 & 73.29 & 75.64 \\
\hline Total Plant Cost (TPC), $\$ / k W e$ & 740 & 1014 & 779 & 1113 \\
\hline
\end{tabular}

\footnotetext{
${ }^{15}$ Turton, R., et al., 2003, 'Analysis, Synthesis, and Design of Chemical Processes'. Third Edition, Prentice Hall.

${ }^{16}$ Green, D.W., 2007, 'Perry's Chemical Engineers' Handbook', Eight Edition, McGraw-Hill.

${ }^{17}$ Kuramochi, T., Turkenburg, W., Faaij, A., 2011, 'Competitiveness of $\mathrm{CO}_{2}$ capture from an industrial solid oxide fuel cell combined heat and power system in the early stage of market introduction', Fuel, 90(3), pp. 958-973.

${ }^{18}$ DOE/NETL-2002/1169 report, 2002, 'Process equipment cost estimation: final report'.

${ }^{19}$ Spare capacity is installed to account and compensate for cell degradation. The sparing strategy is such that the SOFC efficiency and power output are kept nearly constant with time. The cell area-specific-resistance (ASR) increases steadily with time (a linear increase is assumed), and the cell current density is decreased at regular 1000 hour intervals to maintain nearly constant voltage. Consequently, the spare cell surface is gradually enabled (e.g. every $1000 \mathrm{~h}$ ) to maintain the plant power output constant. Since $100 \%$ of the initial cell surface area is assumed to be replaced every 5 years, and with an assumed degradation rate of $0.2 \%$ per $1000 \mathrm{~h}$, the overall stack degradation at the end of life will be around $7 \%$. Consequently, the spare capacity installed is around $7 \%$ of the nominal capacity.
} 
Table 10. NG-P-CCS detailed overnight costs of plant components (continues on the next page)

\begin{tabular}{|c|c|c|c|c|c|}
\hline & \multirow{2}{*}{ Plant component } & \multirow{2}{*}{ Scaling parameter } & \multirow{2}{*}{$\begin{array}{c}\text { Required } \\
\text { capacity }\end{array}$} & \multicolumn{2}{|c|}{$\begin{array}{l}\text { Component } O C \\
\text { costs with } B O P\end{array}$} \\
\hline & & & & $M \$$ & $\$ / k W e$ \\
\hline 1 & \multicolumn{5}{|l|}{ SOFC power core } \\
\hline 1.1 & Atmospheric SOFC & $\mathrm{SOFC}, \mathrm{MWe}-\mathrm{AC}$ & - & \multirow{3}{*}{300.4} & \multirow{3}{*}{588} \\
\hline 1.2 & Pressurized SOFC & SOFC, MWe -AC & 457.0 & & \\
\hline 1.3 & Atm. SOFC spare capacity & SOFC, MWe - AC & - & & \\
\hline \multirow[t]{2}{*}{1.4} & Pres. SOFC spare capacity & SOFC, MWe - AC & 457.0 & 22.4 & 44 \\
\hline & SUBTOTAL 1 & & & 322.8 & 632 \\
\hline 2 & Burners & & & \multirow{3}{*}{11.5} & \multirow{3}{*}{23} \\
\hline 2.1 & Oxy-combustor & Heat duty, MWt & 146.1 & & \\
\hline \multirow[t]{2}{*}{2.2} & After-burner & Heat duty, MWt & - & & \\
\hline & SUBTOTAL 2 & & & 11.5 & 23 \\
\hline \multirow{3}{*}{$\begin{array}{r}3 \\
3.1\end{array}$} & Fuel processing & & & & \\
\hline & NG desulfurizer & NG flow, $\mathrm{kmol} / \mathrm{s}$ & 0.87 & 1.3 & 3 \\
\hline & SUBTOTAL 3 & & & 1.3 & 3 \\
\hline 4 & \multicolumn{3}{|l|}{ Turbomachinary } & & \\
\hline 4.1 & Anode recirculator & Anode exhaust, kmol/s & 3.03 & 0.4 & 1 \\
\hline 4.2 & Cathode recirculator & Cathode exhaust, $\mathrm{kmol} / \mathrm{s}$ & 12.09 & 3.4 & 7 \\
\hline 4.3 & Cathode air compressor & Air flow, $\mathrm{kmol} / \mathrm{s}$ & 11.56 & 18.6 & 36 \\
\hline 4.4 & Cathode expander & Air flow, $\mathrm{kmol} / \mathrm{s}$ & 10.00 & 7.3 & 14 \\
\hline 4.5 & Syngas expander & Power output, MWe & - & & \\
\hline \multirow[t]{2}{*}{4.6} & Oxy-combusted anode expander & Power output, MWe & 47.53 & 11.7 & \\
\hline & SUBTOTAL 4 & & & 41.3 & 58 \\
\hline 5 & \multicolumn{3}{|l|}{ Heat-exchangers } & & \\
\hline 5.2 & High-T metal/ceramic HX (recuperator) & Exchange area, $\mathrm{m}^{2}$ & 3941.7 & 26.0 & 51 \\
\hline \multirow[t]{2}{*}{5.3} & Medium-T SS HX (fuel recuperator) & Exchange area, $\mathrm{m}^{2}$ & 5045.6 & 4.3 & 8 \\
\hline & SUBTOTAL 5 & & & 30.2 & 59 \\
\hline 6 & \multicolumn{3}{|l|}{ Reactors } & & \\
\hline 6.1 & Single reactor methanator with recycle & Methanated flow,kmol/s $\mathrm{CH}_{4}$ & - & & \\
\hline 6.2 & COS hydrolysis & AR coal, MW LHV & - & & \\
\hline 6.3 & Selexol co-capture (CO2 and $\mathrm{H} 2 \mathrm{~S})$ & Raw syngas, $\mathrm{kmol} / \mathrm{s}$ & - & & \\
\hline 6.4 & WGS reactors & AR coal, MW LHV & - & & \\
\hline & Gas cleanup BOP (Hg removal, piping, & & & & \\
\hline 6.5 & foundations) & AR coal, MW LHV & - & & \\
\hline 6.6 & Sulfinol (H2S removal) & $\mathrm{H} 2 \mathrm{~S}, \mathrm{kmol} / \mathrm{s}$ & - & & \\
\hline 6.7 & Sulfur polishing & Syngas, kmol/s & - & & \\
\hline \multirow[t]{2}{*}{6.8} & Claus plant & $\mathrm{S}$ input, $\mathrm{mt} /$ day & - & & \\
\hline & SUBTOTAL 6 & & & 0.0 & 0.0 \\
\hline 7 & \multicolumn{3}{|l|}{ Shell gasifier } & & \\
\hline 7.1 & Coal handling & AR coal, mt/day & - & & \\
\hline 7.2 & Shell - coal preparation \& feeding & AR coal, $\mathrm{mt} /$ day & - & & \\
\hline 7.3 & Shell - ash handling & Coal ash, mt/day & - & & \\
\hline 7.4 & Shell - ASU + oxidant comp. & Pure $\mathrm{O} 2, \mathrm{mt} / \mathrm{day}$ & 758.6 & 69.4 & 136 \\
\hline 7.5 & Shell standard gasifier \& SG coolers & AR coal, MW LHV & - & & \\
\hline 7.6 & Shell partial water quench gasifier & AR coal, MW LHV & - & & \\
\hline \multirow[t]{2}{*}{7.7} & Shell - LT heat recoc \& FG saturation & AR coal, MW LHV & - & & \\
\hline & SUBTOTAL 7 & & & 69.4 & 136 \\
\hline
\end{tabular}




\begin{tabular}{|c|c|c|c|c|c|}
\hline 8 & CO2 compression & & & & \\
\hline \multirow[t]{2}{*}{8.1} & $\mathrm{CO} 2$ compression and drying & Comp. power, MWe & 18.6 & 35.4 & 69 \\
\hline & SUBTOTAL 8 & & & 35.4 & 69.2 \\
\hline 9 & \multicolumn{3}{|l|}{ Heat recovery steam cycle $(\mathrm{HRSC})$} & \multirow{3}{*}{30.8} & \multirow{3}{*}{60} \\
\hline 9.1 & Boiler/steam generator, ductwork, stack & Boiler duty, MWth & 177.6 & & \\
\hline 9.2 & $\begin{array}{l}\text { GT HRSG, ductwork, \& stack } \\
\text { Steam turbine (ST) condenser steam }\end{array}$ & GT net power, MWe & - & & \\
\hline \multirow[t]{5}{*}{9.3} & piping, auxiliaries & ST gross power, MWe & 52.9 & 26.2 & 51 \\
\hline & SUBTOTAL 9 & & & 56.9 & 111.4 \\
\hline & \multicolumn{5}{|l|}{ Power plant BoP and auxiliaries } \\
\hline & $\begin{array}{l}\text { BOP (feedwtr, CW, elec, controls, } \\
\text { sitework, buildings) }\end{array}$ & Percentage of TPC & & & \\
\hline & \multicolumn{3}{|c|}{ Total Plant Cost (TCP), 2007M\$ | Specific plant cost, \$/kWe } & 569.0 & 1091 \\
\hline
\end{tabular}

\section{Integrated Coal Fuel Cell (IGFC) Systems}

\subsection{Introduction}

We describe here various plants in which Illinois \#6 bituminous coal is gasified in a dry-feed Shell gasifier, the cleaned and processed syngas is fed to a pressurized SOFC power island, and $\mathrm{CO}_{2}$ is captured. One set of results is presented for systems utilizing a conventional cryogenic air separation unit (ASU) to supply oxygen to the gasifier and the anode exhaust oxy-combustor. In this set, three alternative designs examine the effect of partial methanation of the syngas upstream of the SOFC. Two cases employ different methanation technologies (TREMP and HICOM), while in the third, clean syngas is directly fed to the SOFC.

A second set of results is presented for plants in which the ASU is replaced by an ion transport membrane (ITM) that uses the pressurized cathode exhaust to generate oxygen. Only the IGFC-HICOM plant configuration is analyzed (with an ITM replacing the ASU) because it was the most attractive IGFC design with a cryogenic ASU. (Note that the efficiency gain achieved by replacing the ASU with the ITM is essentially independent of the specific IGFC configuration.) For reference, the IGFC-HICOM case, both in the ASU and ITM variants, has been also analyzed with $\mathrm{CO}_{2}$ vented to the atmosphere.

\subsection{IGFC Plant Characteristics}

\subsubsection{General considerations}

The basic plant layout, featuring a dry-feed gasifier integrated with a SOFC power island, is shown in Figure 12. Three alternative pathways are shown there for pre-processing the syngas upstream of the SOFC. These are described in detail below. Key assumptions used in the Aspen Plus simulations are provided in Table 11.

Differences in the performance of SOFC plants fuelled by coal vs. NG are dominated by: 1) exergy losses during coal gasification (absent with NG), and 2) the methane content of the SOFC feed stream. In the gasifier, the most significant loss of exergy is in the conversion of chemical energy in the coal into sensible heat (rather than chemical energy) in the $1400{ }^{\circ} \mathrm{C}$ raw syngas. Much of the sensible heat is recovered by raising high pressure steam used to produce electricity in a Rankine cycle, but electrical conversion efficiency of this process is significantly lower than that of the SOFC.

The technical assumptions employed when calculationg the performance of the SOFC power island are identical to those used in the NG-P-CCS case, except that the anode inlet temperature has been decreased from 800 to $700^{\circ} \mathrm{C}$ for IGFC to account for the relative paucity of endothermic reforming. 


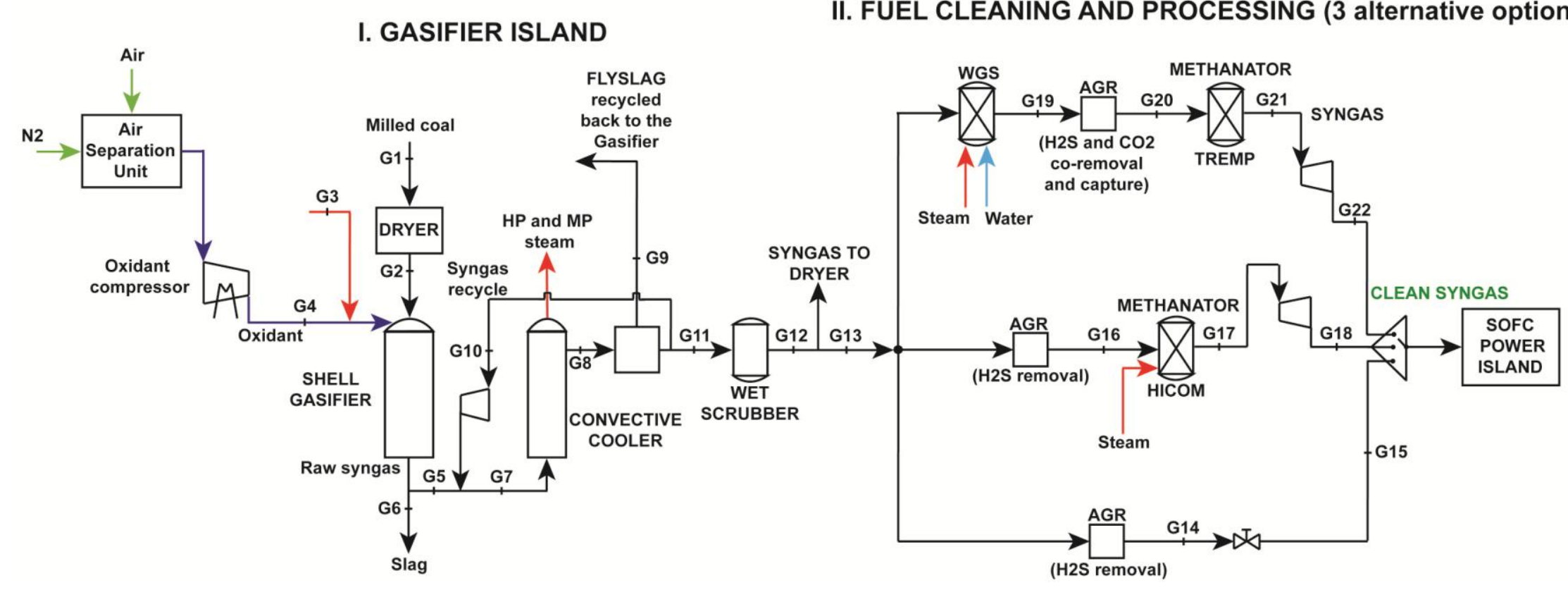

Figure 12. IGFC plant layout

Gasifier Island plus syngas cleaning and processing sections upstream of the SOFC power island are shown. The Shell gasifier island is common to all IGFC cases studied. As far as it concerns the cleaning section, the water scrubbing only is carried out in a slightly different fashion for the TREMP case compared to the DIRECT and 'HICOM' cases; in fact, when TREMP methanation is used, a larger amount of water is entrained by the syngas by use of heated make-up water (close to saturation) in the scrubber column. In Table that follows just below, streams G11bis, G12bis and G13bis depict the TREMP case operation around the scrubber component. Regarding the cleaning and processing sections after the wet scrubber, three different alternative options are available, which determine 'de facto' which IGFC plant configuration is chosen. 


\subsubsection{Syngas methanation upstream of the SOFC}

In the DIRECT plant, the syngas is directly fed to the SOFC. In order to enhance the SOFC conversion efficiency we considered methanation immediately up-stream of the SOFC to convert part of the syngas fuel stream into methane. In SOFC stacks with direct internal reforming - that has become now an established option for planar Ni-based anode-supported stacks ${ }^{20,21}-$, the presence of methane in the fuel gas provides a notable boost in conversion efficiency. Not only does the endothermic reforming process effectively convert SOFC waste heat directly into chemical enthalpy, but the reduced cooling duty lowers the (substantial) auxiliary power required to compress cathode air for SOFC cooling. (Note that cathode air flow is the primary means of removing heat generated within the stack from the heat of reaction and overvoltage irreversibilities.) These considerations motivate adding a methanation unit upstream of the SOFC when the fuel gas (e.g. syngas from a Shell gasifier) contains little methane. The highly exothermic methanation process also provides an effective method for high temperature fuel gas preheating, potentially obviating costly heat exchangers and increasing the efficiency of expanding the syngas in a turbine prior to feeding it to the SOFC. Thus, while it may seem counterproductive to methanate the syngas upstream of the SOFC only to immediately reverse that reaction within the SOFC, the potential advantages are significant.

The three different integrated gasifier SOFC (IGFC) plant designs developed are differentiated primarily by the way in which the raw syngas from the gasifier is processed prior to feeding it to the SOFC. Here, in addition to the DIRECT case, we have designed two alternative plants using different methanation reactors in the configuration shown in Figure 13. Syngas is mixed with a cooled recycle stream to create a dilute feed stream at $250{ }^{\circ} \mathrm{C}$ that enters an adiabatic catalytic methanation (chemical equilibrium) reactor. The recycle fraction limits the reactor temperature to $700^{\circ} \mathrm{C},,^{22,23}$ above which catalyst sintering would occur.

The two different methanation systems employ different Ni-based catalysts: the TREMPTM catalyst developed by Haldor Topsoe ${ }^{24}$ and the HICOM (High CO Methanation) catalyst, developed in the 1980 s by CRC and British Gas ${ }^{25}$. Both processes have generally been used in plants producing synthetic natural gas (SNG) to methanate all available $\mathrm{H}_{2}$ and $\mathrm{CO}$ via processing in several reactors in series. Our objective is to methanate only a fraction of the syngas, so we have used a single adiabatic reactor in each case. The use of only a single methanation reactor limits somewhat the production of methane, but is consonant with our goal of identifying cost-effective ways to improve SOFC performance when using commercial, high temperature, entrained flow gasifiers. As discussed below, the methane conversion is almost complete in the TREMP case, but somewhat less in the HICOM configuration where a second reactor might yield further performance benefits.

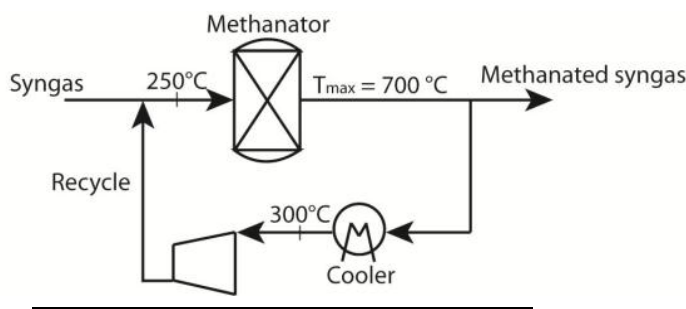

Figure 13. Methanation unit for the TREMP and HICOM cases.

${ }^{20}$ Föger, K., 2010, 'BlueGen - Ceramic Fuel Cells First Product for Commercial Roll-out', Fuel Cell Seminar presentation 2010, San Antonio, TX (USA), October 2010.

${ }^{21}$ Bose, D., Batawi, E.E., Couse, S., Hickey, D., Mcelroy, J., 2007, 'Solid Oxide Fuel Cell system with internal reformation', Patent No. WO 2008/123968.

${ }^{22}$ Rostrup-Nielsen, J.R, Pedersen, K., Sehested, J., 2007, 'High temperature methanation', Applied Catalysis A: General 330, pp. 134-138.

${ }^{23}$ Pedersen, K., Skov, A., Rostrup-Nielsen, J.R., 1980, 'Catalytic aspects of high temperature methanation', ACS Fuel Chem. Div. Preprints, 25(2), pp. 89-100.

${ }^{24}$ Rostrup-Nielsen J.R., Pedersen K., Sehested J., 'High temperature methanation sintering and structure sensitivity', Applied Catalysis A: General, 2007, 330 pp.134-138.

${ }^{25}$ M.V. Twigg, Catalyst Handbook, $2^{\text {nd }}$ edition, 1996. 


\subsection{IGFC plants with Cryogenic Air Separation Unit}

\subsubsection{Plant descriptions}

The IGFC plants with ASU and CCS are reviewed below. The three IGFC plants studied here employ a commercial, pressurized, $\mathrm{O}_{2}$-blown, entrained flow, dry-feed (Shell) coal gasifier whose processed syngas feeds an $800{ }^{\circ} \mathrm{C}$ pressurized SOFC. Post-SOFC $\mathrm{CO}_{2}$ capture is achieved by combusting the anode exhaust in oxygen to create a stream of hot, pressurized $\mathrm{CO}_{2}+\mathrm{H}_{2} \mathrm{O}$ which is expanded and cooled to condense out the water. The remaining (93\% vol. pure) $\mathrm{CO}_{2}$ is dried and compressed in preparation for pipeline transport, and geologic storage. (Note that the power required to compress $\mathrm{CO}_{2}$ to $150 \mathrm{bar}$ is included in the performance calculations for all cases.) An uncooled gas turbine is used to both compress and heat air to feed the SOFC cathode, and to expand the hot cathode exhaust.

DIRECT case. This case represents the baseline IGFC plant, with a pressurized Shell dry-feed gasifier and pressurized SOFC-based power island (Figure 14). The hot raw syngas leaving the gasifier is quenched by recycling clean cooled syngas; the temperature of the syngas is then further lowered in a convective cooler. Thereafter, the cooled syngas is filtered, water-scrubbed to remove additional impurities, and sent to the acid gas removal (AGR) unit to remove sulfur compounds. After these cold cleaning stages, the syngas is directly fed to the SOFC. The power island consists of SOFC modules pressurized to $\sim 20$ bar. Both SOFC exhaust streams (cathode and anode) are partially recirculated. The cathode air compressor is driven by a turbine expanding the hot cathode exhaust leaving the SOFC. The anode exhaust is oxy-combusted and then also expanded in a dedicated turbine to recover additional power.

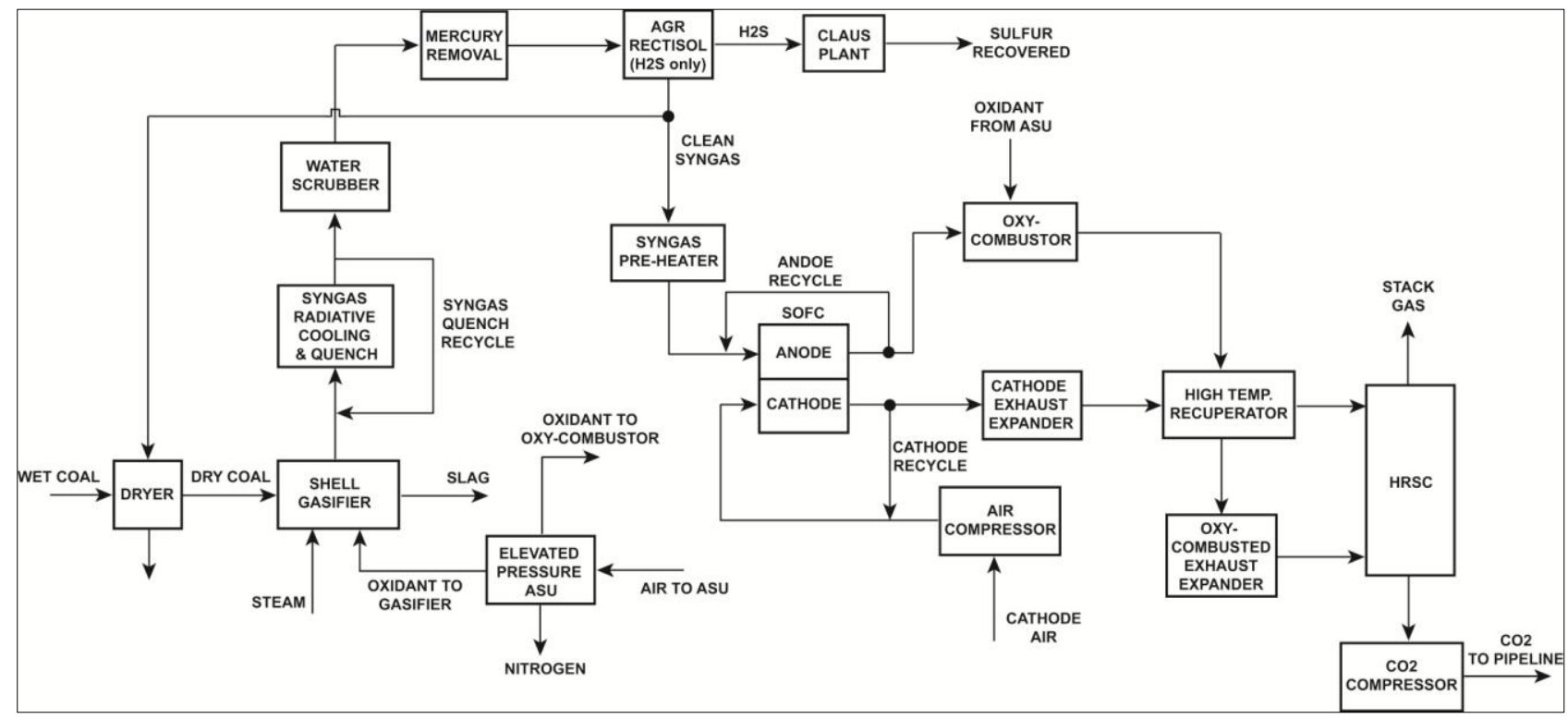

Figure 14. Simplified schematic for coal IGFC power plant with direct use of syngas in the SOFC.

TREMP case. The IGFC-TREMP case utilizes the Shell gasifier and an SOFC-based power cycle. The unique feature of this design is the use of a TREMP methanator ${ }^{26}$ just upstream of the SOFC (Figure 15). The raw syngas is first quenched by recycling cooled syngas. Its temperature is further reduced in a convective cooler. After filtering and water-scrubbing, the syngas undergoes water-gas shift (WGS) with

\footnotetext{
${ }^{26}$ Udengaard, N.R., Olsen, A., Wix-Nielsen, C. High Temperature Methanation Process - Revisited, 23rd Annual International Pittsburgh Coal Conference, September 2006.
} 
steam to yield a gas with an $\mathrm{H}_{2}$ : $\mathrm{CO}$ molar ratio of $3: 1^{27}$. A peculiarity of the plant design using the TREMPTM catalyst is that $\mathrm{CO}_{2}$ is removed in two different sections of the plant i.e. before the SOFC, in a Rectisol unit, and again after the SOFC. The upstream removal is required because the TREMPTM catalyst requires a $\mathrm{CO}_{2}$ free syngas to sustain the methanation. Some carbon leaves the methanator as $\mathrm{CO}_{2}$ and $\mathrm{CO}$. This is removed downstream through the already described oxy-combustion process followed by water condensation and flash separation of the $\mathrm{CO}_{2}$.

A downstream Rectisol-based process is used to capture $\mathrm{CO}_{2}$ and $\mathrm{H}_{2} \mathrm{~S}$. (The $\mathrm{CO}_{2}$ is dried and compressed to supercritical pressures - 150 bar here - for pipeline delivery to underground storage.) The WGS and AGR sections combine to produce a syngas composition suitable for feeding a methanation reactor filled with TREMP catalyst. A portion of the gas exiting this single-step methanation process is cooled and recycled back to the methanator inlet to maintain the reactor temperature below $700{ }^{\circ} \mathrm{C}$. As a result, the methane content in the exiting syngas is quite high ( $37 \%$ vol.), with almost all the carbon in the incoming syngas having been converted to $\mathrm{CH}_{4}$ in the methanator.

As with the DIRECT case, the power island consists of pressurized SOFC modules, both exhausts from which (cathode and anode) are partially recirculated. The cathode air compressor is driven by a turbine expanding the hot cathode exhaust. The anode exhaust is oxy-combusted and expanded in a dedicated turbine to recover additional power.

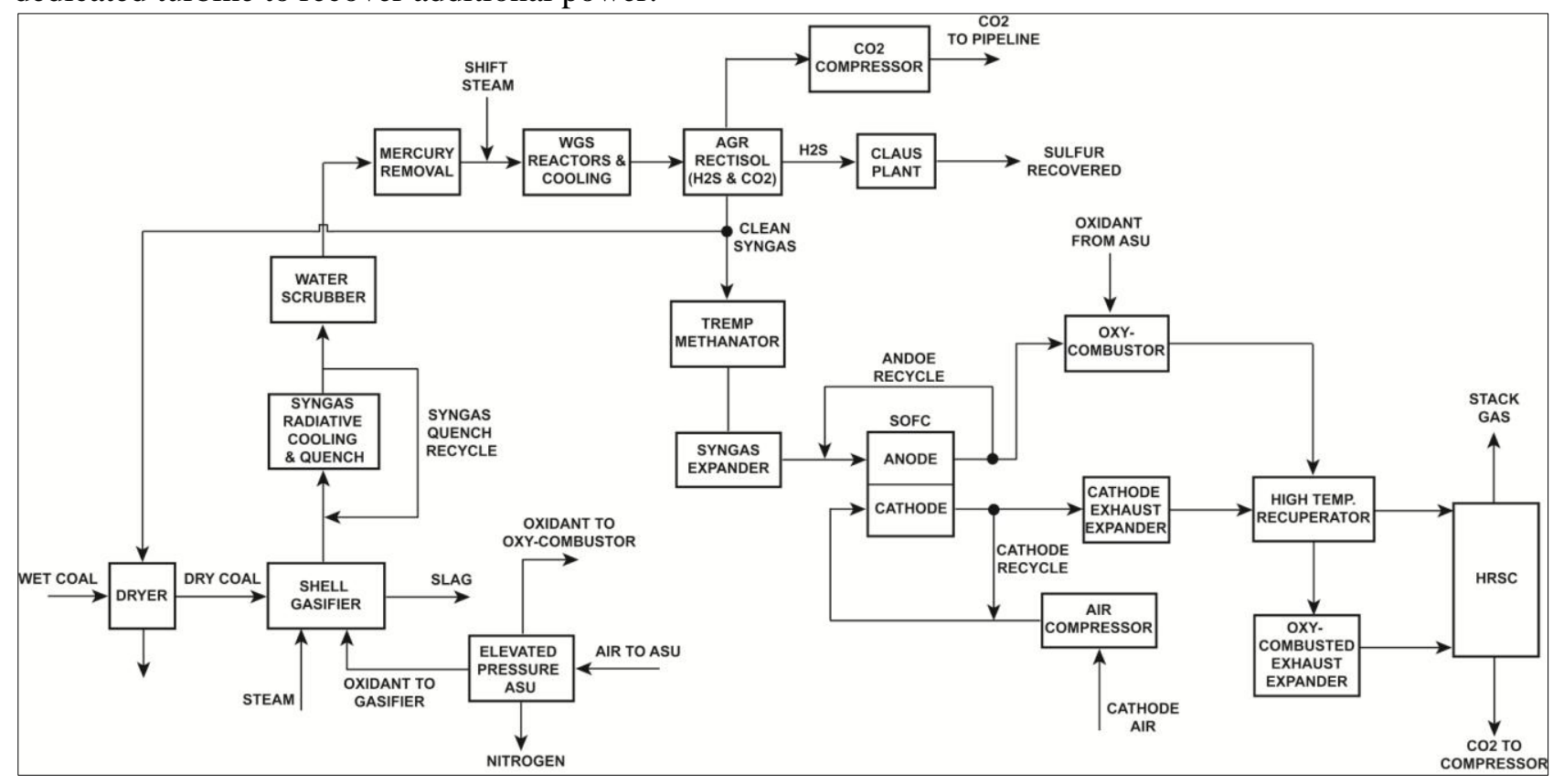

Figure 15. Simplified schematic for coal integrated gasifier solid-oxide fuel cell power plant using TREMP methanator.

\footnotetext{
${ }^{27}$ The TREMPTM methanation catalyst requires a $\mathrm{H}_{2} / \mathrm{CO}$ molar ratio equal to 3 for proper methanation of syngas, so a water gas shift (WGS) reactor is included upstream. We utilize a 2 stage adiabatic reactor, which reduces the steam requirements of the WGS compared with a single stage WGS (see as a reference Martelli E., Kreutz T., Carbo M., Consonni S., Jansen D., Shell coal IGCCS with carbon capture: Conventional gas quench vs. innovative configurations, Applied Energy, 2011, In Press).
} 
HICOM case. The IGFC-HICOM case (Figure 16) closely resembles the TREMP case but utilizes the HICOM (HIgh CO Methanation) methanator ${ }^{28}$ in place of the TREMP system. The HICOM catalyst is nickel-based (as is the TREMP catalyst), but is able to tolerate a syngas having high CO content, provided that sufficient amount of steam is co-fed to the reactor to avoid coking. In the HICOM case, $40 \%$ less methane is produced than in the TREMP case, and although the required cathode air flow is greatly reduced (compared to the DIRECT case), it is not at its lower limit. A multi-stage methanator might achieve this result, although its economic viability is less clear.

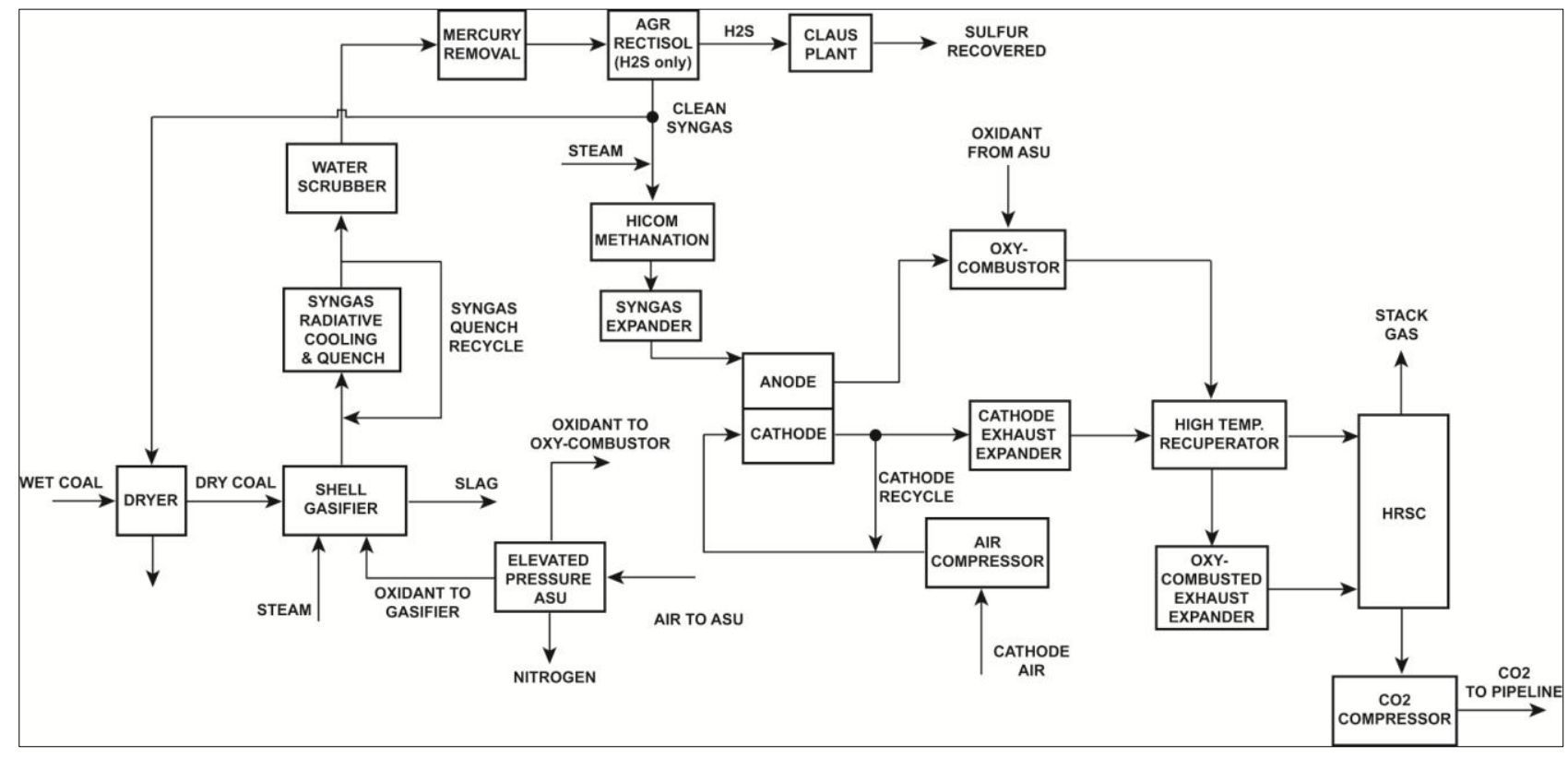

Figure 16. Simplified schematic for coal integrated gasifier solid-oxide fuel cell power plant using HICOM methanator.

\subsubsection{Performance Results}

The performance of all three IGFC plant configurations is given side-by-side in Table 12. Partial methanation prior to the SOFC is seen to increase plant efficiency; in particular, the HICOM methodology boosts efficiency more than two percentage points over direct use of syngas in the SOFC.

Table 12. IGFC plant with cryogenic ASU: performance with optimized HRSC. (continued, next page)

\begin{tabular}{|c|c|c|c|c|}
\hline & Plant design: & DIRECT & TREMP & HICOM \\
\hline \multicolumn{5}{|l|}{ Fuel input } \\
\hline Coal input / HHV & MW & 1916 & 1916 & 1916 \\
\hline Syngas feed to the SOFC power island & $\mathrm{kmol} \mathrm{s}^{-1}$ & 6.06 & 3.38 & 8.26 \\
\hline Syngas HHV to the SOFC power island & $\mathrm{MJ} \mathrm{kmol}^{-1}$ & 1609 & 1356 & 1526 \\
\hline \multicolumn{5}{|l|}{ SOFC power unit } \\
\hline Global fuel utilization, $F U$ & & 0.85 & 0.85 & 0.85 \\
\hline Air recirculation fraction & & 0.52 & 0.54 & 0.53 \\
\hline Global air utilization, $\lambda$ & & 4.49 & 1.73 & 2.36 \\
\hline Local air utilization, $\lambda^{*}$ & & 8.25 & 2.60 & 3.91 \\
\hline Operating voltage & $\mathrm{V}$ & 0.78 & 0.79 & 0.77 \\
\hline
\end{tabular}

${ }^{28}$ Twigg, M. Catalyst Handbook, 2nd edition, 1996, pp. $374-375$. 


\begin{tabular}{|c|c|c|c|c|}
\hline SOFC power & MW & 732.8 & 737.7 & 723.2 \\
\hline \multicolumn{5}{|l|}{ Additional power / cathode side } \\
\hline TIT cathode turbine & ${ }^{\circ} \mathrm{C}$ & 800 & 800 & 800 \\
\hline Air turbine power & MW & 783.1 & 277.7 & 394.8 \\
\hline Air compressor consumption & MW & 787.0 & 303.0 & 415.3 \\
\hline GT net power & MW & -3.9 & -25.3 & -20.5 \\
\hline \multicolumn{5}{|l|}{ Additional power / anode side } \\
\hline TIT anode turbine & ${ }^{\circ} \mathrm{C}$ & 850 & 850 & 850 \\
\hline Anode steam- $\mathrm{CO}_{2}$ expander & MW & 112.7 & 100.9 & 176.0 \\
\hline $\mathrm{O}_{2}$ compressor & MW & 5.4 & 5.3 & 5.3 \\
\hline ASU consumption $\mathrm{I}\left(\mathrm{O}_{2}\right.$ for the oxy-combustor) & MW & 13.4 & 13.1 & 13.3 \\
\hline $\mathrm{CO}_{2}$ compression (post-SOFC capture) & MW & 73.7 & 33.3 & 73.7 \\
\hline \multicolumn{5}{|l|}{ Power recovery from HRSGs } \\
\hline $\begin{array}{l}\text { HRSC (steam cycle recovering heat from gasifier, fuel } \\
\text { cleaning/processing units and SOFC exhausts) }\end{array}$ & MW & 224.1 & 264.3 & 228.9 \\
\hline \multicolumn{5}{|l|}{ Auxiliaries } \\
\hline Coal prep. and handling \& slag handling & MW & 4.6 & 4.6 & 4.6 \\
\hline ASU consumption II ( $\mathrm{O}_{2}$ to the gasifier $)$ & MW & 63.8 & 63.8 & 63.8 \\
\hline Syngas recycle compressor & MW & 0.1 & 0.1 & 0.1 \\
\hline $\begin{array}{l}\text { Rectisol unit }\left(\mathrm{H}_{2} \mathrm{~S} \text { absorption only for DIRECT and }\right. \\
\left.\text { HICOM cases, } \mathrm{H}_{2} \mathrm{~S}+\mathrm{CO}_{2} \text { removal for the TREMP case }\right)\end{array}$ & MW & 10.1 & 87.5 & 10.1 \\
\hline Methanator recirculator & & - & 1.1 & 1.1 \\
\hline Syngas expander & MW & - & 6.9 & 17.2 \\
\hline \multicolumn{5}{|l|}{ Summary } \\
\hline Power output & MW & 894.6 & 875.7 & 952.9 \\
\hline Inlet fuel & MW & 1608.7 & 1355.8 & 1526.5 \\
\hline Inverter efficiency & & $96 \%$ & $96 \%$ & $96 \%$ \\
\hline AC electrical efficiency, $\eta_{A C}$ (HHV of coal input $)$ & & $44.8 \%$ & $43.9 \%$ & $47.8 \%$ \\
\hline $\mathrm{CO}_{2}$ captured post-SOFC & $\mathrm{kg} \mathrm{s}^{-1}$ & 162.3 & 63.7 & 162.2 \\
\hline
\end{tabular}

Additional details of the IGFC mass/energy balances that are relevant for the subsequent cost analysis are reproduced here. Figure 17 shows the gasifier and SOFC power islands in detail. Table 13 reports stream data for Figure 17. Table 14, Table 15, and Table 16 give stream data for the DIRECT, TREMP and HICOM cases, respectively.

The amount of cathode air required to cool the SOFC reactors is inversely proportional to the methane content of the syngas fed to the fuel cell. Increasing methane lowers the required cathode air flow needed to cool the SOFC, which in turn increases overall efficiency by reducing the parasitic power for cathode air compression. (This also lowers the heat given to the HRSG by the cathode.)

Note that the lower limit on cathode air flow is set by the following requirement: the oxygen partial pressure of the cathode exhaust leaving the SOFC should not fall below 10 mol\%; otherwise, the drops in Nernst voltage and SOFC conversion efficiency become too large. Note finally that the methane content in the TREMP and HICOM cases are close to this threshold, demonstrating little need for additional methanation beyond that already accomplished. 


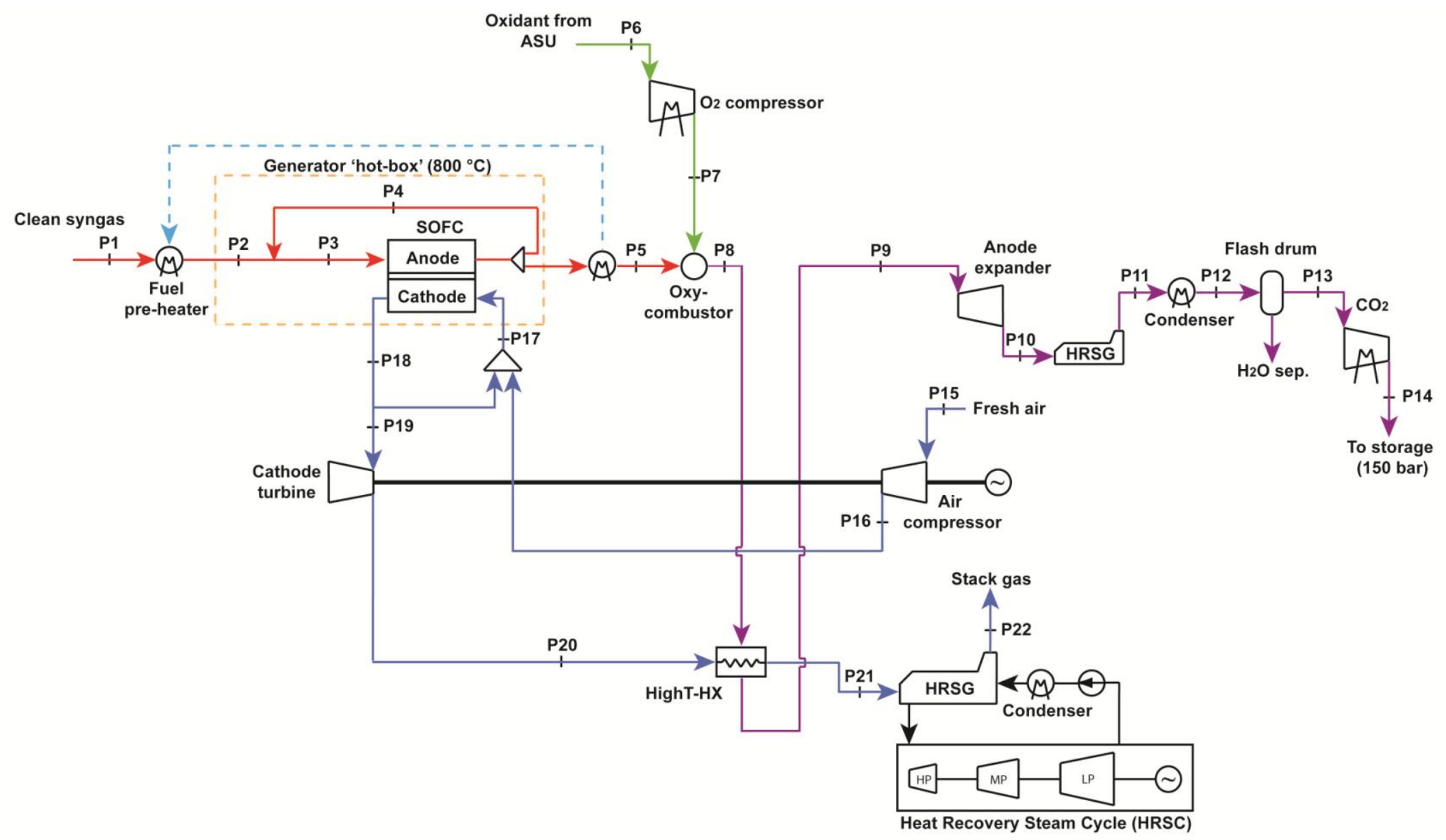

Figure 17 - SOFC power island in the IGFC plants

The SOFC power island is common to all three IGFC configurations. The HRSG shown recovers heat from both the anode and cathode exhausts, and actually represents a plant-wide network of heat-exchangers. The HSRG accounts for all the steam users/providers of the plant, including those of the gasifie island as well as those of the syngas cleaning and processing sections. Once the heat exchange network is balanced, excess available heat (after meeting all internal heat exchange needs) is used to generate additional power through steam turbines. 
Table 13. Stream table for the gasifier island and cleaning and processing sections - see Figure 17. Table continues below.

\begin{tabular}{|c|c|c|c|c|c|c|c|c|c|c|c|c|c|c|c|c|c|c|c|c|}
\hline Stream ID: & G1 & $\mathrm{G} 2$ & G3 & G4 & G5 & G6 & G7 & G8 & G9 & G10 & G11 & G12 & G13 & G14 & G16 & G17 & G18 & G11bis & G12bis & G13bis \\
\hline \multicolumn{21}{|l|}{ Molar composition: } \\
\hline $\mathrm{H} 2 \mathrm{O}$ & $0.0 \%$ & $0.0 \%$ & $100.0 \%$ & $0.0 \%$ & $0.0 \%$ & $0.0 \%$ & $0.0 \%$ & $0.0 \%$ & $0.0 \%$ & $0.0 \%$ & $0.0 \%$ & $8.4 \%$ & $8.4 \%$ & $8.4 \%$ & $8.5 \%$ & $34.9 \%$ & $34.9 \%$ & $0.0 \%$ & $26.0 \%$ & $26.0 \%$ \\
\hline $\mathrm{O} 2$ & $0.0 \%$ & $0.0 \%$ & $0.0 \%$ & $95.0 \%$ & $0.0 \%$ & $0.0 \%$ & $0.0 \%$ & $0.0 \%$ & $0.0 \%$ & $0.0 \%$ & $0.0 \%$ & $0.0 \%$ & $0.0 \%$ & $0.0 \%$ & $0.0 \%$ & $0.0 \%$ & $0.0 \%$ & $0.0 \%$ & $0.0 \%$ & $0.0 \%$ \\
\hline $\mathrm{AR}$ & $0.0 \%$ & $0.0 \%$ & $0.0 \%$ & $3.5 \%$ & $0.9 \%$ & $0.0 \%$ & $0.9 \%$ & $0.9 \%$ & $0.0 \%$ & $0.9 \%$ & $0.9 \%$ & $0.9 \%$ & $0.9 \%$ & $0.9 \%$ & $0.9 \%$ & $0.6 \%$ & $0.6 \%$ & $0.9 \%$ & $0.7 \%$ & $0.7 \%$ \\
\hline $\mathrm{N} 2$ & $0.0 \%$ & $0.0 \%$ & $0.0 \%$ & $1.5 \%$ & $5.0 \%$ & $0.0 \%$ & $5.0 \%$ & $5.0 \%$ & $0.0 \%$ & $5.0 \%$ & $5.0 \%$ & $4.6 \%$ & $4.6 \%$ & $4.6 \%$ & $4.6 \%$ & $3.4 \%$ & $3.4 \%$ & $5.0 \%$ & $3.7 \%$ & $3.7 \%$ \\
\hline $\mathrm{H} 2$ & $0.0 \%$ & $0.0 \%$ & $0.0 \%$ & $0.0 \%$ & $27.2 \%$ & $0.0 \%$ & $27.2 \%$ & $27.2 \%$ & $0.0 \%$ & $27.2 \%$ & $27.2 \%$ & $25.0 \%$ & $25.0 \%$ & $25.2 \%$ & $25.2 \%$ & $16.3 \%$ & $16.3 \%$ & $27.2 \%$ & $20.2 \%$ & $20.2 \%$ \\
\hline $\mathrm{CO}$ & $0.0 \%$ & $0.0 \%$ & $0.0 \%$ & $0.0 \%$ & $62.4 \%$ & $0.0 \%$ & $62.4 \%$ & $62.4 \%$ & $0.0 \%$ & $62.4 \%$ & $62.4 \%$ & $57.4 \%$ & $57.4 \%$ & $57.9 \%$ & $57.9 \%$ & $7.1 \%$ & $7.1 \%$ & $62.4 \%$ & $46.3 \%$ & $46.3 \%$ \\
\hline $\mathrm{CO} 2$ & $0.0 \%$ & $0.0 \%$ & $0.0 \%$ & $0.0 \%$ & $0.0 \%$ & $0.0 \%$ & $0.0 \%$ & $0.0 \%$ & $0.0 \%$ & $0.0 \%$ & $0.0 \%$ & $0.0 \%$ & $0.0 \%$ & $0.0 \%$ & $0.0 \%$ & $26.1 \%$ & $26.1 \%$ & $0.0 \%$ & $0.0 \%$ & $0.0 \%$ \\
\hline $\mathrm{H} 2 \mathrm{~S}$ & $0.0 \%$ & $0.0 \%$ & $0.0 \%$ & $0.0 \%$ & $0.9 \%$ & $0.0 \%$ & $0.9 \%$ & $0.9 \%$ & $0.0 \%$ & $0.9 \%$ & $0.9 \%$ & $0.8 \%$ & $0.8 \%$ & $0.0 \%$ & $0.0 \%$ & $0.0 \%$ & $0.0 \%$ & $0.9 \%$ & $0.6 \%$ & $0.6 \%$ \\
\hline $\mathrm{CH} 4$ & $0.0 \%$ & $0.0 \%$ & $0.0 \%$ & $0.0 \%$ & $3.0 \%$ & $0.0 \%$ & $3.0 \%$ & $3.0 \%$ & $0.0 \%$ & $3.0 \%$ & $3.0 \%$ & $2.8 \%$ & $2.8 \%$ & $2.8 \%$ & $2.8 \%$ & $11.5 \%$ & $11.5 \%$ & $3.0 \%$ & $2.2 \%$ & $2.2 \%$ \\
\hline NH3 & $0.0 \%$ & $0.0 \%$ & $0.0 \%$ & $0.0 \%$ & $0.0 \%$ & $0.0 \%$ & $0.0 \%$ & $0.0 \%$ & $0.0 \%$ & $0.0 \%$ & $0.0 \%$ & $0.0 \%$ & $0.0 \%$ & $0.0 \%$ & $0.0 \%$ & $0.0 \%$ & $0.0 \%$ & $0.0 \%$ & $0.0 \%$ & $0.0 \%$ \\
\hline $\mathrm{COS}$ & $0.0 \%$ & $0.0 \%$ & $0.0 \%$ & $0.0 \%$ & $0.1 \%$ & $0.0 \%$ & $0.1 \%$ & $0.1 \%$ & $0.0 \%$ & $0.1 \%$ & $0.1 \%$ & $0.1 \%$ & $0.1 \%$ & $0.0 \%$ & $0.0 \%$ & $0.0 \%$ & $0.0 \%$ & $0.1 \%$ & $0.1 \%$ & $0.1 \%$ \\
\hline HCN & $0.0 \%$ & $0.0 \%$ & $0.0 \%$ & $0.0 \%$ & $0.3 \%$ & $0.0 \%$ & $0.3 \%$ & $0.3 \%$ & $0.0 \%$ & $0.3 \%$ & $0.3 \%$ & $0.1 \%$ & $0.1 \%$ & $0.1 \%$ & $0.1 \%$ & $0.0 \%$ & $0.0 \%$ & $0.3 \%$ & $0.1 \%$ & $0.1 \%$ \\
\hline Total Flow $(\mathrm{kmol} / \mathrm{s})$ & 0.00 & 0.00 & 0.30 & 1.52 & 5.68 & 0.00 & 10.40 & 10.40 & 0.00 & 4.72 & 5.68 & 6.18 & 6.12 & 6.06 & 6.06 & 8.26 & 8.26 & 5.68 & 7.65 & 7.58 \\
\hline Total Flow ( $\mathrm{kg} / \mathrm{s})$ & 0.0 & 0.0 & 5.4 & 48.9 & 118.0 & 0.0 & 216.1 & 216.1 & 0.0 & 98.1 & 118.0 & 126.8 & 125.6 & 123.6 & 123.5 & 191.2 & 191.2 & 118.0 & 153.3 & 151.8 \\
\hline Temperature $\left({ }^{\circ} \mathrm{C}\right)$ & 15 & 115 & 371 & 120 & 1371 & 1371 & 900 & 250 & 250 & 250 & 250 & 129 & 129 & 40 & 40 & 683 & 635 & 250 & 173 & 173 \\
\hline Pressure (bar) & 25.5 & 25.5 & 42.0 & 40.4 & 38.5 & 38.5 & 38.5 & 38.5 & 38.5 & 38.5 & 38.5 & 34.0 & 34 & 31 & 34 & 31 & 22 & 38.5 & 34 & 34 \\
\hline
\end{tabular}

\begin{tabular}{l|cccc}
\multicolumn{5}{c}{ Table 13 (continued) } \\
Stream ID: & $\mathrm{G} 19$ & $\mathrm{G} 20$ & $\mathrm{G} 21$ & $\mathrm{G} 22$ \\
\hline Molar composition: & & & & \\
$\mathrm{H} 2 \mathrm{O}$ & $0.5 \%$ & $0.0 \%$ & $28.3 \%$ & $28.3 \%$ \\
$\mathrm{O} 2$ & $0.0 \%$ & $0.0 \%$ & $0.0 \%$ & $0.0 \%$ \\
$\mathrm{AR}$ & $0.7 \%$ & $0.9 \%$ & $1.5 \%$ & $1.5 \%$ \\
$\mathrm{~N} 2$ & $3.5 \%$ & $5.0 \%$ & $8.2 \%$ & $8.2 \%$ \\
$\mathrm{H} 2$ & $47.9 \%$ & $68.0 \%$ & $19.0 \%$ & $19.0 \%$ \\
$\mathrm{CO}$ & $15.9 \%$ & $22.6 \%$ & $1.3 \%$ & $1.3 \%$ \\
$\mathrm{CO} 2$ & $28.6 \%$ & $0.5 \%$ & $4.6 \%$ & $4.6 \%$ \\
$\mathrm{H} 2 \mathrm{~S}$ & $0.7 \%$ & $0.0 \%$ & $0.0 \%$ & $0.0 \%$ \\
$\mathrm{CH} 4$ & $2.1 \%$ & $3.0 \%$ & $37.0 \%$ & $37.0 \%$ \\
$\mathrm{NH} 3$ & $0.0 \%$ & $0.0 \%$ & $0.1 \%$ & $0.1 \%$ \\
$\mathrm{COS}$ & $0.0 \%$ & $0.0 \%$ & $0.0 \%$ & $0.0 \%$ \\
$\mathrm{HCN}$ & $0.1 \%$ & $0.0 \%$ & $0.0 \%$ & $0.0 \%$ \\
Total Flow $(\mathrm{kmol} / \mathrm{s})$ & 7.90 & 5.56 & 3.38 & 3.38 \\
Total Flow $(\mathrm{kg} / \mathrm{s})$ & 157.6 & 56.5 & 56.5 & 56.5 \\
Temperature $\left({ }^{\circ} \mathrm{C}\right)$ & 55 & -39 & 603 & 559 \\
Pressure $(\mathrm{bar})$ & 34 & 34 & 31 & 22
\end{tabular}


Table 14. Stream table for the power island for the DIRECT case.

\begin{tabular}{|c|c|c|c|c|c|c|c|c|c|c|c|}
\hline Stream ID: & $\mathrm{P} 1$ & $\mathrm{P} 2$ & P3 & $\mathrm{P} 4$ & P5 & P6 & $\mathrm{P} 7$ & P8 & $\mathrm{P9}$ & $\mathrm{P} 10$ & $\mathrm{P} 11$ \\
\hline \multicolumn{12}{|l|}{ Molar composition: } \\
\hline $\mathrm{H} 2 \mathrm{O}$ & $8.4 \%$ & $8.4 \%$ & $22.6 \%$ & $31.6 \%$ & $31.6 \%$ & $0.0 \%$ & $0.0 \%$ & $37.2 \%$ & $37.2 \%$ & $37.2 \%$ & $37.2 \%$ \\
\hline $\mathrm{O} 2$ & $0.0 \%$ & $0.0 \%$ & $0.0 \%$ & $0.0 \%$ & $0.0 \%$ & $99.5 \%$ & $99.5 \%$ & $0.0 \%$ & $0.0 \%$ & $0.0 \%$ & $0.0 \%$ \\
\hline AR & $0.9 \%$ & $0.9 \%$ & $0.8 \%$ & $0.8 \%$ & $0.8 \%$ & $0.0 \%$ & $0.0 \%$ & $0.8 \%$ & $0.8 \%$ & $0.8 \%$ & $0.8 \%$ \\
\hline N2 & $4.6 \%$ & $4.6 \%$ & $4.5 \%$ & $4.4 \%$ & $4.4 \%$ & $0.5 \%$ & $0.5 \%$ & $4.5 \%$ & $4.5 \%$ & $4.5 \%$ & $4.5 \%$ \\
\hline $\mathrm{H} 2$ & $25.2 \%$ & $25.2 \%$ & $13.2 \%$ & $5.6 \%$ & $5.6 \%$ & $0.0 \%$ & $0.0 \%$ & $0.0 \%$ & $0.0 \%$ & $0.0 \%$ & $0.0 \%$ \\
\hline $\mathrm{CO}$ & $57.9 \%$ & $57.9 \%$ & $27.5 \%$ & $8.1 \%$ & $8.1 \%$ & $0.0 \%$ & $0.0 \%$ & $0.0 \%$ & $0.0 \%$ & $0.0 \%$ & $0.0 \%$ \\
\hline $\mathrm{CO} 2$ & $0.0 \%$ & $0.0 \%$ & $30.2 \%$ & $49.5 \%$ & $49.5 \%$ & $0.0 \%$ & $0.0 \%$ & $57.5 \%$ & $57.5 \%$ & $57.5 \%$ & $57.5 \%$ \\
\hline $\mathrm{H} 2 \mathrm{~S}$ & $0.0 \%$ & $0.0 \%$ & $0.0 \%$ & $0.0 \%$ & $0.0 \%$ & $0.0 \%$ & $0.0 \%$ & $0.0 \%$ & $0.0 \%$ & $0.0 \%$ & $0.0 \%$ \\
\hline $\mathrm{CH} 4$ & $2.8 \%$ & $2.8 \%$ & $1.1 \%$ & $0.0 \%$ & $0.0 \%$ & $0.0 \%$ & $0.0 \%$ & $0.0 \%$ & $0.0 \%$ & $0.0 \%$ & $0.0 \%$ \\
\hline Total Flow $(\mathrm{kmol} / \mathrm{s})$ & 6.1 & 6.1 & 15.6 & 9.5 & 6.4 & 0.4 & 0.4 & 6.4 & 6.4 & 6.4 & 6.4 \\
\hline Total Flow $(\mathrm{kg} / \mathrm{s})$ & 124 & 124 & 422 & 298 & 201 & 14 & 14 & 215 & 215 & 215 & 215 \\
\hline Temperature $\left({ }^{\circ} \mathrm{C}\right)$ & 40 & 700 & 768 & 800 & 800 & 15 & 189 & 1036 & 850 & 456 & 90 \\
\hline Pressure (bar) & 32 & 32 & 20 & 20 & 20 & 1 & 20 & 20 & 20 & 1 & 1 \\
\hline Stream ID: & $\mathrm{P} 12$ & $\mathrm{P} 13$ & $\mathrm{P} 14$ & $\mathrm{P} 15$ & $\mathrm{P} 16$ & $\mathrm{P} 17$ & $\mathrm{P} 18$ & P19 & $\mathrm{P} 20$ & $\mathrm{P} 21$ & $\mathrm{P} 22$ \\
\hline \multicolumn{12}{|l|}{ Molar composition: } \\
\hline $\mathrm{H} 2 \mathrm{O}$ & $37.2 \%$ & $3.6 \%$ & $0.3 \%$ & $0.0 \%$ & $0.0 \%$ & $0.0 \%$ & $0.0 \%$ & $0.0 \%$ & $0.0 \%$ & $0.0 \%$ & $0.0 \%$ \\
\hline $\mathrm{O} 2$ & $0.0 \%$ & $0.1 \%$ & $0.1 \%$ & $21.0 \%$ & $21.0 \%$ & $19.0 \%$ & $17.1 \%$ & $17.1 \%$ & $17.1 \%$ & $17.1 \%$ & $17.1 \%$ \\
\hline $\mathrm{AR}$ & $0.8 \%$ & $1.3 \%$ & $1.3 \%$ & $0.9 \%$ & $0.9 \%$ & $1.0 \%$ & $1.0 \%$ & $1.0 \%$ & $1.0 \%$ & $1.0 \%$ & $1.0 \%$ \\
\hline $\mathrm{N} 2$ & $4.5 \%$ & $6.8 \%$ & $7.1 \%$ & $78.1 \%$ & $78.1 \%$ & $80.1 \%$ & $81.9 \%$ & $81.9 \%$ & $81.9 \%$ & $81.9 \%$ & $81.9 \%$ \\
\hline $\mathrm{H} 2$ & $0.0 \%$ & $0.0 \%$ & $0.0 \%$ & $0.0 \%$ & $0.0 \%$ & $0.0 \%$ & $0.0 \%$ & $0.0 \%$ & $0.0 \%$ & $0.0 \%$ & $0.0 \%$ \\
\hline $\mathrm{CO}$ & $0.0 \%$ & $0.0 \%$ & $0.0 \%$ & $0.0 \%$ & $0.0 \%$ & $0.0 \%$ & $0.0 \%$ & $0.0 \%$ & $0.0 \%$ & $0.0 \%$ & $0.0 \%$ \\
\hline $\mathrm{CO} 2$ & $57.5 \%$ & $88.3 \%$ & $91.3 \%$ & $0.0 \%$ & $0.0 \%$ & $0.0 \%$ & $0.0 \%$ & $0.0 \%$ & $0.0 \%$ & $0.0 \%$ & $0.0 \%$ \\
\hline $\mathrm{H} 2 \mathrm{~S}$ & $0.0 \%$ & $0.0 \%$ & $0.0 \%$ & $0.0 \%$ & $0.0 \%$ & $0.0 \%$ & $0.0 \%$ & $0.0 \%$ & $0.0 \%$ & $0.0 \%$ & $0.0 \%$ \\
\hline $\mathrm{CH} 4$ & $0.0 \%$ & $0.0 \%$ & $0.0 \%$ & $0.0 \%$ & $0.0 \%$ & $0.0 \%$ & $0.0 \%$ & $0.0 \%$ & $0.0 \%$ & $0.0 \%$ & $0.0 \%$ \\
\hline Total Flow $(\mathrm{kmol} / \mathrm{s})$ & 6.4 & 4.2 & 4.0 & 52.0 & 52.0 & 105.5 & 103.1 & 49.6 & 49.6 & 49.6 & 49.6 \\
\hline Total Flow $(\mathrm{kg} / \mathrm{s})$ & 215 & 175 & 173 & 1507 & 1507 & 3048 & 2970 & 1429 & 1429 & 1429 & 1429 \\
\hline Temperature $\left({ }^{\circ} \mathrm{C}\right)$ & 30 & 30 & 160 & 15 & 492 & 650 & 800 & 800 & 278 & 318 & 125 \\
\hline Pressure (bar) & 1 & 1 & 150 & 1 & 22 & 20 & 20 & 20 & 1 & 1 & 1 \\
\hline
\end{tabular}


Table 15. Stream table for the power island for the TREMP case.

\begin{tabular}{|c|c|c|c|c|c|c|c|c|c|c|c|}
\hline Stream ID: & $\mathrm{P} 1$ & $\mathrm{P} 2$ & $\mathrm{P} 3$ & $\mathrm{P} 4$ & P5 & P6 & $\mathrm{P} 7$ & $\mathrm{P} 8$ & $\mathrm{P} 9$ & $\mathrm{P} 10$ & $\mathrm{P} 11$ \\
\hline \multicolumn{12}{|l|}{ Molar composition: } \\
\hline $\mathrm{H} 2 \mathrm{O}$ & $28.3 \%$ & $28.3 \%$ & $41.7 \%$ & $58.9 \%$ & $58.9 \%$ & $0.0 \%$ & $0.0 \%$ & $69.7 \%$ & $69.7 \%$ & $69.7 \%$ & $69.7 \%$ \\
\hline $\mathrm{O} 2$ & $0.0 \%$ & $0.0 \%$ & $0.0 \%$ & $0.0 \%$ & $0.0 \%$ & $99.5 \%$ & $99.5 \%$ & $0.0 \%$ & $0.0 \%$ & $0.0 \%$ & $0.0 \%$ \\
\hline $\mathrm{AR}$ & $1.5 \%$ & $1.5 \%$ & $1.3 \%$ & $0.9 \%$ & $0.9 \%$ & $0.0 \%$ & $0.0 \%$ & $0.9 \%$ & $0.9 \%$ & $0.9 \%$ & $0.9 \%$ \\
\hline $\mathrm{N} 2$ & $8.2 \%$ & $8.2 \%$ & $6.7 \%$ & $4.7 \%$ & $4.7 \%$ & $0.5 \%$ & $0.5 \%$ & $4.8 \%$ & $4.8 \%$ & $4.8 \%$ & $4.8 \%$ \\
\hline $\mathrm{H} 2$ & $19.0 \%$ & $19.0 \%$ & $15.5 \%$ & $10.9 \%$ & $10.9 \%$ & $0.0 \%$ & $0.0 \%$ & $0.0 \%$ & $0.0 \%$ & $0.0 \%$ & $0.0 \%$ \\
\hline $\mathrm{CO}$ & $1.3 \%$ & $1.3 \%$ & $2.3 \%$ & $3.6 \%$ & $3.6 \%$ & $0.0 \%$ & $0.0 \%$ & $0.0 \%$ & $0.0 \%$ & $0.0 \%$ & $0.0 \%$ \\
\hline $\mathrm{CO} 2$ & $4.6 \%$ & $4.6 \%$ & $11.7 \%$ & $21.0 \%$ & $21.0 \%$ & $0.0 \%$ & $0.0 \%$ & $24.6 \%$ & $24.6 \%$ & $24.6 \%$ & $24.6 \%$ \\
\hline $\mathrm{H} 2 \mathrm{~S}$ & $0.0 \%$ & $0.0 \%$ & $0.0 \%$ & $0.0 \%$ & $0.0 \%$ & $0.0 \%$ & $0.0 \%$ & $0.0 \%$ & $0.0 \%$ & $0.0 \%$ & $0.0 \%$ \\
\hline $\mathrm{CH} 4$ & $37.0 \%$ & $37.0 \%$ & $20.8 \%$ & $0.0 \%$ & $0.0 \%$ & $0.0 \%$ & $0.0 \%$ & $0.0 \%$ & $0.0 \%$ & $0.0 \%$ & $0.0 \%$ \\
\hline Total Flow $(\mathrm{kmol} / \mathrm{s})$ & 3.4 & 3.4 & 6.0 & 2.6 & 5.9 & 0.4 & 0.4 & 5.9 & 5.9 & 5.9 & 5.9 \\
\hline Total Flow $(\mathrm{kg} / \mathrm{s})$ & 57 & 57 & 116 & 60 & 134 & 14 & 14 & 148 & 148 & 148 & 148 \\
\hline Temperature $\left({ }^{\circ} \mathrm{C}\right)$ & 559 & 700 & 740 & 800 & 800 & 15 & 189 & 1460 & 850 & 425 & 90 \\
\hline Pressure (bar) & 22 & 22 & 20 & 20 & 20 & 1 & 20 & 20 & 20 & 1 & 1 \\
\hline Stream ID: & $\mathrm{P} 12$ & $\mathrm{P} 13$ & $\mathrm{P} 14$ & $\mathrm{P} 15$ & P16 & $\mathrm{P} 17$ & P18 & P19 & $\mathrm{P} 20$ & $\mathrm{P} 21$ & $\mathrm{P} 22$ \\
\hline \multicolumn{12}{|l|}{ Molar composition: } \\
\hline $\mathrm{H} 2 \mathrm{O}$ & $69.7 \%$ & $3.6 \%$ & $0.3 \%$ & $0.0 \%$ & $0.0 \%$ & $0.0 \%$ & $0.0 \%$ & $0.0 \%$ & $0.0 \%$ & $0.0 \%$ & $0.0 \%$ \\
\hline $\mathrm{O} 2$ & $0.0 \%$ & $0.2 \%$ & $0.2 \%$ & $21.0 \%$ & $21.0 \%$ & $15.4 \%$ & $10.1 \%$ & $10.1 \%$ & $10.1 \%$ & $10.1 \%$ & $10.1 \%$ \\
\hline $\mathrm{AR}$ & $0.9 \%$ & $2.8 \%$ & $2.9 \%$ & $0.9 \%$ & $0.9 \%$ & $1.0 \%$ & $1.1 \%$ & $1.1 \%$ & $1.1 \%$ & $1.1 \%$ & $1.1 \%$ \\
\hline $\mathrm{N} 2$ & $4.8 \%$ & $15.1 \%$ & $15.7 \%$ & $78.1 \%$ & $78.1 \%$ & $83.6 \%$ & $88.8 \%$ & $88.8 \%$ & $88.8 \%$ & $88.8 \%$ & $88.8 \%$ \\
\hline $\mathrm{H} 2$ & $0.0 \%$ & $0.1 \%$ & $0.1 \%$ & $0.0 \%$ & $0.0 \%$ & $0.0 \%$ & $0.0 \%$ & $0.0 \%$ & $0.0 \%$ & $0.0 \%$ & $0.0 \%$ \\
\hline $\mathrm{CO}$ & $0.0 \%$ & $0.1 \%$ & $0.1 \%$ & $0.0 \%$ & $0.0 \%$ & $0.0 \%$ & $0.0 \%$ & $0.0 \%$ & $0.0 \%$ & $0.0 \%$ & $0.0 \%$ \\
\hline $\mathrm{CO} 2$ & $24.6 \%$ & $78.2 \%$ & $80.9 \%$ & $0.0 \%$ & $0.0 \%$ & $0.0 \%$ & $0.0 \%$ & $0.0 \%$ & $0.0 \%$ & $0.0 \%$ & $0.0 \%$ \\
\hline $\mathrm{H} 2 \mathrm{~S}$ & $0.0 \%$ & $0.0 \%$ & $0.0 \%$ & $0.0 \%$ & $0.0 \%$ & $0.0 \%$ & $0.0 \%$ & $0.0 \%$ & $0.0 \%$ & $0.0 \%$ & $0.0 \%$ \\
\hline $\mathrm{CH} 4$ & $0.0 \%$ & $0.0 \%$ & $0.0 \%$ & $0.0 \%$ & $0.0 \%$ & $0.0 \%$ & $0.0 \%$ & $0.0 \%$ & $0.0 \%$ & $0.0 \%$ & $0.0 \%$ \\
\hline Total Flow $(\mathrm{kmol} / \mathrm{s})$ & 5.9 & 1.9 & 1.8 & 20.0 & 20.0 & 40.7 & 38.3 & 17.6 & 17.6 & 17.6 & 17.6 \\
\hline Total Flow $(\mathrm{kg} / \mathrm{s})$ & 148 & 75 & 74 & 580 & 580 & 1171 & 1094 & 503 & 503 & 503 & 503 \\
\hline Temperature $\left({ }^{\circ} \mathrm{C}\right)$ & 30 & 30 & 164 & 15 & 492 & 650 & 800 & 800 & 276 & 596 & 113 \\
\hline Pressure (bar) & 1 & 1 & 150 & 1 & 22 & 20 & 20 & 20 & 1 & 1 & 1 \\
\hline
\end{tabular}


Table 16. Stream table for the power island for the HICOM case.

\begin{tabular}{l|ccccccccccc} 
Stream ID: & $\mathrm{P} 1$ & $\mathrm{P} 2$ & $\mathrm{P} 3$ & $\mathrm{P} 4$ & $\mathrm{P} 5$ & $\mathrm{P} 6$ & $\mathrm{P} 7$ & $\mathrm{P} 8$ & $\mathrm{P} 9$ & $\mathrm{P} 10$ & $\mathrm{P} 11$ \\
\hline Molar composition: & & & & & & & & & & & \\
$\mathrm{H} 2 \mathrm{O}$ & $34.9 \%$ & $34.9 \%$ & $35.0 \%$ & $55.0 \%$ & $55.0 \%$ & $0.0 \%$ & $0.0 \%$ & $60.4 \%$ & $60.4 \%$ & $60.4 \%$ & $60.4 \%$ \\
$\mathrm{O} 2$ & $0.0 \%$ & $0.0 \%$ & $0.0 \%$ & $0.0 \%$ & $0.0 \%$ & $99.5 \%$ & $99.5 \%$ & $0.0 \%$ & $0.0 \%$ & $0.0 \%$ & $0.0 \%$ \\
$\mathrm{AR}$ & $0.6 \%$ & $0.6 \%$ & $0.6 \%$ & $0.5 \%$ & $0.5 \%$ & $0.0 \%$ & $0.0 \%$ & $0.5 \%$ & $0.5 \%$ & $0.5 \%$ & $0.5 \%$ \\
$\mathrm{~N} 2$ & $3.4 \%$ & $3.4 \%$ & $3.4 \%$ & $2.8 \%$ & $2.8 \%$ & $0.5 \%$ & $0.5 \%$ & $2.8 \%$ & $2.8 \%$ & $2.8 \%$ & $2.8 \%$ \\
$\mathrm{H} 2$ & $16.3 \%$ & $16.3 \%$ & $16.3 \%$ & $5.4 \%$ & $5.4 \%$ & $0.0 \%$ & $0.0 \%$ & $0.0 \%$ & $0.0 \%$ & $0.0 \%$ & $0.0 \%$ \\
$\mathrm{CO}$ & $7.1 \%$ & $7.1 \%$ & $7.1 \%$ & $3.0 \%$ & $3.0 \%$ & $0.0 \%$ & $0.0 \%$ & $0.0 \%$ & $0.0 \%$ & $0.0 \%$ & $0.0 \%$ \\
$\mathrm{CO} 2$ & $26.1 \%$ & $26.1 \%$ & $26.1 \%$ & $33.2 \%$ & $33.2 \%$ & $0.0 \%$ & $0.0 \%$ & $36.3 \%$ & $36.3 \%$ & $36.3 \%$ & $36.3 \%$ \\
$\mathrm{H} 2 \mathrm{~S}$ & $0.0 \%$ & $0.0 \%$ & $0.0 \%$ & $0.0 \%$ & $0.0 \%$ & $0.0 \%$ & $0.0 \%$ & $0.0 \%$ & $0.0 \%$ & $0.0 \%$ & $0.0 \%$ \\
$\mathrm{CH} 4$ & $11.5 \%$ & $11.5 \%$ & $11.5 \%$ & $0.0 \%$ & $0.0 \%$ & $0.0 \%$ & $0.0 \%$ & $0.0 \%$ & $0.0 \%$ & $0.0 \%$ & $0.0 \%$ \\
Total Flow $(\mathrm{kmol} / \mathrm{s})$ & 8.3 & 8.3 & 8.3 & 0.0 & 10.2 & 0.4 & 0.4 & 10.2 & 10.2 & 10.2 & 10.2 \\
Total Flow $(\mathrm{kg} / \mathrm{s})$ & 191 & 191 & 191 & 0 & 269 & 14 & 14 & 283 & 283 & 283 & 283 \\
Temperature $\left({ }^{\circ} \mathrm{C}\right)$ & 635 & 700 & 700 & 800 & 800 & 15 & 189 & 1187 & 850 & 438 & 90 \\
Pressure (bar) & 22 & 22 & 20 & 20 & 20 & 1 & 20 & 20 & 20 & 1 & 1
\end{tabular}

\begin{tabular}{l|ccccccccccc} 
Stream ID: & $\mathrm{P} 12$ & $\mathrm{P} 13$ & $\mathrm{P} 14$ & $\mathrm{P} 15$ & $\mathrm{P} 16$ & $\mathrm{P} 17$ & $\mathrm{P} 18$ & $\mathrm{P} 19$ & $\mathrm{P} 20$ & $\mathrm{P} 21$ & $\mathrm{P} 22$ \\
\hline Molar composition: & & & & & & & & & & & \\
$\mathrm{H} 2 \mathrm{O}$ & $60.4 \%$ & $3.6 \%$ & $0.3 \%$ & $0.0 \%$ & $0.0 \%$ & $0.0 \%$ & $0.0 \%$ & $0.0 \%$ & $0.0 \%$ & $0.0 \%$ & $0.0 \%$ \\
$\mathrm{O} 2$ & $0.0 \%$ & $0.1 \%$ & $0.1 \%$ & $21.0 \%$ & $21.0 \%$ & $17.1 \%$ & $13.3 \%$ & $13.3 \%$ & $13.3 \%$ & $13.3 \%$ & $13.3 \%$ \\
$\mathrm{AR}$ & $0.5 \%$ & $1.3 \%$ & $1.3 \%$ & $0.9 \%$ & $0.9 \%$ & $1.0 \%$ & $1.0 \%$ & $1.0 \%$ & $1.0 \%$ & $1.0 \%$ & $1.0 \%$ \\
$\mathrm{~N} 2$ & $2.8 \%$ & $6.8 \%$ & $7.1 \%$ & $78.1 \%$ & $78.1 \%$ & $82.0 \%$ & $85.7 \%$ & $85.7 \%$ & $85.7 \%$ & $85.7 \%$ & $85.7 \%$ \\
$\mathrm{H} 2$ & $0.0 \%$ & $0.0 \%$ & $0.0 \%$ & $0.0 \%$ & $0.0 \%$ & $0.0 \%$ & $0.0 \%$ & $0.0 \%$ & $0.0 \%$ & $0.0 \%$ & $0.0 \%$ \\
$\mathrm{CO}$ & $0.0 \%$ & $0.0 \%$ & $0.0 \%$ & $0.0 \%$ & $0.0 \%$ & $0.0 \%$ & $0.0 \%$ & $0.0 \%$ & $0.0 \%$ & $0.0 \%$ & $0.0 \%$ \\
$\mathrm{CO} 2$ & $36.3 \%$ & $88.3 \%$ & $91.3 \%$ & $0.0 \%$ & $0.0 \%$ & $0.0 \%$ & $0.0 \%$ & $0.0 \%$ & $0.0 \%$ & $0.0 \%$ & $0.0 \%$ \\
$\mathrm{H} 2 \mathrm{~S}$ & $0.0 \%$ & $0.0 \%$ & $0.0 \%$ & $0.0 \%$ & $0.0 \%$ & $0.0 \%$ & $0.0 \%$ & $0.0 \%$ & $0.0 \%$ & $0.0 \%$ & $0.0 \%$ \\
$\mathrm{CH} 4$ & $0.0 \%$ & $0.0 \%$ & $0.0 \%$ & $0.0 \%$ & $0.0 \%$ & $0.0 \%$ & $0.0 \%$ & $0.0 \%$ & $0.0 \%$ & $0.0 \%$ & $0.0 \%$ \\
Total Flow $(\mathrm{kmol} / \mathrm{s})$ & 10.2 & 4.2 & 4.0 & 27.4 & 27.4 & 55.8 & 53.3 & 25.0 & 25.0 & 25.0 & 25.0 \\
Total Flow $(\mathrm{kg} / \mathrm{s})$ & 283 & 175 & 173 & 795 & 795 & 1606 & 1529 & 717 & 717 & 717 & 717 \\
Temperature $\left({ }^{\circ} \mathrm{C}\right)$ & 30 & 30 & 160 & 15 & 492 & 650 & 800 & 800 & 277 & 496 & 108 \\
Pressure (bar) & 1 & 1 & 150 & 1 & 22 & 20 & 20 & 20 & 1 & 1 & 1
\end{tabular}




\subsubsection{Economics Results}

The economic assumptions used previously in the NG-fed SOFC plants are also used here; the price of coal is assumed to be $\$ 2.04 / \mathrm{GJ}_{\mathrm{HHV}}(2007 \$)$. The cost analysis for the three IGFC plants is summarized in Table 17 and compared with the estimated performance of an IGCC using a dry-feed (Shell) gasifier. The siginficantly higher efficiency of the IGFC plant (true for all IGFC cases) relative to IGCC reduces both fuel expenses and the specific installed capital cost $(\$ / \mathrm{kW})$.

\begin{tabular}{|c|c|c|c|c|c|}
\hline & Electricity & $\eta(\mathrm{LHV})$ & \multicolumn{2}{|c|}{$T P C$} & $L C O E$ \\
\hline & $M W e$ & & $M \$$ & $\$ / k W e$ & $\$ / M W h$ \\
\hline IGCC-CCS* & 517 & $33.5 \%$ & 1,424 & 3,069 & 109.6 \\
\hline IGFC-CCS-DIRECT $^{\dagger}$ & 859 & $47.0 \%$ & 1,897 & 2,460 & 85.6 \\
\hline IGFC-CCS-TREMP $^{\dagger}$ & 841 & $46.0 \%$ & 1,926 & 2,551 & 89.8 \\
\hline IGFC-CCS-HICOM $^{\dagger}$ & 915.4 & $50.1 \%$ & 1,851 & 2,253 & 78.9 \\
\hline \multicolumn{6}{|c|}{$\begin{array}{l}\text { * IGCC results are for system using Shell gasifier, based on DOE/NETL-2010/1397,2010, } \\
\text { "Cost and Performance Baseline for Fossil Energy Plants Volume 1: Bituminous Coal and } \\
\text { Natural Gas to Electricity." } \\
\text { 'SOFC cost at } 657 \$ / \mathrm{kW} \mathrm{AC}\end{array}$} \\
\hline
\end{tabular}

A more detailed comparison of electricity cost components for the HICOM plant (i.e. the IGFC configuration with the lowest LCOE in Table 17) and for the reference IGCC is shown in Table 18. The reduced capital and fuel costs for the IGFC plant are evident there (and also for all IGFC configurations).

Table 18. Comparison of IGFC-HICOM plant with reference IGCC plants.
\begin{tabular}{|l|cc|}
\hline Electricity Cost Components, 2007 \$/MWh: & IGFC-CCS-HICOM $^{\dagger}$ & IGCC-CCS \\
\hline Installed capital (at 14.38\% of TPI) & 43.48 & 59.22 \\
O\&M (at 4\% of TPC per yr) & 10.86 & 14.79 \\
O\&M SOFC modules & 3.28 & - \\
Coal/biomass (at 2.04/5 \$/GJ, HHV) & 15.34 & 22.90 \\
CO2 emissions (at 50 \$/tonne CO2) & 2.07 & 6.80 \\
CO2 disposal (at $6.1 \$ /$ tonne CO2) & 3.92 & 5.94 \\
\hline Levelized cost of electricity (LCOE) & 78.94 \\
\hline 'ंSOFC cost at 657\$/kW AC & & 109.65 \\
\hline
\end{tabular}

As seen in Table 19 and Table 20, the SOFC power island is responsible for nearly one-third of the total plant capital cost. (The SOFC power island includes the SOFC modules, high-temperature heatexchangers/recuperators for pre-heat or heat recovery from the anode and cathode gases, the oxycombustor, high-temperature exhaust recirculators, and the turbomachinary of the SOFC upper bottoming cycle, i.e. the cathode air turbine group and the expander for the oxy-combusted anode exhaust.) The high capital cost fraction for the SOFC power island can be justified by its high efficiency in converting syngas into electricity (Table 18).

Table 19. Plant capital cost disaggregation for HICOM case.

\begin{tabular}{|l|cc|}
\hline Plant Costs $(\mathbf{2 0 0 7} \boldsymbol{U S} \$$ ) & $M \$$ & $\$ / \mathrm{kWe}$ \\
\hline Gasifier + HRSC, TPC & 1,184 & 1,293 \\
SOFC power island (at 657\$/kW AC) & 668 & 729 \\
Total Plant Cost (TPC) & 1,851 & 2,022 \\
AFDC (at 11,4 \% of TPC) & 211 & 231 \\
\hline Total Plant Investment (TPI) & 2,062 & 2,253 \\
\hline
\end{tabular}


Table 20. IGFC-HICOM total plant cost (SOFC module @ 657 \$/kW AC). Table continues next page

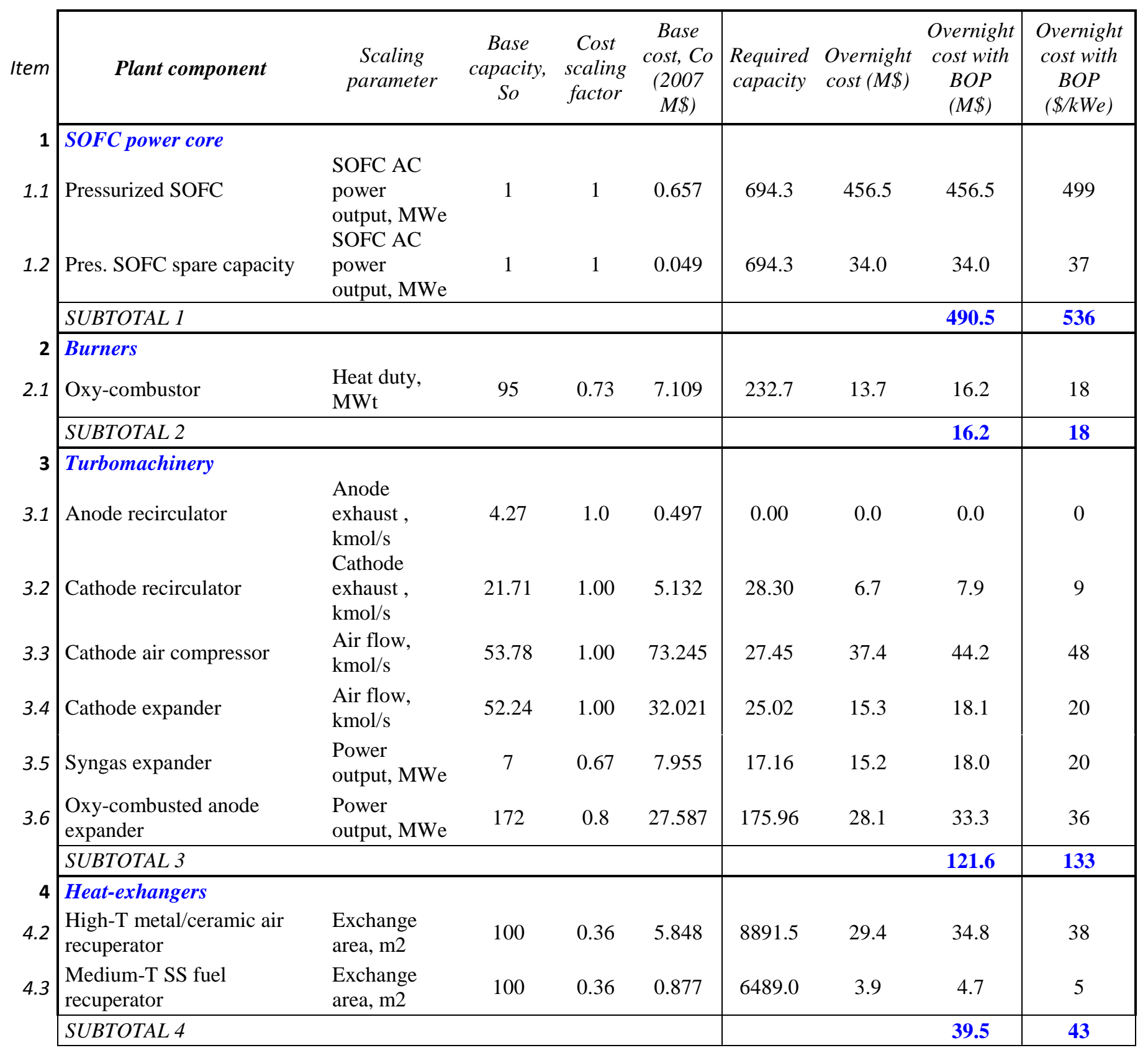


Table 20 (continued)

\begin{tabular}{|c|c|c|c|c|c|c|c|c|c|}
\hline Item & Plant component & $\begin{array}{l}\text { Scaling } \\
\text { parameter }\end{array}$ & $\begin{array}{l}\text { Base } \\
\text { capacity, } \\
\text { So }\end{array}$ & $\begin{array}{l}\text { Cost } \\
\text { scaling } \\
\text { factor }\end{array}$ & $\begin{array}{c}\text { Base } \\
\text { cost, Co } \\
(2007 \\
M \$)\end{array}$ & $\begin{array}{l}\text { Required } \\
\text { capacity }\end{array}$ & $\begin{array}{l}\text { Overnight } \\
\operatorname{cost}(M \$)\end{array}$ & $\begin{array}{c}\text { Overnight } \\
\text { cost with } \\
\text { BOP } \\
(M \$)\end{array}$ & $\begin{array}{c}\text { Overnight } \\
\text { cost with } \\
\text { BOP } \\
(\$ / k W e)\end{array}$ \\
\hline 5 & Reactors & & & & & & & & \\
\hline 5.1 & Single methanator reactor & $\begin{array}{l}\mathrm{CH} 4 \\
\text { produced, } \\
\mathrm{kmol} / \mathrm{s}\end{array}$ & 0.17 & 0.84 & 0.063 & 0.78 & 0.2 & 27 & 32 \\
\hline 5.2 & $\begin{array}{l}\text { Gas cleanup BOP }(\mathrm{Hg} \\
\text { removal, piping, } \\
\text { foundations) }\end{array}$ & $\begin{array}{l}\text { AR coal, MW } \\
\text { LHV }\end{array}$ & 815.228 & 0.67 & 5.490 & 1827.8 & 9.4 & 11.2 & 12 \\
\hline 5.3 & Sulfinol (H2S removal) & $\mathrm{H} 2 \mathrm{~S}, \mathrm{kmol} / \mathrm{s}$ & 0.04 & 0.67 & 85.194 & 0.05 & 117.3 & 111.9 & 121 \\
\hline 5.4 & Sulfur polishing & $\begin{array}{l}\text { Syngas, } \\
\mathrm{kmol} / \mathrm{s}\end{array}$ & 5 & 0.67 & 3.762 & 6.1 & 5.7 & 6.7 & 7 \\
\hline \multirow[t]{2}{*}{5.5} & Claus plant & $\begin{array}{l}\text { S input, } \\
\mathrm{mt} / \mathrm{day}\end{array}$ & 137 & 0.67 & 33.832 & 18.0 & 8.7 & 10.3 & 11 \\
\hline & SUBTOTAL 5 & & & & & & & 167.1 & 183 \\
\hline 6 & Shell gasifier & & & & & & 0.0 & 0.0 & \\
\hline 6.1 & Coal handling & $\begin{array}{l}\text { AR coal, } \\
\mathrm{mt} / \text { day }\end{array}$ & 5447 & 0.67 & 36.415 & 1828 & 17.5 & 20.7 & 23 \\
\hline 6.2 & $\begin{array}{l}\text { Coal preparation \& } \\
\text { feeding }\end{array}$ & $\begin{array}{l}\text { AR coal, } \\
\mathrm{mt} / \mathrm{day}\end{array}$ & 2464 & 0.67 & 91.568 & 1828 & 75.0 & 88.7 & 97 \\
\hline 6.3 & Ash handling & $\begin{array}{l}\text { Coal ash, } \\
\mathrm{mt} / \text { day }\end{array}$ & 478 & 0.67 & 34.293 & 591.8 & 39.6 & 46.8 & 51 \\
\hline 6.4 & Stand-alone ASU & $\begin{array}{l}\text { Pure O2, } \\
\mathrm{mt} / \text { day }\end{array}$ & 2035 & 0.50 & 96.143 & 5429.3 & 157.0 & 185.7 & 203 \\
\hline 6.5 & $\begin{array}{l}\text { Shell standard gasifier \& } \\
\text { SG coolers }\end{array}$ & $\begin{array}{l}\text { AR coal, MW } \\
\text { LHV }\end{array}$ & 737 & 0.67 & 160.448 & 1828 & 294.7 & 348.6 & 381 \\
\hline \multirow[t]{2}{*}{6.6} & $\begin{array}{l}\text { Shell - LT heat recovery \& } \\
\text { FG saturation }\end{array}$ & $\begin{array}{l}\text { AR coal, MW } \\
\text { LHV }\end{array}$ & 737 & 0.67 & 15.610 & 1828 & 28.7 & 33.9 & 37 \\
\hline & SUBTOTAL 6 & & & & & & & 724.5 & 791 \\
\hline 7 & CO2 compression & & & & & & & & \\
\hline \multirow[t]{2}{*}{7.1} & $\begin{array}{l}\mathrm{CO} 2 \text { compression and } \\
\text { drying }\end{array}$ & $\begin{array}{l}\text { Comp. power, } \\
\text { MWe }\end{array}$ & 27 & 0.67 & 38.765 & 73.7 & 75.2 & 88.9 & 97 \\
\hline & SUBTOTAL 7 & & & & & & & 88.9 & 97.2 \\
\hline 8 & \multicolumn{5}{|c|}{ Heat recovery steam cycle (HRSC) } & & & & \\
\hline 8.1 & $\begin{array}{l}\text { Boiler/steam generator, } \\
\text { ductwork, \& stack }\end{array}$ & $\begin{array}{l}\text { Boiler duty, } \\
\text { MWth }\end{array}$ & 355 & 1.00 & 52.043 & 768.3 & 112.6 & 133.2 & 146 \\
\hline \multirow[t]{2}{*}{8.2} & $\begin{array}{l}\text { Steam turbine (ST), } \\
\text { condenser, steam piping, } \\
\text { auxiliaries }\end{array}$ & $\begin{array}{l}\text { ST gross } \\
\text { power, MWe }\end{array}$ & 275 & 0.67 & 66.700 & 228.9 & 59.0027 & 69.8 & 76 \\
\hline & SUBTOTAL 8 & & & & & & & 203.0 & 221.8 \\
\hline \multirow[t]{3}{*}{9} & \multicolumn{5}{|c|}{ Power plant BoP and auxiliaries } & & & & \\
\hline & $\begin{array}{l}\text { BOP (feedwtr, CW, elec, } \\
\text { controls, sitework, } \\
\text { buildings) }\end{array}$ & $\begin{array}{l}\text { Percentage of } \\
\text { TPC }\end{array}$ & & & $15.5 \%$ & & & & \\
\hline & \multicolumn{7}{|c|}{ Total Plant Cost (TCP), 2007M\$ / Specific plant cost, $\$ / k W e$} & 1851.2 & 2022 \\
\hline
\end{tabular}




\subsection{Concluding Remarks}

Our analysis of the natural gas SOFC highlights the fact that methane is an ideal SOFC fuel because the waste heat produced internally in the SOFC (both reaction heat and irreversibility heat) is directly used/recycled to reform/upgrade methane to $\mathrm{H}_{2}$ and $\mathrm{CO}$, which are the actual fuels consumed in the electrochemical reactions. If the fuel is instead only a mixture of $\mathrm{H}_{2}$ and $\mathrm{CO}$ (as with syngas), some of these favorable internal heat management and recycle possibilities are lost. For example, without internal reforming, all of the surplus heat generated in the stack must be removed by the cathode air, leading to increased cathode air flow, increased power to compress that air, increased waste heat associated with the generation of that extra power, etc...

\section{IGFC with integrated ITM for oxygen supply}

\subsection{Introduction}

We have developed two IGFC cases that integrate an ion transport membrane (ITM) for oxygen production in place of the conventional cryogenic ASU. In the previous analyses of IGFC, the HICOM configuration resulted in the best efficiency and economic performance; thus, we have analyzed only this configuration for ITM integration.

\subsection{ITM Oxygen technology}

ITM, sometimes referred to as ceramic oxygen separator membrane, is an advanced technology that has been under development for over two decades ${ }^{29}$ but is not yet commercial. Parallel developmental efforts in the US have been led by Air Products and Praxair in partnership with DOE and others. The ITM is an intriguing option for integrating with SOFC-based power systems because the ITM technology and materials are similar to those used for the SOFC and operate at similar temperatures. In particular, the membrane is made of ceramic materials exhibiting mixed ionic-electronic conductivity ${ }^{30}$. Key ITM properties are that it: 1) conducts oxygen ions, driven by the difference in partial pressures across the membrane, 2) is chemically and mechanically stable at high operating temperatures, and 3) is able to conduct electrons to maintain a neutral electrical flux. As with an SOFC, the scale-up of an ITM's active area to generate large amounts of oxygen is accomplished by stacking together piles of membranes, separated by high-temperature interconnectors typically made of ferritic stainless steel. Figure 18 shows a schematic of a stand-alone ITM oxygen plant as well a stack of membranes constituting its core.

\footnotetext{
${ }^{29}$ Dyer, P.N, Richard, R.E., Russek, S.L., Taylor, D.M., 2000, 'Ion transport membrane technology for oxygen separation and syngas production', Solid State Ionics, 134, pp. 21-33.

${ }^{30}$ Sunarso, J., Baumann, S., Serra, J.M., Meulenberg, W.A., Liu, S. Lin, Y.S., Diniz da Costa J.C., 2008, 'Mixed ionicelectronic conducting (MIEC) ceramic-based membranes for oxygen separation', Journal of Membrane Science, 320, pp. 13-41.
} 

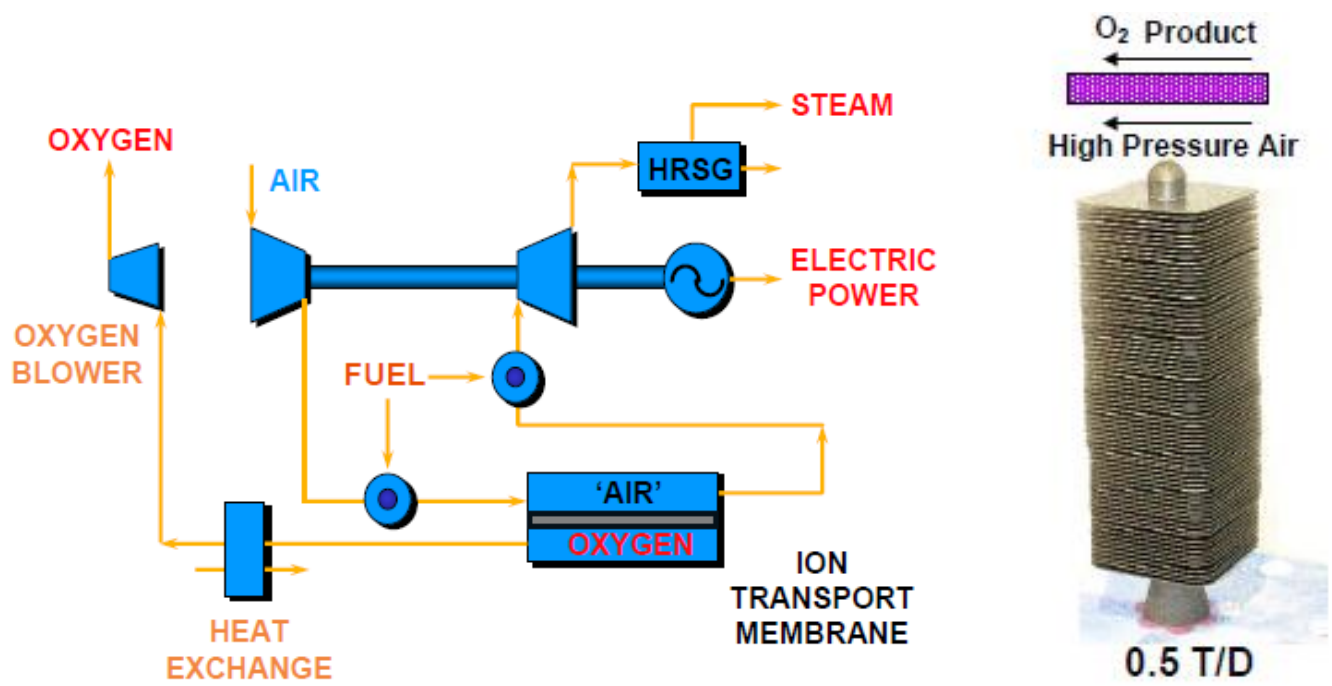

Figure 18. ITM Oxygen plant (left); ITM stack (right) ${ }^{31}$.

\section{3 'HICOM-ITM' Plant Performance}

Our plant design integrates ITM reactors with the SOFC generator as follows. The ITM extracts oxygen from the pressurized SOFC cathode exhaust, which contains significant residual oxygen; in the HICOM case, $\sim 57 \%$ of the oxygen in the cathode exhaust is sufficient to cover the requirements of the gasifier and the anode exhaust oxy-combustor. A schematic of the IGFC 'HICOM-ITM' plant is given in Figure 19. The permeate side of the membrane is designed to operate at 0.2 bar. The pure oxygen available at this pressure must be compressed to feed both the gasifier and the anode exhaust oxycombustor. The portion of this compression work from 0.2 bar to atmospheric pressure is the only added parasitic power requirement (relative to using a cryogenic ASU). In addition, the cathode turbine produces less power (than without an ITM) due to the reduced mass flow after oxygen extraction by the ITM. Offsetting these power losses are the significant power demands of the cryogenic ASU. Figure 20 shows the SOFC power island in detail, while Table 21 reports stream data for the same. Table 22 gives a detailed performance comparison for the HICOM case with oxidant production via ASU vs. ITM, and both with and without $\mathrm{CO}_{2}$ capture.

The use of ITM oxygen production increases overall plant efficiency about 1.7 percentage points for the IGFC HICOM case, relative to ASU analogs.

\footnotetext{
${ }^{31}$ Armstrong, P.A., et al., 'ITM Oxygen: The New Oxygen Supply for the New IGCC Market', Air Products and Chemical Inc., Gasifier Technologies 2005 conference, San Francisco, California, 9-12 October 2005.
} 


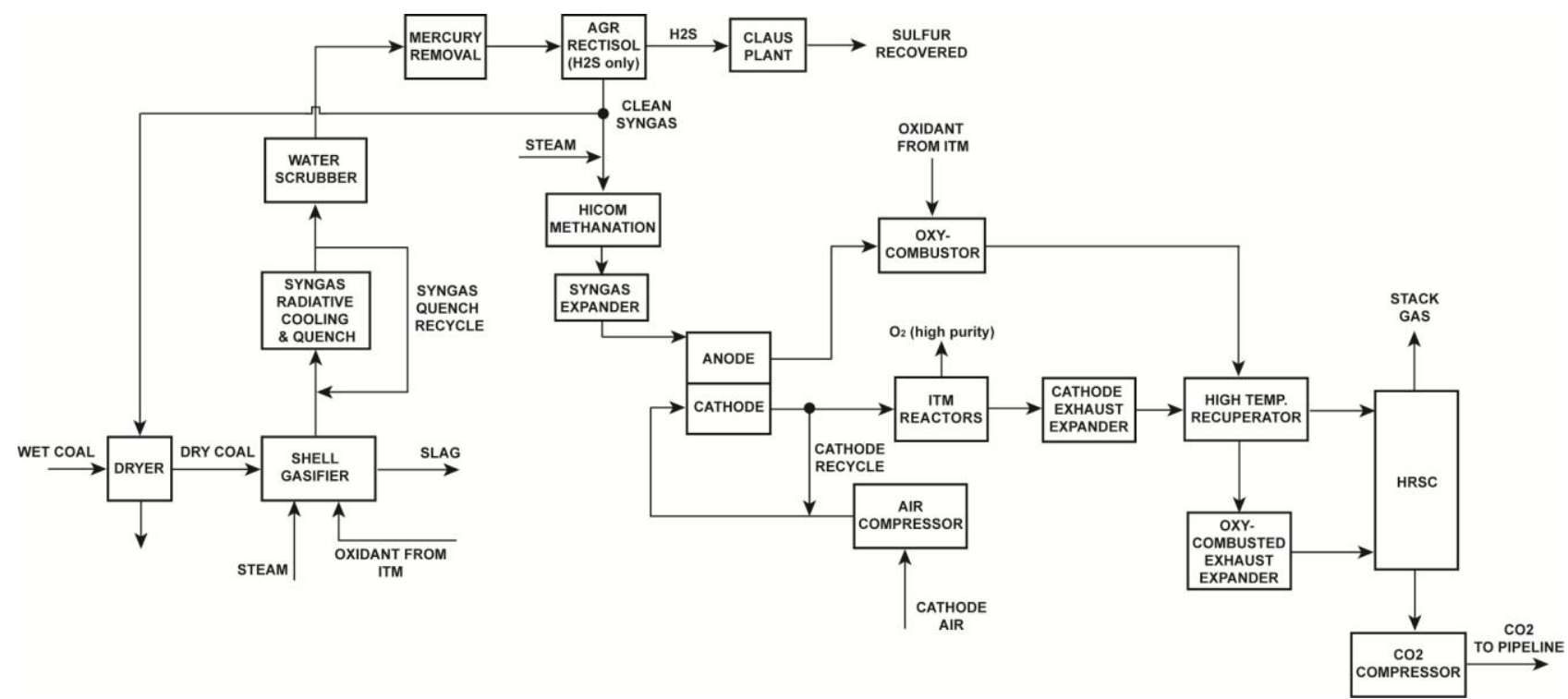

Figure 19. Simplified schematic for coal integrated gasifier solid-oxide fuel cell power plant with HICOM methanation upstream of the SOFC and oxygen production via ITM rectors integrated with the cathode exhaust

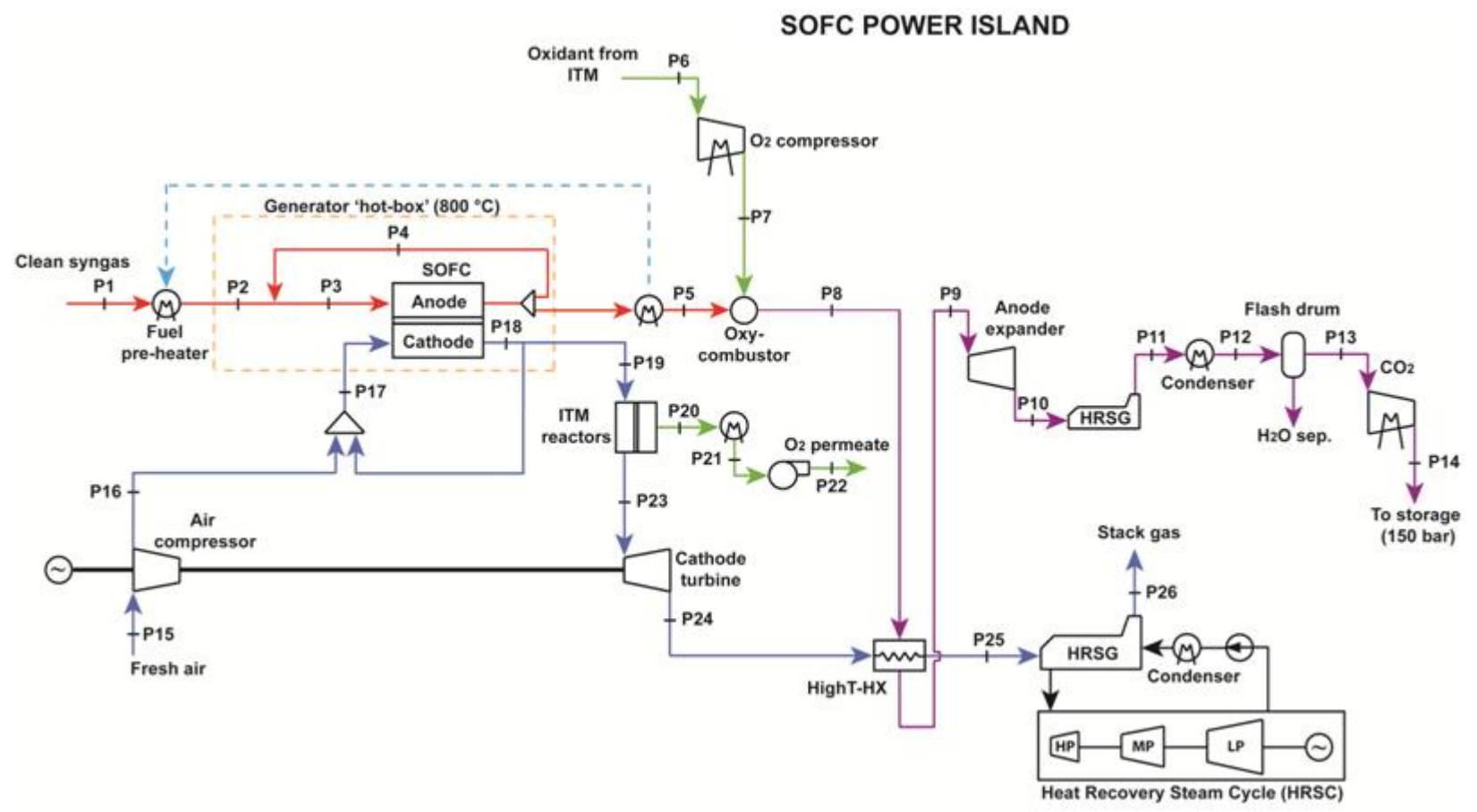

Figure 20. SOFC power island integfrated with ITM reactors. 
Table 21. Stream table for the power island in Figure 20.

\begin{tabular}{l|ccccccccccc} 
Stream ID: & $\mathrm{P} 1$ & $\mathrm{P} 2$ & $\mathrm{P} 3$ & $\mathrm{P} 4$ & $\mathrm{P} 5$ & $\mathrm{P} 6$ & $\mathrm{P} 7$ & $\mathrm{P} 8$ & $\mathrm{P} 9$ & $\mathrm{P} 10$ & $\mathrm{P} 11$ \\
\hline $\begin{array}{l}\text { Molar } \\
\text { composition: }\end{array}$ & & & & & & & & & & & \\
$\mathrm{H} 2 \mathrm{O}$ & $34.9 \%$ & $34.9 \%$ & $35.0 \%$ & $55.0 \%$ & $55.0 \%$ & $0.0 \%$ & $0.0 \%$ & $60.4 \%$ & $60.4 \%$ & $60.4 \%$ & $60.4 \%$ \\
$\mathrm{O} 2$ & $0.0 \%$ & $0.0 \%$ & $0.0 \%$ & $0.0 \%$ & $0.0 \%$ & $99.5 \%$ & $99.5 \%$ & $0.0 \%$ & $0.0 \%$ & $0.0 \%$ & $0.0 \%$ \\
$\mathrm{AR}$ & $0.6 \%$ & $0.6 \%$ & $0.6 \%$ & $0.5 \%$ & $0.5 \%$ & $0.0 \%$ & $0.0 \%$ & $0.5 \%$ & $0.5 \%$ & $0.5 \%$ & $0.5 \%$ \\
$\mathrm{~N} 2$ & $3.4 \%$ & $3.4 \%$ & $3.4 \%$ & $2.8 \%$ & $2.8 \%$ & $0.5 \%$ & $0.5 \%$ & $2.8 \%$ & $2.8 \%$ & $2.8 \%$ & $2.8 \%$ \\
$\mathrm{H} 2$ & $16.3 \%$ & $16.3 \%$ & $16.3 \%$ & $5.4 \%$ & $5.4 \%$ & $0.0 \%$ & $0.0 \%$ & $0.0 \%$ & $0.0 \%$ & $0.0 \%$ & $0.0 \%$ \\
$\mathrm{CO}$ & $7.1 \%$ & $7.1 \%$ & $7.1 \%$ & $3.0 \%$ & $3.0 \%$ & $0.0 \%$ & $0.0 \%$ & $0.0 \%$ & $0.0 \%$ & $0.0 \%$ & $0.0 \%$ \\
$\mathrm{CO} 2$ & $26.1 \%$ & $26.1 \%$ & $26.1 \%$ & $33.2 \%$ & $33.2 \%$ & $0.0 \%$ & $0.0 \%$ & $36.3 \%$ & $36.3 \%$ & $36.3 \%$ & $36.3 \%$ \\
$\mathrm{H} 2 \mathrm{~S}$ & $0.0 \%$ & $0.0 \%$ & $0.0 \%$ & $0.0 \%$ & $0.0 \%$ & $0.0 \%$ & $0.0 \%$ & $0.0 \%$ & $0.0 \%$ & $0.0 \%$ & $0.0 \%$ \\
$\mathrm{CH} 4$ & $11.5 \%$ & $11.5 \%$ & $11.5 \%$ & $0.0 \%$ & $0.0 \%$ & $0.0 \%$ & $0.0 \%$ & $0.0 \%$ & $0.0 \%$ & $0.0 \%$ & $0.0 \%$ \\
$\begin{array}{l}\text { Total Flow } \\
\text { (kmol/s) }\end{array}$ & & & & & & & & & & \\
Total Flow ( $\mathrm{kg} / \mathrm{s})$ & 191 & 191 & 191 & 0 & 269 & 14 & 14 & 283 & 283 & 283 & 283 \\
Temperature $\left({ }^{\circ} \mathrm{C}\right)$ & 635 & 700 & 700 & 800 & 800 & 15 & 189 & 1187 & 850 & 438 & 90 \\
Pressure (bar) & 22 & 22 & 20 & 20 & 20 & 1 & 20 & 20 & 20 & 1 & 1
\end{tabular}

\begin{tabular}{l|ccccccccccc} 
Stream ID: & $\mathrm{P} 12$ & $\mathrm{P} 13$ & $\mathrm{P} 14$ & $\mathrm{P} 15$ & $\mathrm{P} 16$ & $\mathrm{P} 17$ & $\mathrm{P} 18$ & $\mathrm{P} 19$ & $\mathrm{P} 20$ & $\mathrm{P} 21$ & $\mathrm{P} 22$ \\
\hline $\begin{array}{l}\text { Molar } \\
\text { composition: }\end{array}$ & & & & & & & & & & & \\
$\mathrm{H} 2 \mathrm{O}$ & $60.4 \%$ & $3.6 \%$ & $0.3 \%$ & $0.0 \%$ & $0.0 \%$ & $0.0 \%$ & $0.0 \%$ & $0.0 \%$ & $0.0 \%$ & $0.0 \%$ & $0.0 \%$ \\
$\mathrm{O} 2$ & $0.0 \%$ & $0.1 \%$ & $0.1 \%$ & $21.0 \%$ & $21.0 \%$ & $17.1 \%$ & $13.3 \%$ & $13.3 \%$ & $13.3 \%$ & $13.3 \%$ & $13.3 \%$ \\
$\mathrm{AR}$ & $0.5 \%$ & $1.3 \%$ & $1.3 \%$ & $0.9 \%$ & $0.9 \%$ & $1.0 \%$ & $1.0 \%$ & $1.0 \%$ & $1.0 \%$ & $1.0 \%$ & $1.0 \%$ \\
$\mathrm{~N} 2$ & $2.8 \%$ & $6.8 \%$ & $7.1 \%$ & $78.1 \%$ & $78.1 \%$ & $82.0 \%$ & $85.7 \%$ & $85.7 \%$ & $85.7 \%$ & $85.7 \%$ & $85.7 \%$ \\
$\mathrm{H} 2$ & $0.0 \%$ & $0.0 \%$ & $0.0 \%$ & $0.0 \%$ & $0.0 \%$ & $0.0 \%$ & $0.0 \%$ & $0.0 \%$ & $0.0 \%$ & $0.0 \%$ & $0.0 \%$ \\
$\mathrm{CO}$ & $0.0 \%$ & $0.0 \%$ & $0.0 \%$ & $0.0 \%$ & $0.0 \%$ & $0.0 \%$ & $0.0 \%$ & $0.0 \%$ & $0.0 \%$ & $0.0 \%$ & $0.0 \%$ \\
$\mathrm{CO} 2$ & $36.3 \%$ & $88.3 \%$ & $91.3 \%$ & $0.0 \%$ & $0.0 \%$ & $0.0 \%$ & $0.0 \%$ & $0.0 \%$ & $0.0 \%$ & $0.0 \%$ & $0.0 \%$ \\
$\mathrm{H} 2 \mathrm{~S}$ & $0.0 \%$ & $0.0 \%$ & $0.0 \%$ & $0.0 \%$ & $0.0 \%$ & $0.0 \%$ & $0.0 \%$ & $0.0 \%$ & $0.0 \%$ & $0.0 \%$ & $0.0 \%$ \\
$\mathrm{CH} 4$ & $0.0 \%$ & $0.0 \%$ & $0.0 \%$ & $0.0 \%$ & $0.0 \%$ & $0.0 \%$ & $0.0 \%$ & $0.0 \%$ & $0.0 \%$ & $0.0 \%$ & $0.0 \%$ \\
Total Flow & & & & & & & & & & & \\
(kmol/s) & 10.2 & 4.2 & 4.0 & 27.4 & 27.4 & 55.8 & 53.3 & 25.0 & 25.0 & 25.0 & 25.0 \\
Total Flow $(\mathrm{kg} / \mathrm{s})$ & 283 & 175 & 173 & 795 & 795 & 1606 & 1529 & 717 & 717 & 717 & 717 \\
Temperature $\left({ }^{\circ} \mathrm{C}\right)$ & 30 & 30 & 160 & 15 & 492 & 650 & 800 & 800 & 277 & 496 & 108 \\
Pressure (bar) & 1 & 1 & 150 & 1 & 22 & 20 & 20 & 20 & 1 & 1 & 1
\end{tabular}


Table 22. IGFC-HICOM plant: ASU vs. ITM with and without carbon capture.

\begin{tabular}{|c|c|c|c|c|c|}
\hline Plant design: & & ASU-V & $\begin{array}{l}\text { ASU- } \\
\text { CCS }\end{array}$ & ITM-V & $\begin{array}{l}\text { ITM- } \\
\text { CCS }\end{array}$ \\
\hline \multicolumn{6}{|l|}{ Input fuel } \\
\hline Syngas feed & kmol s-1 & 8.25 & 8.26 & 8.24 & 8.24 \\
\hline Syngas HHV & MJ kmol-1 & 184 & 185 & 187 & 187 \\
\hline Coal input / HHV & MWt & 1916 & 1916 & 1916 & 1916 \\
\hline \multicolumn{6}{|l|}{ SOFC power unit } \\
\hline Global fuel utilization, $F U$ & & $85 \%$ & $85 \%$ & $85 \%$ & $85 \%$ \\
\hline Air recirculation fraction & & 0.53 & 0.53 & 0.53 & 0.53 \\
\hline Global air utilization, $\lambda$ & & 2.38 & 2.36 & 2.31 & 2.32 \\
\hline Local air utilization, $\lambda^{*}$ & & 3.95 & 3.91 & 3.81 & 3.82 \\
\hline Operating voltage & $\mathrm{V}$ & 0.77 & 0.77 & 0.77 & 0.77 \\
\hline SOFC power (DC) & MWe & 719.8 & 723.2 & 729.8 & 729.9 \\
\hline \multicolumn{6}{|l|}{ Additional power / cathode side } \\
\hline TIT cathode turbine & ${ }^{\circ} \mathrm{C}$ & 953 & 800 & 960 & 800 \\
\hline Air turbine power & MWe & 653.2 & 394.8 & 625.7 & 361.0 \\
\hline Air compressor consumption & MWe & 415.6 & 415.3 & 410.7 & 411.9 \\
\hline GT net power & MWe & 237.5 & -20.5 & 215.0 & -50.8 \\
\hline \multicolumn{6}{|l|}{ Additional power / anode side } \\
\hline TIT anode turbine & ${ }^{\circ} \mathrm{C}$ & - & 850 & - & 850 \\
\hline Anode steam- $\mathrm{CO}_{2}$ expander & MWe & - & 176.0 & - & 176.6 \\
\hline $\mathrm{O}_{2}$ compressor & MWe & - & 5.3 & - & 5.4 \\
\hline $\begin{array}{l}\text { ASU consumption for the oxy-combustor (for plants } \\
\text { with ASU) / } \mathrm{O}_{2} \text { pump (for plants with ITM) }\end{array}$ & MWe & - & 13.3 & 8.9 & 11.2 \\
\hline $\mathrm{CO}_{2}$ compression & MWe & - & 73.7 & - & 72.1 \\
\hline \multicolumn{6}{|l|}{ Power recovery from HRSGs } \\
\hline $\begin{array}{l}\text { HRSC (steam cycle recovering heat from gasifier, } \\
\text { fuel cleaning/processing units and SOFC exhausts) }\end{array}$ & MWe & 142.1 & 228.9 & 153.4 & 238.4 \\
\hline \multicolumn{6}{|l|}{ Auxiliaries } \\
\hline Coal prep. and handling \& slag handling & MWe & 4.6 & 4.6 & 4.6 & 4.6 \\
\hline $\begin{array}{l}\text { Oxygen to the gasifier (ASU) / Oxygen to the } \\
\text { gasifier (ITM), compressor only }\end{array}$ & MWe & 63.8 & 63.8 & 22.3 & 22.3 \\
\hline Syngas recycle compressor & MWe & 0.1 & 0.1 & 0.1 & 0.1 \\
\hline Rectisol unit & MWe & 10.1 & 10.1 & 10.1 & 10.1 \\
\hline Methanator recirculator & MWe & 0.5 & 0.5 & 0.5 & 0.5 \\
\hline Syngas expander & MWe & 17.0 & 17.2 & 17.0 & 17.0 \\
\hline \multicolumn{6}{|l|}{ Summary } \\
\hline Power output (net, DC) & MWe & 1037.4 & 953.5 & 1068.7 & 984.7 \\
\hline Inlet fuel & MWt & 1521.1 & 1526.5 & 1537.9 & 1537.9 \\
\hline Inverter efficiency & & $96 \%$ & $96 \%$ & $96 \%$ & $96 \%$ \\
\hline AC electrical efficiency, $\eta_{A C}$ (HHV Coal) & & $\mathbf{5 2 . 0 \%}$ & $47.8 \%$ & $53.5 \%$ & $49.3 \%$ \\
\hline $\mathrm{CO}_{2}$ captured post-SOFC & $\mathrm{kg} \mathrm{s}-1$ & 0.0 & 162.2 & 0.0 & 162.0 \\
\hline
\end{tabular}




\section{4 'ITM’ Plant Economics}

This section presents a comparative economic analysis between an IGFC HICOM plant with an ASU and one an ITM. According to Air Products, a leading ITM developer, an IGCC with an ITM instead of an ASU would require 35\% less capital and 35-60\% less energy, i.e. a $\sim 1 \%$ point increase in plant efficiency and a $\sim 7 \%$ reduction in capital $\operatorname{cost}^{32}$. More details have not been provided in the open literature.

According to NETL, ${ }^{33}$ the cost of ITM includes the main air compressor, the ITM boost compressor, a recuperator, two membrane stages, an air heater, oxygen coolers, oxygen compressors, and a fluff gas cooler and compressor. The capital cost of the ITM section is assumed to be equal to (the target development cost of) $67 \%$ of the cost of a comparable cryogenic ASU. However, when ITM is integrated with an SOFC, the air compressor, ITM boost compressor, recuperator and air heater are unnecessary; thus, we assume here that the capital cost of ITM in IGFC plants is only half that of an ASU (based on a 500 MWe IGCC.) As with SOFC, ITM technology is essentially modular, so a scaling factor of unity was used in costing.

Table 23 compares the performance and economics of various IGFC plants with CCS; the performance of a Shell-based IGCC plant is provided for reference. Integrating ITM with SOFC is seen to improve both the efficiency and economics of the IGFC HICOM plant.

Table 23. Economics (2007 \$) of different coal gasifier based power plants with CCS

\begin{tabular}{|c|c|c|c|c|c|c|}
\hline & \multirow{2}{*}{$\begin{array}{c}\text { Electricity } \\
M W e\end{array}$} & \multirow[t]{2}{*}{$\eta(\mathrm{LHV})$} & \multicolumn{2}{|c|}{$T P C$} & \multirow{2}{*}{$\begin{array}{l}L C O E \\
\$ / M W h\end{array}$} & \multirow{2}{*}{$\begin{array}{c}\text { IRR on } \\
\text { TPI }\end{array}$} \\
\hline & & & $M \$$ & $\$ / k W e$ & & \\
\hline IGCC-CCS & 517 & $33.5 \%$ & 1,424 & 3,069 & 109.6 & $7.8 \%$ \\
\hline IGFC-DIRECT-CCS & 858.8 & $47.0 \%$ & 1,864 & 2,170 & 84.6 & $20.5 \%$ \\
\hline IGFC-TREMP-CCS & 841 & $46.0 \%$ & 1,924 & 2,549 & 89.8 & $18.1 \%$ \\
\hline IGFC-HICOM-CCS & 915.4 & $50.1 \%$ & 1,829 & 2,226 & 78.3 & $23.0 \%$ \\
\hline IGFC-HICOM-ITM-CCS & 945 & $51.7 \%$ & 1,654 & 1,949 & 70.9 & $27.0 \%$ \\
\hline
\end{tabular}

SOFC cost at 657 \$/kW AC (module cost @ $0.054 \$ / \mathrm{cm}^{2}$; power density @ $500 \mathrm{~mW} / \mathrm{cm}^{2}$ )

Table 24 compares the disaggregated LCOE for IGFC HICOM with ASU vs. ITM. The reduction in LCOE caused by replacing the ASU with an ITM is dominated by the reduced capital cost of the latter.

Table 24. Levelized cost of electricity breakdown for the HICOM plant either with ASU or with ITM.

Electricity Cost Components, 2007 \$/MWh:
\begin{tabular}{|l|cc|}
\hline Installed capital (at 14.38\% of TPI) & HICOM & HICOM-ITM \\
O\&M (at 4\% of TPC per yr) & 10.73 & 37.62 \\
O\&M SOFC modules & 3.28 & 9.39 \\
Coal/biomass (at 2.04/5 \$/GJ, HHV) & 15.34 & 3.20 \\
CO2 emissions (at 50 \$/tonne CO2) & 2.07 & 2.03 \\
CO2 disposal (at 6.1 \$/tonne CO2) & 3.92 & 3.79 \\
\hline Levelized cost of electricity (LCOE) & 78.30 & 70.89 \\
\hline
\end{tabular}

SOFC cost at 657 \$/kW AC (module cost @ $0.054 \$ / \mathrm{cm}^{2}$; power density @ $500 \mathrm{~mW} / \mathrm{cm}^{2}$ )

\footnotetext{
${ }^{32}$ Armstrong, P.A., et al., 'ITM Oxygen: The New Oxygen Supply for the New IGCC Market', Air Products and Chemical Inc., Gasifier Technologies 2005 conference, San Francisco, California, 9-12 October 2005.

${ }^{33}$ DOE/NETL-2009/1389 (Rev.1 2010) report entitled 'Current and Future Technologies for Gasification-Based Power Generation' Vol.2.
} 


\subsection{Additional Considerations on the Cost of ITM Reactors}

As mentioned above, our assumed ITM capital cost was based on assertions by Air Products and NETL. In order to test this assumption, we estimated the fundamental ITM reactor cost using the same methodology/cost structure used for SOFC reactors because of the many similarities between the two technologies. Both have comparable: 1) active materials, e.g. perovskites, 2) modularity, and 3) operating conditions (i.e. temperature and pressure). Also, because the ITM is fed raw SOFC cathode exhaust, it also requires insulation and a pressure containment vessel.

Table 25 details the technical specifications assumed for state-of-the-art membranes based on perovskites, which have the highest oxygen flux among several candidate mixed ionic electronic conductors. The $\mathrm{O}_{2}$ flux permeating through the membrane is calculated according to the following formula:

$$
j_{O_{2}}=\frac{\sigma_{i} R T}{4 L n^{2} L^{2}} \ln \left(\frac{p_{O_{2}}^{\prime}}{p_{O_{2}}^{\prime \prime}}\right)
$$

where $\mathrm{j}_{\mathrm{O}_{2}}$ is the oxygen flux, $F$ is Faraday's constant, $L$ is the membrane thickness, $n$ is the charge of the charge carrier (then equal to 2 for oxygen ions), $R$ is the ideal gas constant, $T$ is membrane's absolute temperature, $\mathrm{p}_{\mathrm{O}_{2}}^{\prime}$ is the oxygen partial pressure at the feed surface of the membrane, and $\mathrm{p}_{\mathrm{O}_{2}}^{\prime \prime}$ is the oxygen partial pressure at the permeate conditions of the membrane; $\sigma_{\mathrm{i}}$ is the ionic conductivity stream (the only material property in the equation).

Table 26 disaggregates the ITM cost and compares it to the previous cost estimate; the new estimate is similar, but smaller than the previous one. (Note that the first estimate does not include BoP, i.e. the permeate $\mathrm{O}_{2}$ pump and heat-exchanger.) Both estimates suggest that an ITM integrated in an IGFC plant has a significantly lower capital cost than a conventional ASU, as we have assumed in the results presented in the previous section.

Table 25. ITM technical specifications

\begin{tabular}{|c|c|}
\hline Air pressure $\mathrm{pO}_{2}{ }^{\prime}$, bar & 4.2 \\
\hline Permeate side pressure $\mathrm{pO}_{2}$ ", bar & 0.2 \\
\hline $\mathrm{pO}_{2}{ }^{\prime} / \mathrm{pO}_{2}{ }^{\prime \prime}$ & 21 \\
\hline Ideal gas constant $(R), \mathrm{J} / \mathrm{mol} / \mathrm{K}$ & 8.314 \\
\hline Faraday constant $(F), \mathrm{C} / \mathrm{mol}$ & 96485 \\
\hline Membrane thickness $(L), \mathrm{mm}$ (a) & 0.01 \\
\hline ITM temperature $(T), \mathrm{K}$ & 1073.2 \\
\hline Membrane conductivity $(\sigma), \mathrm{S} / \mathrm{cm}$ (a) & $5.00 \mathrm{E}-02$ \\
\hline ITM membrane $\mathrm{O}_{2}$ flux, $\mathrm{mol} \mathrm{s}^{-1} \mathrm{~cm}^{-2}$ & 3.96E-06 \\
\hline ITM equivalent current density $j_{I T M}, A \mathrm{~cm}^{-2}(\mathrm{~b})$ & 1.53 \\
\hline 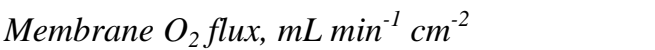 & 5.33 \\
\hline
\end{tabular}


